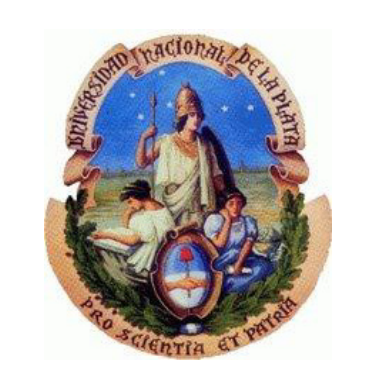

\title{
Estabilidad y vida útil de caballa (Scomber japonicus) preservada mediante combinación de barreras
}

\section{Tesis Doctoral presentada por Gerardo Checmarev}

\author{
ante la \\ Facultad de Ingeniería de la \\ Universidad Nacional de La Plata \\ para acceder al grado académico de
}

DOCTOR EN INGENIERIA

Dirección de tesis: Alicia Bevilacqua

Codirección de tesis: María Rosa Casales

La Plata, Marzo de 2015 
El presente trabajo de Tesis para obtener el título de Doctor en Ingeniería de la Facultad de Ingeniería de la Universidad Nacional de La Plata fue realizado en el Grupo de Investigación en Preservación y Calidad de Alimentos (GIPCAL-FI-UNMdP) y en el Centro de Investigación y Desarrollo en Criotecnología de Alimentos (CIDCAUNLP-CONICET), bajo la dirección de la Dra. Alicia Eva Bevilacqua (CIDCA-UNLPCONICET) y la codirección de la Ing. María Rosa Casales (CONICET-GIPCALUNMdP).

Para la realización del doctorado se dispuso de una Beca Doctoral Interna de Postgrado Tipo I (3 años de duración a partir del $1^{\circ}$ de abril de 2010) otorgada por el Consejo Nacional de Investigaciones Científicas y Técnicas (CONICET) y de una Beca de Perfeccionamiento (2 años de duración a partir del $1^{\circ}$ de abril de 2013 ) otorgada por la Universidad Nacional de Mar del Plata (UNMdP). Ambas becas fueron dirigidas por la Ing. María Rosa Casales y co-dirigidas por la Ing. María Isabel Yeannes (CONICET-UNMdP). 


\section{AGRADECIMIENTOS}

A mi directora de tesis, la Dra. Alicia Eva Bevilacqua por su apoyo y colaboración en el desarrollo de la tesis.

A mi codirectora de tesis, la Ing. María Rosa Casales por brindarme su conocimiento y por estar siempre al lado mío cada vez que la necesité.

A mi codirectora de beca, la Ing. María Isabel Yeannes por permitirme ingresar al grupo de trabajo y brindarme su apoyo y sabiduría.

A la Universidad Nacional de La Plata por permitirme realizar el Doctorado en Ingeniería.

Al Consejo Nacional de Investigaciones Científicas y Técnicas (CONICET) por haberme otorgado la Beca Interna de Postgrado Tipo I que me permitió iniciar el Doctorado y a la Universidad Nacional de Mar del Plata (UNMdP) por haberme otorgado la Beca de Perfeccionamiento que me permitió finalizar el Doctorado.

Al Departamento de Ing. Química y en Alimentos de la Facultad de Ingeniería de la Universidad Nacional de Mar del Plata donde se desarrolló esta tesis.

Al Grupo de Investigación en Preservación y Calidad de Alimentos y a todas las chicas que lo componen por sus consejos y por crear un ambiente agradable para trabajar. $A$ Celia, Gabi, Mari, María Rosa, Marisa, Moni, Sil A., Sil. P. y especialmente a Alejandra Tomac por ayudarme siempre que la necesité y a Irene Amestoy por su incondicional apoyo en la parte microbiológica de la tesis.

Al Centro de Investigación y Desarrollo en Criotecnología de Alimentos (CIDCA) por iniciarme en la investigación (previo al Doctorado) y por permitirme utilizar equipamiento para el desarrollo de esta tesis.

A la Ing. Lorena Suárez y a la empresa Copeca S.A. por facilitar los ejemplares de caballa utilizados para realizar las distintas experiencias.

Al frigorífico MIA S.A. por permitirme utilizar sus instalaciones y a los Ingenieros Mauro Cardoni y Diego D’addato por su gran ayuda prestada. 
A los integrantes del Grupo de Ingeniería en Alimentos (GIA) y del Grupo de Ingeniería Bioquímica (GIB) de la UNMdP por la ayuda brindada.

A la empresa Omega Sur que permitió el uso del cromatógrafo gaseoso para las determinaciones de los perfiles de ácidos grasos. 


\section{PRODUCIDO POR LA TESIS}

\section{Publicaciones en revistas internacionales con referato}

-Checmarev G., Bevilacqua A., Yeannes M.I. y Casales M.R. 2014. Mass Transfer During Osmotic Dehydration of Chub Mackerel Cylinders in Ternary Solution. Journal of Food Research, v. 3 (5): 49-58.

-Checmarev G., Casales M.R. y Yeannes M.I. 2013. Analysis of the applicability of Peleg model to the cooking-infusion of mackerel (Scomber japonicus) slices. Food Science and Technology (Campinas), v. 33(4), p. 685-689.

-Checmarev G., Yeannes M.I., Bevilacqua A. y Casales M.R. 2013. Mass transfer modeling during osmotic dehydration of chub mackerel (Scomber japonicus) slices in salt and glycerol solution at different temperatures. Journal of Food Processing and Preservation, 38: 1599-1607.

-Checmarev G., Yeannes M. I., Bevilacqua A. E. y Casales M. R. Kinetic of color change of osmotically dehydrated chub mackerel (Scomber japonicus) during storage at different temperatures. Remitido para su publicación (año 2014).

\section{Trabajos presentados y publicados en congresos}

-Checmarev G., Yeannes M. I., Bevilacqua A. E. y Casales M. R. Lomitos de caballa preservados mediante tecnología de obstáculos. Trabajo completo publicado en Proceedings del International Conference on Food Innovation, Foodlnnova 2014. Concordia, 20-23/10/2014.

-Checmarev G., Yeannes M. I., Bevilacqua A. E. y Casales M. R. Modelado matemático del comportamiento de la microflora en lomitos de caballa deshidratados osmóticamente y envasados al vacío. Resumen 95, Conference on Food Innovation, Foodlnnova 2014. Concordia, 20-23/10/2014.

-Checmarev G., Yeannes M.I., Bevilacqua A.E. y Casales, M.R. Cinética del cambio de color de lomitos de caballa (Scomber japonicus) deshidratados osmóticamente durante el almacenamiento a distintas temperaturas. XIV Congreso Argentino de Ciencia y 
Tecnología de Alimentos. Buenos Aires, 23 - 25/10/13. Resumen 512, Ingeniería de Alimentos. 978-987-22165-5-9

-Checmarev G., Yeannes M.I., Bevilacqua A.E. y Casales, M.R. Modelado matemático de la difusión de agua y solutos en lomitos de caballa (Scomber japonicus) durante la deshidratación osmótica en solución ternaria agua-glicerol-sal. XIV Congreso Argentino de Ciencia y Tecnología de Alimentos. Buenos Aires, 23-25/10/13. Resumen 513, Ingeniería de Alimentos.978-987-22165-5-9

-Checmarev Gerardo, Casales María Rosa y Yeannes María Isabel. Coeficientes de difusión de rodajas de caballa (Scomber japonicus) durante la deshidratación osmótica a diferentes temperaturas. Trabajo completo publicado en Proceedings del XIII Congreso Argentino de Ciencia y Tecnología de Alimentos (CYTAL). Universidad Católica Argentina (UCA), Puerto Madero, Bs. As., Argentina. 19 al 21/10/2011.

-Checmarev Gerardo, Casales María Rosa y Yeannes María Isabel. Perfil sensorial de lomitos de caballa (Scomber japonicus) de humedad intermedia. Trabajo completo publicado en Proceedings del XIII Congreso Argentino de Ciencia y Tecnología de Alimentos (CYTAL). Universidad Católica Argentina (UCA), Puerto Madero, Bs. As., Argentina. 19 al 21/10/2011.

-Checmarev Gerardo, Casales María Rosa y Yeannes María Isabel. Análisis de la aplicabilidad del modelo de Peleg en la cocción-infusión de rodajas de caballa (Scomber japonicus). Resumen publicado en Proceedings del XIII Congreso Argentino de Ciencia y Tecnología de Alimentos (CYTAL). Universidad Católica Argentina (UCA), Puerto Madero, Bs. As., Argentina. 19 al 21/10/2011.

-Checmarev Gerardo, Casales María Rosa y Yeannes María Isabel. Análisis difusional de solutos en caballa (Scomber japonicus) durante la cocción-infusión en soluciones de glicerol y sal. Trabajo completo publicado en Proceedings del II Congreso Latinoamericano sobre Inocuidad y Calidad de los Alimentos. La Habana, Cuba. 26 al 28/08/2011.

-Checmarev Gerardo, Casales María Rosa y Yeannes María Isabel. Estimación del tiempo de pasteurización en lomitos de caballa de $a_{w}$ reducida. Trabajo completo publicado en Proceedings del II Congreso Latinoamericano sobre Inocuidad y Calidad de los Alimentos. La Habana, Cuba. 26 al 28/08/2011. 


\section{RESUMEN}

El objetivo de la presente tesis fue estudiar la estabilidad y la vida útil de caballa (Scomber japonicus) preservada mediante combinación de barreras de stress microbiano (cocción, disminución de $a_{w}$, envasado al vacío, pasteurización a baja temperatura y refrigeración). Se trabajó con lomitos de caballa, así se llama a la parte del pescado que queda luego de separar las vísceras, cabeza, cola, parte ósea y además quitar la piel y el músculo rojo.

En el Capítulo 1 se estudia el proceso de elaboración de los lomitos de caballa de humedad intermedia incluyendo el estudio teórico de la pasteurización. También se realiza una caracterización sensorial y fisicoquímica del producto terminado.

En el Capítulo 2 se estudia la difusión de los solutos (glicerol y sal) y del agua durante la infusión de caballa en la solución de baja $a_{w}$. En este estudio se utilizaron dos geometrías, se trabajó con rodajas, a las que se consideró como placas planas semiinfinitas, y con lomitos, a los que se consideró como cilindros finitos y como cilindros semiinfinitos. Se utilizaron los modelos de Crank, Peleg, Zugarramurdi \& Lupín, Weibull y Azuara para ajustar los datos experimentales.

En el Capítulo 3 se analiza el comportamiento de los microorganismos presentes en la preserva (flora nativa) durante el almacenamiento. Además, se realiza un estudio de reto microbiano con el fin de validar experimentalmente la etapa de pasteurización y analizar el comportamiento durante el almacenamiento del Staphylococcus aureus (microorganismo objetivo de la pasteurización) sobreviviente al pasteurizado.

En el Capítulo 4 se estima la vida útil de la preserva almacenada en refrigeración. Para esto se realizó un estudio de vida útil acelerado utilizando tres temperaturas: 15,25 y $35^{\circ} \mathrm{C}$. Para cada tiempo de muestreo se realizaron análisis fisicoquímicos ( $a_{w}$, humedad, TBA, color instrumental y perfil de ácidos grasos) y sensoriales (evaluación de aroma rancio y color amarillo-rojizo). La evaluación sensorial se realizó mediante un panel de 10 evaluadores entrenados. El tiempo de vida útil se determinó cuando el valor de los indicadores críticos de deterioro llegó a valores inaceptables sensorialmente. Finalmente, se halló una relación para estimar la vida útil de la preserva a distintas temperaturas. A partir de esta relación se extrapolaron los resultados a temperatura de refrigeración.

Se desarrolló un producto a partir de caballa preservado mediante la tecnología de obstáculos. Las barreras de stress microbiano aplicadas fueron efectivas para reducir la flora bacteriana inicial y mantener sin desarrollo microbiológico durante al menos 12 meses de almacenamiento. 


\section{INDICE}

RESUMEN

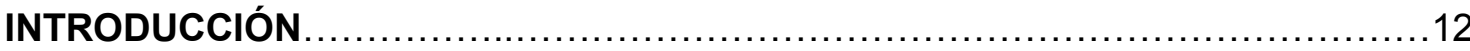

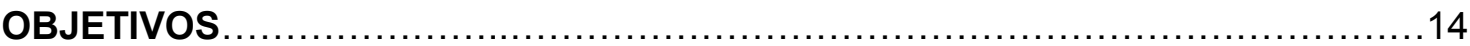

MARCO TEORICO

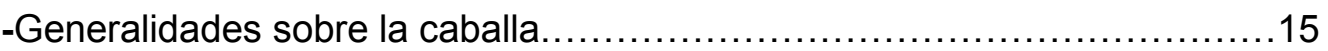

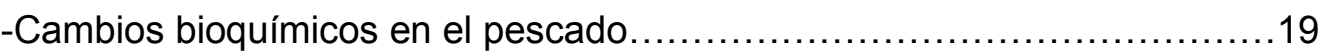

-Deterioro microbiológico e inocuidad en el pescado.............................21

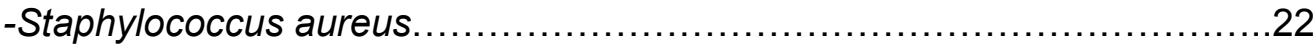

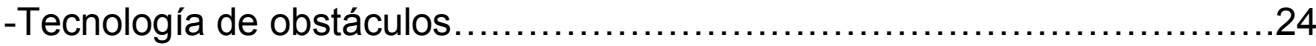

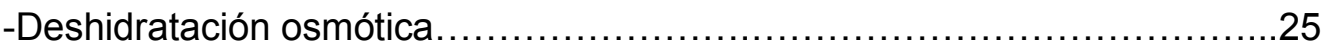

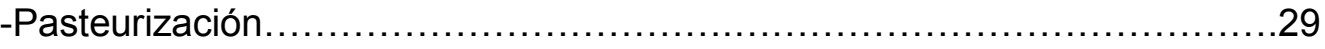

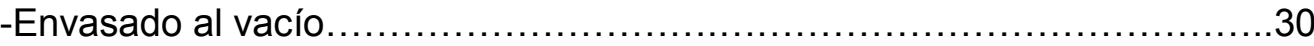

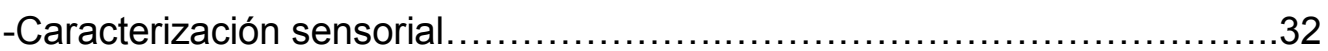

\section{CAPITULO 1: DESARROLLO Y CARACTERIZACIÓN DE LA PRESERVA}

1.1 Resumen

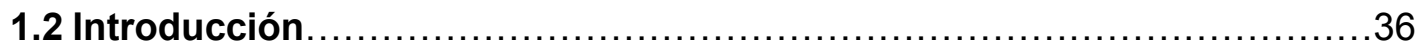

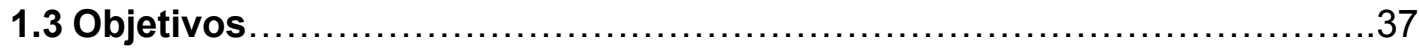

\subsection{Materiales y métodos}

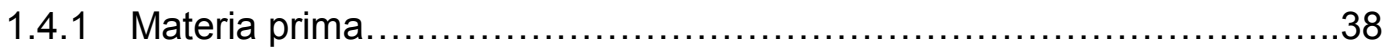

1.4.2 Análisis fisicoquímicos

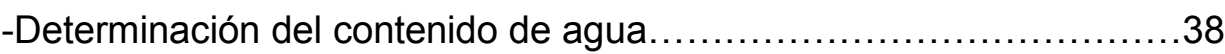

-Determinación del contenido de lípidos.....................................38

-Determinación del contenido total de proteínas............................39

-Determinación del contenido de cenizas......................................39

-Determinación del contenido de cloruro de sodio..........................39

-Determinación del contenido de glicerol..................................40

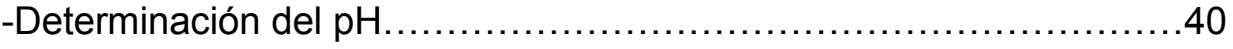

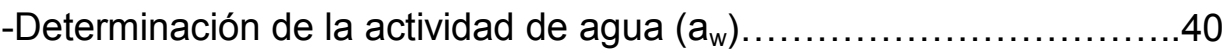

-Determinación instrumental del color.........................................40

-Determinación instrumental de la textura...................................41

1.4.3 Calculo teórico de la pasteurización...........................................42

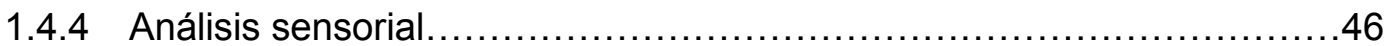

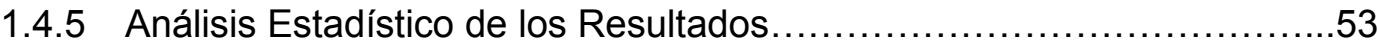




\subsection{Resultados y discusión}

1.5.1 Composición química proximal......................................54

1.5.2 Formulación de la solución de infusión para la DO.......................54

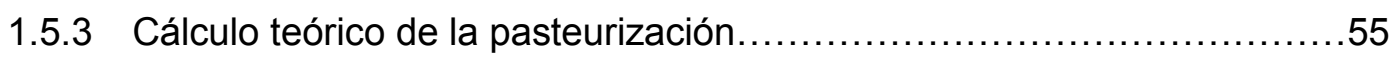

1.5.4 Proceso de elaboración de lomitos de caballa de humedad intermedia...56

1.5.5 Evaluación sensorial

-Selección de evaluadores..........................................61

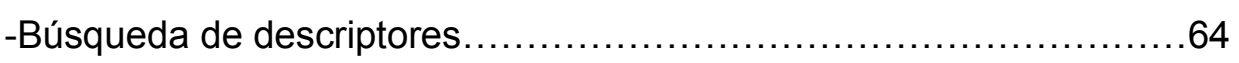

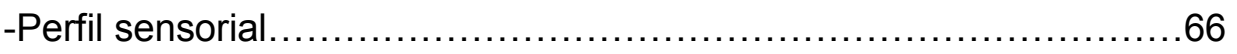

-Reducción de la intensidad del gusto dulce...........................68

-Perfil sensorial de los lomitos de humedad intermedia y comparación con lomitos cocidos ..............................................69

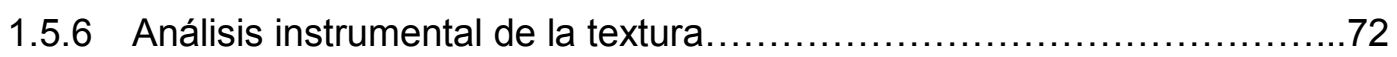

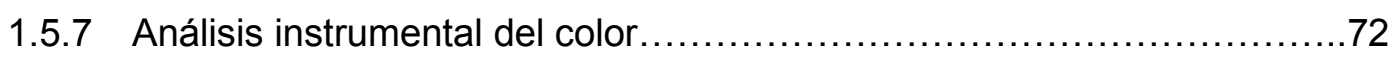

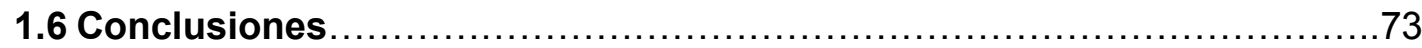

\section{CAPÍTULO 2: ESTUDIO DE DIFUSIÓN DE AGUA Y SOLUTOS}

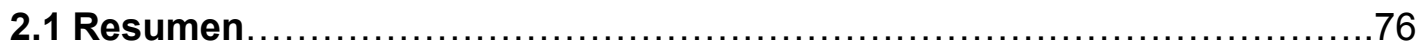

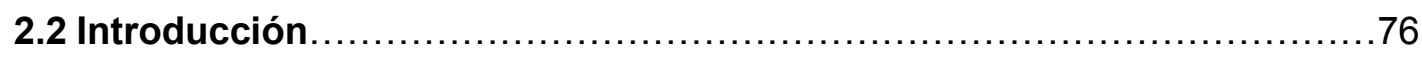

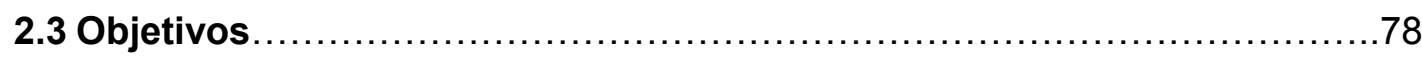

\subsection{Materiales y métodos}

2.4.1 Deshidratación osmótica de rodajas de caballa

-Proceso de elaboración................................................ 79

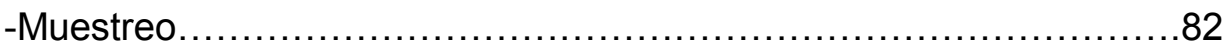

2.4.2 Deshidratación osmótica de lomitos de caballa

-Proceso de elaboración...............................................83

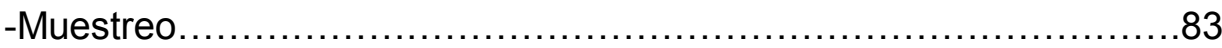

2.4.3 Porcentaje de incorporación de solutos (\%IS) .........................83

2.4.4 Modelos matemáticos

-Modelo de Crank para rodajas (placa plana semiinfinita)...............84

-Modelo de Crank para lomitos (cilindro)............................................85

-Modelo de Zugarramurdi y Lupín (Z \& L), Weibull, Peleg y Azuara.....87

2.4.5 Perfiles de concentración de agua y solutos durante la DO de cilindros de caballa....

2.4.6 Ecuación de Arrhenius................................................90

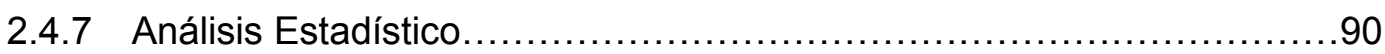




\subsection{Resultados y discusión}

2.5.1 Composición química proximal.....................................91

2.5.2 DO de rodajas de caballa

-Cinética de la DO de rodajas.......................................

-Estimación de los coeficientes de difusión (modelo de Crank)...........93

-Modelo de Zugarramurdi \& Lupín (Z \& L), Weibull y Peleg..............96

2.5.3 Deshidratación osmótica de lomitos de caballa

-Estimación de los coeficientes de difusión (modelo de Crank).........102

-Cinética de la DO y modelado mediante Z \& L y Azuara...............104

-Perfiles de agua y solutos durante la DO.........................106

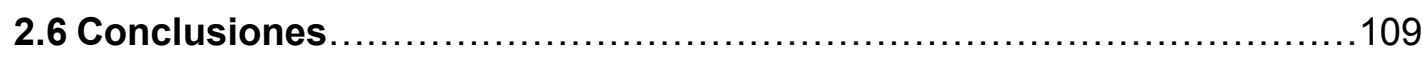

\section{CAPÍTULO 3: EFECTIVIDAD DE LAS BARRERAS}

3.1. Resumen...

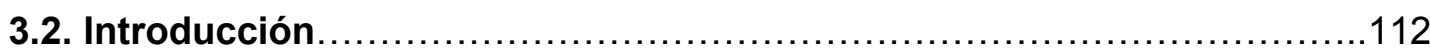

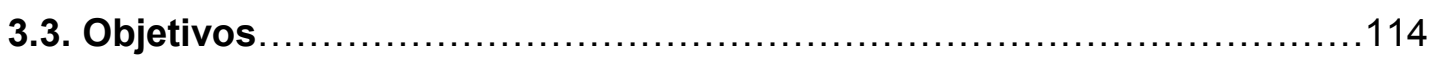

\subsection{Materiales y Métodos}

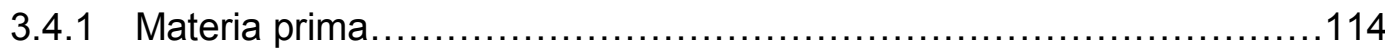

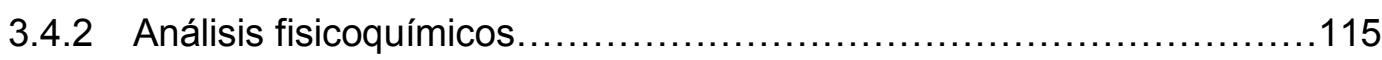

3.4.3 Estudio de la flora nativa

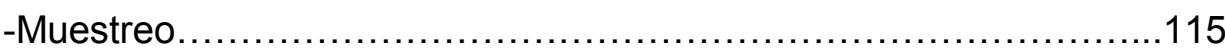

-Recuento de bacterias psicrótrofas, aerobias mesófilas,

hongos y levaduras y Staphylococcus spp...........................116

-Investigación de S. aureus y clostridio sulfito reductores..............116

3.4.4 Modelado matemático

-Modelo de Gompertz modificado y logístico.........................117

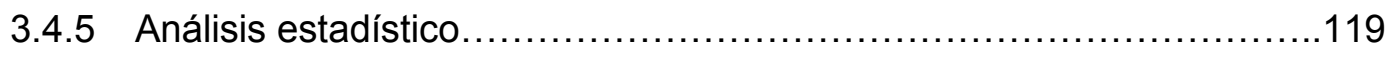

3.4.6 Reto microbiano

-Diseño experimental...........................................119

\subsection{Resultados y discusión}

3.5.1 Análisis fisicoquímicos

3.5.2 Estudio de la flora nativa

-Análisis microbiológico.

-Modelado matemático.

3.5.3 Reto microbiano

-Inactivación bacteriana.

-Comportamiento de la flora sobreviviente al pasteurizado. 


\section{CAPÍTULO 4: VIDA UTIL DE LA PRESERVA}

4.1 Resumen 136

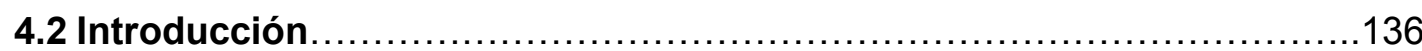

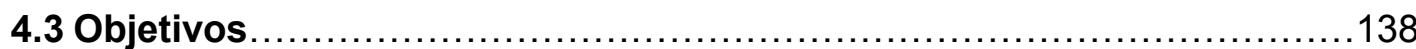

\subsection{Materiales y Métodos}

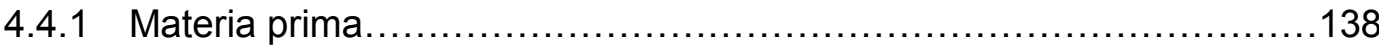

4.4.2 Proceso de elaboración................................................139

4.4.3 Análisis fisicoquímicos

-Determinación de la oxidación de lípidos. Sustancias reactivas

al ácido 2- Tiobarbitúrico (TBARS) ................................139

-Perfil de ácidos grasos.............................................. 140

4.4.4 Diseño experimental....................................................

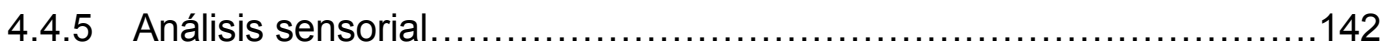

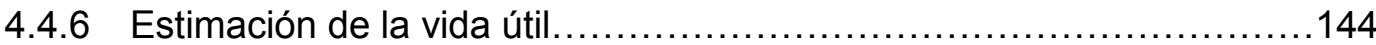

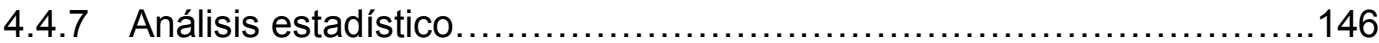

\subsection{Resultados y discusión}

4.5.1 Análisis fisicoquímicos

-Composición química proximal.....................................147

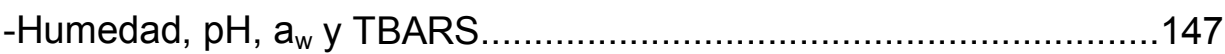

-Perfil de ácidos grasos............................................... 148

-Color instrumental.........................................................

4.5.2 Análisis sensorial

-Color amarillo-rojizo.............................................. 156

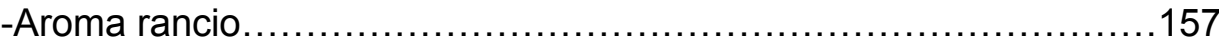

4.5.3 Correlación entre color instrumental y sensorial.......................157

4.5.4 Determinación del tiempo del punto final sensorial (vida útil) a $35^{\circ} \mathrm{C} \ldots .159$

4.5.5 Estudio acelerado de la Vida Útil Sensorial..............................162

-Dependencia con la temperatura ...................................... 164

-Determinación de la vida útil a temperatura de refrigeración...........166

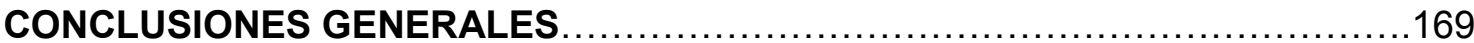

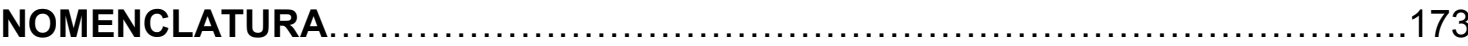

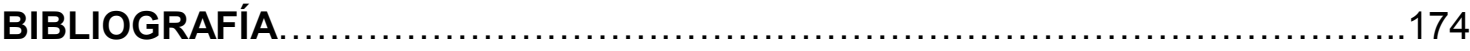

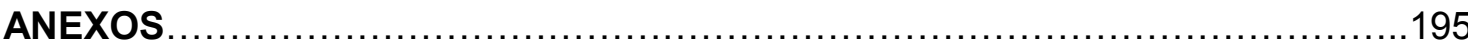




\section{INTRODUCCION}

El sector pesquero desempeña un papel muy importante para la seguridad alimentaria, para el desarrollo de industrias alimentarias y para el alivio de la pobreza alrededor del mundo. A nivel mundial, más de 38 millones de personas trabajan directamente en la pesca y la piscicultura y los productos pesqueros representan el 15$16 \%$ de la ingesta global de proteína animal. El setenta por ciento del pescado para el consumo humano está actualmente suministrado por los países en desarrollo y el sector de la pesca es particularmente importante para distintos países de África, Asia, y América Latina (Rahman, 2007).

En Argentina, las exportaciones en materia pesquera en el año 2014 superaron la barrera de los 1500 millones de dólares. Los productos del caladero nacional son muy requeridos en los mercados internacionales, producto de sus cualidades naturales y de las acciones mancomunadas del Estado Nacional y las empresas del sector pesquero en la promoción en ferias internacionales (MAGYP, 2015).

El consumo de pescado y productos pesqueros ha sido fuertemente influenciado por mejoras en el manejo poscosecha, embalaje, almacenamiento, transporte y comercialización, que han dado lugar a mejoras significativas en la eficiencia de la postproducción, menores costos, mayor oferta de productos y una mejora de los productos y su inocuidad. En general, ha habido un crecimiento en la producción de pescados y productos pesqueros comercializados en forma fresca y en la producción de alimentos listos para cocinar o listos para su consumo. Esto se da en parte debido a la creciente comprensión del rol del pescado para la salud (Rahman, 2007).

El pescado representa una valiosa fuente de micronutrientes, minerales, ácidos grasos esenciales y proteínas. La carne del pescado contiene entre $8-25 \%$ de proteínas, $0,5-30 \%$ de grasa y $0,6-1,5 \%$ de compuestos minerales. Posee cantidades abundantes de vitaminas solubles en agua y el aceite de pescado (sobre todo en el hígado) es rico en vitaminas $A$ y $D$. Además, el valor biológico de la proteína de pescado supera a la de proteínas de la carne roja, debido a la baja proporción de colágeno (Opara y col., 2007). Los lípidos contenidos en el pescado son ricos en ácidos grasos poliinsaturados, particularmente en ácidos grasos omega-3 que pueden alcanzar hasta un $40 \%$ del contenido de aceite de pescado.

La tendencia de los últimos 10 años indica que se han ido incrementando las capturas de caballa en Argentina, siendo los mayores desembarques realizados principalmente en el puerto de Mar del Plata (MAGYP, 2013). La caballa tiene como destino principal la industria conservera (76 \%) (comercializada en el mercado interno) 
y el resto se exporta como pescado entero congelado, siendo Brasil el principal país importador (MAGYP, 2013).

La industria conservera realiza el tradicional enlatado seguido de una esterilización comercial. El elevado contenido de lípidos, sumado a sus características musculares, hacen que la caballa sea muy apreciada por la excelencia del producto que se obtiene luego del tratamiento de cocción (Casales y Yeannes, 1987). Sin embargo, este proceso afecta las propiedades nutricionales así como también algunos atributos de calidad sensorial como la textura y el sabor. Las vitaminas A, C, biotina, piridoxina, el ácido pantoténico, la tiamina, riboflavina y la niacina son los nutrientes más dañados por el proceso de esterilización comercial (Pigott y Tucker, 1990). Actualmente debido a la posibilidad de utilización de las nuevas tecnologías de envasado y distintas técnicas de preservación, se ha reducido la necesidad de aplicar procesos tan intensos.

Considerando lo expresado anteriormente, es importante desarrollar nuevas formas de preservación de esta especie. La preservación mediante la tecnología de obstáculos representa una buena alternativa para la producción industrial de caballa.

En este trabajo de tesis se propone la combinación de las siguientes técnicas: cocción al vacío (para acondicionar la materia prima, reducir la carga microbiana e inactivar enzimas), deshidratación osmótica (para reducir la actividad de agua), envasado al vacío (para generar condiciones anaeróbicas), pasteurización a bajas temperaturas (para eliminar microorganismos patógenos en el producto final) y refrigeración. De esta manera, se busca obtener un producto listo para consumir de larga vida útil. 


\section{OBJETIVOS}

El objetivo general de esta investigación es la preservación de caballa (Scomber japonicus) por métodos combinados. Se pretende determinar la estabilidad y vida útil de lomitos de caballa (filete sin piel y sin músculo oscuro) preservados mediante combinación de barreras. Se busca obtener un producto seguro para la comercialización y que pueda ser distribuido a grandes distancias y con un ahorro energético durante el procesamiento tratando también de evitar el agregado de conservantes químicos. Se obtendría un producto listo para consumir saludable y de larga vida útil.

A partir del objetivo general se plantearon los siguientes objetivos particulares:

Desarrollar el proceso de elaboración de la preserva de caballa

$>$ Determinar la efectividad de las barreras de stress microbiano mediante reto microbiano

$>$ Estudiar el comportamiento de la flora nativa y del Staphylococcus aureus (microorganismo de control) durante el almacenamiento a distintas temperaturas

Determinar la vida útil de la preserva de lomitos de caballa a tiempo acelerado

> Modelar el comportamiento de los factores de deterioro durante el almacenamiento de la preserva para poder estimar la vida útil a temperatura de refrigeración

Dstudiar la difusión de glicerol y sal y la pérdida de agua durante la etapa de deshidratación osmótica 


\section{MARCO TEORICO}

\section{Generalidades sobre la caballa}

La caballa (Scomber japonicus) pertenece a la Familia Scombridae y es un pez de hábitos pelágicos que, debido a la cantidad de lípidos que posee, se clasifica como una especie grasa. Esto la hace una de las tres especies más apreciadas para la elaboración de conservas en nuestro país junto a la anchoita (Engraulis anchoita) y el bonito (Sarda sarda) (Pereira y Molina, 2001). En la Argentina se la conoce también con el nombre común de "magrú". Como se puede observar en la Figura 1, posee un cuerpo alargado, fusiforme, robusto, ligeramente comprimido y cubierto con escamas diminutas. La línea lateral es bien evidente. Tiene cabeza pequeña; boca desprovista de dientes; ojos laterales, grandes y protegidos por una membrana adiposa transparente que tiene una abertura central de contorno oval; narinas pares próximas a los ojos; dos aletas dorsales, la primera espinosa y la segunda formada por radios blandos; aleta caudal bifurcada; aleta anal semejante a la segunda dorsal y aletas pectorales y ventrales cortas (Pereira y Molina, 2001).

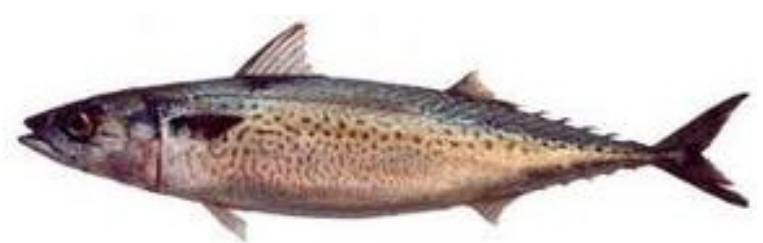

Figura 1 Ejemplar de caballa (Scomber japonicus)

La talla máxima observada fue de $57 \mathrm{~cm} \mathrm{y}$, frecuentemente, se capturan comercialmente ejemplares entre 20 a $45 \mathrm{~cm}$. La reproducción tiene lugar a fines de noviembre y diciembre sólo de noche, con una temperatura en superficie de alrededor de 16 o $17^{\circ} \mathrm{C}$. Su edad de maduración sexual está entre 1 y 2 años. Se alimentan de plancton, peces y calamaretes. En los dos primeros años de vida alcanza algo más del $50 \%$ de la talla máxima. La mayor edad observada es de 13 años, pero los desembarques comerciales tienen tallas de 2 a 4 años. Es una especie pelágica de aguas templado-cálidas (Cousseau y Perrota, 2000).

Se encuentra a lo largo de la costa atlántica sudamericana desde la Zona Común de pesca Argentino-Uruguaya ( $35^{\circ} \mathrm{S}$ ) hasta el paralelo de $45^{\circ} \mathrm{S}$, incluyendo el Golfo de San Matías. Se distinguen dos zonas de pesca (denominadas efectivos) separadas entre sí por el paralelo $39^{\circ} \mathrm{S}$. Uno de ellos, el "efectivo marplatense" o 
"norte", que se distribuye desde el paralelo $35^{\circ} \mathrm{S}$ hasta proximidades de Mar del Plata (38 ㅇ) y el otro, el "efectivo sur" (que comprende la zona denominada "El Rincón"), que se distribuye al sur del $39^{\circ} \mathrm{S}$ hasta el $45^{\circ} \mathrm{S}$ (Cousseau y Perrota, 2000).

Según Perrota y col. (2001), históricamente la pesquería de caballa se realizó sobre el efectivo norte por la flota de rada con asiento en el puerto de Mar del Plata, hacia fines de la primavera y principios de verano, cuando el recurso se acerca a la costa a reproducirse. Es a comienzos de la década del noventa que el efectivo sur empieza a ser explotado por embarcaciones de altura, entre agosto y noviembre, en la zona denominada “El Rincón”, entre el paralelo $39^{\circ} \mathrm{S}$ y el $41^{\circ} 30^{\prime}$ S. Posteriormente, se incorporaron embarcaciones costeras y fresqueras de altura con redes de arrastre de fondo (Perrotta, 1992; Perrotta y col., 2001). La pesca de especímenes adultos en el efectivo sur, se lleva a cabo desde fines de invierno y durante la primavera y es efectuada principalmente por buques fresqueros costeros y de altura provenientes de Mar del Plata (Garciarena y Buratti, 2012).

Las variaciones en las capturas de la flota marplatense son producidas principalmente por cambios en la accesibilidad del recurso. El factor de la capturabilidad puede aumentar cuando las embarcaciones se desplazan hacia aguas más profundas, o bien si las masas de agua de zonas más oceánicas se aproximan a la costa. Aunque la disponibilidad de caballas en el área de pesca sea abundante, cuando el mercado requiere pocos volúmenes de captura se produce una disminución del esfuerzo y del área de acción de la flota. De esta forma el mercado se convierte en el principal regulador de la magnitud de los desembarques de la especie (Agustinelli, 2014).

La tendencia de los últimos 10 años indica que se ha ido incrementando las capturas de caballa en Argentina, tal es así que, durante los años 2010 y 2011 la flota pesquera realizó las mayores capturas históricas de caballa con 27558 y 28253 toneladas respectivamente (MAGYP, 2011). En la actualidad, los mayores desembarques se realizan en el puerto de Mar del Plata, donde es procesado el 97,83 $\%$ del total capturado, seguido por pequeños porcentajes en los puertos de Puerto Madryn, Ushuaia, Necochea y San Antonio Este (MAGYP, 2013). Tiene como destino principal la industria conservera (76\%), donde se comercializa en el mercado interno, y el resto se exporta como pescado entero congelado, siendo Brasil el principal país importador (MAGYP, 2013). 


\section{Estructura y composición química de la especie}

La composición química de los peces varía considerablemente entre las diferentes especies y también entre individuos de una misma especie, dependiendo de la edad, sexo, medio ambiente y estación del año. Los principales constituyentes de la caballa son el agua (60-75\%), las proteínas (19-23,5\%), los lípidos (1-19\%) y las cenizas (1,2 -2,3\%) (Agustinelli, 2014). La fracción lipídica es el componente que muestra la mayor variación sobre todo en las especies grasas como la caballa.

El contenido de grasa en el pescado, independientemente de que sea magro o graso, tiene consecuencias sobre las características tecnológicas post mortem. Los cambios que ocurren en el pescado magro fresco pueden ser anticipados mediante el conocimiento de las reacciones bioquímicas en la fracción proteica, mientras que en las especies grasas deben incluirse los cambios en la fracción lipídica (que reducen el tiempo de almacenamiento debido a la oxidación lipídica).

El tejido muscular del pez se divide en músculo claro y músculo oscuro, siendo la proporción entre los mismos dependiente de la actividad del pez (Huss, 1999). Esto se debe a que ambos músculos representan dos sistemas motores separados que operan de forma independiente y utilizan distintos sustratos como combustible. El músculo oscuro cumple funciones en los movimientos de nado continuo (aeróbico) mientras que el músculo claro actúa como reserva de energía para nados cortos (anaeróbico) con alta actividad. La caballa pertenece al grupo de las especies pelágicas, que nadan de forma casi continua, por lo que el contenido de músculo oscuro puede llegar hasta un $48 \%$ de su peso (Huss, 1999). Este se encuentra debajo de la piel, a lo largo de los laterales del cuerpo y en las regiones asociadas a una gran actividad como lo es la zona cercana a la cola y aletas. El alto contenido de mioglobina, enzimas y contenido lipídico en el músculo oscuro respecto al músculo claro, lo hacen altamente susceptible al deterioro por reacciones de oxidación (Huss, 1999).

El contenido de agua y de lípidos presenta una alta variabilidad, estrechamente relacionada con factores como la alimentación, nado migratorio, cambios sexuales relacionados con el desove, la estación del año, entre otros (Huss, 1999). La caballa (especie grasa) se diferencia de las especies magras en cuanto a la distribución del contenido lipídico en el músculo. Los lípidos se sitúan tanto en el músculo oscuro como en las células de depósito ubicadas en el músculo blanco, en el tejido subcutáneo, en los músculos del vientre y en los músculos que mueven las aletas y cola. Mientras que en las especies magras utilizan el hígado como depósito de 
energía. Los lípidos almacenados son utilizados durante las épocas de migración y durante el desarrollo de las gónadas (Huss, 1999).

Los lípidos presentes en las especies de peces óseos pueden ser divididos en dos grandes grupos: los fosfolípidos y los triglicéridos. Los fosfolípidos constituyen la estructura integral de la unidad de membranas en la célula, por lo tanto, a menudo se le denomina lípidos estructurales. Los triglicéridos son lípidos empleados para el almacenamiento de energía en depósitos de grasas, generalmente dentro de células especiales rodeadas por una membrana fosfolipídica y una red de colágeno relativamente débil. Los triglicéridos son a menudo denominados depósitos de grasa (Connell, 1990; Huss, 1999).

La caballa posee características en su composición lipídica que la enriquece desde el punto de vista nutricional, debido a la presencia de Ácido Eicosapentaenoico (EPA) y el Ácido Docosahexaenóico (DHA). El consumo de estos ácidos grasos está altamente relacionado con la disminución de enfermedades cardíacas (Connor, 2000).

Las proteínas del músculo del pez se pueden dividir en tres grupos:

> Proteínas estructurales (actina, miosina, tropomiosina y actomiosina), que constituyen el 70-80 por ciento del contenido total de proteínas.

> Proteínas sarcoplasmáticas (mioalbúmina, globulina y enzimas), que son solubles en soluciones salinas neutras de baja fuerza iónica $(0,15 \mathrm{M})$. Esta fracción constituye el 25-30 por ciento del total de proteínas.

> Proteínas del tejido conectivo (colágeno), que constituyen aproximadamente el 3 por ciento del total de las proteínas en teleósteos y cerca del 10 por ciento en elasmobranquios.

El pescado es considerado como una fuente de proteínas rica en aminoácidos esenciales (lisina, metionina, cisteína, treonina, triptófano, entre otros). Además, contiene minerales ( $K, P, M g, I$ y Fe) y vitaminas (grupos $A, D$ y $E$ ). Las proteínas de alto valor biológico son el componente más importante en cuanto al aporte que brinda la carne de pescado para la alimentación humana. El alto grado de aprovechamiento de la proteína de pescado obedece a la clase y relación existente entre los aminoácidos que la componen, sobre todo en lo referente a aminoácidos esenciales (Huss, 1999; Suzuki, 1987) 


\section{Cambios bioquímicos en el pescado}

El pescado es uno de los alimentos del reino animal más susceptibles al deterioro ya que sus tejidos musculares se deterioran más rápidamente que los músculos de los mamíferos. El alto contenido de agua y aminoácidos libres y el bajo contenido de tejido conectivo, comparado con otras carnes, contribuyen a su veloz deterioro. Inmediatamente luego de su muerte, distintos cambios bioquímicos y enzimáticos son activados en los músculos del pescado, especialmente si se manipulan incorrectamente (Pereira de Abreu y col., 2010).

\section{$\underline{\text { Cambios en las proteínas }}$}

Los cambios en la calidad del pescado pueden ser monitoreados mediante parámetros bioquímicos o enzimáticos de la frescura y mediante cambios microbiológicos durante la manipulación y el almacenamiento. Las enzimas endógenas juegan un rol muy importante en la degradación de las proteínas del músculo del pescado luego de la muerte. Se considera que la degradación de la estructura muscular es causada por proteasas como la calpaína y la catepsina D, B y L (Godiksen y col., 2009). En pescado refrigerado en hielo, la miosina es la proteína mas hidrolizada, seguida por la troponina-T y las a y $\beta$-tropomiosina. An y col. (1994), reportaron que la degradación de miofibrillas en filetes de merluza del Pacífico a $0^{\circ} \mathrm{C}$ es causada por las catepsinas. Además de las proteasas endógenas, distintos microorganismos que crecen en el músculo secretan una gran variedad de enzimas hidrolíticas, particularmente proteasas. Pseudomonas spp. es el gran responsable del deterioro de las proteínas de los alimentos (Pantazi y col., 2008). El deterioro del músculo del pescado causa una disminución en el valor nutritivo, en la aceptabilidad y en la funcionalidad de las proteínas (Masniyom, 2011).

El colágeno es uno de los principales constituyentes del tejido conectivo intramuscular en el pescado. Es considerado como una proteína relativamente estable, que rodea cada fibra muscular y conecta al miosepto. La degradación del colágeno lleva a una alteración de la textura del músculo. Según Montero y Borderias (1990), la disminución de la dureza de la carne es debida a la desintegración de las fibras del colágeno causada por degradación enzimática y por la producción de ácido láctico durante la glicólisis anaeróbica post-mortem. Hernandez-Herrero y col. (2003), indicaron que la reducción de la dureza de la carne de pescado luego de su muerte se debió en mayor grado a cambios en la estructura del colágeno que por los cambios en las proteínas miofibrilares. 
Para obtener un producto final de buena calidad es indispensable contar con materia prima en óptimas condiciones. El manejo de la caballa desde que se pesca hasta que llega a procesarse dentro de los frigoríficos es de fundamental importancia para que no se deteriore, de acuerdo a lo mencionado anteriormente.

\section{$\underline{\text { Cambios en los lípidos }}$}

El cambio en los lípidos del pescado es responsable de la pérdida de calidad durante el almacenamiento extendido, especialmente si las condiciones ambientales no son las adecuadas. Los cambios están dados debido a lipólisis, oxidación lipídica y la interacción de los productos de estos procesos con componentes no lipídicos como las proteínas. Los músculos de pescado contienen una abundante cantidad de lípidos de cadena larga con una alta proporción de ácidos grasos poliinsaturados (AGPI), los cuales sufren cambios debido a su oxidación durante el procesamiento y el almacenamiento. Además del alto grado de AGPI, la presencia de distintos pigmentos hemo y de iones metálicos genera una aceleración de la oxidación lipídica. Estas reacciones resultan en la producción de diversas sustancias, algunas de las cuales tienen sabores y olores desagradables. La magnitud de estas reacciones depende principalmente de la especie de pescado y de la temperatura de almacenamiento (Connell, 1990; Huss, 1999). Los pescados grasos como la caballa son particularmente susceptibles a la degradación lipídica, la cual puede ocasionar severos problemas en la calidad, incluso durante el almacenamiento a temperaturas bajo cero.

La oxidación lipídica se genera mediante un mecanismo autocatalítico (Huss, 1999; Ólafsdóttir y col., 1997), se inicia por la escisión de un átomo de hidrógeno del átomo de carbono central de la estructura pentahédrica presente en la mayoría de las acilcadenas de los ácidos grasos con más de un doble enlace. El radical lipídico (L•) que se forma reacciona muy rápidamente con el oxígeno atmosférico formando un radical peróxido (LOO•), el cual puede nuevamente escindir un hidrógeno de otra acilcadena produciendo un hidroperóxido $(\mathrm{LOOH})$ y un nuevo radical $L \cdot$. Esta propagación continúa hasta que uno de los radicales es removido mediante reacción con otro radical o con un antioxidante $(\mathrm{AH})$ del cual resulta un radical $(A \bullet)$ mucho menos reactivo. Posteriormente, debido a la catálisis de iones de metales pesados, los hidroperóxidos continúan dividiéndose hasta formar cadenas carbonadas más cortas, que son los productos secundarios de la autooxidación: aldehídos, cetonas, alcoholes, pequeños ácidos carboxílicos y alcanos. Estos productos producen diferentes aromas y sabores y, en algunos casos, decoloración amarillenta. Según Thanonkaew y col. (2006), el cambio de color en calamar está acompañado por el desarrollo de olor 
rancio durante el almacenamiento congelado. Algunos de los aldehídos formados pueden ser determinados como sustancias reactivas al ácido tiobarbitúrico. Los iones metálicos son de gran importancia en el proceso de iniciación, ya que catalizan la formación de especies reactivas al oxígeno, como el radical hidróxilo $(\mathrm{OH} \bullet)$, el cual reacciona inmediatamente con los lípidos o cualquier otra molécula en el lugar donde ha sido generado (Huss, 1999).

Durante el almacenamiento se generan ácidos grasos libres (hidrólisis de los triglicéridos) debido a la actividad de enzimas originadas en el tracto digestivo o excretadas por ciertos microorganismos. También debido a lipasas celulares, pero en menor grado (Connell, 1990; Huss, 1999).

Algunos factores que determinan el deterioro de los lípidos son el oxígeno, el $\mathrm{pH}$, la luz, la temperatura y la $\mathrm{a}_{\mathrm{w}}$. En presencia de altos contenidos de oxígeno en el envase se acelera la rancidez de los lípidos, generando colores y aromas indeseables. Es posible disminuir la lipólisis y la oxidación lipídica mediante la modificación de la atmósfera del envase (Ej. envasado al vacío).

\section{Deterioro microbiológico e inocuidad en el pescado}

El deterioro microbiológico del pescado puede ser causado por la actividad de enzimas y microorganismos, generando el rechazo de los productos para consumo humano. El músculo de un pez saludable o de un pescado recién capturado es estéril, debido a que el sistema inmunológico del pez previene el crecimiento de bacterias en el músculo. Cuando el pez muere, el sistema inmunológico colapsa y las bacterias proliferan libremente. En la superficie de la piel, las bacterias colonizan en una amplia extensión la base de las escamas. Durante el almacenamiento, las bacterias invaden el músculo penetrando entre las fibras musculares. Durante el almacenamiento en hielo, la población bacteriana se duplica en aproximadamente 1 día y después de 2 o 3 semanas alcanza unas $10^{8}$ a $10^{9} \mathrm{UFC} / g$ (Huss, 1999). Los microorganismos asociados con el pescado dependen de factores como la locación geográfica, factores medioambientales, los métodos de captura, de almacenamiento y transporte.

Uno de los mayores problemas asociados al consumo de caballa es la posible formación bacteriana de una amplia variedad de aminas, como resultado de la descarboxilación directa de aminoácidos. La caballa, como otros escómbridos (atún, bonito, jurel) tiene la particularidad de presentar un alto contenido de histidina libre en su tejido muscular, principalmente en el músculo rojo (Taylor, 1986). La histidina es un aminoácido esencial, el cual se encuentra presente principalmente en los pigmentos 
(hemoglobina, mioglobina y hematina), en los citocromos (especialmente en el citocromo C) y en enzimas como la catalasa. La formación bacteriana de histamina depende de la disponibilidad de histidina libre, la acción descarboxilasa y de las condiciones del medio (temperatura, $\mathrm{pH}$ ). Para que ocurra la formación de histamina deben coexistir los tres factores mencionados (Guizani y col., 2005; Yeannes, 1995). La intoxicación escombroide o por histamina se relaciona generalmente con el consumo de pescado contaminado con una carga microbiana capaz de provocar la descarboxilación de histidina libre por acción enzimática, atribuida fundamentalmente a Morganella morganii, Proteus spp. como las bacterias mas rápidamente formadoras de histamina y también a la acción de Clebsiela pneumoniae, Enterobacteriaceae, Clostridium spp y Lactobacillus spp, resultando en un alto contenido de la amina biógena histamina (Graü y col., 2003; Lehane y Olley, 2000; Taylor, 1986).

En los productos de la pesca, como en cualquier otro alimento listo para consumir que requiere de la manipulación por parte de operarios, aparece un grave peligro asociado a la contaminación del alimento con Staphylococcus aureus.

\section{Staphylococcus aureus}

El Staphylococcus aureus (S. aureus) ha sido reconocido como un microorganismo indicador de una deficiente higiene durante el procesamiento de los alimentos y una de las mayores causas de gastroenteritis (debido a la ingesta de alimentos) alrededor del mundo (Soriano y col. 2002). Es una bacteria anaerobia facultativa, con forma de coco, gram-positiva y no tiene requerimientos particulares en cuanto a su crecimiento (nutrición y medio ambiente), tolerando la sal y $a_{w}$ tan bajas como 0,86 . Puede crecer hasta valores de $\mathrm{pH}$ de 4,5 y la temperatura mínima de crecimiento se encuentra entre 7 y $10^{\circ} \mathrm{C}$ (Bennett y Lancette, 1995; Valero y col., 2009). Estas características le permiten crecer y sobrevivir en una gran variedad de condiciones ambientales así como también la posibilidad de persistir en ambientes hostiles (Ej. superficies secas) durante largos períodos.

Los estafilococos son organismos ubicuos y se pueden encontrar en el agua, el aire, el polvo, la leche, las aguas residuales, el pavimento, otras superficies y todos los artículos que entran en contacto con el hombre, además, sobreviven muy bien en el medio ambiente. No obstante, su principal reservorio y hábitat es la nariz, garganta y piel del hombre y animales. La tasa de portadores humanos puede ser hasta del 60 por ciento de los individuos sanos, con una media del 25-30 por ciento de la población que es positiva para las cepas productoras de enterotoxina (Valero y col., 2009). 
La intoxicación por $S$. aureus se debe a la ingesta de alimentos que contienen su enterotoxina. Una dosis de enterotoxina de $1 \mu \mathrm{g}$ en un alimento contaminado produce síntomas de intoxicación. Este nivel de toxina es típicamente alcanzado cuando la población de $S$. aureus alcanza valores entre $10^{5}$ y $10^{6} \mathrm{UFC/g}$ (FDA, 1992; Notermans y Heuvelman, 1983). Si las condiciones ambientales durante el almacenamiento del alimento permiten el desarrollo del microorganismo (Ej. un abuso de tiempo y temperatura), la enterotoxina puede ser producida generando un alto riesgo de intoxicación para los consumidores (Todd y col., 2008). Es una pobre competidora contra otras bacterias y es fácil de destruir mediante la cocción, sin embargo, sus toxinas pueden sobrevivir los procesos de cocción (Bennett y Lancette, 1995).

Los síntomas comunes, que pueden aparecer entre 2 y 4 horas después del consumo de alimentos contaminados, son náuseas, vómitos y algunas veces diarrea. Normalmente, los síntomas no duran más de 24 horas, pero en casos graves, la deshidratación puede llevar a la conmoción y al colapso.

Según el reporte del año 2006 de la European Food Safety Authority (EFSA, 2007), 35 brotes asociados a intoxicación por $S$. aureus fueron reportados durante el año 2006 en la Unión Europea. Estos brotes resultaron en 777 casos, 14 hospitalizaciones y una muerte. En España, el número de casos reportados al Sistema Español de Información Microbiológica debido a la ingesta de $S$. aureus se incrementó de 442 casos en 2001 a 649 casos en 2006. Sin embargo, la real incidencia de la intoxicación alimentaria por ingesta de $S$. aureus resulta mucho mayor debido a que muchos casos no son reportados a las autoridades sanitarias. Entre 2005 y 2010, el S. aureus fue responsable de cerca del $6,8 \%$ de todos los brotes de ETA en Korea (Park y col. 2012). Además, la intoxicación causada por este microorganismo representa una considerable carga social incluyendo gastos médicos y bajas en la productividad.

Distintos cortes de carne, productos de carne cocidos y alimentos preparados mantenidos en condiciones inadecuadas de almacenamiento luego de su cocción han sido frecuentemente implicados como fuente de intoxicación debido a $S$. aureus (Castillejo-Rodríguez y col., 2002). Diversos estudios reportan la presencia de esta bacteria en comidas listas para consumir y en alimentos perecederos como en jamón ahumado y cerdo crudo (Atanassova y col. 2001), pescado (Simon y Sanjeev, 2007) y pollo (Pepe y col., 2006).

La presencia de $S$. aureus en las zonas de manipulación de alimentos ha sido ampliamente demostrada por distintos estudios, reportando su presencia en las superficies de trabajo y utensilios (DeVita y col., 2007; Sneed y col., 2004). Otros estudios han reportado también su presencia en las manos de los trabajadores ya que 
este microorganismo suele ser miembro transitorio y/o residente de la piel (Sattar, 2001).

Por todo lo expresado anteriormente, los lomitos de caballa pueden ser contaminados con $S$. aureus durante el proceso de elaboración a través de manipuladores infectados o a partir del medio ambiente.

\section{Tecnología de obstáculos}

La preservación de alimentos implica exponer los microorganismos a un ambiente hostil a fin de inhibir su crecimiento, acortar su supervivencia o causar su muerte. La estabilidad y seguridad microbiana de la mayoría de los alimentos se basa en la combinación de varios factores (obstáculos), que no deberían ser vencidos por los microorganismos. Se tiene en cuenta la influencia de los diferentes métodos de preservación en la fisiología y el comportamiento de los microorganismos, por ejemplo su homeostasis, el agotamiento metabólico, las reacciones de estrés, etc.; surge entonces el concepto de preservación de alimentos multitarget (multiblancomultiobjetivo) (Leistner y Rodel, 1976, Leistner, 1987, 1994, 2000).

La homeostasis (equilibrio interno) de las bacterias es alterado por diferentes obstáculos y, durante el almacenamiento, utilizan todo posible mecanismo reparador para poder sobrevivir al ambiente hostil. Durante esta supervivencia, los microorganismos usan toda su energía y mueren (Leistner, 2000).

El "efecto barrera", es de fundamental importancia para la preservación de alimentos dado que en un producto estable las barreras controlan los procesos de deterioro, intoxicación y fermentación no deseados. Además, las complejas interacciones entre temperatura, actividad de agua, $\mathrm{pH}$, potencial redox, etc., son significativas para la estabilidad microbiana de los alimentos. La tecnología de barreras (o tecnología de obstáculos o métodos combinados), permite mejoras en la seguridad y calidad mediante una combinación inteligente de obstáculos que aseguran la estabilidad y seguridad microbiana, así como propiedades nutritivas satisfactorias (Leitsner, 2000).

En el desarrollo de esta tesis se utilizaron distintas técnicas de preservación, siendo las más importantes: disminución de la $\mathrm{a}_{\mathrm{w}}$ (mediante $\mathrm{DO}$ ), envasado al vacío y pasteurización a bajas temperaturas. 


\section{Deshidratación Osmótica (DO)}

El proceso de DO es frecuentemente aplicado para conservar la calidad y estabilidad de los alimentos. La DO produce una disminución de la actividad de agua $\left(a_{w}\right)$, prolongando así su vida útil (Rastogi y Raghavarao, 2002). El nivel de $a_{w}$ alcanzado en los productos deshidratados osmóticamente generalmente no es suficiente para proporcionar la estabilidad microbiológica durante el almacenamiento por lo que es necesario combinar con otros métodos de conservación tales como tratamientos térmicos moderados o refrigeración, entre otros (Ayala-Aponte y col., 2009; Collignan y col., 2001).

La DO es un proceso que consiste en la inmersión del alimento sólido, ya sea entero o en piezas, en soluciones acuosas de alta concentración en azúcares y/o sales para provocar al menos dos flujos principales, simultáneos y en contracorriente: el flujo de agua desde el alimento hacia la solución y la transferencia simultánea de soluto desde la solución hacia el alimento. Estos flujos se deben a los gradientes de concentración del agua y soluto existentes a un lado y otro de las membranas que forman el tejido del alimento. Durante el proceso, los contenidos de agua y de soluto en el alimento cambian hasta lograr un contenido en equilibrio con la solución osmótica (Corzo y Bracho, 2009; Lemus-Mondaca, 2009).

La solución osmótica que se usa para deshidratar el producto debe ser rica en solutos que reduzcan la actividad de agua del mismo y que generen una diferencia de presión osmótica entre el producto a deshidratar y la solución. Distintos solutos, incluyendo azúcares, sales y humectantes pueden ser utilizados para reducir la $a_{w}$ en el rango que va desde 0,6 a 0,9 y de esta manera obtener alimentos de humedad intermedia. La selección de los solutos adecuados para la estabilización de los alimentos implica consideraciones acerca de la capacidad de reducción de la $a_{w}$, el impacto del sabor, la textura, el costo y la seguridad. Teniendo en cuenta estas características, una combinación de cloruro de sodio y glicerol ha sido convenientemente utilizada para generar productos de humedad intermedia (Brockman, 1970; Favetto y col., 1981; Moreira y col., 2007; Sánchez Pascua y col., 1994).

Además de disminuir la $\mathrm{a}_{\mathrm{w}}$, la DO es utilizada como un pretratamiento para mejorar las características sensoriales, nutricionales y funcionales de los alimentos sin cambiar su integridad (Lemus-Mondaca y col., 2009). Los productos adquieren las propiedades mecánicas necesarias (firmeza, dureza) para permitir un eficiente posttratamiento. Además, se modifican las propiedades térmicas (conductividad y 
difusividad) mejorando la eficiencia de tratamientos térmicos posteriores (Ochoa Martínez y Ayala Aponte, 2005).

Las soluciones osmóticas pueden ser re-utilizadas durante algunos ciclos y así disminuir el costo del proceso. Cuando ya no se pueden re-utilizar deben ser tratadas para evitar contaminación microbiana (Dalla Rosa y Giroux, 2001; Keqing, 2004).

A pesar de sus ventajas, la DO aún tiene restricciones para su implementación a nivel industrial tanto en el diseño de los equipos como de los procesos. Estas restricciones están relacionadas principalmente con la falta de modelos predictivos de cinéticas de pérdida de agua y ganancia de sólidos que permitan relacionar con precisión las características de los productos deshidratados con las de la materia prima y las variables del proceso. Aunque la deshidratación osmótica ha sido utilizada desde muchos años atrás, generalmente se ha trabajado en forma empírica y la información experimental se interpreta con modelos que son válidos solamente para reproducir condiciones semejantes a las del trabajo del cual fueron obtenidos. Las limitaciones en el modelado de la DO se deben principalmente a la presencia de un mecanismo complejo de transferencia de masa simultánea de dos flujos en contracorriente en un sistema que es polifásico y multicomponente (Barat, 1998).

El conocimiento de la cinética de transferencia de masa durante la DO es de gran importancia tecnológica, ya que permite estimar el tiempo de inmersión de un alimento en la solución osmótica para obtener productos con determinados contenidos de agua y solutos. Esto permite diseñar adecuadamente un proceso (Schmidt y col., 2009).

\section{Variables que afectan el proceso de DO}

Las principales variables que afectan el proceso de DO son: la concentración y temperatura de la solución osmótica, el tiempo de inmersión, la estructura del alimento, la relación alimento:solución, la agitación, el tamaño y la geometría del alimento, la naturaleza y peso molecular de los solutos, la presión de trabajo y el pretratamiento del producto (Rastogi y Raghavarao, 1996; Uribe y col., 2011). A continuación se describen algunas.

Agente osmótico: la naturaleza del agente osmótico es fundamental para definir el comportamiento del producto durante el proceso de deshidratación osmótica. Las soluciones concentradas de sacarosa han sido las más comúnmente utilizadas en frutas y el $\mathrm{NaCl}$ en vegetales, pescados y carnes, debido al sabor que le imparten a los alimentos. La interacción de los solutos con el agua y la 
matriz sólida del alimento dependerá de la naturaleza y propiedades físicas del soluto (viscosidad, poder depresor de la $a_{w}$, etc.). A iguales concentraciones iniciales, cuanto mayor peso molecular tenga el agente osmótico (como en el caso de los polisacáridos) menor será la ganancia de sólidos (difunden poco hacia el interior del tejido) y mayor la pérdida de agua. En la actualidad existe gran cantidad de agentes osmóticos tales como la sacarosa, glucosa, azúcar invertido, jarabe de maíz, maltosa, melaza, cloruro de sodio, cloruro de potasio, glicerol, manitol, propilenglicol, sorbitol, entre otros (Keqing, 2004).

Concentración de la solución: la concentración de la solución osmótica define la fuerza impulsora para la transferencia de materia. El intercambio de masa se ve favorecido usando una solución altamente concentrada. Según Ramallo (2010), la pérdida de agua se incrementa más que la ganancia de sólidos cuando hay un aumento en la concentración de la solución osmótica.

Temperatura: La velocidad de la DO está afectada en gran medida por la temperatura. Esta es la variable que más afecta a la cinética de pérdida de agua y de ganancia de sólidos. El incremento de la temperatura de proceso provoca un aumento de la velocidad de transferencia de masa, tanto en lo que refiere a la salida de agua como a la entrada de sólidos solubles (Keqing, 2004). La pérdida de agua se incrementa con la temperatura, sin embargo la ganancia de sólidos es menos afectada por esta variable del proceso (Ramallo, 2010). Cuando se emplean altas temperaturas el soluto no puede difundir a través de la membrana celular tan fácilmente como el agua y el equilibrio osmótico se alcanza en principio por el flujo de agua desde la célula (se concentran las soluciones internas de las células). Este tipo de equilibrio produce un alimento con menor ganancia de sólidos. Además hay que tener en cuenta que la viscosidad de la solución hipertónica disminuye con la temperatura incrementándose el coeficiente de difusión del agua. A temperaturas mayores de $45{ }^{\circ} \mathrm{C}$ se incrementa la velocidad de transferencia de masa al mismo tiempo que pueden tener lugar reacciones de pardeamiento y deterioro del aroma. Altas temperaturas, mayores de $60{ }^{\circ} \mathrm{C}$, modifican las características del tejido favoreciendo el fenómeno de impregnación y de este modo la ganancia de sólidos. La temperatura óptima de procesamiento depende del alimento utilizado.

Naturaleza y propiedades fisicoquímicas del alimento: la composición química (proteínas, carbohidratos, sales, grasas, etc.), la estructura física (porosidad, tipo 
y arreglo de las células, orientación de las fibras, etc.) y los pretratamientos pueden afectar la cinética de la ósmosis en los alimentos. La complejidad de la estructura y la variabilidad de la respuesta fisiológica del tejido ante el proceso osmótico plantean dificultades al modelar la cinética y predecir los cambios físicos y químicos inducidos en el producto durante la ósmosis (Chiralt y Talens, 2005).

Geometría del material: el proceso de deshidratación osmótica depende de la geometría del material a deshidratar. Depende de la relación área superficial por unidad de volumen y de la longitud de difusión, es decir del espacio que deben recorrer el agua y los solutos involucrados en el transporte de masa. Según Sablani y Rahman (2003), la ganancia de sólidos se incrementa con el área superficial y disminuye cuando la longitud de difusión se incrementa, mientras que la pérdida de agua pasa por un máximo (dependiendo de la forma) y luego disminuye. Esta disminución de la pérdida de agua podría deberse a una reducción de la difusión causada por una alta ganancia de sólidos en la superficie con formación de una capa de solutos (Ramallo, 2010).

Agitación de la solución osmótica: la velocidad de deshidratación osmótica puede aumentarse mediante la agitación del fluido, en tanto que la ganancia de sólidos se ve menos afectada por esta variable de operación (Moreira y Sereno, 2003). En algunos casos el incremento en la velocidad de deshidratación es tan pequeño que puede ser más económico no utilizar agitación. Para determinados rangos de temperatura, se encontró que la velocidad de agitación favorece la pérdida de agua y disminuye la ganancia de sacarosa (Tonon y col., 2007).

Presión de operación: la presión de operación es otro parámetro a tener en cuenta. El vacío en la deshidratación osmótica produce cambios en el mecanismo de transferencia de masa ya que intensifica el flujo capilar y el total de agua transferido resulta de una combinación de difusión tradicional y flujo por capilaridad, y es afectado por la porosidad del material. Se ha observado que la ganancia de soluto, en el proceso osmótico, se ve favorecida con el uso de bajas presiones (Fito, 1994). Las altas presiones pueden ser utilizadas como un tratamiento previo para acelerar el transporte difusivo dentro de los alimentos durante pasos subsecuentes del proceso. 


\section{Pasteurización}

La pasteurización es ampliamente aceptada como un método efectivo de destrucción de microorganismos vegetativos patógenos en alimentos (Wilbey, 2014). Su uso es muy común hoy en día por ser eficiente, ambientalmente "amigable", saludable y de bajo costo en comparación con otras tecnologías de conservación. Las temperaturas utilizadas permiten una mayor retención de las propiedades originales de los alimentos. El objetivo principal de la pasteurización de los alimentos de baja acidez es la reducción de los agentes patógenos responsables de las enfermedades transmitidas por los alimentos (Silva y Gibbs, 2010).

La palabra "pasteurización" tiene su origen en el trabajo del científico francés Louis Pasteur y se refiere a un tratamiento térmico suave (entre 50 y $90^{\circ} \mathrm{C}$ ) utilizado para la preservación de alimentos, cuyo objetivo es inactivar formas vegetativas de microorganismos patógenos y deteriorantes. A diferencia de la esterilización, el alimento pasteurizado no es estéril debido a la posible presencia de esporas microbianas resistentes al calor (Lund, 1975). Por lo tanto, otras formas de preservación tales como la refrigeración, atmósfera modificada (por ejemplo, envasado al vacío), la adición de conservantes antimicrobianos, la disminución de la $a_{w} 0$ combinaciones de las técnicas mencionadas, se requieren para la estabilización y la distribución del producto (Silva y Gibbs, 2010).

La pasteurización fue re-definida por el Departamento de Agricultura de los Estados Unidos como "cualquier proceso, tratamiento, o combinación de los mismos, que se aplica a los alimentos para reducir los microorganismo más resistentes de importancia para la salud pública a un nivel que sea improbable que presenten un riesgo para la salud pública en condiciones normales de distribución y almacenamiento" (NACMCF, 2006).

En general, los productos alimenticios pueden tener una vida útil de 10 días siempre y cuando alcancen alguno de estos requerimientos: una $a_{w}<0,97$, un porcentaje de sal $>3,5 \%$, un $\mathrm{pH}<5,0$ o un tratamiento térmico de $90^{\circ} \mathrm{C}$ durante 10min (FSA, 2008). Sin embargo, si se desea obtener un alimento con un tiempo de conservación prolongado, la siguiente información debe ser obtenida para establecer un proceso de pasteurización adecuado (Silva y Gibbs, 2010):

Identificar los microorganismos patógenos capaces de crecer en la comida a ser pasteurizada que puedan proliferar bajo las condiciones de almacenamiento establecidas. 
$>$ Obtener de la literatura los datos de la resistencia al calor (valores de D y z), en particular aquellos microorganismos capaces de crecer en el alimento a pasteurizar.

> Seleccionar el microorganismo patógeno más resistente térmicamente como el objetivo de la pasteurización.

> Siempre revisar el potencial crecimiento de Clostridium botulinum en el nuevo alimento de baja acidez

$>$ Establecer un valor de P mínimo (valor de pasteurización), que proporcione la letalidad necesaria en el microorganismo elegido en el punto de calentamiento más lento de los alimentos (Betts y Gaze , 1992).

$>$ Realizar pruebas de reto microbiano para validar experimentalmente el proceso térmico en condiciones de almacenamiento específicas.

> Analizar el uso de conservantes para asegurar la inocuidad y aumentar la vida útil.

\section{Envasado al vacío}

Las tecnologías de envasado son muy importantes para proteger los productos alimenticios contra los efectos deteriorantes, ya sean microbiológicos, bioquímicos o físicos. Las funciones principales son: el control del crecimiento microbiano y de la calidad del alimento y la extensión de su vida útil. Además, el envase sirve de contención y contribuye al marketing y a la comunicación al consumidor (Restuccia y col., 2010). La velocidad del deterioro durante el almacenamiento de un producto depende de la composición bioquímica de los sustratos y de los metabolitos presentes en el alimento, de la contaminación microbiana y de las condiciones ambientales durante el tiempo de guarda. Los productos del mar frescos se deterioran más rápidamente que otros alimentos frescos. Es por esto que el marketing ha hecho hincapié en conservas enlatadas y productos congelados. Desde que los alimentos marinos listos para cocinar o frescos se han vuelto cada vez más populares, estos se encuentran presentes en los distintos mercados. Diversas técnicas se han utilizado para extender la vida útil de los productos de la pesca ya que su corta vida útil es un factor limitante.

El envasado en atmósfera modificada (EAM) es un método de preservación de alimentos que ha recibido mucha atención en los últimos años. El EAM es definido como el aislamiento de productos alimenticios dentro de un material barrera a los gases, en donde el ambiente gaseoso ha sido cambiado (Sivertsvik y col., 2002). Es 
utilizado para extender el período de vida útil de alimentos frescos o mínimamente procesados. Ha sido demostrado que el EAM retrasa el crecimiento microbiano y el deterioro enzimático. La vida útil de productos de la pesca refrigerados y envasados en atmósfera modificada ha sido incrementada como resultado de la extensión de la fase de latencia de distintas bacterias aeróbicas deteriorantes. Generalmente, la vida útil del pescado refrigerado está limitada debido al crecimiento bajo condiciones aeróbicas de microorganismos Gram-negativos como Pseudomonas, Shewanella putrefaciens, y Aeromonas (Ravi-Sankar y col., 2008).

La aplicación exitosa del EAM para inhibir el deterioro y extender la vida útil de los productos de la pesca está asociada a un número de factores interrelacionados, como el desarrollo de nuevos materiales de empaque incluyendo el envasado bajo vacío y el envasado con gases (como respuesta a las demandas del consumidor en busca de productos atractivos y de aspecto fresco); las preocupaciones de los consumidores en cuanto al uso de conservantes y la percepción favorable del consumidor hacia la tecnología de EAM (Masniyom, 2011).

El EAM es utilizado para modificar la atmósfera que rodea los productos frescos. Bajo esta denominación se encuentran el envasado bajo vacío, la aplicación de gases dentro del envase y el envasado activo. El envasado al vacío, es utilizado para almacenar por largos períodos de tiempo productos deshidratados y para alargar la vida útil de distintos productos del mar. El alimento es envasado en bolsas especialmente diseñadas con propiedades barrera contra el oxígeno y el agua. El aire es removido bajo vacío y la bolsa es sellada mediante la aplicación de calor. En la Figura 2 se puede observar la envasadora al vacío utilizada en esta tesis. 


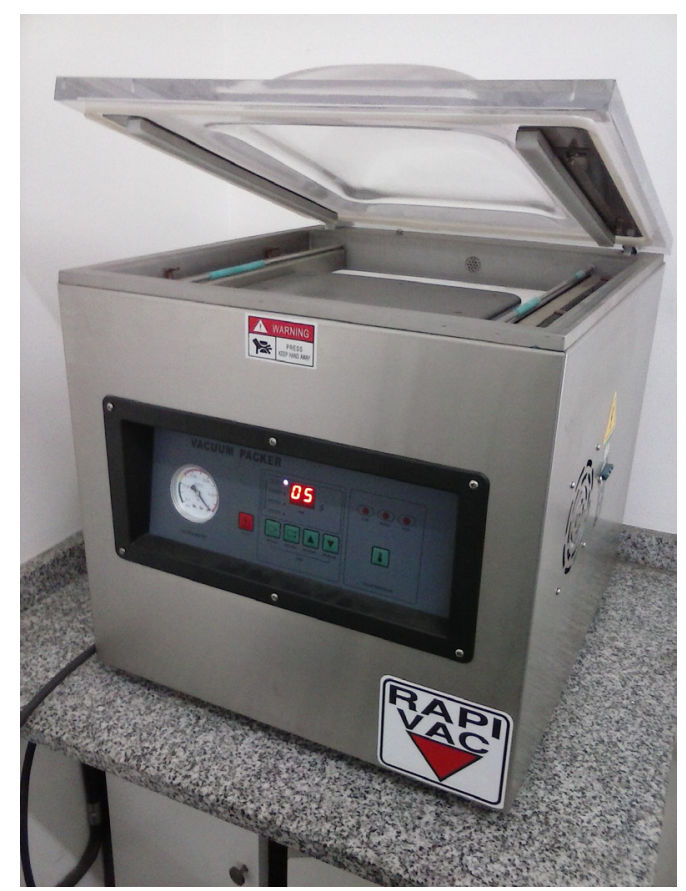

Figura 2 Envasadora al vacío

Los microorganismos aerobios (particularmente Psuedomonas spp. y Aeromonas spp.) no pueden crecer en productos almacenados en una atmósfera conteniendo niveles bajos de oxígeno (menores al 1\%). Arashisar y col. (2004), reportaron una disminución en los recuentos de bacterias psicrótrofas y mesófilas en trucha envasada al vacío. Además, el envasado al vacío puede prevenir la rancidez oxidativa manteniendo los caracteres organolépticos del pescado procesado. Pantazi y col. (2008) y Giménez y col. (2012), encontraron que productos de pez espada y trucha arco iris envasados al vacío tuvieron menores valores de malonaldehido con respecto a iguales productos envasados en aire. Esto fue consecuencia de la ausencia de oxígeno en los envases.

\section{Caracterización sensorial}

El análisis sensorial es una disciplina científica usada para evocar, medir, analizar e interpretar las reacciones a aquellas características de los alimentos y otras sustancias, que son percibidas por los sentidos de la vista, el olfato, gusto, tacto y oído (Barda N., 2012).

Las tres metodologías utilizadas dentro del análisis sensorial son la discriminativa, descriptiva y afectiva. El análisis descriptivo representa la metodología más sofisticada en comparación con los otros métodos. Los resultados de este análisis 
comprenden una descripción completa de los productos y proveen la base para determinar las características sensoriales que son importantes para la aceptabilidad, como así mismo para poder relacionar variables de proceso de formulación o cambios puntuales en las características sensoriales. Entre otras aplicaciones, los ensayos descriptivos son útiles para realizar (DESA, 2010):

$>$ Pruebas de almacenamiento: Si existen cambios en los productos durante el almacenamiento, el análisis descriptivo provee la base para comparar productos.

Desarrollo de nuevos productos: El análisis descriptivo se usa para establecer el producto deseado, determinar en qué difieren del ideal los productos de ensayo y proveer información precisa sobre el producto final. Esto último es útil para la promoción y control de calidad del producto.

Control de calidad: Puede ser utilizado para identificar los límites de tolerancia sensoriales de un producto y para controlar desviaciones del standard a lo largo del tiempo.

Relaciones instrumentales-sensoriales: El análisis descriptivo es especialmente útil en la identificación de diferencias sensoriales en el producto que se correlacionan con diferencias en medidas instrumentales.

Dentro de los métodos para realizar análisis descriptivos se decidió utilizar uno de los más completos, el Análisis Descriptivo Cualitativo (ADC). Este método fue desarrollado en el año 1974 por Tragon Corp. Las características más importantes de este método son las siguientes (DESA, 2010):

Analiza más de un producto a la vez: la evaluación de más de un producto por sesión implica capitalizar la habilidad del evaluador en realizar juicios relativos con un alto grado de precisión. Los seres humanos son malos evaluadores de lo absoluto, pero muy buenos para detectar diferencias relativas. Muchos productos en una prueba implica mucha información a procesar. Sin embargo, el uso de modernos paquetes estadísticos minimiza este problema.

$>$ Emplea un número limitado de evaluadores: un panel sensorial para realizar el ADC debe constar de 8 a 12 evaluadores. Si son más de 12 es difícil mantener la atención de todos en la etapa de discusión abierta y suelen presentarse problemas 
de horarios, presentación de muestras, etc. Con menos de 8 existe el riesgo de confiar demasiado en muy pocos evaluadores.

Los evaluadores se seleccionan y monitorean: Ios evaluadores deben demostrar habilidad para percibir diferencia dentro del tipo de productos que se van a analizar regularmente. Asimismo deben tener habilidad para verbalizar sus impresiones sensoriales y ser capaces de trabajar en grupo. Una de las virtudes del método ADC es la posibilidad de verificar que cada evaluador está diferenciando entre productos en la mayoría de los descriptores. La confiabilidad de cada evaluador se mide obteniendo respuestas repetidas para cada producto. Para cada evaluador se realiza un análisis de varianza y así se determina su poder de discriminación. Si estos resultados se almacenan, con el tiempo se tendrá un registro del trabajo de cada evaluador que servirá de base para renovar los componentes del panel.

$>$ Emplea descriptores obtenidos por consenso: el éxito de una prueba descriptiva depende del lenguaje sensorial que representa a los productos a ser evaluados. Para el desarrollo de este lenguaje los evaluadores deben probar distintos productos y verbalizar sus impresiones. El descriptor debe ser definido y, en lo posible, incluir material de referencia.

$>$ Es un método cuantitativo: la tarea del evaluador es hacer una marca vertical sobre la línea que mejor refleje la intensidad relativa del descriptor en cuestión sobre la escala seleccionada. La cuantificación se realiza midiendo la distancia desde el extremo hasta la marca que realizó el evaluador. Otro aspecto importante de la cuantificación es la repetición de los ensayos. Además de servir para monitorear a los evaluadores, es importante para obtener un nivel adecuado de discriminación, es muy arriesgado confiar en resultados descriptivos sobre los cuales no ha habido repeticiones.

Los resultados se analizan estadísticamente: el modelo más utilizado es el de análisis de varianza que permite estudiar la diferencia existente entre los productos para cada uno de los descriptores. Asimismo, permite monitorear el funcionamiento del panel y la validez de los descriptores utilizados.

Para representar los resultados del ADC se utilizan métodos gráficos, siendo los más comunes el perfil lineal, los gráficos radiales e histogramas. 


\section{CAPITULO 1:}

Desarrollo y caracterización de la preserva

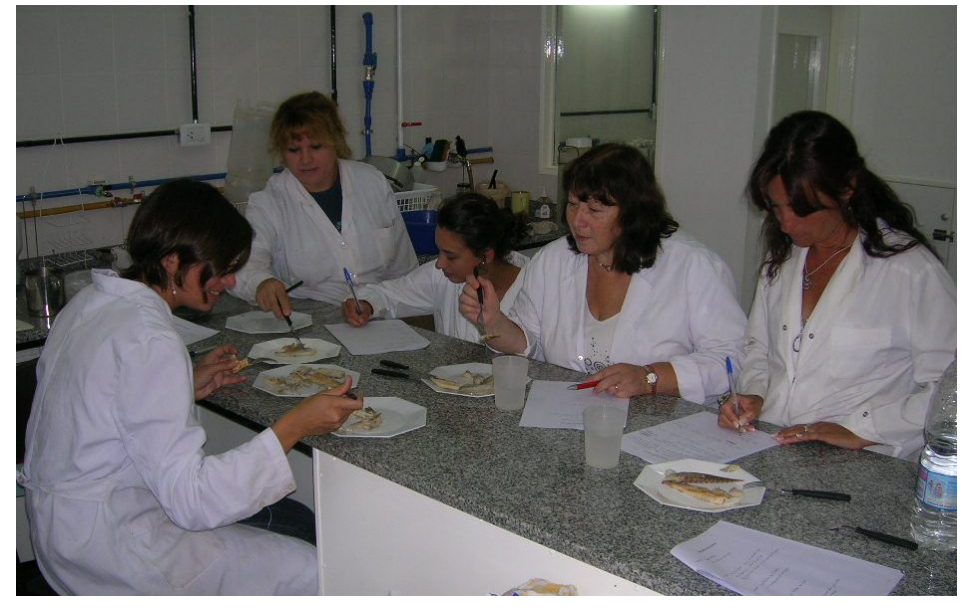




\subsection{Resumen}

El propósito de este capítulo fue diseñar el proceso de elaboración de los lomitos de caballa de humedad intermedia y realizar una caracterización sensorial y fisicoquímica del producto terminado.

Los troncos de caballa (pescado sin cola, cabeza ni vísceras) fueron cocidos al vapor para acondicionar la materia prima, producir una disminución de la carga bacteriana y una inactivación enzimática. Una vez cocidos, se les sacó el esqueleto, la piel, las espinas y el músculo oscuro obteniendo los lomitos. Para disminuir la $a_{w}$, los lomitos fueron deshidratados osmóticamente utilizando una solución de glicerol (40\%), sal $(5 \%)$ y ácido cítrico $(0,5 \%)$. Los lomitos deshidratados osmóticamente se envasaron al vacío, se pasteurizaron y se almacenaron en refrigeración $\left(5 \pm 1^{\circ} \mathrm{C}\right)$.

Se calculó el tiempo necesario de pasteurización a una temperatura de $60^{\circ} \mathrm{C}$ para lograr 5 reducciones decimales con Staphylococcus aureus como microorganismo control (utilizando el método general y el método de la fórmula de Stumbo y de Hayakawa).

Por último, se realizó una caracterización de la preserva mediante análisis fisicoquímicos y perfiles sensoriales. Además, se comparó sensorial y fisicoquímicamente las muestras de lomitos de caballa de humedad intermedia con muestras de lomitos cocidos al vapor.

\subsection{Introducción}

La inocuidad de los alimentos así como también su calidad sensorial y nutritiva está basada en la aplicación de una combinación de factores de preservación llamados obstáculos. Los alimentos de humedad intermedia (AHI) se encuentran en el rango de actividad de agua $\left(a_{w}\right)$ entre 0,60 y 0,90. La $a_{w}$ es el obstáculo primario de preservación para asegurar la estabilidad microbiológica, sin embargo, los $\mathrm{AHI}$ suelen ser estabilizados mediante el uso de otros obstáculos como la pasteurización, la acidez $(\mathrm{pH})$, el potencial redox (Eh), los preservantes (nitritos, sorbatos, sulfito, etc.) y microorganismos competitivos (por ejemplo, bacterias ácido lácticas) (Leistner, 2000). Estos alimentos son fáciles de preparar y se almacenan sin refrigeración, generando que su procesamiento sea eficiente en cuanto a costos y energía utilizada.

Los $\mathrm{AHI}$ tradicionales basados en carnes, pescados, frutas y vegetales son muy comunes en diferentes partes del mundo debido a que son sabrosos, nutritivos e 
inocuos. Por otro lado, se han desarrollado nuevos $\mathrm{AHI}$ pero no han superado las expectativas en cuanto a su calidad sensorial y nutricional. Algunas razones de esta performance desalentadora fueron la baja palatabilidad de la mayoría de estos productos debido a la alta concentración de humectantes y la necesidad de introducir frecuentemente altas cantidades de aditivos químicos antimicrobianos (Leistner, 1999).

El glicerol es un excelente depresor de la $\mathrm{a}_{\mathrm{w}}$ durante la DO de productos alimenticios. Sus grupos polares forman enlaces de hidrógeno con el agua disponible en el sistema generando que ese agua ya no esté disponible (Lombard y col., 2000). Además, es un aditivo comúnmente utilizado para mejorar la textura de los alimentos (plastificante) y también ha mostrado ciertas ventajas como agente antimicrobiano (Moreira y col., 2007).

Distintos autores han utilizado glicerol como depresor de la $a_{w}$ en alimentos deshidratados osmóticamente. En Argentina, se ha investigado el uso de glicerol y sal para deshidratar osmóticamente carne de vaca (Favetto y col., 1981). Actualmente, el Código Alimentario Argentino contiene un producto denominado "Carne vacuna cocida conservada de humedad intermedia" (Capítulo VI, Artículo 379bis). En este artículo se dan detalles de su elaboración: "la carne debe ser trozada convenientemente, reducida en su actividad acuosa y preservada por cocción en una solución que contiene sal común, glicerina y sorbato de potasio".

Moreira y col. (2007), utilizaron soluciones de glicerol y sal para deshidratar osmóticamente castañas. Sánchez Pascua y col. (2001), utilizaron glicerol y sal para disminuir la $a_{w}$ de pastas de pescado (caballa y salmón de mar), y Farahnaky y col. (2009) elaboraron higos disecados con el agregado de glicerol. En la bibliografía existen antecedentes de deshidratación osmótica de caballa para obtener un producto de humedad intermedia, Sánchez Pascua y col., (1994 y 1998) deshidrataron osmóticamente caballa mediante una cocción e infusión en soluciones de glicerol y sal.

\subsection{Objetivos}

> Diseñar las etapas del proceso de elaboración de los lomitos de caballa de humedad intermedia, incluyendo la formulación de la solución osmótica (y el tiempo de inmersión) y el cálculo teórico del tiempo de pasteurización a una temperatura de $60^{\circ} \mathrm{C}$ para lograr 5 reducciones decimales con Staphylococcus aureus como microorganismo control (utilizando el método general y de la fórmula de Stumbo y de Hayakawa). 
Realizar una caracterización sensorial mediante la realización de perfiles sensoriales utilizando el método del Análisis Descriptivo Cualitativo.

Realizar una caracterización fisicoquímica mediante determinaciones de la composición química proximal; contenido de glicerol, $\mathrm{NaCl}$ y ácido cítrico; $\mathrm{pH} ; \mathrm{a}_{\mathrm{w}} \mathrm{y}$ determinaciones instrumentales de color y textura.

\subsection{Materiales y métodos}

\subsubsection{Materia Prima}

Se utilizó caballa (Scomber japonicus) capturada en el mes de octubre de 2010 en las costas de la provincia de Buenos Aires y conservada a bordo en hielo. Luego de su arribo al puerto de la ciudad de Mar del Plata, la materia prima fue transportada en cajones con hielo para su posterior lavado, envasado y congelado en la planta procesadora MIA S.A. La etapa de congelado se realizó en un túnel de congelación a $38 \pm 4^{\circ} \mathrm{C}$ y se almacenó en freezer a $-18 \pm 2^{\circ} \mathrm{C}$ hasta su utilización.

Se utilizaron aproximadamente 40 piezas de $40 \pm 2 \mathrm{~cm}$ de largo con un peso de $0,59 \pm 0,03 \mathrm{~kg}$.

\subsubsection{Análisis fisicoquímicos}

Durante el diseño del proceso de elaboración de la preserva se realizaron distintos análisis fisicoquímicos. A continuación se detallan cada uno de ellos.

\section{Determinación del contenido de agua}

El contenido de agua se determinó a $105 \pm 1{ }^{\circ} \mathrm{C}$ hasta peso constante (AOAC, Sec. 984.25, 1990) utilizando un horno de secado modelo 644 (Marne, Córdoba, Argentina). Se realizó por triplicado.

Determinación del contenido de lípidos

Los lípidos totales se determinaron por hidrólisis ácida (AOAC, 1990. Sec. 922.06). 
Se pesaron $2 \mathrm{~g}$ de muestra en un erlenmeyer de $150 \mathrm{ml}$ previamente tarado. Se agregaron $2 \mathrm{ml}$ de etanol con agitación continua hasta humedecer totalmente la muestra. Se adicionaron $10 \mathrm{ml}$ de solución de ácido clorhídrico ( 25 partes de $\mathrm{HCl}$ y 11 partes de agua) y se colocó en baño termostático a $70-80{ }^{\circ} \mathrm{C}$ durante 30 minutos. Durante el calentamiento se agitó el erlenmeyer con intervalos de $5 \mathrm{~min}$. Una vez finalizada la etapa de calentamiento, se agregaron $10 \mathrm{ml}$ de etanol y se transfirió la mezcla a una ampolla de decantación. Se agregaron $25 \mathrm{ml}$ de éter etílico y $25 \mathrm{ml}$ de éter de petróleo y se dejó reposar hasta lograr la separación de las fases. Se filtró la fase superior sobre un erlenmeyer de $125 \mathrm{ml}$ previamente tarado. Estos últimos pasos de extracción del líquido remanente se repitieron dos veces utilizando $15 \mathrm{ml}$ de cada éter. Se evaporó el éter en un baño termostático a $80^{\circ} \mathrm{C}$ y luego en estufa a $100{ }^{\circ} \mathrm{C}$ hasta peso constante. Se determinó el contenido de grasa presente en la muestra mediante la diferencia de peso del erlenmeyer vacío y con el residuo graso luego de la evaporación. Esta determinación se realizó por duplicado.

\section{Determinación del contenido total de proteínas}

El contenido total de proteínas se determinó utilizando el método de Kjeldahl (AOAC, 1990. Sec. 920.152). Este método se basa en la digestión de la muestra con ácido sulfúrico concentrado usando sulfato de cobre como catalizador. Se le agregó a la muestra $\mathrm{NaOH} 40 \%$ y se destiló el nitrógeno liberado hacia una solución de ácido bórico. El destilado fue titulado con ácido sulfúrico normalizado. Se utilizó el factor 6,25 para trasformar el nitrógeno total en proteína total (Kirk y col., 1996). Esta determinación se realizó por duplicado.

\section{Determinación del contenido de cenizas}

Las cenizas fueron determinadas por calcinación a $550^{\circ} \mathrm{C}$ como lo describe la técnica de la AOAC, Sec. 945.46 (1990) utilizando un horno eléctrico modelo 332 (Indef, Córdoba, Argentina). Se realizó por duplicado.

\section{Determinación del contenido de cloruro de sodio}

El contenido de cloruro de sodio se determinó mediante el método de Mohr adaptado a alimentos (Kirk y col., 1996). Se realizó por duplicado. 


\section{Determinación del contenido de Glicerol}

Para determinar el contenido de glicerol se siguió el procedimiento descripto en el kit para medición de glicerol mediante método enzimático UV (Boehringer Mannheim/R-Biopharm, Darmstadt, Germany) utilizando un espectrofotómetro Shimadzu UV-1601 PC (Kyoto, Japón).

Se picó la muestra utilizando una procesadora y se pesaron aproximadamente $5 \mathrm{~g}$. Se colocaron los $5 \mathrm{~g}$ en un vaso de precipitados de $100 \mathrm{ml}$ y se añadió aproximadamente $60 \mathrm{ml}$ de agua destilada. Se homogeneizó y colocó en baño termostatizado a $60^{\circ} \mathrm{C}$ durante 15 minutos. Se dejó enfriar y se enrasó a $100 \mathrm{ml}$. Se colocó la solución en un baño con hielo por 15 min. para permitir la separación de las grasas y se filtró. La muestra a medir se debió diluir hasta obtener una concentración de glicerol entre 0,04 y 0,4 g/l. Se determinó por duplicado.

\section{Determinación del contenido de acidez}

La acidez se determinó por titulación con solución acuosa de $\mathrm{NaOH}$ 0,1 N (Kirk et al., 1996). Los resultados se expresaron como porcentaje de ácido cítrico (\%). Se determinó por triplicado.

\section{Determinación del pH}

El pH se midió utilizando una relación muestra:agua destilada de 1:1 (AOAC, 1990, Sec. 981.12) con pH-metro digital marca INSTRU modelo IN07601. Se determinó por triplicado.

\section{Determinación de la actividad de agua $\left(\mathrm{a}_{\mathrm{w}}\right)$}

La $\mathrm{a}_{\mathrm{w}}$ fue determinada mediante higrómetro Aqualab, modelo CX-2T (Decagon, Pulman, WA, USA). Se determinó por triplicado.

\section{Determinación instrumental del color}

El color es un atributo de calidad muy importante y una de las características sensoriales más apreciadas por los consumidores (Birkeland y Bjerkeng, 2005; Corzo y col., 2008; Sohn y col., 2005; Valencia García y col., 2012). Si bien se realizó un análisis sensorial del cambio en el color del producto, también se midió este parámetro 
de forma objetiva mediante el uso de un colorímetro a fin de correlacionar los valores obtenidos con la evaluación sensorial.

Las mediciones de color se realizaron utilizando un colorímetro portátil (Lovibond, SP60, Reino Unido) bajo la escala de color CieLab (CIE, 1978), con iluminante D65 y un ángulo de visión de $10^{\circ}$. En este espacio de color, $L^{*}$ es un indicador de la luminosidad que varía entre el color negro (0) y blanco (100). Los valores positivos de $a^{*}(0$ a 60 ) son una medida de la intensidad de color rojo mientras que los negativos ( 0 a -60$)$ representan las tonalidades verdes. Por su parte $b^{*}$ mide la intensidad de color amarillo (valores de 0 a 60) y azul (valores de 0 a -60). Los datos obtenidos son promedio de 5 mediciones.

\section{Análisis instrumental de la textura}

Se realizó un análisis instrumental de la textura de los lomitos de caballa cocidos al vapor $\mathrm{y}$, por otro lado, de los lomitos cocidos y deshidratados osmóticamente con el fin de investigar los cambios introducidos en el producto a partir de la deshidratación osmótica.

Se analizó la textura mediante el uso de la técnica Texture Profile Analisis (TPA) (Bourne, 1978) utilizando un texturómetro marca Stable Microsystems Ltd. Technologies, modelo TA.XT2 (Scarsdale, NY) controlado por el software Texture Expert® (CIDCA, La Plata) y con una celda de carga de $25 \mathrm{~kg}$. Las condiciones del test fueron dos ciclos consecutivos de $15 \%$ de compresión con 5 s entre los ciclos. Las mediciones fueron hechas con una sonda cilíndrica de $15 \mathrm{~mm}$ de diámetro. La velocidad pre y post-ensayo fue $3 \mathrm{~mm} / \mathrm{s}$ y la velocidad de ensayo $0,5 \mathrm{~mm} / \mathrm{s}$. Las muestras fueron mantenidas por una hora a temperatura ambiente antes de cada análisis. Los datos obtenidos son el promedio de 9 mediciones.

De la curva fuerza-tiempo resultante fueron determinados los siguientes parámetros (Bourne, 1978):

Dureza $(\mathrm{N})$ : máxima fuerza requerida para comprimir la muestra.

Cohesividad: El trabajo hecho durante la segunda compresión dividido por el trabajo hecho durante la primera compresión $\left(A_{2} / A_{1}\right.$, donde $A_{1}$ es la energía total requerida por la primera compresión y $A_{2}$ la energía total requerida para la segunda compresión). El resultado obtenido es un indicador de la visco-elasticidad del alimento. Un valor próximo a 1 indica total elasticidad y un valor próximo a cero indica que la muestra no se recuperó en absoluto. 
Adhesividad (Ns): área negativa de la fuerza ejercida luego del primer ciclo, representa el trabajo requerido para despegar la muestra completamente del dispositivo.

En la Figura 1.1 se puede observar un ejemplo de análisis de TPA con sus dos ciclos característicos, sus dos áreas $\left(A_{1}\right.$ y $\left.A_{2}\right)$, la dureza representada por el pico de fuerza y el área negativa luego del primer ciclo que representa la adhesividad.

Fuerza (N)

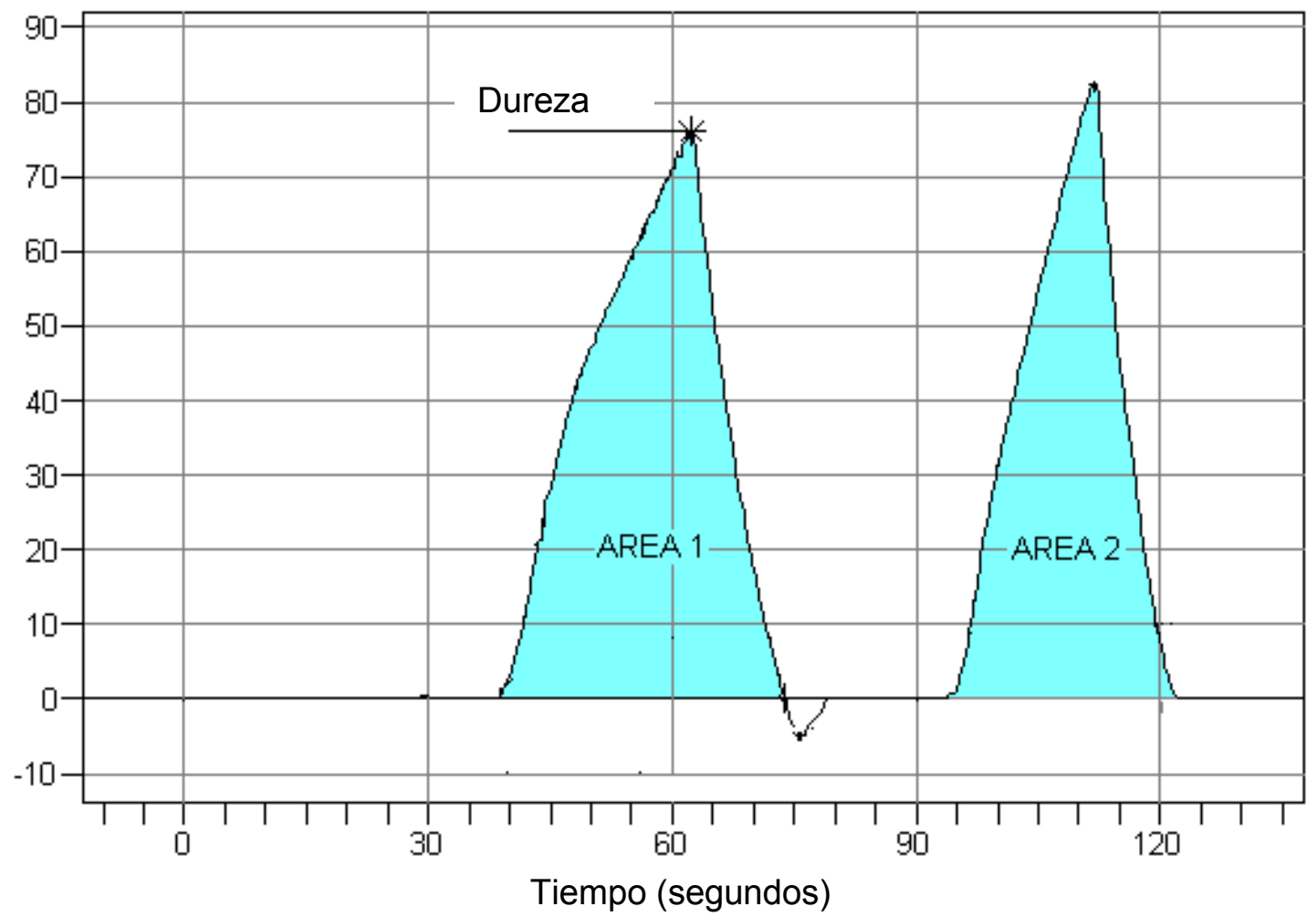

Figura 1.1 Ejemplo de análisis de TPA.

\subsubsection{Calculo teórico de la pasteurización}

Se realizó el cálculo teórico del tiempo de pasteurización a una temperatura de proceso de $60^{\circ} \mathrm{C}$ con Staphylococcus aureus como microorganismo control. Los lomitos de caballa de humedad intermedia poseen una $a_{w}$ de 0,89 $\pm 0,01$ y un pH de $5,11 \pm 0,05$. Bajo estas condiciones el $C$. botulinum es incapaz de crecer ya que necesita de una $a_{w}$ mayor a 0,93. Se eligió el Staphylococcus aureus como el microorganismo objetivo dado que es el único microorganismo patógeno que puede 
crecer a una $a_{w}$ menor a 0,90 (DHHS, 2011; IFT, 2003; NACMCF, 2010). En el Anexo 1 se listan las condiciones límites de crecimiento de bacterias patógenas de interés según DHHS, (2011).

El cálculo teórico estudiado en el presente Capítulo fue validado mediante la realización de un estudio de reto microbiano detallado en el Capítulo 4.

Para el cálculo del tiempo de pasteurización se utilizó el método general y el de la fórmula de Stumbo y de Hayakawa. Se estimó la evolución de la temperatura en estado no estacionario en el centro geométrico del lomito considerado como un cilindro finito. Las ecuaciones para transferencia de calor en estado no estacionario para objetos sólidos con geometría placa plana y cilindro son las siguientes:

\section{Placa plana (coordenadas cartesianas)}

$$
\frac{\partial^{2} T}{\partial x^{2}}+\frac{\partial^{2} T}{\partial y^{2}}+\frac{\partial^{2} T}{\partial z^{2}}=\frac{1}{\alpha} \frac{\partial T}{\partial t}
$$

\section{Cilindro (coordenadas cilíndricas)}

$$
\frac{1}{r} \cdot \frac{\partial}{\partial r}\left(r \cdot \frac{\partial T}{\partial r}\right)+\frac{1}{r^{2}} \frac{\partial^{2} T}{\partial \theta^{2}}+\frac{\partial^{2} T}{\partial z^{2}}=\frac{1}{\alpha} \frac{\partial T}{\partial t}
$$

La transferencia de calor para una placa infinita y un cilindro infinito se puede considerar como unidimensional. Las soluciones para temperatura inicial uniforme y $1<\mathrm{Bi}<40$ (Bi: Número de Biot) están dadas por (Toledo, 2007):

\section{Placa infinita}

$$
\frac{T_{e}-T}{T_{e}-T_{0}}=\sum_{n=1}^{\infty} \frac{2 B i}{\partial_{n}^{2}+B i^{2}+B i} \frac{\cos \left(\frac{x}{L} \partial_{n}\right)}{\cos \left(\partial_{n}\right)} \exp \left(-\partial_{n}^{2} F o\right)
$$

Siendo $\delta_{\mathrm{n}}$ las raíces de $\delta$ tang $\delta=\mathrm{Bi}$, Tc la temperatura del medio $\left({ }^{\circ} \mathrm{C}\right)$, T la temperatura a tiempo $\mathrm{t}(\mathrm{seg}), \mathrm{T}_{0}$ la temperatura inicial $\left({ }^{\circ} \mathrm{C}\right), \mathrm{L}$ mitad del espesor $(\mathrm{m}), \mathrm{x}$ distancia al centro $(m)$, Bi el número de Biot $\left(h L / K_{0}\right)$, Fo el número de Fourier $\left(\alpha_{1} t / L^{2}\right)$. $\mathrm{x} / \mathrm{L}$ se considera igual a 0,0001 cuando se calcula la temperatura en el centro geométrico de la placa (Singh, 1996) 


\section{$\underline{\text { Cilindro infinito }}$}

$$
\frac{T_{e}-T}{T_{e}-T_{0}}=\sum_{n=1}^{\infty} \frac{2 B i}{\partial_{n}^{2}+B i^{2}} \frac{J_{0}\left(\frac{r}{R} \partial_{n}\right)}{J_{0}\left(\partial_{n}\right)} \exp \left(-\partial_{n}^{2} F o\right)
$$

Siendo $\delta n$ las raíces de $\delta J_{1}(\delta)=B i J_{0}(\delta), J_{0}$ y $J_{1}$ las funciones de Bessel de orden 0 y 1 respectivamente, $R$ el radio $(m)$, $r$ distancia al centro $(m), r / R$ se considera igual a 0,0001 cuando se calcula la temperatura en el centro geométrico del cilindro (Singh, 1996).

Se calcularon las propiedades termofísicas del lomito a $60^{\circ} \mathrm{C}$ y a $18^{\circ} \mathrm{C}$ de acuerdo a las correlaciones de Choi y Okos (Urbicain y Lozano, 1997) y a partir de las mismas los números de $\mathrm{Bi}$ y Fo. El coeficiente de convección en agua estanca obtenido de bibliografía fue de $60 \mathrm{~W} / \mathrm{m}^{20} \mathrm{C}$ (Singh y Heldman, 1993).

Las dimensiones promedio del lomito de caballa fueron: largo 0,14 m, diámetro $0,03 \mathrm{~m}$, por lo que se consideró como un cilindro finito. La temperatura adimensional para un cilindro finito está dada por:

$$
\left(\frac{T_{a}-T}{T_{a}-T_{i}}\right)_{\text {cilindrofinito }}=\left(\frac{T_{a}-T}{T_{a}-T_{i}}\right)_{\text {cilindroinfinito }}\left(\frac{T_{a}-T}{T_{a}-T_{i}}\right)_{\text {placainfinito }}
$$

Se calculó la historia térmica en el centro geométrico del lomito para la etapa de calentamiento a $60^{\circ} \mathrm{C}$ y de enfriamiento a $18^{\circ} \mathrm{C}$ utilizando planilla de cálculo de Excel 2007. Cuando el Fo> 0,2 se consideró sólo el primer término de la serie para el cálculo de la temperatura.

Se graficó Log (TR-T) en función del tiempo para el calentamiento y Log (T-TC) para el enfriamiento, siendo TR la temperatura del medio de calentamiento, TC la temperatura del medio de enfriamiento, $\mathrm{T}$ la temperatura a tiempo $\mathrm{t}$. A partir de estas rectas se obtuvieron los valores de $f_{h}, j_{h}, f_{c}, j_{c}$, donde $f$ es el tiempo necesario para que la curva de calentamiento/enfriamiento atraviese un ciclo logarítmico de temperatura (inversa de la pendiente), $\mathrm{j}_{\mathrm{h}}=$ (TR-Tpsi)/(TR-Ti), $\mathrm{j}_{\mathrm{c}}=(\mathrm{TC}-\mathrm{Tpsi}) /(\mathrm{TC}-\mathrm{Ti})$, Tpsi es la temperatura pseudoinicial y Ti la inicial para el calentamiento en el caso del $\mathrm{j}_{\mathrm{h}}$ y para el enfriamiento en el caso del $\mathrm{j}_{\mathrm{c}}$. El valor de $\mathrm{j}$ se obtuvo a partir de la ordenada al origen de la curva dada por $\log (\mathrm{IJ})$ siendo I= TR-Ti para el calentamiento y I=Tc-Ti para el enfriamiento.

Como se mencionó anteriormente, el microorganismo seleccionado para el cálculo de la pasteurización fue el Staphylococcus aureus dado que es el único 
microorganismo patógeno capaz de crecer a este valor de $a_{w}$. El parámetro $D$ (tiempo de reducción decimal) del $S$. aureus a la temperatura de referencia $\left(65^{\circ} \mathrm{C}\right)$ para el cálculo de procesos de pasteurización y el valor de z (grados Fahrenheit necesarios para reducir el valor de $D$ por un factor de 10) se obtuvieron de Stumbo (1973). El $F_{0}$ requerido a $65^{\circ} \mathrm{C}$ con $\mathrm{D}=0,9 \mathrm{~min}$. y $z=12^{\circ} \mathrm{F}$ y para 5 reducciones decimales es de 4,5 min. Según Stumbo (1973), es suficiente un criterio de 5 reducciones decimales cuando se trabaja con bacterias mesófilas. Kennedy y col. (2005), reportaron que generalmente se acepta una reducción de 5 log como la reducción objetivo en bacterias patógenas que se encuentran en alimentos.

El tiempo de pasteurización a $60^{\circ} \mathrm{C}$ para lograr valor letal equivalente a 4,5 min. a $65^{\circ} \mathrm{C}$ se calculó por método general y por el método de la fórmula de Stumbo y Hayakawa.

Se calculó la letalidad para las etapas de calentamiento y enfriamiento de acuerdo a:

$$
\begin{gathered}
L=(10)^{T-\frac{T_{0}}{z}} \\
F_{0}^{z}=\int_{0}^{t} L_{t} d t
\end{gathered}
$$

El método de la fórmula se basa en valores tabulados de letalidad expresados como $f_{h} / U$ vs el parámetro g. Stumbo combina las letalidades del calentamiento y del enfriamiento en las tablas de $f_{h} / U$ vs $g$ para diferentes valores de $j_{c} y$ de $z$, supone que $\mathrm{f}_{\mathrm{h}}=\mathrm{f}_{\mathrm{c}}$. Siendo $\mathrm{U}$ el tiempo requerido, a temperatura del medio de calentamiento, para generar la misma destrucción bacteriana que la generada por un proceso térmico a un valor dado de $F$, y $g=(T R-T)$ donde $T$ es la temperatura final de la etapa de calentamiento.

Hayakawa presenta la letalidad de las etapas de calentamiento y enfriamiento en tablas separadas de $\mathrm{g} / \mathrm{K}_{\mathrm{s}}$ vs $\mathrm{U} / \mathrm{f}_{\mathrm{h}}$ para $\mathrm{z}=20^{\circ} \mathrm{F}$, con $\mathrm{K}_{\mathrm{s}}=\mathrm{z} / 20$ para el calentamiento $\mathrm{y}$ de $I_{c} / K_{s}$ vs U'/ $f_{h}$ para distintos valores de $j_{c}$ con $I_{c}=(T R-g-T C)$ para el enfriamiento. El valor de $U$ para el enfriamiento se calcula de acuerdo a $U=U^{\prime} 10(-\mathrm{g} / \mathrm{z})$. El $U$ del proceso se obtiene sumando los valores de $U$ para calentamiento y enfriamiento (Toledo, 2007).

Ambos métodos de la fórmula utilizan la siguiente ecuación para el cálculo del tiempo de calentamiento: 
$B_{b}=f_{h}(\log (j I)-\log (g))$

Siendo I $=(\mathrm{TR}-\mathrm{Ti})$

\subsubsection{Análisis sensorial}

Para la caracterización sensorial de la preserva primero se realizó una selección de los panelistas. Luego de la selección, se los entrenó y, por último, se realizaron perfiles sensoriales. A continuación se describen las experiencias realizadas.

\section{$\underline{\text { Selección de evaluadores }}$}

Se realizó una selección de evaluadores de acuerdo a los lineamientos propuestos en la norma ISO 8586-1:1993 o su equivalente IRAM 20005-1:1996. Se les asignó puntos a los errores cometidos en cada prueba, siendo los mejores evaluadores aquellos con menor puntaje total. Los ensayos se realizaron con 11 candidatos.

La metodología utilizada incluyó:

Sesión teórica: se explicaron las pruebas a realizar, se indicó la importancia de estos ensayos y el compromiso que deberían asumir al realizarlos.

Reconocimiento de gustos básicos: se evaluó la sensibilidad de los candidatos para los gustos dulce (sacarosa), salado (sal de mesa), amargo (cafeína), ácido (ácido cítrico) y umami (glutamato monosódico) según la Norma IRAM 200051:1996. Cada solución se preparó por duplicado y todos los participantes recibieron el mismo orden de presentación. Las muestras fueron codificadas según la tabla 1.1. En la misma se pueden ver las concentraciones utilizadas. 
Tabla 1.1 Códigos y concentraciones de gustos básicos

\begin{tabular}{ccc}
\hline Código & Gusto & Concentración(g/l) \\
\hline 557 & Agua & \\
477 & Agua & \\
924 & Salado & 5 \\
738 & Salado & 5 \\
125 & Amargo & 0,5 \\
355 & Amargo & 0,5 \\
172 & Dulce & 16 \\
765 & Dulce & 16 \\
831 & Acido & 1 \\
616 & Acido & 1 \\
111 & Umami & 0,6 \\
143 & Umami & 0,6 \\
\hline
\end{tabular}

Cada error en la determinación de los gustos se consideró como un 1 para el puntaje final.

Reconocimiento de aromas: se presentaron tiras de papel embebidas en esencias aromáticas dentro de tubos plásticos con tapa (Figura 1.2), cada tubo codificado con un número de tres cifras seleccionado al azar. Las muestras utilizadas y sus códigos figuran en la Tabla 1.2.
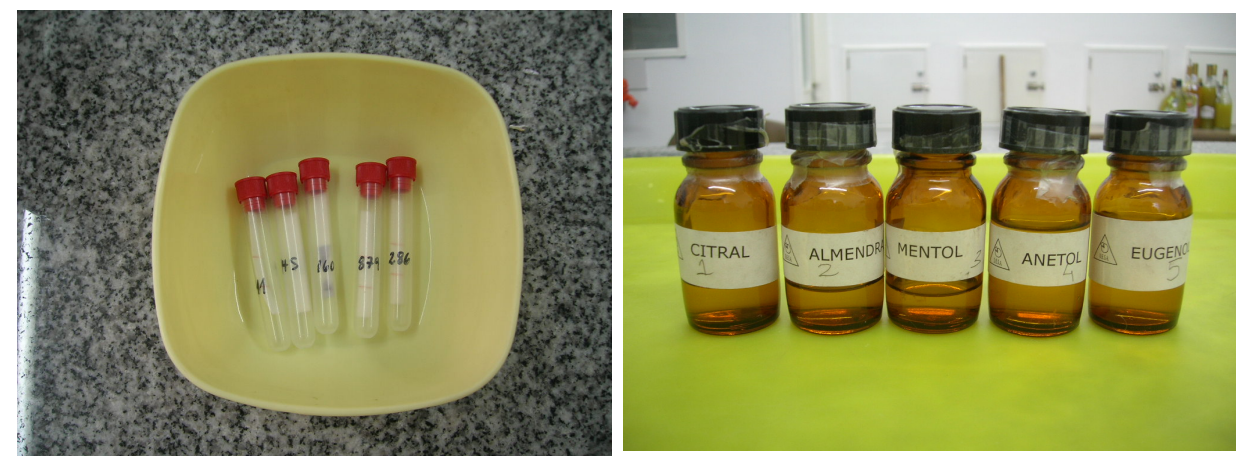

Figura 1.2 Tubos conteniendo tiritas de papel embebidas en esencias

Tabla 1.2 Códigos de las esencias utilizadas

\begin{tabular}{cc}
\hline Muestra & Código \\
\hline Anetol & 879 \\
Almendras & 445 \\
Mentol & 286 \\
Citral & 411 \\
Eugenol & 160
\end{tabular}


Los resultados fueron calificados como puede verse en la Tabla 1.3 de forma tal de analizar la capacidad de cada evaluador.

Tabla 1.3 Calificación de las respuestas

\begin{tabular}{cc}
\hline Calificación & Definición \\
\hline A & Resultado correcto \\
B & Asociación correcta \\
C & Incorrecto o insuficiente \\
\hline
\end{tabular}

Las calificaciones A y B se consideraron como un 0 (cero) para el puntaje final mientras que la $\mathrm{C}$ se consideró como un 1.

Discriminación de color: Los evaluadores debieron ordenar 5 diluciones de jugo de durazno (BC, La Campagnola) colocadas en tubos de ensayo (Figura 1.3). Las diluciones empleadas se pueden ver en la Tabla 1.4 .

Tabla 1.4 Diluciones de jugo de durazno

\begin{tabular}{cc}
\hline Muestra & $\%$ \\
\hline 211 & 100 \\
509 & 90 \\
108 & 80 \\
771 & 70 \\
199 & 60 \\
\hline
\end{tabular}

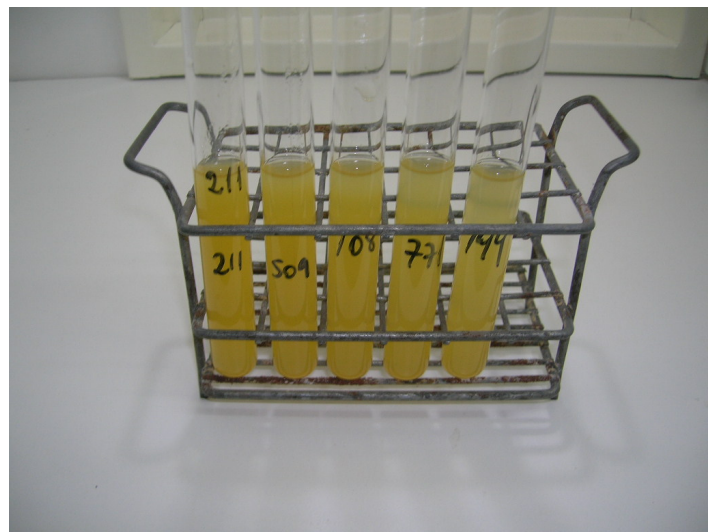

Figura 1.3 Diluciones de jugo de durazno

Cada error en la asignación del orden en la intensidad del color se consideró como un 1 para el puntaje final.

> Prueba de perfil sensorial: se realizó el perfil sensorial de galletitas de agua de tres marcas distintas. Se tuvieron en cuenta sólo 4 descriptores de fácil comprensión (aspecto tostado, fracturabilidad, gusto salado y sabor tostado). Para cada descriptor se consideró correcta la respuesta cuando el orden del evaluador coincidió con el orden promedio de todo el grupo. A la respuesta incorrecta se le asigno un 1 para el puntaje final. Las marcas de galletitas y los códigos utilizados figuran en la Tabla 1.5. 


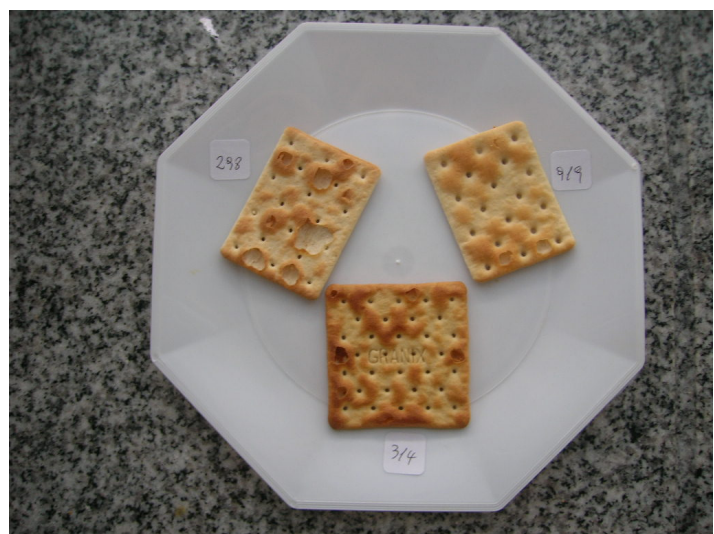

Figura 1.4 Presentación de las galletitas

Tabla 1.5 Marca y código de las muestras

\begin{tabular}{cc}
\hline Marca & Código \\
\hline Traviata(Bagley) & 298 \\
Media Tarde(Lía) & 919 \\
Granix & 314 \\
\hline
\end{tabular}

Puntaje final: se sumaron los puntos obtenidos por cada evaluador y se armaron planillas con el orden de mérito, siendo los mejores evaluadores aquellos que obtuvieron los menores puntajes finales.

\section{Entrenamiento}

Se siguieron los lineamientos propuestos por las Normas IRAM 20005-1/2 que proveen las bases para el desarrollo de las etapas de entrenamiento de los evaluadores sensoriales.

Los objetivos del entrenamiento de los evaluadores durante las distintas sesiones fueron:

> Aprender a evaluar los productos.

$>$ Familiarizarse con las muestras.

$>$ Emitir juicios objetivos.

$>$ Equiparar el vocabulario del grupo.

$>$ Comparar intensidades.

$>$ Mejorar la repetibilidad. 
Los evaluadores fueron entrenados para desarrollar la capacidad de evaluar las propiedades del producto: color, aroma, textura manual y bucal y sabor. Recibieron entrenamiento en el uso de escalas y en el desarrollo y uso de descriptores. Además, fueron instruidos para realizar las pruebas con objetividad y descartando sus gustos $o$ desagrados.

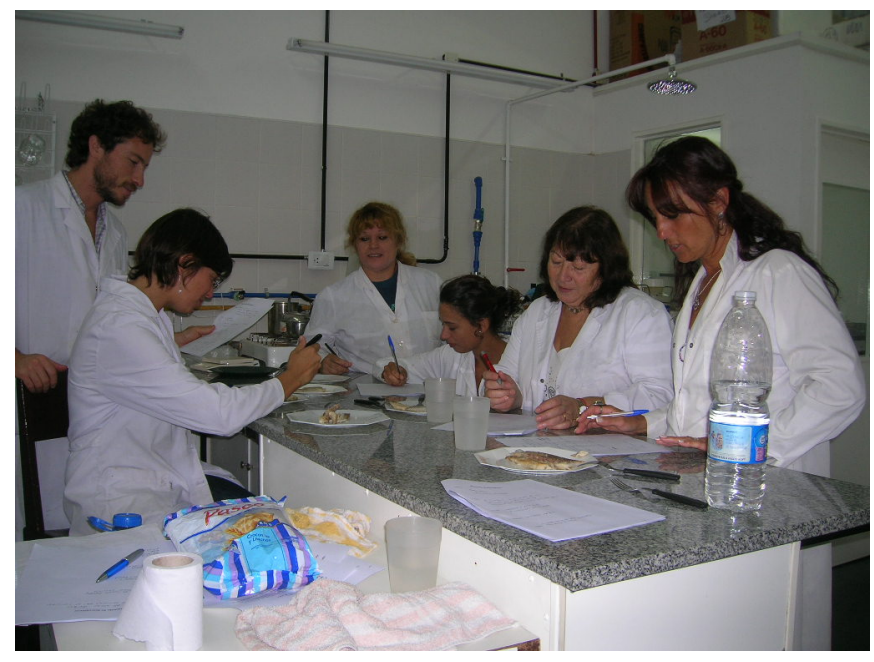

Figura 1.5: Sesión de entrenamiento

\section{Lugar de los Ensayos}

Se utilizaron las instalaciones del Grupo de Investigación en Preservación y Calidad de Alimentos (GIPCAL) perteneciente al Departamento de Ingeniería Química y de Alimentos de la Facultad de Ingeniería, Universidad Nacional de Mar del Plata. El grupo cuenta con cabinas especialmente diseñadas para realizar evaluaciones sensoriales y mesadas para trabajos en grupo (Figura 1.6).
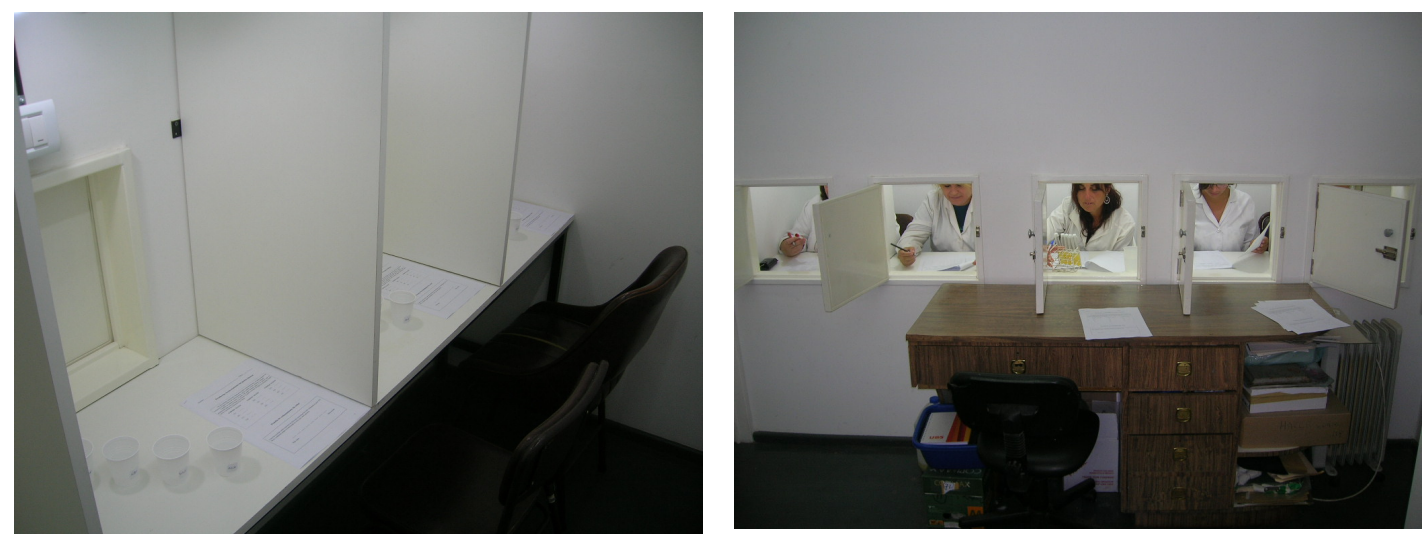

Figura 1.6 Cabinas para realizar evaluaciones sensoriales 


\section{Perfil Sensorial}

Para la realización del Perfil Sensorial de los lomitos se utilizó el método de Análisis Descriptivo Cualitativo (DESA, 2010).

Los análisis descriptivos pueden ser considerados como la primera instancia en la caracterización de un producto alimenticio, proveyendo una terminología predefinida para describir las percepciones sensoriales lo más objetivamente posible. Sin embargo, la validez de los resultados obtenidos depende de la selección inicial de los descriptores y en la habilidad de los jueces de identificar y cuantificar cada atributo (Montouto-Graña y col. 2002).

La búsqueda de descriptores se dividió en dos partes, inicialmente se les pidió a los panelistas que busquen características sensoriales que consideren importantes para describir las muestras (Generoso y col., 2005; Generoso y col., 2006; Gokoglu, 2002; Trinchero y col., 2007). Los evaluadores analizaron y verbalizaron sus impresiones con el fin de desarrollar un lenguaje sensorial representativo (Figura 1.7).

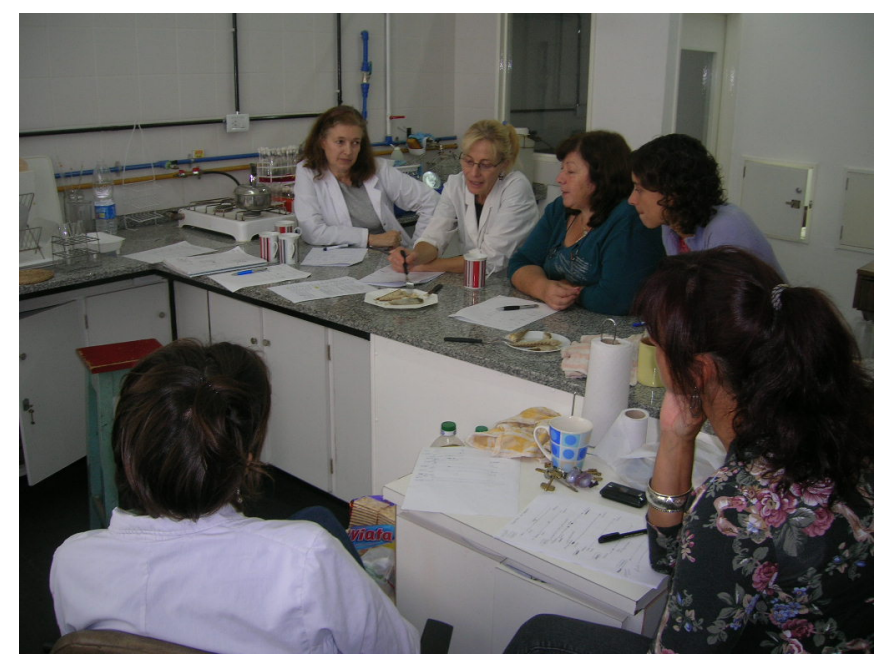

Figura 1.7 Evaluadores analizando descriptores

Cada descriptor fue definido y en los casos que se consideró necesario, se incluyó un material de referencia. Se realizaron las escalas propias de cada descriptor. Se decidió utilizar escalas no estructuradas ancladas en los extremos con el centro definido. En una segunda parte se eligieron los descriptores más representativos obtenidos por consenso entre los jueces y el líder del panel (DESA, 2010; Gokoglu, 2002).

Para el gusto salado se realizó un mínimo de escala utilizando una solución al $0,5 \%$ de sal y un máximo de $2,5 \%$ y se entrenó al panel con esta escala. 
De cada filete de caballa se obtienen 2 lomitos, cada uno de ellos tiene un color característico. En la Figura 1.8 se puede ver el lomito ubicado en la zona ventral (que se asemeja a un color té con leche) y el lomito ubicado en la zona dorsal (que se asemeja a un color gris).

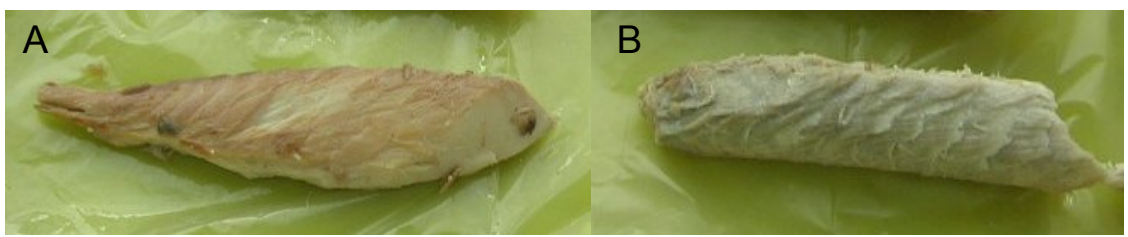

Figura 1.8 Lomito color té con leche $(A)$ y lomito color gris $(B)$

Para la evaluación del color se crearon sus respectivas escalas. Para el color té con leche se realizaron soluciones conteniendo proporciones variables de té y leche como se puede ver en la Tabla 1.6 y en la Figura 1.9. Se utilizó leche en sachet marca La Serenísima y té marca La Virginia infusionando durante 5 minutos un saquito en $250 \mathrm{ml}$ de agua a $95^{\circ} \mathrm{C}$. Para el color gris se utilizó una escala de grises obtenida del programa Microsoft Office Word 2003 (Figura 1.10).

Tabla 1.6. Porcentajes utilizados para color té con leche

\begin{tabular}{ccccccccccc}
\hline & $\mathbf{0 , 5}$ & $\mathbf{1}$ & $\mathbf{2}$ & $\mathbf{3}$ & $\mathbf{4}$ & $\mathbf{5}$ & $\mathbf{6}$ & $\mathbf{7}$ & $\mathbf{8}$ & $\mathbf{9}$ \\
\hline Te & 95 & 90 & 80 & 70 & 60 & 50 & 40 & 30 & 20 & 10 \\
Leche & 5 & 10 & 20 & 30 & 40 & 50 & 60 & 70 & 80 & 90 \\
\hline
\end{tabular}

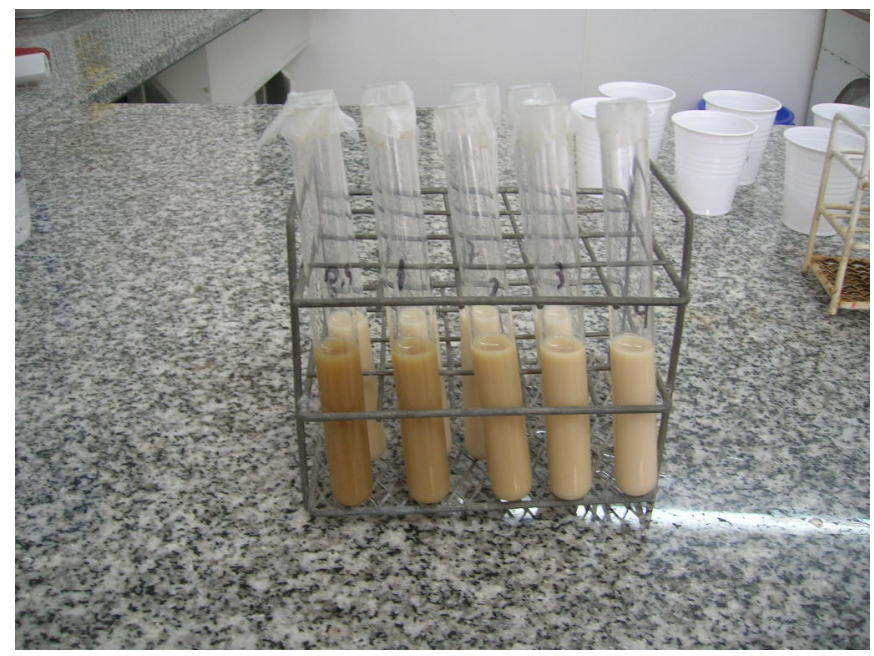

Figura 1.9 Tubos de ensayo conteniendo las soluciones de té con leche 


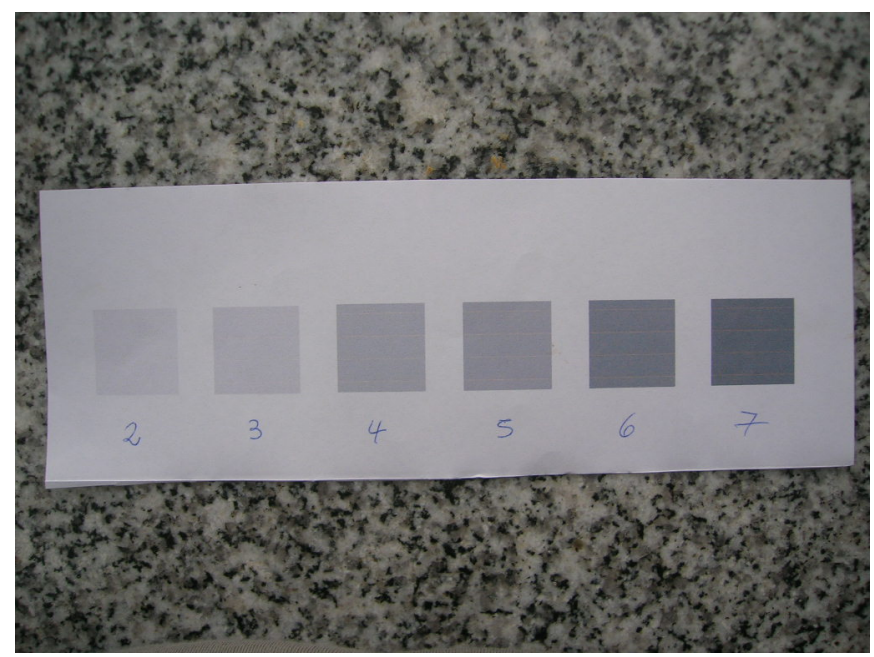

Figura 1.10 Escala de grises

Luego de la definición de los descriptores y sus respectivas escalas, se realizaron sesiones de entrenamiento para que los evaluadores se familiaricen con los mismos.

Una vez hecho el entrenamiento, se procedió a realizar las evaluaciones sensoriales. En cada sesión, los panelistas recibieron muestras de lomitos de caballa elaboradas según se muestra en el diagrama de flujo de la Figura 1.13. Con el fin de evaluar el efecto que produce en los lomitos la deshidratación osmótica, se realizaron perfiles sensoriales de lomitos cocidos al vapor (lomitos cocidos) y de lomitos cocidos al vapor y deshidratados osmóticamente (lomitos de humedad intermedia).

Cada panelista recibió una muestra de aproximadamente $20 \mathrm{~g}$ a temperatura ambiente $\left(18 \pm 2^{\circ} \mathrm{C}\right)$ dispuesta sobre un recipiente plástico con tapa y se le entregó una planilla con las escalas de los descriptores.

\subsubsection{Análisis Estadístico de los Resultados}

Para determinar la capacidad discriminatoria de cada panelista, los resultados se analizaron mediante un análisis de varianza (ANOVA) de un factor (evaluadores). De esta manera, se determinó si el efecto del mismo fue significativo para los descriptores estudiados $(p<0,05)$. En análisis posteriores se compararon las medias mediante el Test de Tukey $(p<0,05)$.

Para comparar los lomitos cocidos con los lomitos deshidratados osmóticamente (tanto para comparar perfiles sensoriales como la textura instrumental) se realizó un ANOVA de un factor (tratamiento). De esta manera, se determinó si la etapa de deshidratación osmótica tuvo un efecto significativo $(p<0,05)$ sobre los 
descriptores analizados. Posteriormente se compararon las medias mediante el Test de Tukey $(p<0,05)$.

El análisis estadístico se llevó a cabo con el programa InfoStat, 2011 (Grupo InfoStat, FCA, Universidad Nacional de Córdoba, Argentina).

\subsection{Resultados y discusión}

\subsubsection{Composición química proximal}

La composición química proximal de la materia prima cruda se muestra en la Tabla 1.7 .

Tabla 1.7 Composición química proximal (\% en base húmeda) de caballa entera y lomitos

\begin{tabular}{ccccc}
\hline & Humedad & Proteínas & Lípidos & Cenizas \\
\hline Caballa entera & $69,42 \pm 0,38$ & $21,31 \pm 0,19$ & $8,26 \pm 0,18$ & $1,31 \pm 0,07$ \\
\hline Lomitos & $71,66 \pm 0,20$ & $21,48 \pm 0,52$ & $5,50 \pm 0,69$ & $1,36 \pm 0,03$ \\
\hline
\end{tabular}

\subsubsection{Formulación de la solución de infusión para la deshidratación osmótica}

Para la elección de la concentración de la solución osmótica se tomó como referencia a la solución de infusión utilizada por Sánchez Pascua y col. (1998) para la cocción y deshidratación osmótica de lomitos de caballa. Esta solución estuvo compuesta por $54 \%$ de glicerol; $38,3 \%$ de agua; $7 \%$ de sal y $0,7 \%$ de sorbato de potasio.

Como se decidió no utilizar conservantes químicos en la elaboración de la preserva, en primera instancia se eliminó el sorbato de potasio de la composición de la solución.

Teniendo como objetivo obtener un producto con una $a_{w}$ de entre 0,88 y 0,90 , se buscó disminuir lo más posible los porcentajes de glicerol y sal de la solución. La búsqueda de una disminución del contenido de glicerol en la solución obedeció a optimizar los costos de producción. La limitación mas importante del desarrollo de la DO a escala industrial se encuentra en la viabilidad económica del uso de soluciones concentradas, dependiendo de la disponibilidad de los solutos a bajos costos (Dalla Rosa y Giroux, 2001). 
En cuanto al contenido de $\mathrm{NaCl}$, se buscó que el contenido final de la preserva fuera cercano al $2 \%$. Además, se estableció que el tiempo de inmersión de los lomitos en la solución de infusión no fuera mayor de $20 \mathrm{~h}$.

Teniendo en cuenta los requisitos mencionados, se experimentó con distintos porcentajes de glicerol y sal en la solución. Se investigó utilizando $54,40,30$ y $20 \%$ de glicerol y 4, 5, 6 y $7 \%$ de sal. Se realizaron análisis de $a_{w}$ y contenido de glicerol y sal y se determinó que la composición que cumplió con los requisitos establecidos fue: $40 \%$ de glicerol, $5 \%$ de sal y $55 \%$ de agua.

Luego de la realización del perfil sensorial de los lomitos de humedad intermedia se decidió agregarle ácido cítrico a la solución con el fin de contrarrestar el gusto dulce. Este análisis se detalla en la Sección 1.5.5. La solución final fue: $54,5 \%$ de agua; $40 \%$ de glicerol; $5 \%$ de sal y $0,5 \%$ de ácido cítrico. Con esta solución de infusión, en $19 \mathrm{~h}$ de deshidratación osmótica se llegó a una $\mathrm{a}_{\mathrm{w}}$ de 0,89 \pm 0,01 con un contenido de $\mathrm{NaCl}$ de 1,99 $\pm 0,01 \%$; un contenido de glicerol de 16,03 $\pm 0,63 \%$; un contenido de ácido cítrico de 0,16 $\pm 0,01 \%$ y un $\mathrm{pH}$ de $5,11 \pm 0,05$.

\subsubsection{Cálculo teórico de la pasteurización}

Se calcularon las propiedades termofísicas de los lomitos a $60^{\circ} \mathrm{C}$ y a $18^{\circ} \mathrm{C}$ de acuerdo a las correlaciones de Choi y Okos (Urbicain y Lozano, 1997). Estas propiedades y el Bi para cilindro y para placa a ambas temperaturas se muestran en la Tabla 1.8.

Tabla 1.8 Propiedades termofísicas de los lomitos de caballa de $a_{w}$ intermedia

\begin{tabular}{ccc}
\hline \multirow{2}{*}{ Propiedad Termofísica } & \multicolumn{2}{c}{ Temperatura $\left(^{\circ} \mathbf{C}\right)$} \\
\cline { 2 - 3 } & $\mathbf{1 8}$ & $\mathbf{6 0}$ \\
\hline $\mathbf{\rho}\left(\mathbf{K g} / \mathbf{m}^{3}\right)$ & 1287,42 & 1270,73 \\
$\mathbf{K}_{\mathbf{0}}\left(\mathbf{W} / \mathbf{m}^{\circ} \mathbf{C}\right)$ & 0,489 & 0,460 \\
$\mathbf{C p}\left(\mathbf{J} / \mathbf{K g}^{\circ} \mathbf{C}\right)$ & 2868,93 & 2890,58 \\
$\boldsymbol{\alpha}_{\mathbf{1}}\left(\mathbf{m}^{2} / \mathbf{s}\right)$ & $1,042 \times 10^{-7}$ & $1,173 \times 10^{-7}$ \\
$\mathbf{B i}_{\text {placa }}$ & 8,594 & 9,123 \\
$\mathbf{B i}_{\text {cilindro }}$ & 1,841 & 1,955 \\
\hline
\end{tabular}

En las Figuras 1.11 y 1.12 se muestran las curvas de calentamiento y enfriamiento del lomito de caballa a $60^{\circ} \mathrm{C}$ y $18^{\circ} \mathrm{C}$ respectivamente. Se obtuvieron valores de $\mathrm{R}$ de 0,9996 y 0,9992 para calentamiento y enfriamiento respectivamente. 
Los valores de $f_{h}$ y $f_{c}$ fueron 25,06 y 27,32 respectivamente. El $j_{h}$ fue de 0,926 y el $j_{c}$ de 0,974 .

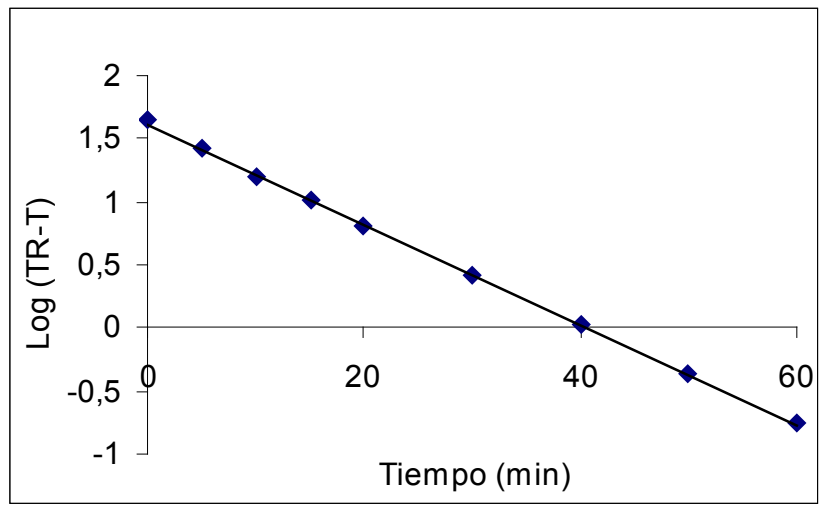

Figura 1.11 Curva de calentamiento

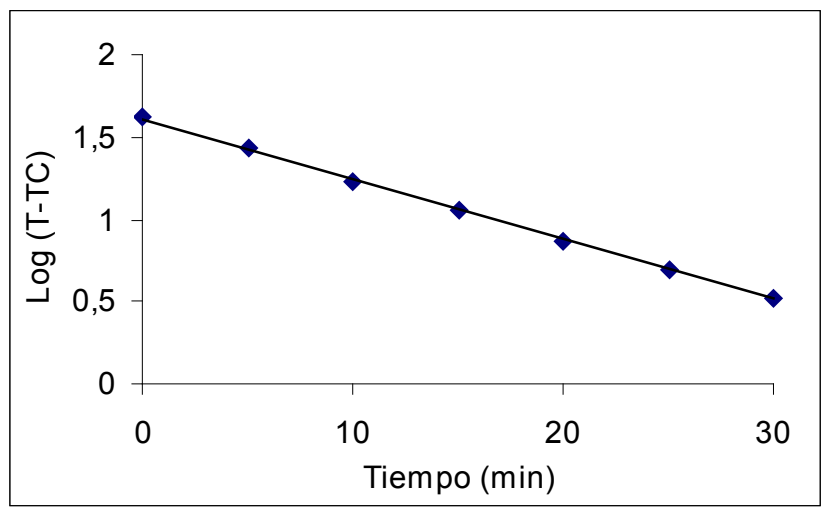

Figura 1.12 Curva de enfriamiento

De acuerdo a los valores de $f_{h}$ y $f_{c}$ obtenidos es posible utilizar el método de Stumbo para el cálculo del tiempo de pasteurización.

El tiempo de pasteurización determinado por el método general fue de 53,5 min. y de 52,0 y 52,5 min. por el método de Stumbo y Hayakawa respectivamente.

Las tablas utilizadas por el método de Stumbo y Hayakawa se pueden ver en los Anexos 2, 3 y 4.

\subsubsection{Proceso de elaboración de lomitos de caballa de humedad intermedia}

El proceso de elaboración de los lomitos se muestra en el diagrama de flujo de la Figura 1.13. 


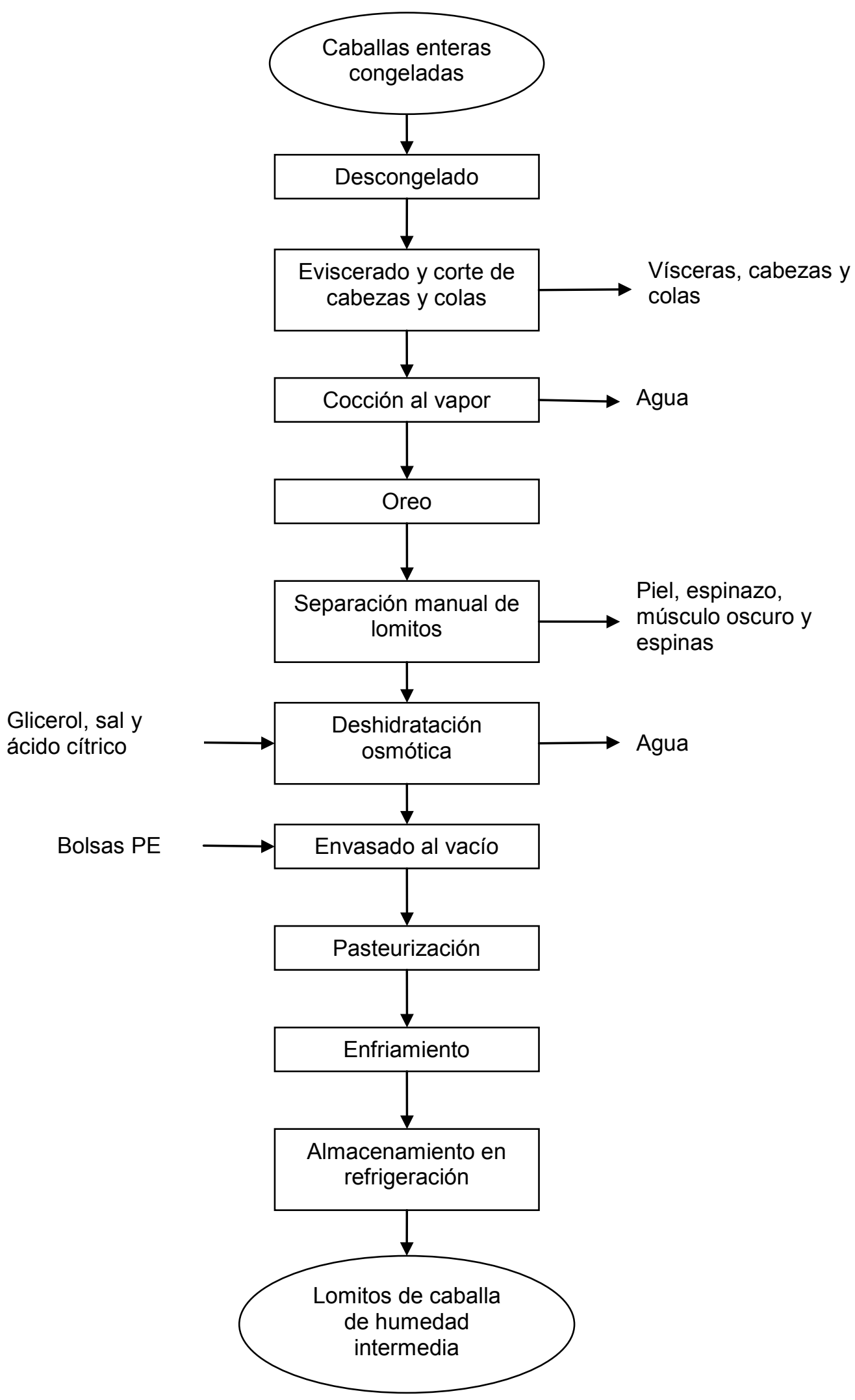

Figura 1.13 Diagrama de Flujo del proceso de elaboración de lomitos de caballa de humedad intermedia 
A continuación se describen en detalle las etapas de este proceso.

Descongelado: las caballas (Figura 1.14) fueron descongeladas en refrigeración (5 $\pm 1^{\circ} \mathrm{C}$ ) durante $48 \mathrm{hs}$.

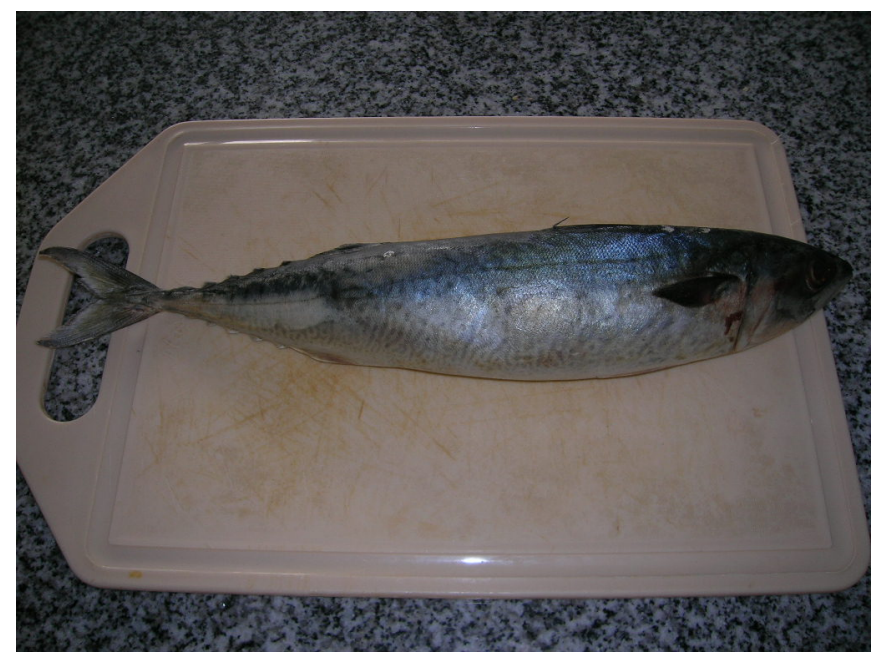

Figura 1.14 Ejemplar congelado de caballa (Scomber japonicus)

Eviscerado y corte de cabezas y colas: una vez descongeladas las piezas, se les abrió el abdomen aplicando un corte con cuchillo de acero inoxidable desde el ano hasta debajo de la cabeza. Luego se aplicó otro corte debajo de las aletas pectorales (un corte de cada lado) para separar la cabeza y, mediante un tirón, se retiraron las vísceras junto con la cabeza. Finalmente se cortó la aleta caudal (cola). A la parte del pescado que resulta del retirado de las vísceras, cabeza y cola se la denomina "tronco" (Figura 1.15).

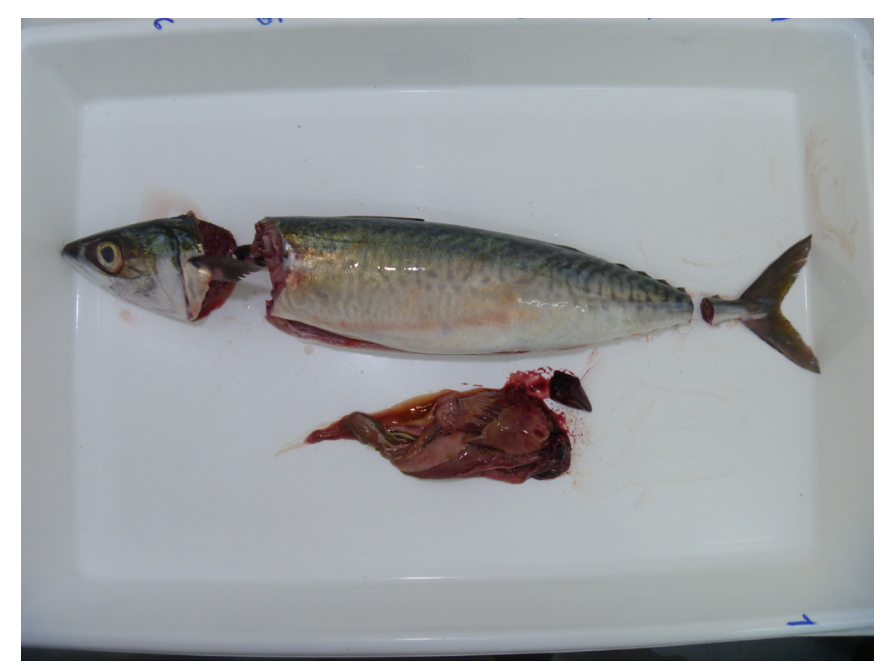

Figura 1.15: Obtención del tronco de caballa. 
Lavado: los troncos fueron lavados con agua de red para retirar restos de sangre y vísceras adheridas al abdomen.

Cocción al vapor: los troncos lavados fueron cocidos al vapor $\left(100^{\circ} \mathrm{C}\right)$ utilizando una olla acondicionada para tal fin. El tiempo de cocción fue de 20 minutos. La cocción se realizó con el fin de acondicionar las muestras para poder realizar la separación del músculo blanco de forma eficiente. Además, durante la cocción se inactivan enzimas y se reduce la carga bacteriana.

Oreo: una vez cocidos, se dejaron enfriar los troncos por 20 minutos a temperatura ambiente y luego fueron mantenidos en refrigeración $\left(5 \pm 1^{\circ} \mathrm{C}\right)$ durante 2 horas.

Separación manual de lomitos: la separación de los lomitos se realizó de forma manual. Se retiró la piel, el esqueleto, el músculo oscuro y las espinas. De esta manera se obtuvo el músculo limpio al que se denominó "lomito" (Figura 1.16).

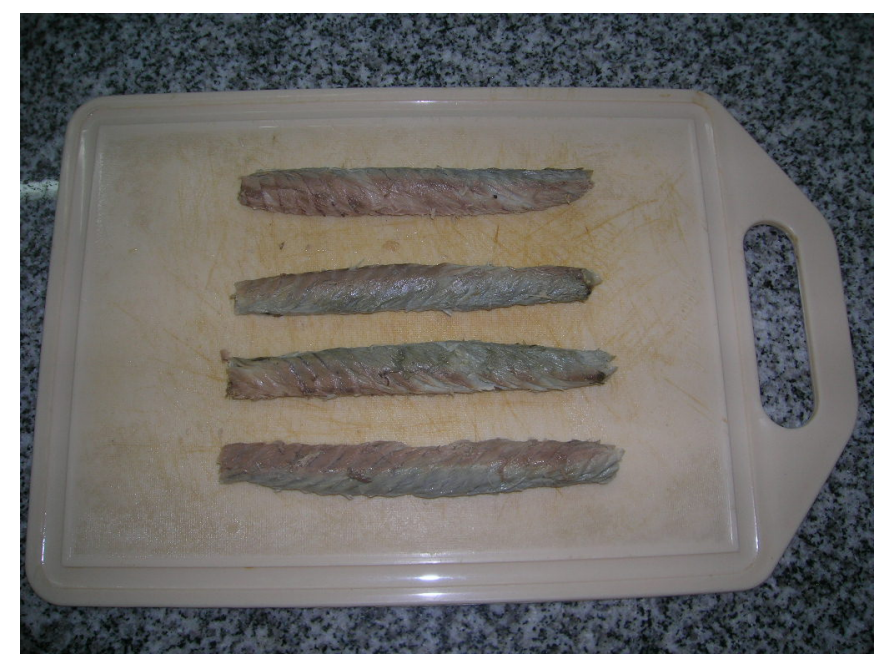

Figura 1.16: Lomitos de caballa.

Deshidratación osmótica: se colocaron los lomitos en la solución de infusión a temperatura de refrigeración $\left(5 \pm 1^{\circ} \mathrm{C}\right)$ durante 19 horas. La composición de la solución se puede ver en la Tabla 1.9. La $a_{w}$ de la solución fue de 0,68 y la proporción pescado:solución fue de 1:2. Una vez deshidratados, los lomitos se sacaron de la solución y se escurrieron sobre bandejas. 
Tabla 1.9: Composición de la solución de infusión.

\begin{tabular}{lc}
\hline Componente & Porcentaje(p/p) \\
\hline Agua & 54,5 \\
Glicerol & 40 \\
Sal & 5 \\
Acido cítrico & 0,5 \\
\hline
\end{tabular}

> Envasado al vacío: Ios lomitos escurridos se colocaron en bolsas termosellables de polietileno de baja densidad (PEBD) y poliamida (PA) de 75 micrómetros de espesor (Cryovac®) y se procedió al envasado al vacío utilizando una envasadora Rapi Vac modelo DZ 400 (Servivac, Argentina).

Las propiedades de permeabilidad de las bolsas utilizadas fue la siguiente:

- velocidad de transferencia de oxígeno: $75 \mathrm{cc} / \mathrm{m}^{2} / 24 \mathrm{~h}$

- velocidad de transferencia de vapor de agua: $11 \mathrm{~g} / \mathrm{m}^{2} / 24 \mathrm{~h}$

Pasteurización: los lomitos envasados al vacío se pasteurizaron en agua a $60 \pm$ $1^{\circ} \mathrm{C}$ durante 54 minutos mediante el uso de un baño termostático modelo Masson D (Vicking, Argentina). El estudio teórico de la pasteurización fue detallado en la Sección 1.5 .3 y la validación de esta etapa se puede ver en el Capítulo 3.

Almacenamiento en refrigeración: luego de la pasteurización, se enfriaron en un baño de agua a $18^{\circ} \mathrm{C}$ durante 30 minutos, se secaron con papel y se almacenaron en refrigeración $\left(5 \pm 1^{\circ} \mathrm{C}\right)$.

El producto final (Figura 1.17) presentó un contenido de humedad del $50,32 \pm$ $0,02 \%$; un $1,99 \pm 0,01 \%$ de $\mathrm{NaCl}$; un $16,03 \pm 0,63 \%$ de glicerol y un $0,16 \pm 0,01 \%$ de ácido cítrico. Además, el pH fue $5,11 \pm 0,05$ y la $a_{w} 0,89 \pm 0,01$. 


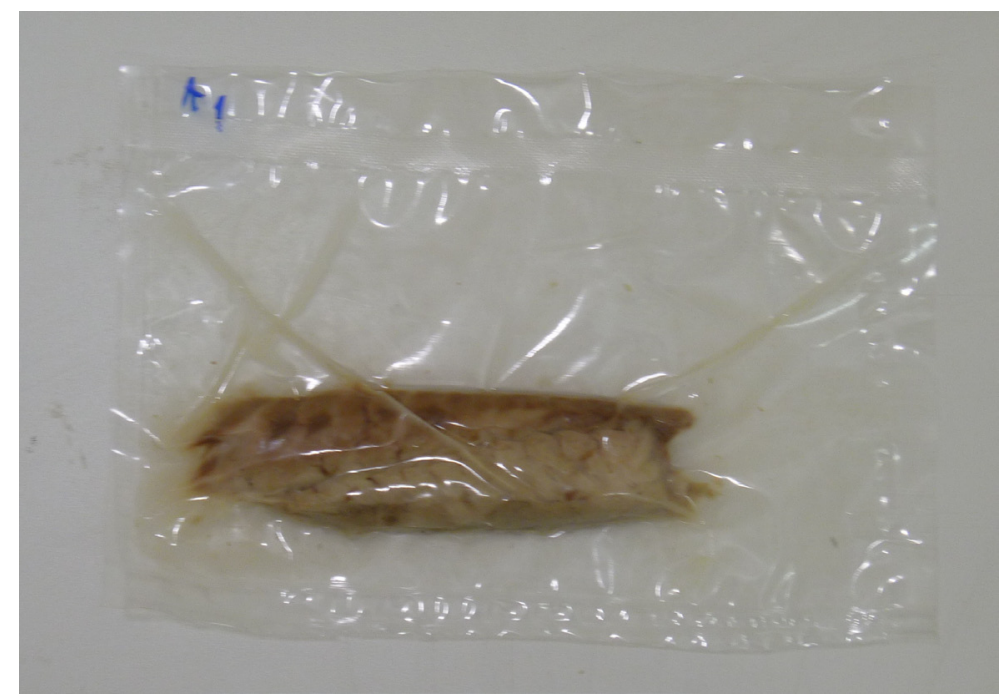

Figura 1.17 Lomito de caballa DO, envasado al vacío y pasteurizado

\subsubsection{Evaluación sensorial}

A continuación se detallan los resultados de las pruebas de selección y la realización del perfil sensorial.

\section{Selección de Evaluadores}

En las tablas $1.10,1.11,1.12$ y 1.13 se pueden ver los resultados de las pruebas de reconocimiento de gustos básicos, de aromas, de color y de perfil sensorial.

Tabla 1.10 Resultados de la prueba de gustos básicos

\begin{tabular}{|c|c|c|c|c|c|c|c|c|c|c|c|c|c|}
\hline \multirow{2}{*}{ Evaluador } & \multicolumn{12}{|c|}{ Muestras } & \multirow{2}{*}{ Puntaje } \\
\hline & 172 & 831 & 111 & 738 & 924 & 125 & 765 & 143 & 557 & 616 & 477 & 355 & \\
\hline 1 & Dul & Ac & Uma & Sal & Sal & Ama & Dul & Agua & Uma & Ac & Agua & Ama & 2 \\
\hline 2 & Dul & Ac & Uma & Sal & Sal & Ama & Dul & Uma & Ama & Ac & Agua & Ama & 1 \\
\hline 3 & Dul & Ac & Uma & Sal & Sal & Ama & Dul & Agua & Ama & Ac & Agua & Ama & 2 \\
\hline 4 & Dul & Ac & Agua & Sal & Sal & Ama & Dul & Agua & Agua & Ac & Uma & Ama & 3 \\
\hline 5 & Dul & Ac & Uma & Sal & Sal & Ama & Dul & Uma & Uma & Ac & Uma & Ama & 2 \\
\hline 6 & Dul & Ac & Uma & Sal & Sal & Ama & Dul & Agua & Ama & Ac & Agua & Ama & 2 \\
\hline 7 & Dul & Ac & Uma & Sal & Sal & Ama & Dul & Agua & Agua & Ac & Uma & Ama & 2 \\
\hline 8 & Dul & Ac & Uma & Sal & Sal & Ama & Dul & Uma & Agua & Ac & Agua & Ama & 0 \\
\hline 9 & Dul & Ac & Uma & Sal & Sal & Ama & Dul & Agua & Agua & Ac & Agua & Ama & 1 \\
\hline 10 & Dul & Ac & Uma & Sal & Sal & Ama & Dul & Uma & Agua & Ac & Agua & Ama & 0 \\
\hline 11 & Dul & Ac & Agua & Sal & Sal & Ama & Dul & Uma & Ama & Ac & Uma & Ama & 3 \\
\hline
\end{tabular}


Tabla 1.11 Resultados de la prueba de reconocimiento de aromas

\begin{tabular}{|c|c|c|c|c|c|c|}
\hline \multirow[b]{2}{*}{ Evaluador } & \multicolumn{5}{|c|}{ Muestras } & \multirow[b]{2}{*}{ Puntaje } \\
\hline & $\begin{array}{c}\text { Anetol } \\
879\end{array}$ & $\begin{array}{c}\text { Almendra } \\
445\end{array}$ & $\begin{array}{c}\text { Mentol } \\
286\end{array}$ & $\begin{array}{c}\text { Citral } \\
411\end{array}$ & $\begin{array}{c}\text { Eugenol } \\
160\end{array}$ & \\
\hline 1 & $A$ & $A$ & $B$ & $A$ & $B$ & 0 \\
\hline 2 & $A$ & $A$ & $A$ & $A$ & C & 1 \\
\hline 3 & $A$ & $A$ & $A$ & $A$ & C & 1 \\
\hline 4 & $A$ & C & $B$ & $A$ & C & 2 \\
\hline 5 & $A$ & $A$ & $A$ & $A$ & $A$ & 0 \\
\hline 6 & $A$ & B & B & $A$ & $B$ & 0 \\
\hline 7 & $A$ & $B$ & $B$ & $A$ & C & 1 \\
\hline 8 & $A$ & $A$ & $A$ & $A$ & $A$ & 0 \\
\hline 9 & $A$ & B & $A$ & B & $A$ & 0 \\
\hline 10 & $A$ & A & A & A & A & 0 \\
\hline 11 & $A$ & B & A & B & C & 1 \\
\hline
\end{tabular}

Tabla 1.12 Resultados de la prueba de discriminación de color

\begin{tabular}{ccccccc}
\hline \multirow{2}{*}{ Evaluador } & \multicolumn{5}{c}{ Muestras } & \multirow{2}{*}{ Puntaje } \\
\cline { 2 - 5 } & $\mathbf{1 9 9}$ & $\mathbf{7 7 1}$ & $\mathbf{1 0 8}$ & $\mathbf{5 0 9}$ & $\mathbf{2 1 1}$ & \\
\hline $\mathbf{1}$ & 199 & 771 & 108 & 509 & 211 & 0 \\
$\mathbf{2}$ & 199 & 771 & 108 & 509 & 211 & 0 \\
$\mathbf{3}$ & 199 & 771 & 108 & 509 & 211 & 0 \\
$\mathbf{4}$ & 199 & 108 & 771 & 509 & 211 & 1 \\
$\mathbf{5}$ & 199 & 771 & 108 & 509 & 211 & 0 \\
$\mathbf{6}$ & 199 & 771 & 108 & 509 & 211 & 0 \\
$\mathbf{7}$ & 199 & 771 & 108 & 211 & 509 & 1 \\
$\mathbf{8}$ & 199 & 771 & 108 & 509 & 211 & 0 \\
$\mathbf{9}$ & 199 & 771 & 108 & 509 & 211 & 0 \\
$\mathbf{1 0}$ & 199 & 771 & 108 & 509 & 211 & 0 \\
$\mathbf{1 1}$ & 199 & 771 & 108 & 211 & 509 & 1 \\
\hline
\end{tabular}


Tabla 1.13 Resultados de la prueba del perfil sensorial

\begin{tabular}{rrrrr}
\hline Evaluador & $\begin{array}{r}\text { Aspecto } \\
\text { Tostado }\end{array}$ & Fracturabilidad & Salado & $\begin{array}{c}\text { Sabor } \\
\text { Tostado }\end{array}$ \\
$\mathbf{1}$ & 0 & 0 & 0 & 1 \\
$\mathbf{2}$ & 0 & 0 & 0 & 1 \\
$\mathbf{3}$ & 0 & 0 & 0 & 1 \\
$\mathbf{4}$ & 0 & 0 & 1 & 0 \\
$\mathbf{5}$ & 0 & 0 & 0 & 1 \\
$\mathbf{6}$ & 0 & 1 & 0 & 0 \\
$\mathbf{7}$ & 0 & 0 & 0 & 0 \\
$\mathbf{8}$ & 0 & 1 & 0 & 0 \\
$\mathbf{9}$ & 0 & 1 & 0 & 0 \\
$\mathbf{1 0}$ & 0 & 0 & 0 & 0 \\
$\mathbf{1 1}$ & 0 & 1 & 0 & 0 \\
\hline
\end{tabular}

En cuanto a los resultados de la prueba del perfil sensorial, para el descriptor aspecto tostado, el orden de todos los evaluadores coincidió con el orden promedio del grupo. La galletita con el código 314 resultó la más tostada seguida por la 298.

Con respecto a la fracturabilidad, los evaluadores $6,8,9$ y 11 presentaron un desvío con respecto al orden del grupo.

Una de las muestras, la 314 , no contenía sal, esto fue percibido por todos los evaluadores. El evaluador 4 dio un puntaje demasiado alto a la muestra 298 con respecto al resto.

Con respecto al sabor tostado, 4 evaluadores presentaron diferencias con respecto al orden del grupo (1, 2, 3 y 5).

Puntaje final:

Tabla 1.14: Puntaje final

\begin{tabular}{cc}
\hline Evaluador & Suma total \\
\hline 1 & 3 \\
2 & 3 \\
3 & 3 \\
4 & 7 \\
5 & 3 \\
6 & 4 \\
7 & 3 \\
8 & 1 \\
9 & 2 \\
10 & 0 \\
11 & 6 \\
\hline
\end{tabular}


Se decidió tomar como puntaje máximo admisible un valor de 4 . En la tabla 1.15 se puede ver el orden de mérito final.

Tabla 1.15 Orden de mérito

\begin{tabular}{cc}
\hline Evaluador & Puntaje \\
\hline 10 & 0 \\
8 & 1 \\
9 & 2 \\
1 & 3 \\
2 & 3 \\
3 & 3 \\
5 & 3 \\
7 & 3 \\
6 & 4 \\
11 & 6 \\
4 & 7 \\
\hline
\end{tabular}

Se puede apreciar que los evaluadores número 11 y 4 no lograron pasar las pruebas de selección.

\section{Búsqueda de descriptores}

El análisis descriptivo de lomitos de caballa se realizó con los 9 evaluadores que superaron las pruebas de selección.

La búsqueda de descriptores se dividió en dos. Inicialmente, se les pidió a los panelistas que busquen características sensoriales que consideren importantes para describir las muestras.

Estos fueron los descriptores encontrados por los evaluadores:

$>$ Presencia de músculo oscuro

$>$ Uniformidad de color

$>$ Manchas doradas

$>$ Color grisáceo

$>$ Color té con leche

$>$ Color crema

$>$ Aroma a pescado

$>$ Aroma dulzón 
Aroma a mar

$>$ Aroma a sal

$>$ Aroma a rancio

$>$ Fibrosidad

$>$ Dureza

$>$ Jugosidad

$>$ Elasticidad

$>$ Masticabilidad

$>$ Gusto dulce

$>$ Gusto salado

$>$ Gusto amargo

$>$ Sabor a pescado

$>$ Sabor rancio

$>$ Sabor residual

Luego, fue elegida una lista final de atributos, se los definió y se creó una escala verbal. Esta segunda parte fue realizada por el líder del panel junto con los evaluadores y se puede ver en la Tabla 1.16. 
Tabla 1.16 Lista de descriptores con escala y definición

\begin{tabular}{|c|c|c|}
\hline & Escala & Definición \\
\hline \multicolumn{3}{|l|}{ Color } \\
\hline Grisáceo & Impresa & Color asociado con el color gris \\
\hline Té con leche & Diluciones & $\begin{array}{c}\text { Color asociado con el color del té con el agregado de } \\
\text { leche }\end{array}$ \\
\hline \multicolumn{3}{|l|}{ Aroma } \\
\hline Pescado & Nada-Mucho & Aroma característico del pescado fresco cocido \\
\hline Dulzón & Nada-Mucho & \\
\hline Rancio & Nada-Mucho & $\begin{array}{l}\begin{array}{c}\text { Aroma característico de la oxidación de los lípidos del } \\
\text { pescado }\end{array}\end{array}$ \\
\hline \multicolumn{3}{|l|}{ Textura } \\
\hline Jugosidad & Nada-Mucho & Grado de humedad del producto al masticar \\
\hline Dureza al Tacto & $\begin{array}{l}\text { Blando-Duro } \\
\text { (Flan-Corcho) }\end{array}$ & $\begin{array}{c}\text { Fuerza requerida para lograr cortar el producto con la } \\
\text { ayuda de un tenedor. }\end{array}$ \\
\hline Dureza & $\begin{array}{l}\text { Blando-Duro } \\
\text { (Flan-Corcho) }\end{array}$ & $\begin{array}{c}\text { Fuerza requerida para lograr deformar o penetrar el } \\
\text { producto al masticar. }\end{array}$ \\
\hline \multicolumn{3}{|l|}{ Sabor } \\
\hline Dulce & Nada-Mucho & Gusto dulce \\
\hline Salado & $\begin{array}{l}\text { Sción salina al 0,5\%- } \\
2,5 \%\end{array}$ & Gusto salado \\
\hline Amargo & Nada-Mucho & Gusto amargo \\
\hline Pescado & Nada-Mucho & Sabor asociado al pescado fresco cocido \\
\hline Rancio & Nada-Mucho & $\begin{array}{c}\text { Sabor originado por la oxidación de los lípidos del } \\
\text { pescado }\end{array}$ \\
\hline
\end{tabular}

\section{$\underline{\text { Perfil Sensorial }}$}

Se realizó el perfil sensorial de acuerdo al método del Análisis Descriptivo Cualitativo (DESA, 2010). Para la realización de este estudio un evaluador no fue tenido en cuenta debido a que sus evaluaciones fueron significativamente diferentes con respecto al resto $(p<0,05)$. 
Luego de analizar por ANOVA los resultados para cada descriptor, se observó que el color gris y el té con leche, los sabores amargo, dulce y rancio, la dureza al corte, la jugosidad y los aromas a pescado y rancio no presentaron diferencias significativas entre los evaluadores $(p>0,05)$. Los demás descriptores presentaron diferencias significativas, por lo tanto se realizó un Test de Tukey $(p<0,05)$ con el fin de detectar diferencias entre las medias de los evaluadores.

En cuanto al aroma dulzón, el evaluador 7 mostró una tendencia a marcar muy por encima de la media general por lo que no se tuvo en cuenta su evaluación para este descriptor. Para la dureza en boca, el evaluador 2 tuvo una tendencia a marcar por debajo de la media general y los evaluadores 1 y 8 por encima de la misma. La evaluación de estos tres no se tuvo en cuenta.

Para los descriptores sabor a pescado y gusto salado hubo una gran disparidad de resultados. Los lomitos contienen diversos ingredientes y sustancias propias del pescado que se solapan entre ellos produciendo en los evaluadores distintos estímulos haciendo que cada uno tenga sus propias percepciones (Multon, 1988; Sánchez Pascua y col., 2010). Esta disparidad de resultados se corrigió con más sesiones de entrenamiento en los descriptores mencionados anteriormente. En cuanto al gusto salado, además, se decidió cambiar la escala del estilo nada-mucho por otra en que se utilizaron dos soluciones acuosas con concentraciones distintas de sal para el mínimo y máximo de escala. Las concentraciones elegidas fueron $0,5 \%$ y $2,5 \%$. De esta manera se logró mejorar las evaluaciones.

En la Figura 1.18 se muestran los resultados del perfil en un gráfico radial. Se puede apreciar una característica muy distintiva del producto dada por el gusto dulce aportado por el glicerol. Según Multon (1988), el glicerol, en ciertas concentraciones, puede aportar un gusto residual dulce. Además del gusto dulce, también aportó un leve aroma dulzón.

Cabe destacar que el producto no presentó ni aroma ni sabor rancio. Además, no tuvo gusto amargo, este es un dato relevante dado que el glicerol puede aportar también un sabor residual amargo (Sánchez Pascua y col., 2010). 


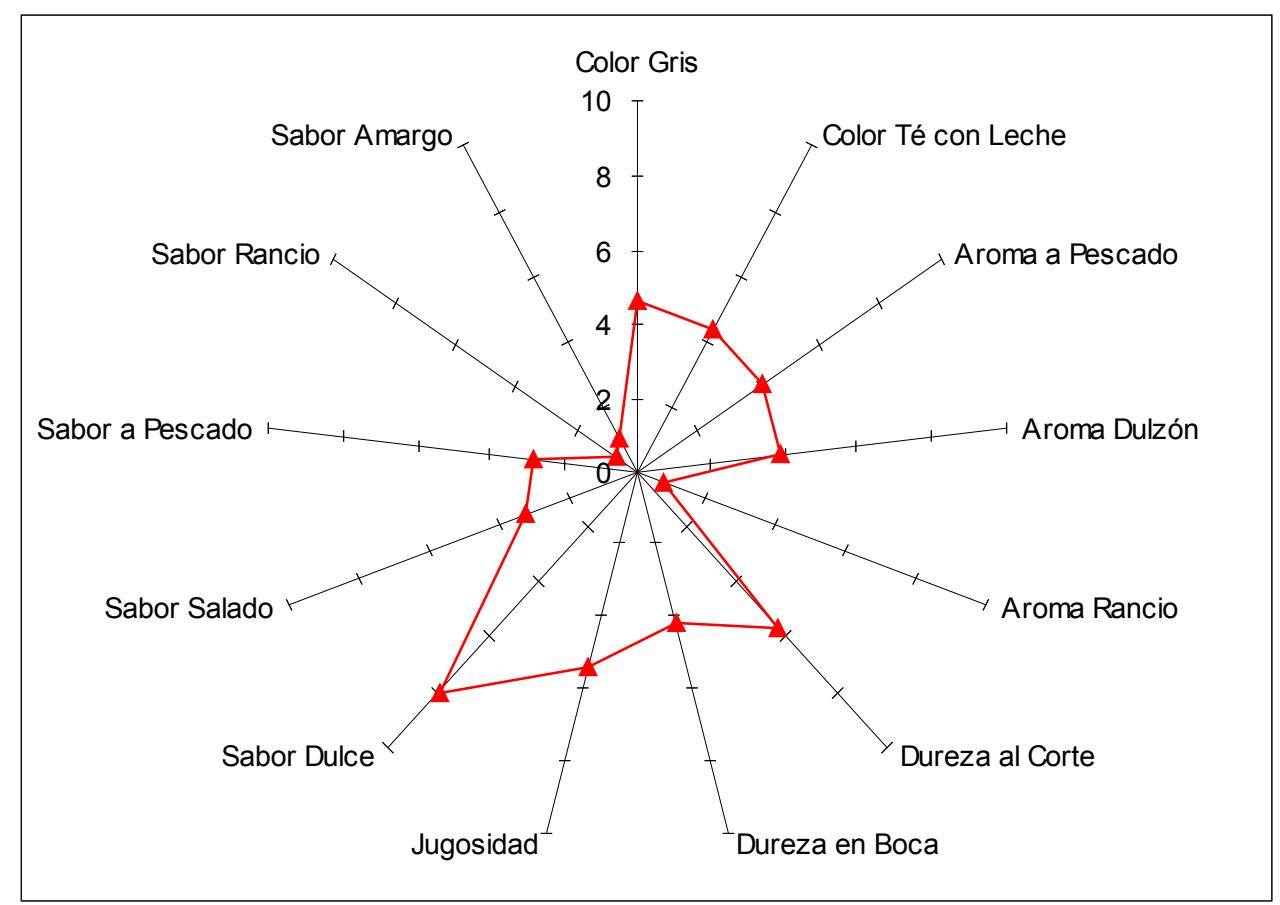

Figura 1.18 Perfil sensorial de lomitos deshidratados osmóticamente

\section{$\underline{\text { Reducción de la intensidad del gusto dulce }}$}

Luego de realizar el perfil sensorial de los lomitos, se decidió trabajar sobre la formulación del producto para intentar disminuir la intensidad del gusto dulce percibida por los evaluadores.

Diversos autores han utilizado una combinación de glicerol y sal para disminuir la $\mathrm{a}_{\mathrm{w}}$ de productos cárnicos (Brockman, 1970; Chirife y col., 1979; Favetto y col., 1981). Dependiendo la $a_{w}$ buscada, los productos frecuentemente son rechazados sensorialmente debido al gusto residual dulce (Leistner, 1987; Sánchez Pascua y col. 1994). Por este motivo se decidió incorporar ácido cítrico en la solución de infusión para contrarrestar el gusto dulce. La interacción acido-dulce ha sido ampliamente estudiada (Bonnans y Noble, 1993; Marsh y col., 2003, 2006; Sanchez Pascua y col., 2010; Schifferstein y Frijsters, 1990). Estos autores determinaron que el ácido cítrico suprime el dulzor de la sacarosa. La combinación ácido-dulce ha sido utilizada en pescados marinados con ácido acético y sacarosa (McLay, 1972) y con ácido acético y sorbitol (Casales y Yeannes, 2006). Distintos ácidos han sido utilizados como complemento de la sal para tiernizar mantos de calamar (Collignan y Montet, 1998) o para estabilizar y dar propiedades organolépticas específicas en anchoas (Poligné y Collignan, 2000). 
Se realizaron ensayos para determinar el porcentaje de ácido cítrico a utilizar en la solución osmótica. Para esto se analizaron diferentes porcentajes: 0,$25 ; 0,5 ; 1 ; 2$ y $3 \%$. El panel sensorial se reunió para evaluar el sabor de las muestras y decidir el porcentaje óptimo que permitiera balancear el dulzor y la acidez. Con 0,25\% de ácido cítrico el dulzor de las muestras siguió siendo muy elevado y, por otro lado, a partir del $1 \%$ el sabor ácido fue muy fuerte. Es por esto que se determinó que la concentración que contrarrestó el gusto dulce sin prevalecer en exceso el ácido fue $0,5 \%$ de ácido cítrico.

Perfil sensorial de los lomitos de humedad intermedia y comparación con lomitos cocidos

Se realizó un segundo perfil sensorial a los lomitos elaborados con la nueva solución de infusión conteniendo ácido cítrico. El agregado de ácido cítrico disminuyó significativamente $(p<0,05)$ el gusto dulce de los lomitos (de un valor de 7,96 $\pm 0,75$ pasó a tener un valor de $5,47 \pm 1,06)$. Además del gusto dulce, también disminuyeron significativamente el aroma dulzón y el color té con leche. Distintos autores han informado del cambio de color de filetes de pescado debido a la inmersión en soluciones conteniendo ácidos. Kołakowski y Bednarczyk (2002), reportaron un aumento de la claridad y un descenso del color rojo en filetes de arenque inmersos en solución de sal y ácido acético. Se detectó el sabor ácido aportado por el ácido cítrico (con un valor de $1,89 \pm 1,12$ ) y los otros parámetros estudiados no presentaron diferencias significativas $(p>0,05)$.

Una vez obtenido el perfil sensorial definitivo de los lomitos DO (con el agregado de ácido cítrico a la solución osmótica), los panelistas analizaron también muestras de lomitos de caballa cocidos al vapor (sin el proceso de DO). Este análisis se llevó a cabo con el fin de comparar el producto cocido con el producto de humedad intermedia y poder determinar cómo afecta la DO a las características sensoriales de la caballa. Los resultados se muestran en la Figura 1.19. 


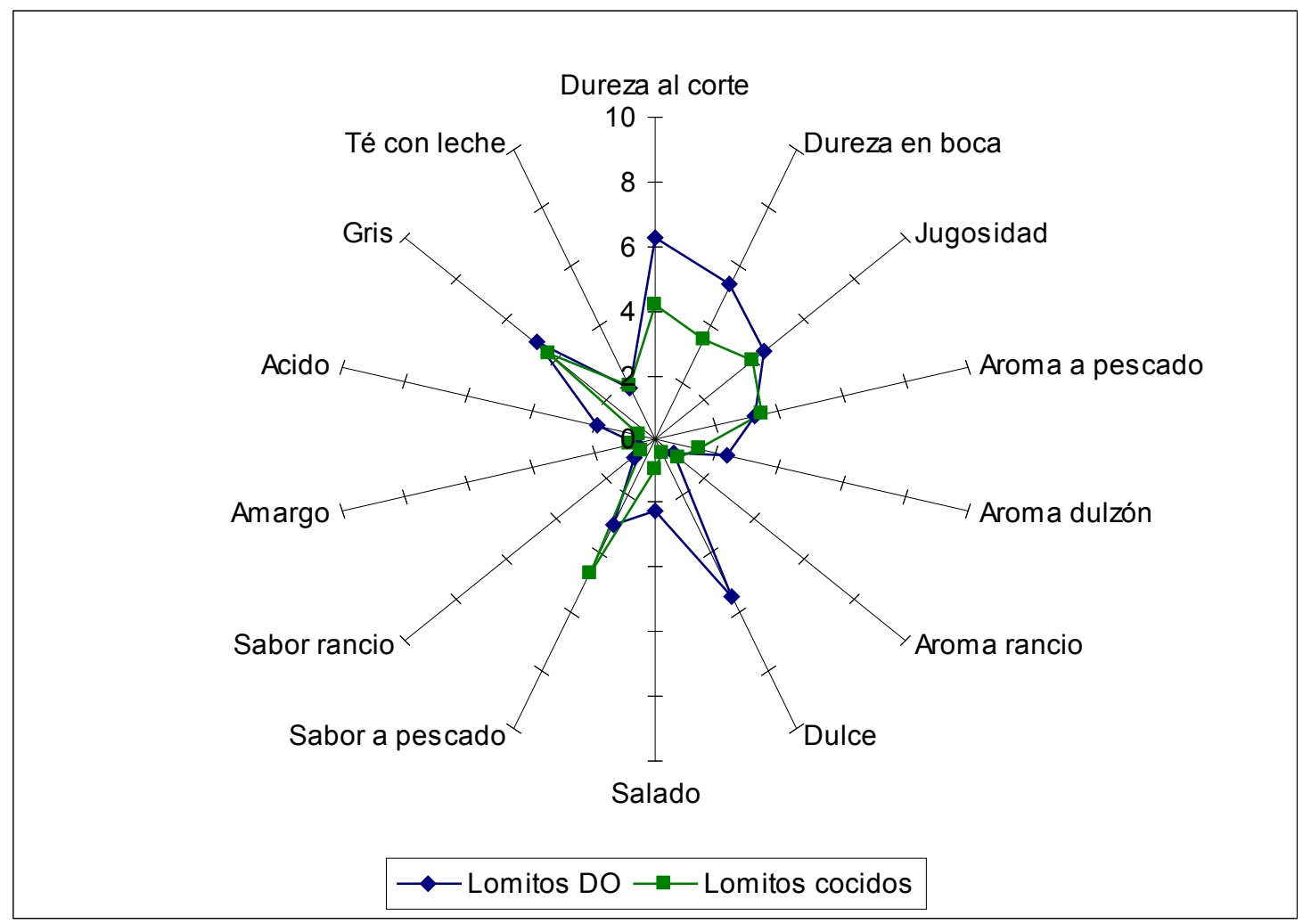

Figura 1.19 Perfiles sensoriales de lomitos deshidratados osmóticamente (DO) y de lomitos solamente cocidos

Además, en la Tabla 1.17 se observan los resultados de los perfiles y el análisis estadístico realizado (ANOVA).

Tabla 1.17 Resultado del perfil sensorial de lomitos cocidos y lomitos deshidratados osmóticamente (DO)

\begin{tabular}{lcc}
\hline \multicolumn{1}{c}{ Atributos } & Lomitos cocidos & Lomitos DO \\
\hline Gris & $4,22 \pm 0,94 \mathrm{a}^{*}$ & $4,72 \pm 0,75 \mathrm{a}$ \\
Té con leche & $1,89 \pm 1,05 \mathrm{a}$ & $1,78 \pm 0,67 \mathrm{a}$ \\
Dureza al corte & $4,16 \pm 1,11 \mathrm{a}$ & $6,28 \pm 1,51 \mathrm{~b}$ \\
Dureza en boca & $3,42 \pm 0,94 \mathrm{a}$ & $5,31 \pm 0,88 \mathrm{~b}$ \\
Jugosidad & $3,89 \pm 0,99 \mathrm{a}$ & $4,42 \pm 0,86 \mathrm{a}$ \\
Aroma a pescado & $3,39 \pm 1,55 \mathrm{a}$ & $3,19 \pm 1,44 \mathrm{a}$ \\
Aroma dulzón & $1,39 \pm 1,18 \mathrm{a}$ & $2,33 \pm 0,95 \mathrm{~b}$ \\
Aroma rancio & $0,92 \pm 0,73 \mathrm{a}$ & $0,75 \pm 0,67 \mathrm{a}$ \\
Dulce & $0,47 \pm 0,47 \mathrm{a}$ & $5,47 \pm 1,06 \mathrm{~b}$ \\
Salado & $0,94 \pm 0,66 \mathrm{a}$ & $2,22 \pm 0,93 \mathrm{~b}$ \\
Sabor a pescado & $4,64 \pm 0,89 \mathrm{~b}$ & $2,94 \pm 0,75 \mathrm{a}$ \\
Sabor rancio & $0,61 \pm 0,56 \mathrm{a}$ & $0,83 \pm 0,91 \mathrm{a}$ \\
Amargo & $0,78 \pm 0,69 \mathrm{a}$ & $0,61 \pm 0,56 \mathrm{a}$ \\
Acido & $0,50 \pm 0,54 \mathrm{a}$ & $1,89 \pm 1,12 \mathrm{~b}$ \\
\hline
\end{tabular}

*Valores medios seguidos por letras distintas en una misma fila son significativamente diferentes $(p<0,05)$. 
No hubo diferencias significativas $(p>0,05)$ en los parámetros gris y té con leche. La DO no influyó sobre la percepción sensorial del color del producto.

Los lomitos DO tuvieron una dureza significativamente mayor $(p<0,05)$ tanto al corte como en boca. Esta característica distintiva de los lomitos de humedad intermedia se pudo deber a la pérdida de agua por deshidratación (Ruiz-Ramírez y col., 2005), así como también al efecto plastificante del glicerol (Multon, 1988; Moreira y col., 2007). Los plastificantes como el glicerol ejercen una gran influencia sobre las propiedades reológicas de los productos alimenticios ya que cambian su organización molecular (Farahnaky y col., 2009).

La pérdida de agua durante la DO no afectó la jugosidad de los lomitos ya que no hubo diferencias significativas $(p>0,05)$ entre las muestras. Esto se puede deber a que si bien se perdió alrededor de un $18 \%$ de agua durante la $\mathrm{DO}$, el producto incorporó alrededor del $16 \%$ de glicerol. Además de plastificante, el glicerol es un excelente humectante (Muguruma y col., 1987).

En cuanto al aroma a pescado y a rancio, estos no se vieron afectados por el tratamiento aplicado $(p>0,05)$. Por el contrario, se encontraron diferencias significativas $(p<0,05)$ en el aroma dulzón debido al glicerol.

Como se dijo anteriormente, con el agregado de ácido cítrico a la solución osmótica se redujo significativamente el gusto dulce de un valor de 7,96 a 5,47. A pesar de esta reducción, el gusto dulce se siguió percibiendo ya que los evaluadores encontraron diferencias significativas $(p<0,05)$ entre la muestra cocida y la procesada. Esta es una característica intrínseca de la preserva.

Tanto en el gusto ácido como en el salado las muestras deshidratadas tuvieron una intensidad significativamente mayor $(p<0,05)$. Esto fue debido al ácido cítrico y a la sal incorporados durante la DO.

Los sabores amargo y rancio fueron percibidos levemente (en todos los casos tuvieron una puntuación menor a 1) y no hubo diferencias significativas $(p>0,05)$ entre las muestras evaluadas.

Por último, existieron diferencias significativas $(p<0,05)$ en el sabor a pescado. Los evaluadores percibieron un mayor sabor a pescado en las muestras cocidas. Esta disminución en el sabor a pescado debido al procesamiento puede atribuirse a un enmascaramiento producido por los gustos dulce, salado y ácido aportados por el glicerol, la sal y el ácido cítrico respectivamente. Además, durante la DO se produce una salida de solutos, que forman parte del sabor, desde el producto hacia la solución (Sablani y Rahman, 2003). 


\subsubsection{Análisis instrumental de la textura}

Se realizó un análisis instrumental de textura de los lomitos deshidratados osmóticamente (lomitos DO) mediante la técnica Texture Profile Analisis (TPA) (Bourne, 1978). Además, se analizó con la misma técnica la textura de los lomitos cocidos con el fin de investigar el aporte de la DO a la textura del producto. Los resultados se muestran en la Tabla 1.18.

Tabla 1.18 Resultado del análisis instrumental de textura de lomitos cocidos y lomitos deshidratados osmóticamente (DO)

\begin{tabular}{lccc}
\hline \multicolumn{1}{c}{ Muestra } & Dureza (N) & Adhesividad (Ns) & Cohesividad \\
\hline Lomitos cocidos & $4,33 \pm 1,38 \mathrm{a}^{*}$ & $0,03 \pm 0,01 \mathrm{a}$ & $0,43 \pm 0,02 \mathrm{a}$ \\
Lomitos Do & $9,81 \pm 1,77 \mathrm{~b}$ & $0,03 \pm 0,01 \mathrm{a}$ & $0,44 \pm 0,02 \mathrm{a}$ \\
\hline
\end{tabular}

*Valores medios seguidos por letras distintas en una misma columna son significativamente diferentes $(p<0,05)$.

Como se puede observar, la dureza de los lomitos DO fue significativamente mayor $(p<0,05)$ que la dureza de los lomitos cocidos. Estos resultados están de acuerdo con los resultados del análisis sensorial. Como se vio anteriormente, la dureza evaluada en boca y al corte de los lomitos de humedad intermedia también fue significativamente mayor. Este estudio sirvió para confirmar de forma objetiva los resultados sensoriales.

Además de la dureza, se analizó la adhesividad y la cohesividad de las muestras. No hubo diferencias significativas $(p<0,05)$ entre las muestras estudiadas en ambos parámetros. Por lo tanto, la deshidratación osmótica generó una mayor dureza en los lomitos pero no afectó a la adhesividad ni a la cohesividad.

\subsubsection{Análisis instrumental del color}

Se analizó el color de los lomitos mediante el uso de un colorímetro para obtener resultados objetivos de este parámetro y poder comparar con los resultados del análisis sensorial del color.

Al igual que en el análisis instrumental de la textura, se analizaron también muestras de lomitos cocidos con el fin de estudiar el efecto de la DO sobre el color de los mismos. Los resultados se muestran en la Tabla 1.19. 
Tabla 1.19 Resultado del análisis instrumental de color de lomitos cocidos y lomitos deshidratados osmóticamente (DO)

\begin{tabular}{lcccc}
\hline \multirow{2}{*}{ Parámetro } & \multicolumn{2}{c}{ Gris } & \multicolumn{2}{c}{ Té con leche } \\
\cline { 2 - 5 } & $\begin{array}{c}\text { Lomitos } \\
\text { cocidos }\end{array}$ & Lomitos Do & $\begin{array}{c}\text { Lomitos } \\
\text { cocidos }\end{array}$ & Lomitos Do \\
\hline $\mathbf{L}^{*}$ & $67,19 \pm 4,51$ a & $65,38 \pm 2,09$ a & $66,35 \pm 2,70$ a & $65,95 \pm 5,04$ a \\
a $^{*}$ & $0,86 \pm 1,38$ a & $0,74 \pm 1,25$ a & $4,45 \pm 0,85$ a & $3,64 \pm 1,08$ a \\
b $^{*}$ & $15,38 \pm 3,99$ a & $13,07 \pm 4,21$ a & $19,96 \pm 1,48$ a & $20,36 \pm 2,15$ a \\
\hline
\end{tabular}

*Valores medios seguidos por letras distintas en una misma columna son significativamente diferentes $(p<0,05)$.

Tanto para el color gris como para el color té con leche, ninguno de los parámetros estudiados $\left(L^{*}, a^{*} y b^{*}\right)$ presentó diferencias significativas $(p>0,05)$ entre las muestras cocidas y las DO. Estos resultados concuerdan con el análisis sensorial, ya que tanto en el color gris como el té con leche los evaluadores no encontraron diferencias significativas entre las muestras cocidas y las DO.

\subsection{Conclusiones}

Se realizó el diseño del proceso de elaboración de la preserva de caballa. Las etapas del proceso de elaboración de lomitos de humedad intermedia fueron: descongelado de la caballa, eviscerado y corte de cabezas y colas, cocción al vapor, oreo, separación de los lomitos, deshidratación osmótica, envasado al vacío, pasteurización y almacenamiento refrigerado.

Mediante la deshidratación osmótica en solución de glicerol (40\%), sal (5\%) y ácido cítrico $(0,5 \%)$ se obtuvo un producto con un contenido de humedad del $50,32 \pm$ $0,02 \%$, un $1,99 \pm 0,01 \%$ de $\mathrm{NaCl}$ y $16,03 \pm 0,63 \%$ de glicerol. Además, el pH fue 5,11 $\pm 0,05$ y la $a_{w} 0,89 \pm 0,01$. De acuerdo a estas características fisicoquímicas, el único microorganismo patógeno capaz de crecer en la preserva es el Staphylococcus aureus, por lo que se diseñó la etapa de pasteurización teniendo a este microorganismo como referencia. Se estimó la evolución de la temperatura en estado no estacionario en el centro geométrico del lomito. El tiempo de pasteurización para lograr una letalidad de 5D (5 reducciones decimales) determinado por el método general fue de $53,5 \mathrm{~min}$. y de 52,0 y $52,5 \mathrm{~min}$. por el método de Stumbo y de Hayakawa respectivamente. El tiempo de pasteurización teórico calculado en este Capítulo fue validado experimentalmente mediante un estudio de reto microbiano en el que se inoculó una cepa de Staphylococcus aureus (Capítulo 3). 
Se realizó un perfil sensorial mediante el método del Análisis Descriptivo Cualitativo analizando aspecto, aroma, textura y sabor de los lomitos de humedad intermedia. Para este fin se seleccionó un grupo de panelistas y se los entrenó para poder evaluar los descriptores característicos del producto bajo estudio. A partir del perfil realizado, se decidió agregarle ácido cítrico a la solución osmótica $(0,5 \%)$ para contrarrestar el gusto dulce aportado por el glicerol. Con el agregado de ácido cítrico se logró disminuir significativamente el gusto dulce de la preserva.

Para describir los cambios sensoriales producidos debido a la DO, se comparó el producto final con lomitos cocidos (sin deshidratar). La DO no cambió el color, la jugosidad, los aromas a rancio y a pescado, el sabor a rancio ni el gusto amargo. En cambio, esta etapa aumentó significativamente la dureza (tanto al corte como en boca), el aroma dulzón, los gustos dulce, ácido y salado, y disminuyó significativamente el sabor a pescado.

Para completar la caracterización fisicoquímica, se realizaron análisis instrumentales de textura y color del producto final. Los cambios en textura y color debido a la etapa de deshidratación también fueron analizados. La dureza de los lomitos DO fue significativamente mayor que la dureza de los lomitos cocidos. Este estudio sirvió para confirmar de forma objetiva los resultados sensoriales de dureza. Además se halló que tanto la adhesividad como la cohesividad de las muestras no tuvieron diferencias significativas. Por lo tanto, la DO generó una mayor dureza en los lomitos pero no afectó a la adhesividad ni a la cohesividad.

Tanto para el color gris como para el color té con leche, ninguno de los parámetros estudiados $\left(L^{*}, a^{*} y b^{*}\right)$ presentó diferencias significativas $(p>0,05)$ entre las muestras cocidas y las DO. Estos resultados concuerdan con el análisis sensorial ya que, tanto en el color gris como el té con leche, los evaluadores no encontraron diferencias significativas entre las muestras. 


\section{CAPITULO 2:}

\section{Difusión de agua y solutos durante la}

deshidratación osmótica

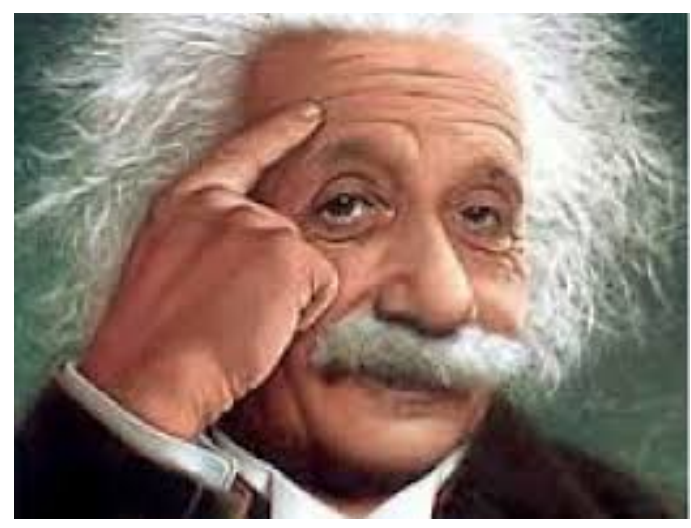




\subsection{Resumen}

El objetivo de este capítulo fue estudiar la difusión de solutos (glicerol y sal) y de agua durante la infusión de caballa en la solución de baja $a_{w}$. Se utilizaron dos geometrías, se trabajó con rodajas, a las que se consideró como placas planas semiinfinitas, y con lomitos, a los que se consideró como cilindros finitos y como cilindros semiinfinitos.

La transferencia de masa durante la deshidratación osmótica fue modelada utilizando el modelo de Crank, de Zugarramurdi y Lupín, de Azuara, de Peleg y de Weibull. Además, se determinaron los perfiles de concentración de agua y solutos durante la deshidratación osmótica de los lomitos.

\subsection{Introducción}

El desarrollo de nuevos productos y la optimización del proceso de deshidratación osmótica (DO) dependen del correcto entendimiento del contenido de agua y sólidos y en el conocimiento de los coeficientes de difusión durante la DO. Los resultados de este trabajo son de gran importancia para la industria pesquera para poder desarrollar productos de humedad intermedia listos para consumir o como materia prima de otros procesos.

La alta complejidad del sistema hace que la precisión predictiva sea difícil cuando se usan modelos matemáticos rigurosos y que ésta dependa de la determinación apropiada de las condiciones de equilibrio y de parámetros como la difusividad (Ochoa Martínez y Ayala Aponte, 2005). Diferentes modelos matemáticos han sido aplicados para ajustar los resultados experimentales de los procesos de DO con el objetivo de predecir el comportamiento de los productos alimenticios. Generalmente, cuando se quiere utilizar un modelo fenomenológico para procesos a presión atmosférica, como la $\mathrm{DO}$, se emplea el modelo de Crank, que consiste en una solución de la Ley de Fick en estado no estacionario y que representa el mecanismo difusional (Crank, 1975). La solución analítica de esta ecuación diferencial está limitada a geometrías regulares simples y tiene la forma de una serie infinita dependiente del tiempo, de la cual suele emplearse sólo el primer término. Este modelo, utilizado por distintos autores (Casales y col., 2009; Corzo y Bracho, 2007; Gerla y Rubiolo, 2003; Gou y col., 2003; Graiver y col, 2006; Rodger y col., 1984; Telis y col., 2003 entre otros), asume que la concentración de la solución permanece 
constante, la resistencia externa es despreciable comparada con la resistencia interna y la geometría de las muestras es simple como, por ejemplo, una placa semiinfinita. La Ley de Fick resuelta de acuerdo a Crank (1975) (considerando al medio como un sólido poroso homogéneo con propiedades constantes), en la mayoría de los casos, suele ajustar bien a los resultados de las experiencias de deshidratación osmótica en lo que respecta a los contenidos promedio de agua y solutos (azúcar o sal) en función del tiempo (Ramallo, 2010). Los coeficientes de difusión efectivos del agua y solutos obtenidos de este modo son valores "globales" que minimizan los errores pero que no son los verdaderos ya que engloban en sí distintos fenómenos (resistencia transmembrana, variación del volumen, interacción entre los flujos, heterogeneidad del sólido, etc.).

Otra alternativa para modelar el proceso de DO es el uso de modelos empíricos basados en representaciones matemáticas de los datos observados experimentalmente, cubriendo algunas de las imprecisiones del modelo de Crank. Estos modelos usualmente no tienen en cuenta las dimensiones ni la estructura del material. Algunos modelos empíricos fueron desarrollados a partir de ajustes polinómicos, mientras que otros a partir de balances de masa y relaciones entre distintas variables de proceso (Corzo y Bracho, 2009; Ochoa Martínez y Ayala Aponte, 2005). Dentro de los modelos empíricos se encuentran los de Peleg (Corzo y Bracho, 2006; Czerner y Yeannes, 2010; Schmidt y col., 2009; Turhan y col., 2002), Azuara (Azuara, 1998; Corzo y col, 2012) y Zugarramurdi y Lupín (Corzo y Bracho, 2005; Czerner y Yeannes, 2010; Zugarramurdi y Lupín, 1980). También han sido utilizados modelos probabilísticos como el de Weibull (Corzo y Bracho, 2008, 2009). Los modelos empíricos y probabilísticos están basados en la representación matemática de los procesos naturales y tienen una aplicación simple (Ochoa Martínez y Ayala Aponte, 2005). En la mayoría de los casos, esta interpretación de la información experimental es válida solamente para reproducir condiciones semejantes a las del trabajo del cual se obtuvieron. La metodología que se utiliza es la correlación directa de la pérdida de agua y la ganancia de sólidos con algunas variables de proceso o el planteamiento de un ajuste polinómico, sin embargo, estos métodos no permiten la extrapolación más allá del rango experimental, necesitan un alto número de parámetros que no tienen significado físico o no siempre generan un buen coeficiente de correlación (Parjoko y col., 1996).

Dentro del grupo de los modelos empíricos se puede mencionar el modelo de Azuara, que simula la pérdida de agua y la ganancia de sólidos a partir de los balances de masa, obteniendo ecuaciones que requieren dos parámetros ajustables (Azuara y col., 1992, 1998). La principal ventaja del modelo de Azuara es que no se 
requiere llegar al equilibrio para predecirlo. Su gran desventaja es su validez, ya que se limita al rango experimental para el cual se obtuvieron los parámetros. Peleg (1988) propuso un modelo de dos parámetros para representar la adsorción de agua en leche en polvo y en granos de arroz enteros. Este modelo empírico ha sido utilizado para modelar las curvas de sorción de distintos alimentos. La mayor ventaja del modelo de Peleg es que se ahorra tiempo al predecir la cinética de sorción del alimento deshidratado osmóticamente. Además, utilizando datos a tiempos experimentales cortos se puede obtener el valor de equilibrio (Peleg, 1988; Turhan y col., 2002). Por último, el modelo de Zugarramurdi y Lupín (1980) fue propuesto para explicar el comportamiento observado durante el salado de pescado. Este modelo presenta una aproximación exponencial a los valores de equilibrio de sal y agua.

Otra posibilidad es utilizar modelos de ajustes polinómicos. Se utilizan modelos estadísticos o empíricos para evaluar el efecto de las variables del proceso sobre la cinética de transferencia de agua y soluto, a partir de análisis de regresión. Los ajustes polinómicos son modelos empíricos sencillos, válidos solamente para las condiciones experimentales a partir de las que se obtuvo el modelo. Los parámetros no tienen significado físico (Ochoa Martínez y Ayala Aponte, 2005).

Debido a que todos los modelos utilizados para representar la DO tienen limitaciones, se decidió estudiar tanto el modelo de Crank como modelos empíricos y probabilísticos con el fin de analizar su desempeño en el ajuste de los datos experimentales de la DO de caballa.

\subsection{Objetivos}

- Estudiar la difusión de glicerol, sal y agua durante la infusión en la solución de baja $a_{w}$ utilizando dos geometrías distintas (rodajas y cilindros).

> Analizar el modelado de la transferencia de masa durante la deshidratación osmótica.

> Determinar los coeficientes de difusión de agua y solutos.

$>$ Estimar los perfiles de concentración de agua y solutos. 


\subsection{Materiales y métodos}

Para realizar el estudio de difusión se utilizó caballa (Scomber japonicus) capturada en el mes de octubre de 2010 en las costas de la provincia de Buenos Aires y mantenida a bordo en hielo. Luego de su arribo al puerto de la ciudad de Mar del Plata, la materia prima fue transportada en cajones con hielo para su posterior lavado, envasado y congelado en la planta procesadora MIA S.A. La etapa de congelado se realizó en un túnel de congelación a $-38 \pm 4^{\circ} \mathrm{C}$ y se almacenó en freezer a $-18 \pm 2^{\circ} \mathrm{C}$ hasta su utilización.

En el estudio de difusión de agua y solutos durante la deshidratación osmótica de caballa se utilizaron dos geometrías. Se trabajó con rodajas, a las que se consideró como placas planas semiinfinitas, y con lomitos, a los que se consideró como cilindros finitos y como cilindros semiinfinitos.

\subsubsection{Deshidratación osmótica de rodajas de caballa}

\section{Proceso de elaboración}

La Figura 2.1 muestra el diagrama de flujo del proceso de elaboración de las rodajas. Se utilizó el procedimiento descripto por Sánchez Pascua y col. (1998) donde la etapa de cocción y la deshidratación osmótica se realizaron juntas en la solución osmótica. 


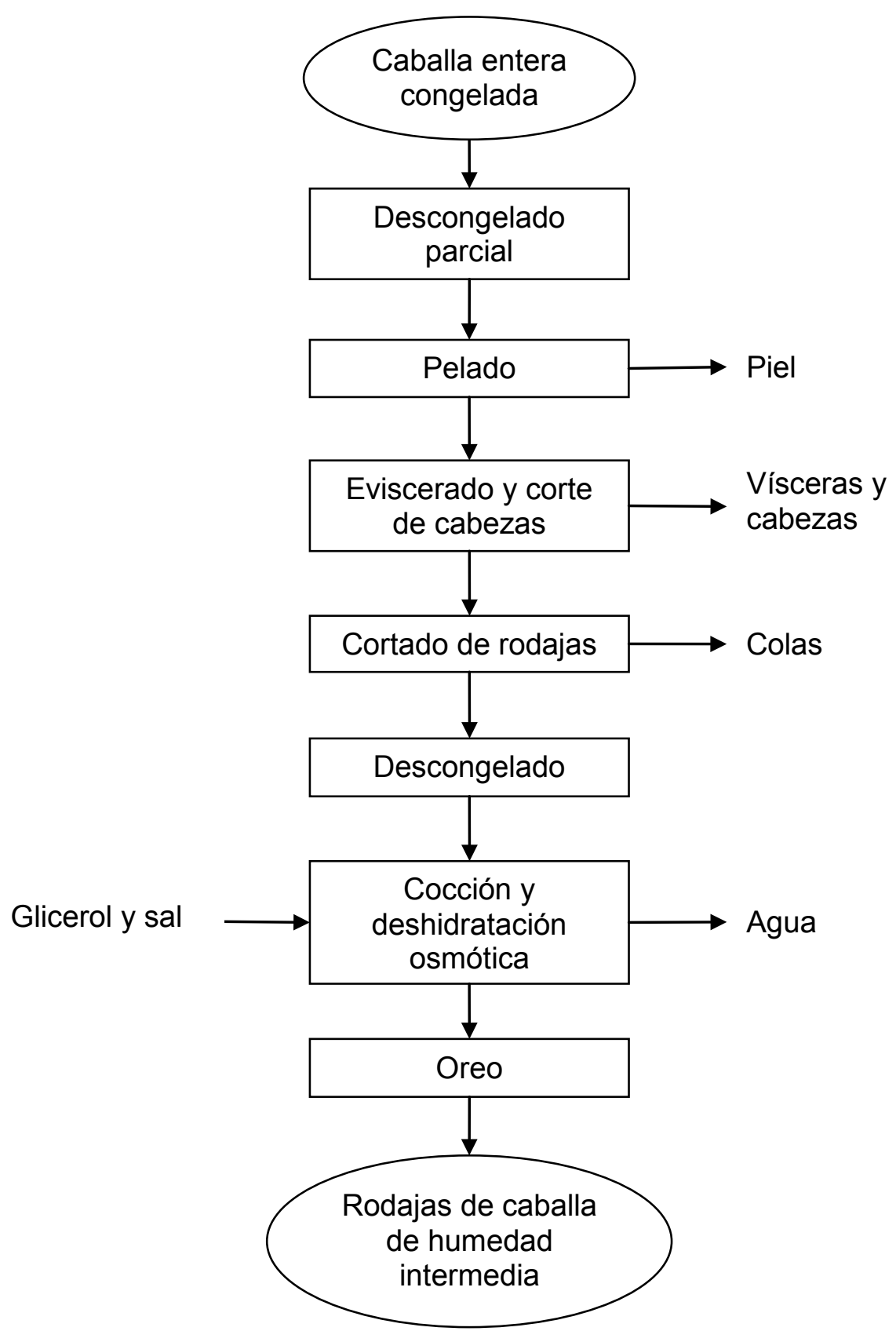

Figura 2.1 Diagrama de Flujo del proceso de elaboración de rodajas de caballa de humedad intermedia

A continuación se explica en detalle cada una de las etapas involucradas.

Descongelado parcial: las caballas enteras congeladas $\left(-18^{\circ} \mathrm{C}\right)$ se mantuvieron en refrigeración $\left(5 \pm 1^{\circ} \mathrm{C}\right)$ durante aproximadamente 10 horas con el fin de facilitar la etapa de eliminación de la piel. Si bien el pescado no llegó a descongelarse al cabo de estas 10 horas, adquirió una textura apropiada como para facilitar el pelado y el corte de las rodajas. Se buscó que no estuviese tan 
duro como congelado a $-18^{\circ} \mathrm{C}$ ni tan blando como si estuviese totalmente descongelado.

$>$ Pelado: con la ayuda de un cuchillo de acero inoxidable se les retiró la piel mediante cortes longitudinales (Figura 2.2).

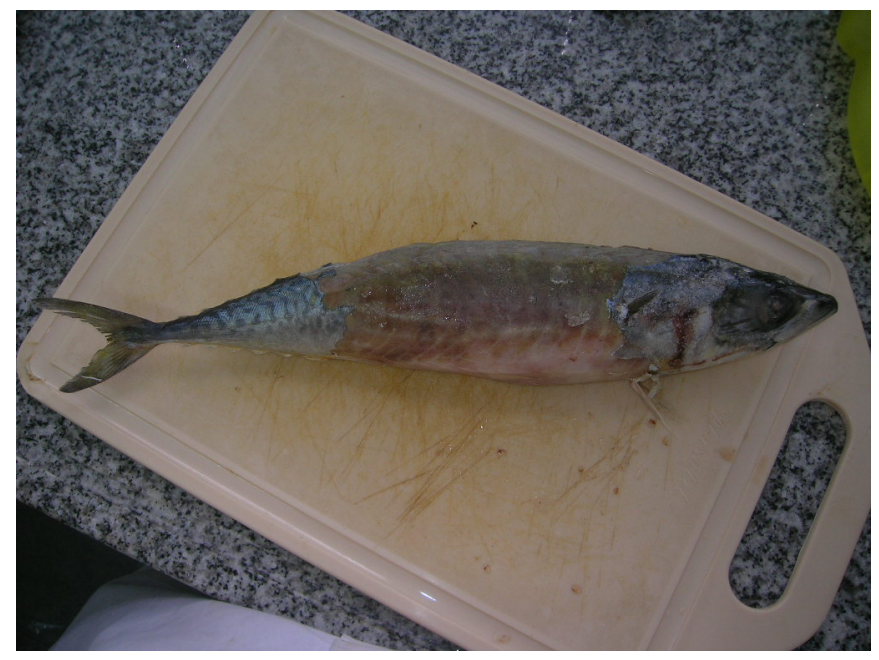

Figura 2.2 Caballa sin piel

$>$ Eviscerado y corte de cabezas: a los pescados enteros ya pelados se les realizó un corte de lado a lado debajo de las aletas pectorales para retirar la cabeza. Luego se abrió el abdomen mediante un corte longitudinal desde el ano hacia la cabeza y se les retiró las vísceras.

> Corte de rodajas: las rodajas fueron cortadas con un cuchillo de acero inoxidable. El diámetro promedio de las rodajas fue de $5,15 \pm 0,15 \mathrm{~cm}$ y un espesor de 0,72 \pm 0,05 (Figura 2.3).

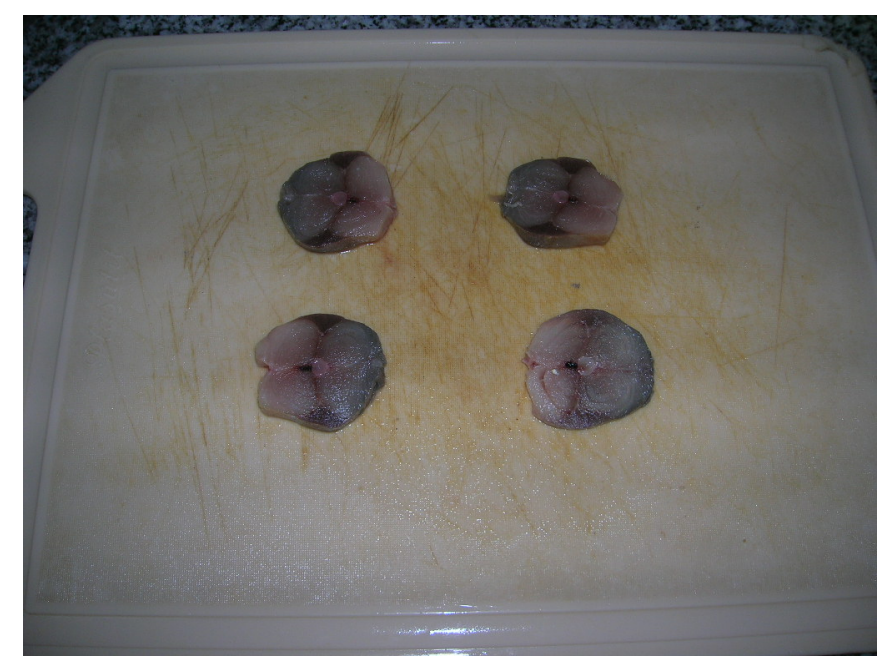

Figura 2.3 Rodajas de caballa 
Descongelado: se descongelaron las rodajas en refrigeración $\left(5 \pm 1^{\circ} \mathrm{C}\right)$ durante 5 horas.

Cocción y deshidratación osmótica: se sumergieron las rodajas en la solución osmótica hasta que el equilibrio fue alcanzado (180 min). La composición de la solución de infusión se puede ver en la Tabla 2.1 (Sánchez Pascua y col., 1998). La $a_{w}$ de la solución fue de 0,64. La proporción pescado:solución fue de 1:10 con el fin de evitar la dilución de la solución osmótica como resultado de la pérdida de agua desde el pescado hacia la solución y el ingreso de los solutos desde la solución hacia el pescado.

Tabla 2.1 Composición de la solución de infusión para la cocción y deshidratación osmótica de las rodajas

\begin{tabular}{lc}
\hline & Porcentaje(p/p) \\
\hline Glicerol & 54 \\
Agua & 39 \\
Sal & 7 \\
\hline
\end{tabular}

Oreo: se retiraron las rodajas de la solución y se dejaron escurrir y enfriar durante 30 minutos a temperatura ambiente.

\section{Muestreo}

Las rodajas fueron sumergidas en la solución de infusión a tres temperaturas distintas $\left(50,70\right.$ y $90 \pm 1^{\circ} \mathrm{C}$ ) hasta que el equilibrio fue alcanzado (un tiempo máximo de 3 horas). A cada tiempo de muestreo se retiraron tres rodajas de la solución, se escurrieron, se enjuagaron con agua destilada, se secaron con papel absorbente y se realizaron los siguientes análisis fisicoquímicos: $a_{w}$, humedad, contenido de sal y de glicerol (ver técnicas en Sección 1.4.2). Los tiempos de muestreo fueron los siguientes: $5,10,15,20,25,40,60,80,120$, y $180 \mathrm{~min}$. Se realizaron dos experiencias por cada temperatura. 


\subsubsection{Deshidratación osmótica de lomitos}

\section{Proceso de elaboración}

El proceso de elaboración de los lomitos de caballa se explica en la Sección 1.5 .4 .

Muestreo

El trabajo experimental se realizó con muestras cilíndricas suficientemente largas de modo que el proceso de difusión se consideró como unidimensional en la dirección radial.

Para determinar la cinética de transferencia de masa y los coeficientes de difusión, lomitos cilíndricos de 16,5 $\pm 0,3 \mathrm{~cm}$ de largo y 1,9 \pm 0,2 cm de diámetro se sumergieron en la solución de infusión (la proporción pescado:solución fue de 1:10) y se mantuvieron bajo temperatura de refrigeración $\left(5 \pm 1^{\circ} \mathrm{C}\right)$. En diferentes tiempos, tres cilindros se retiraron de la solución y los extremos fueron descartados con el fin de evitar los efectos de borde, sólo el área central de cada cilindro (9 $\mathrm{cm}$ de longitud) se analizó (Graiver y col., 2006). Los lomitos se escurrieron, se enjuagaron con agua destilada, se secaron con papel absorbente, se pesaron y se les realizaron los siguientes análisis fisicoquímicos: $a_{w}$, humedad, contenido de sal y de glicerol (ver técnicas en Sección 1.5.4). El muestreo se realizó a los siguientes tiempos: 0,$5 ; 1 ; 1,5$; $2 ; 2,5 ; 3 ; 4 ; 7 ; 10,5 ; 15 ; 17 ; 19$ y 24 h. Se realizaron dos experiencias.

Además, se realizaron dos experiencias a $10^{\circ} \mathrm{C}$ con el fin de validar los diferentes modelos.

\subsubsection{Porcentaje de incorporación de solutos (\%IS)}

El \%IS se calculó utilizando la Ecuación 2.1:

$$
\% I S_{t}=\left(\frac{C_{\text {tsolrod }}}{C_{\text {isolsción }}}\right) x 100
$$

donde $C_{t \text { sol rod }}$ es la concentración de soluto en las rodajas a tiempo t y $C_{i}$ sol sción es la concentración inicial de soluto en la solución. 


\subsubsection{Modelos matemáticos}

\section{Modelo de Crank para rodajas (placa plana semiinfinita)}

El modelo de Crank se basa en un conjunto de soluciones de la ley de difusión de Fick para diferentes geometrías (Crank, 1975). La difusión de cloruro de sodio y glicerol a través de las rodajas de caballa puede ser considerada como difusión a través de una placa plana de espesor 2l. A tiempo $t=0$ la región $-\mid<x<1$ tiene una concentración uniforme $\left(C_{0}\right)$ y la superficie se mantiene a una concentración constante $\left(C_{l}\right)$. La ecuación de difusión para movimiento unidimensional se puede expresar de la siguiente manera (Crank, 1975):

$\frac{\partial C_{t}}{\partial t}=\frac{\partial\left(D \frac{\partial C_{t}}{\partial x}\right)}{\partial x}$

donde $C_{t}$ es la concentración a tiempo $t$ y coordenada $x$ y $D$ es el coeficiente de difusión. Si $D$ es constante la Ecuación 2.2 puede ser expresada como:

$$
\frac{\partial C_{t}}{\partial t}=D \frac{\partial^{2} C_{t}}{\partial x}
$$

La solución de la Ecuación 2.3 para placa plana semiinfinita para tiempos cortos es la siguiente:

$$
\left(\frac{C_{t}-C_{0}}{C_{\infty}-C_{0}}\right)=\frac{M_{t}}{M_{\infty}}=2\left(\frac{D t}{\pi l^{2}}\right)^{\frac{1}{2}}
$$

donde $M_{\mathrm{t}}$ y $M_{\infty}$ son la pérdida de agua o la ganancia de solutos (expresado como $\mathrm{g}$ en base seca sin sal ni glicerol, g/gbs) a tiempo $t$ y a tiempo infinito respectivamente y $l$ es la mitad del espesor de la rodaja.

Este modelo asume que la concentración en la superficie permanece constante y que la resistencia externa es despreciable comparada con la resistencia interna. Además, se asume que la geometría es placa plana semiinfinita. 


\section{Modelo de Crank para lomitos (cilindro)}

El modelo de difusión de Fick en estado no estacionario fue aplicado para describir la difusión de agua y solutos en el cilindro (Crank, 1975).

$$
\frac{\partial C}{\partial t}=\frac{1}{r} \frac{\partial}{\partial r}\left(\frac{1}{r} \frac{\partial C}{\partial r}\right)
$$

La solución analítica de la Ecuación 2.5 se obtiene asumiendo lo siguiente:

Concentraciones iniciales uniformes de agua y solutos:

$$
C(r, 0)=C_{0}
$$

Simetría de concentración en el centro:

$$
\frac{\partial C}{\partial r}=0 \text { para } r=0
$$

$>$ Concentraciones constantes de agua y solutos de la superficie en el equilibrio (resistencia externa despreciable para la transferencia de masa)

$$
C(r, t)=C_{e q} \text { para } r=R
$$

> Concentración de la solución constante (alta relación solución:pescado).

La Ecuación 2.2 y las condiciones de contorno pueden ser escritas en forma adimensional:

$$
\begin{aligned}
& \frac{\partial \varphi}{\partial \tau}=\frac{1}{x} \frac{\partial}{\partial x}\left(x \frac{\partial \varphi}{\partial \tau}\right) \varphi=\varphi(x, \tau) ; 0 \leq x \leq 1 ; \tau \geq 0 \\
& \varphi(x, 0)=1 \\
& \frac{\partial \varphi}{\partial x}=0 x=0, \tau>0
\end{aligned}
$$




$$
\varphi(x, \tau)=0, x=0, \tau>0
$$

Siendo

$$
\varphi=\frac{C-C_{e q}}{C_{0}-C_{e q}} ; x=\frac{r}{R} ; \tau=\frac{D t}{R^{2}}
$$

La solución de la Ecuación 2.9 para la relación media de pérdida de agua y ganancia de soluto está dada por

$$
\frac{x_{t}-x_{e q}}{x_{0}-x_{e q}}=\sum \frac{4}{\delta_{n}^{2}} \exp \left(-\delta_{n}^{2} \frac{D t}{R^{2}}\right)
$$

donde $x_{t}$ es la pérdida de agua o la ganancia de solutos (expresado como $\mathrm{g}$ en base seca sin sal ni glicerol, g/gbs) a tiempo $t, x_{e q}$ el valor de equilibrio y $x_{0}$ el valor inicial, $\delta_{\mathrm{n}}$ son las raíces de la ecuación de Bessel de primer clase de orden cero : Jo $\left(\delta_{n}\right)=0$.

1- Modelo basado en la segunda ley de Fick para cilindro infinito

El coeficiente efectivo de difusión fue calculado usando 1, 3 y 5 términos de la Ecuación 2.14. Esta ecuación puede ser simplificada considerando sólo el primer término de la serie y escrita en forma logarítmica como:

$$
\ln \left(\frac{x_{t}-x_{e q}}{x_{0}-x_{e q}}\right)=\ln \frac{4}{\delta_{1}^{2}}-\delta_{1}^{2} \frac{D t}{R^{2}}
$$

La difusividad efectiva del agua y de los solutos es calculada a partir de la pendiente del gráfico de: $\ln \left(\frac{x_{t}-x_{e q}}{x_{0}-x_{e q}}\right)$ vs. tiempo.

2- Modelo basado en la segunda ley de Fick para cilindro finito

La predicción de la transferencia de masa en un cilindro finito requiere el uso de soluciones analíticas para ambos cilindro infinito y placa infinita y está dada por: 


$$
\frac{x_{t}-x_{e q}}{x_{0}-x_{e q}}=\left[\sum_{n=1}^{n=\infty} \frac{4}{\delta_{n}^{2}} \exp \left(-\delta_{n}^{2} \frac{D t}{R^{2}}\right)\right]\left[\sum_{n=0}^{n=\infty} \frac{8}{(2 n+1)^{2} \pi^{2}} \exp \left(-\frac{(2 n+1)^{2} \pi^{2} D t}{4 l^{2}}\right)\right]
$$

El coeficiente efectivo de difusión fue calculado usando 5 términos de cada serie.

\section{Modelo de Zugarramurdi y Lupín (Z \& L)}

Zugarramurdi y Lupín (1980) propusieron un modelo matemático con una aproximación exponencial a los valores de equilibrio de sal y agua.

$$
\frac{\partial x_{t}}{\partial t}=K\left(x_{e q}-x_{t}\right)
$$

donde $x_{t}$ y $x_{e q}$ son los contenidos de agua, sal o glicerol (expresado como $\mathrm{g}$ en base seca sin sal ni glicerol, g/gbs) a tiempo $t$ (h) y en el equilibrio respectivamente y $K$ es la constante de velocidad específica $\left(\mathrm{h}^{-1}\right)$.

Integrando la Ecuación 2.17 con la condición inicial $x_{t=0}=x_{0}$ se obtiene:

$$
x_{t}=x_{0} e^{-K t}+x_{e q}\left(1-e^{-K t}\right)
$$

\section{Modelo de Weibull}

El modelo de Weibull describe el comportamiento de sistemas o eventos que tienen algún grado de variabilidad, tal como la cinética de la deshidratación osmótica. La función de densidad de la distribución de probabilidad de Weibull se puede escribir como (Cunha y col., 1998, Corzo y Bracho, 2008):

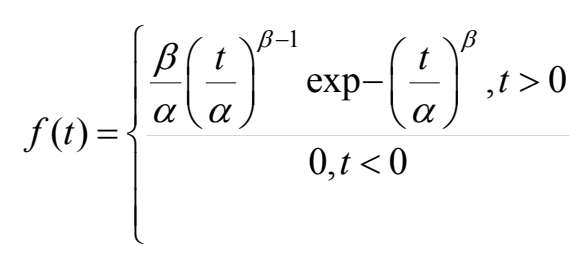

siendo $\alpha$ el parámetro de escala del modelo de Weibull, $\beta$ el parámetro de forma, y $t$ el tiempo de muestreo. 
Si se considera que $n_{t}$ corresponde a la fracción de un componente dado $x$, que cambia desde un valor inicial $\left(x_{0}\right)$ hasta un valor de equilibrio $\left(x_{e}\right)$ y que el tiempo requerido para alcanzar un cierto valor de $n_{t}$ está representado por la variable continua y aleatoria $G$, con una función de densidad de la probabilidad $f(t)$, donde $f(t)$ es la función de distribución de Weibull, luego $n_{t}$ se puede definir como la probabilidad de tener una cierta fracción de $x$ en, al menos, un tiempo especificado $t$, bajo condiciones experimentales específicas (Cunha y col., 1998). Por lo tanto:

$$
n_{t}=P(G>t)=\int_{t}^{\infty} f(u) d u=1-F(t)=\exp -\left(\frac{t}{\alpha}\right)^{\beta}
$$

siendo $F(t)$ la distribución acumulativa correspondiente.

La fracción del contenido de agua durante la deshidratación osmótica se puede expresar como:

$$
n_{t}=\frac{x_{t}-x^{e q}}{x_{0}-x^{e q}}=\exp -\left(\frac{t}{\alpha}\right)^{\beta}
$$

siendo $x_{0}, x_{t}$ y $x_{e q}$ los contenidos de agua o solutos (expresado como $\mathrm{g}$ en base seca sin sal ni glicerol, $g / g b s$ ) a tiempo $t=0$, a tiempo $t$ y en el equilibrio respectivamente, $\alpha$ el parámetro de escala del modelo, $\beta$ el parámetro de forma del modelo (adimensional) y t el tiempo de deshidratación o muestreo.

\section{Modelo de Peleg}

Peleg (1988) propuso una ecuación de sorción de dos parámetros:

$$
x_{t}=x_{0} \pm \frac{t}{K_{1}+K_{2} t}
$$

donde $x_{0}$ y $x_{t}$ son el contenido de agua, sal y glicerol (expresado como $\mathrm{g}$ en base seca sin sal ni glicerol, g/gbs) a tiempo 0 y a tiempo $t$ respectivamente. $K_{l}$ es la constante de velocidad de Peleg (h/(g/gbs)) y $K_{2}$ es la constante de capacidad de Peleg (1/(g/gbs)). En la Ecuación 2.22 " \pm " se transforma en "+" para la ganancia de sal y glicerol y en "-" para la pérdida de agua. $K_{l}$ está relacionada con la velocidad de transferencia de 
masa al principio del proceso de DO (Ecuación 2.23). $K_{2}$ está relacionada con el contenido de agua, sal o glicerol a tiempo $t \rightarrow \infty$ (Ecuación 2.24).

$d x_{t} / d t= \pm 1 / K_{1}$

$x_{e q}=x_{0} \pm 1 / K_{2}$

donde $x_{e q}$ es el contenido de agua, sal o glicerol en el equilibrio $(t \rightarrow \infty)$.

\section{Modelo de Azuara}

Azuara y col., (1992) desarrollaron un modelo de dos parámetros a partir de la siguiente expresión:

$$
x_{t}=\frac{S t x_{e q}}{1+s t}
$$

donde $x_{t}$ y $x_{e q}$ son la pérdida de agua o la ganancia de sal o glicerol (expresado como $\mathrm{g}$ en base seca sin sal ni glicerol, g/gbs) a tiempo $t$ y en el equilibrio respectivamente y $S$ $(1 / h)$ es la constante del modelo (constante de velocidad).

\subsubsection{Perfiles de concentración de agua y solutos durante la deshidratación osmótica de cilindros de caballa}

La distribución de la concentración de agua y solutos fue considerada en forma radial con $\mathrm{R}$ como función del tiempo $(t)$ dado que el largo del cilindro de caballa es mayor que tres veces su diámetro $2 \mathrm{R}$. Las distribuciones de agua y solutos a lo largo del radio están dados por (Crank, 1975):

$$
\frac{C_{(r, t)}-C_{e q}}{C_{0}-C_{e q}}=\sum_{n=1}^{\infty} \frac{2}{\delta_{n} J_{1}\left(\delta_{n}\right)} J_{0}\left(\delta_{n} \frac{r}{R}\right) \exp \left(-\delta_{n}^{2} \frac{D t}{R^{2}}\right)
$$

o en la forma adimensional: 


$$
\varphi(x, \tau)=\sum_{n=1}^{\infty} \frac{2}{\delta_{n} J_{1}\left(\delta_{n}\right)} J_{0}\left(\delta_{n} x\right) \exp \left(-\delta_{n}^{2} \tau\right)
$$

\subsubsection{Ecuación de Arrhenius}

La dependencia de la temperatura de los coeficientes de difusión estudiados y de los parámetros cinéticos de los modelos fueron representados por la ecuación de Arrhenius linealizada:

$$
\ln (A)=\ln \left(A_{a}\right)-\left(\frac{E_{a}}{R T}\right)
$$

donde $A$ es el parámetro estudiado, $A_{a}$ el factor de Arrhenius $\left(\mathrm{cm}^{2} \mathrm{~s}^{-1}\right), E_{a}$ la energía de activación $(\mathrm{kJ} / \mathrm{mol}), R$ la constante general de los gases $(8,314(\mathrm{~J} /(\mathrm{mol} \mathrm{K}))$ y $T$ la temperatura absoluta $(\mathrm{K})$.

A partir de la ecuación 2.28 se puede estimar la $E_{a}$ mediante la representación del $\ln (A)$ en función de la inversa de la temperatura absoluta $\left(T^{-1}\right)$. Al graficar se obtiene una recta con pendiente $-E_{a} / R$.

\subsubsection{Análisis Estadístico}

El ajuste de los modelos a los datos experimentales se realizó con el programa OriginPro 8. La bondad de ajuste se calculó utilizando el coeficiente de determinación $\left(R^{2}\right)$, la raíz del error cuadrático medio (RMSE, Ecuación 2.29) y la desviación relativa media ( $P$, Ecuación 2.30).

$$
\begin{aligned}
& \text { RMSE }=\sqrt{\frac{1}{n} \sum_{i=1}^{n}\left(x_{i p}-x_{i}\right)^{2}} \\
& P=\frac{100}{n} \sum_{i=1}^{n} \frac{\left|x_{i}-x_{i p}\right|}{x_{i}}
\end{aligned}
$$

donde $x_{i}$ es el valor experimental, $x_{i p}$ es el valor predicho y $n$ es el número de pares de datos. El ajuste fue considerado satisfactorio si los valores de $\mathrm{P}$ fueron menores $\mathrm{O}$ iguales a 10\% (Azoubel y Murr, 2003). 


\subsection{Resultados y discusión}

\subsubsection{Composición química proximal}

La composición química proximal de la materia prima (caballa entera, rodajas y lomitos) se puede ver en la Tabla 2.2.

Tabla 2.2 Composición química proximal (\% en base húmeda) de caballa entera, rodajas y lomitos

\begin{tabular}{lcccc}
\hline & Humedad & Proteínas & Lípidos & Cenizas \\
\hline Caballa entera & $69,42 \pm 0,38$ & $21,31 \pm 0,19$ & $8,26 \pm 0,18$ & $1,31 \pm 0,07$ \\
Rodajas & $73,85 \pm 0,28$ & $21,59 \pm 0,31$ & $3,69 \pm 0,12$ & $1,33 \pm 0,01$ \\
Lomitos & $71,66 \pm 0,20$ & $21,68 \pm 0,52$ & $5,50 \pm 0,69$ & $1,36 \pm 0,03$ \\
\hline
\end{tabular}

\subsubsection{Deshidratación osmótica de rodajas de caballa}

\section{Cinética de la deshidratación osmótica de rodajas}

Se analizó el efecto de la temperatura sobre la pérdida de agua y la ganancia de solutos. La pérdida de agua (expresada como contenido inicial de agua - contenido de agua a tiempo t, $\left(x_{0}-x_{t}\right)$ ) y el contenido de sal y glicerol durante la DO a diferentes temperaturas se muestra en la Figura 2.4.
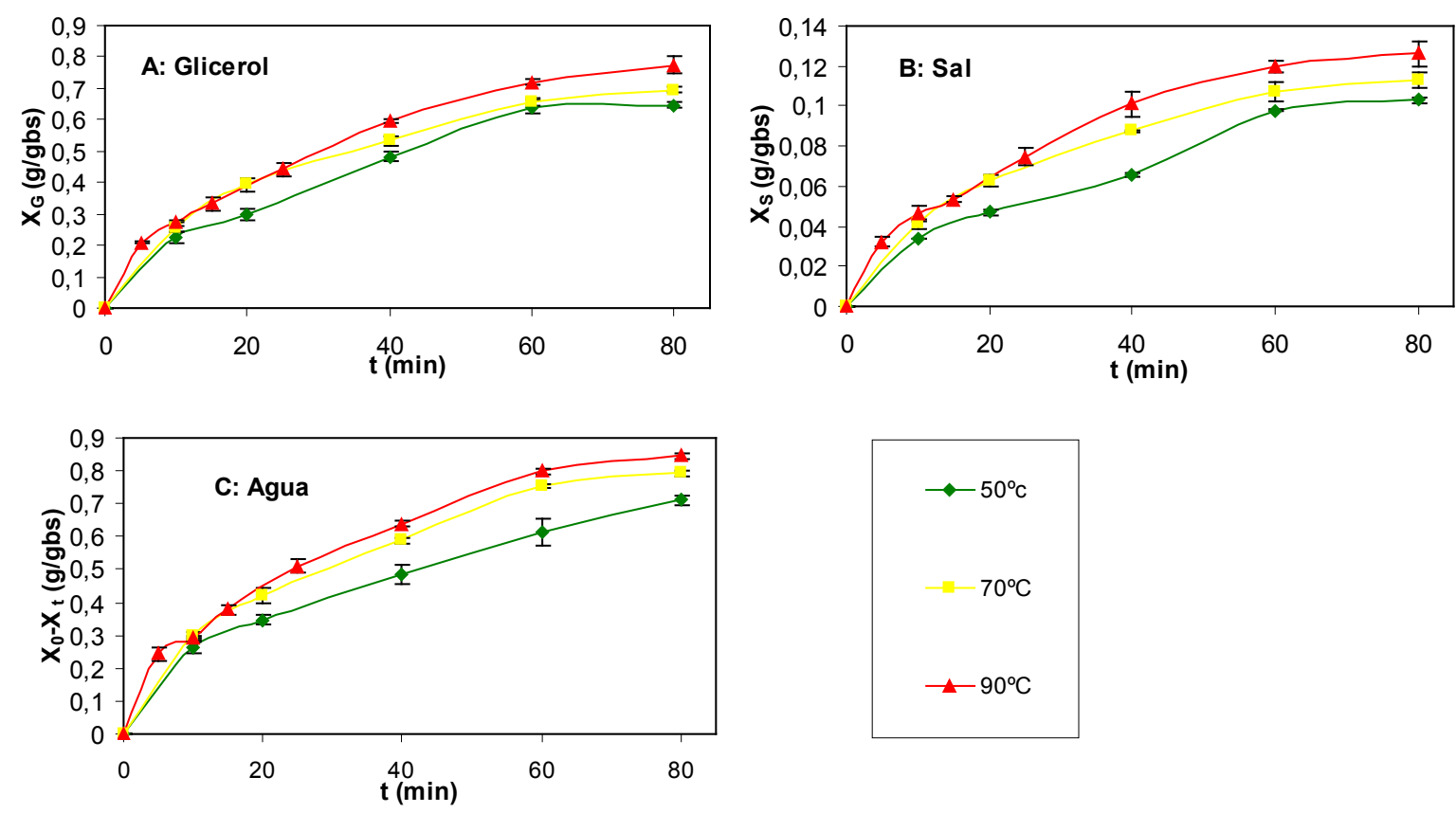

Figura 2.4 Cinética de deshidratación osmótica de rodajas de caballa a diferentes temperaturas 
Se observó que el aumento en la temperatura de proceso aceleró la transferencia de agua y solutos. Un comportamiento similar fue reportado por Corzo y Bracho (2006) durante la DO de láminas de sardina. Las temperaturas mas altas aceleraron la pérdida de agua debido a un hinchamiento y a un efecto plastificante de las membranas celulares así como también debido a una mejor transferencia de masa en la superficie del producto por una menor viscosidad de la solución osmótica (Burhan Uddin y col., 2004; Tortoe, 2010). Además, el aumento de la ganancia de sólidos a mayores temperaturas pudo deberse a la destrucción de la estructura de las membranas celulares (Corzo y Bracho, 2006). Este fenómeno se observa también al analizar el porcentaje de incorporación de solutos (Figura 2.5).
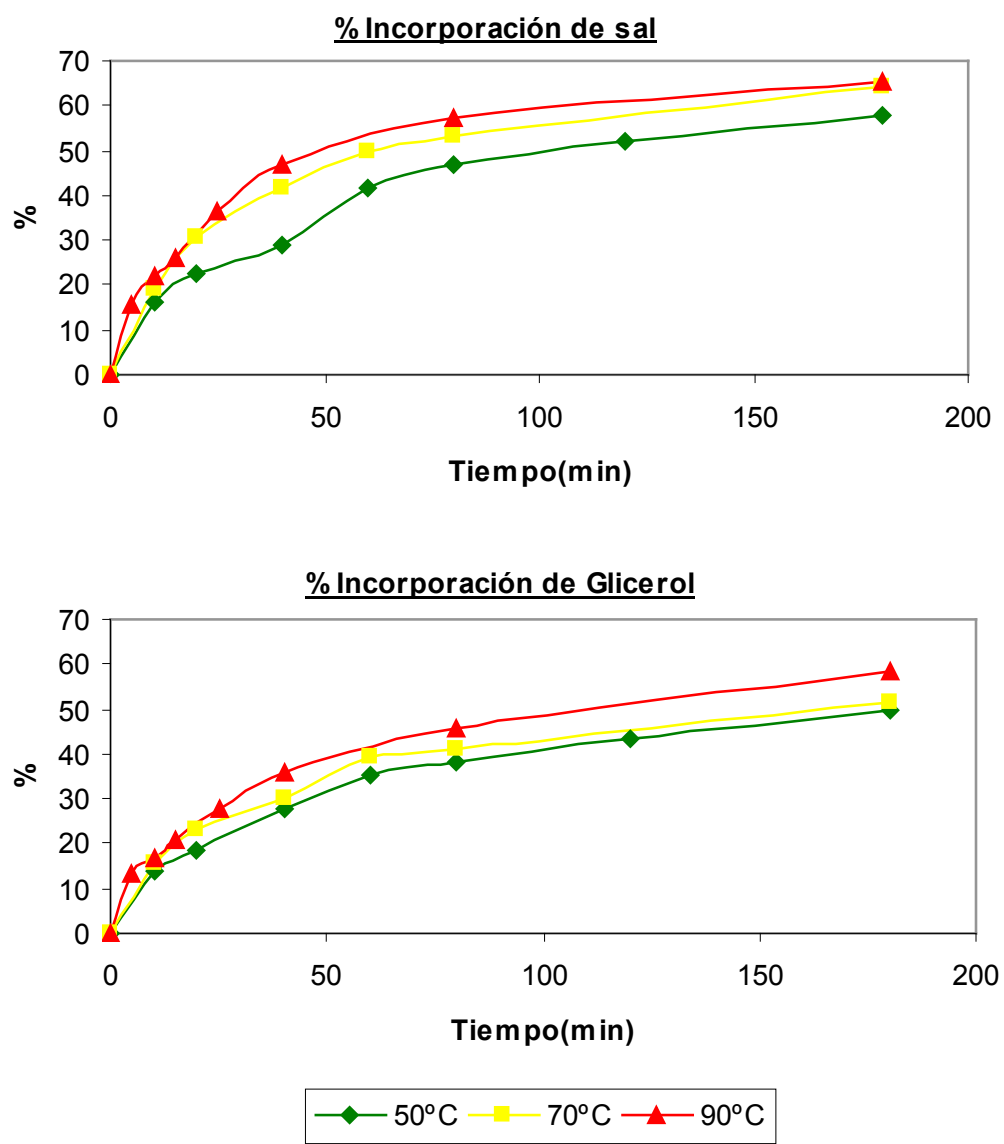

Figura 2.5 Porcentaje de incorporación de sal y glicerol durante la $\mathrm{DO}$ a 50,70 y $90^{\circ} \mathrm{C}$

La disminución del contenido de agua y el aumento en el contenido de solutos presentó una velocidad máxima al comienzo del proceso debido a un mayor gradiente de concentración de agua y solutos existente a ambos lados de las membranas que constituyen el alimento. Luego, se observó una disminución de la velocidad de 
transferencia de masa hasta que el equilibrio fue alcanzado (en la Figura 2.4 no se muestran los valores de equilibro).

Como se muestra en la Figura 2.6, la $a_{w}$ de las rodajas disminuyó durante el proceso debido a la transferencia de solutos desde la solución hacia el alimento y también debido al flujo de agua desde el alimento hacia la solución.

Mayores temperaturas generaron un descenso más rápido de la $a_{w}$ debido a un aumento de la velocidad de transferencia de masa. El tiempo necesario para alcanzar determinada $\mathrm{a}_{\mathrm{w}}$ disminuyó al aumentar la temperatura de proceso.

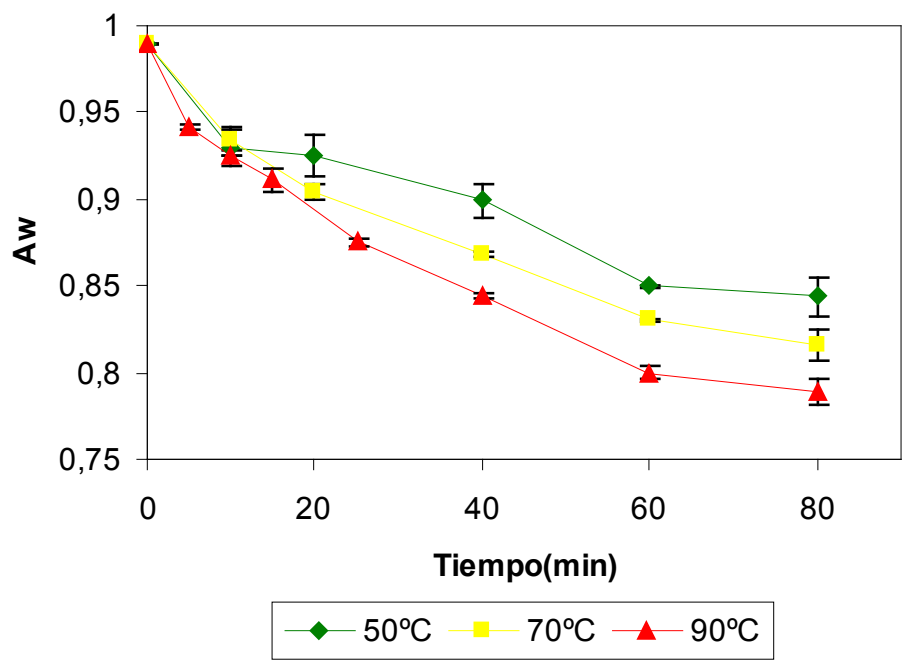

Figura 2.6 Descenso de la $a_{w}$ a diferentes temperaturas

\section{Estimación de los coeficientes de difusión (modelo de Crank)}

Los valores de la difusividad de la sal en pescados dependen de la especie, la temperatura de proceso, la orientación del músculo, el contenido de grasa, la presencia o ausencia de piel, entre otros factores (Zugarramurdi y Lupín, 1980; Collignan y col., 2001).

Los valores de los coeficientes de difusión (D) de agua, sal y glicerol obtenidos para las rodajas de caballa se muestran en la Tabla 2.3. Los datos experimentales ajustaron al modelo de Crank tal como lo indican los altos valores de los coeficientes de determinación $\left(0,94<\mathrm{R}^{2}<0,99\right)$ y los bajos valores de RMSE $(0,016<\mathrm{RMSE}<$ 0,076) (Tabla 2.3). 
Tabla 2.3 Coeficientes de difusión (D) y parámetros estadísticos

\begin{tabular}{|c|c|c|c|c|}
\hline Soluto & Temperatura & $D\left(m^{2} s^{-1}\right)$ & $\mathbf{R}^{2}$ & RMSE \\
\hline \multirow{3}{*}{ Sal } & $50^{\circ} \mathrm{C}$ & $0,98 \times 10^{-9}$ & 0,98 & 0,046 \\
\hline & $70^{\circ} \mathrm{C}$ & $1,30 \times 10^{-9}$ & 0,99 & 0,032 \\
\hline & $90^{\circ} \mathrm{C}$ & $1,50 \times 10^{-9}$ & 0,99 & 0,026 \\
\hline \multirow{3}{*}{ Glicerol } & $50^{\circ} \mathrm{C}$ & $0,85 \times 10^{-9}$ & 0,97 & 0,041 \\
\hline & $70^{\circ} \mathrm{C}$ & $1,05 \times 10^{-9}$ & 0,97 & 0,052 \\
\hline & $90^{\circ} \mathrm{C}$ & $1,15 \times 10^{-9}$ & 0,99 & 0,016 \\
\hline \multirow{3}{*}{ Agua } & $50^{\circ} \mathrm{C}$ & $0,96 \times 10^{-9}$ & 0,99 & 0,020 \\
\hline & $70^{\circ} \mathrm{C}$ & $1,16 \times 10^{-9}$ & 0,94 & 0,076 \\
\hline & $90^{\circ} \mathrm{C}$ & $1,34 \times 10^{-9}$ & 0,99 & 0,023 \\
\hline
\end{tabular}

Los valores de $D_{\text {sal }}$ y $D_{\text {agua }}$ para las rodajas de caballa están en concordancia con los resultados reportados por Uribe y col. (2011) en calamar deshidratado osmóticamente a temperaturas entre 75 y $95^{\circ} \mathrm{C}$. Sin embargo, valores mas bajos de $D_{\text {sal }}$ fueron reportados durante la DO de salmón del Atlántico (Wang y col., 2000).

Es importante tener en cuenta que no hay información disponible en la literatura sobre difusividad de glicerol en pescado. Sin embargo, un coeficiente de difusión $\left(D_{\text {gli }}\right)$ de $0,47 \times 10^{-9} \mathrm{~m}^{2} / \mathrm{s}$ fue reportado para bife deshidratado osmóticamente a $30^{\circ} \mathrm{C}$ (Favetto et al, 1981).

Se observó que la temperatura de proceso influye sobre los valores de los coeficientes de difusión de agua, sal y glicerol. Al aumentar la temperatura se observó un aumento en los valores de D. Estos resultados concuerdan con los resultados obtenidos por Uribe y col. (2011) en calamar, Hashiba y col. (2009) en carne de cerdo y Sanjay Sarang y col. (2007) en vegetales para $D_{\text {sal }}$ a distintas temperaturas.

La comparación de $M_{t} / M_{\infty}$ experimental con los valores estimados por el modelo de Crank se muestra en la Figura 2.7. 

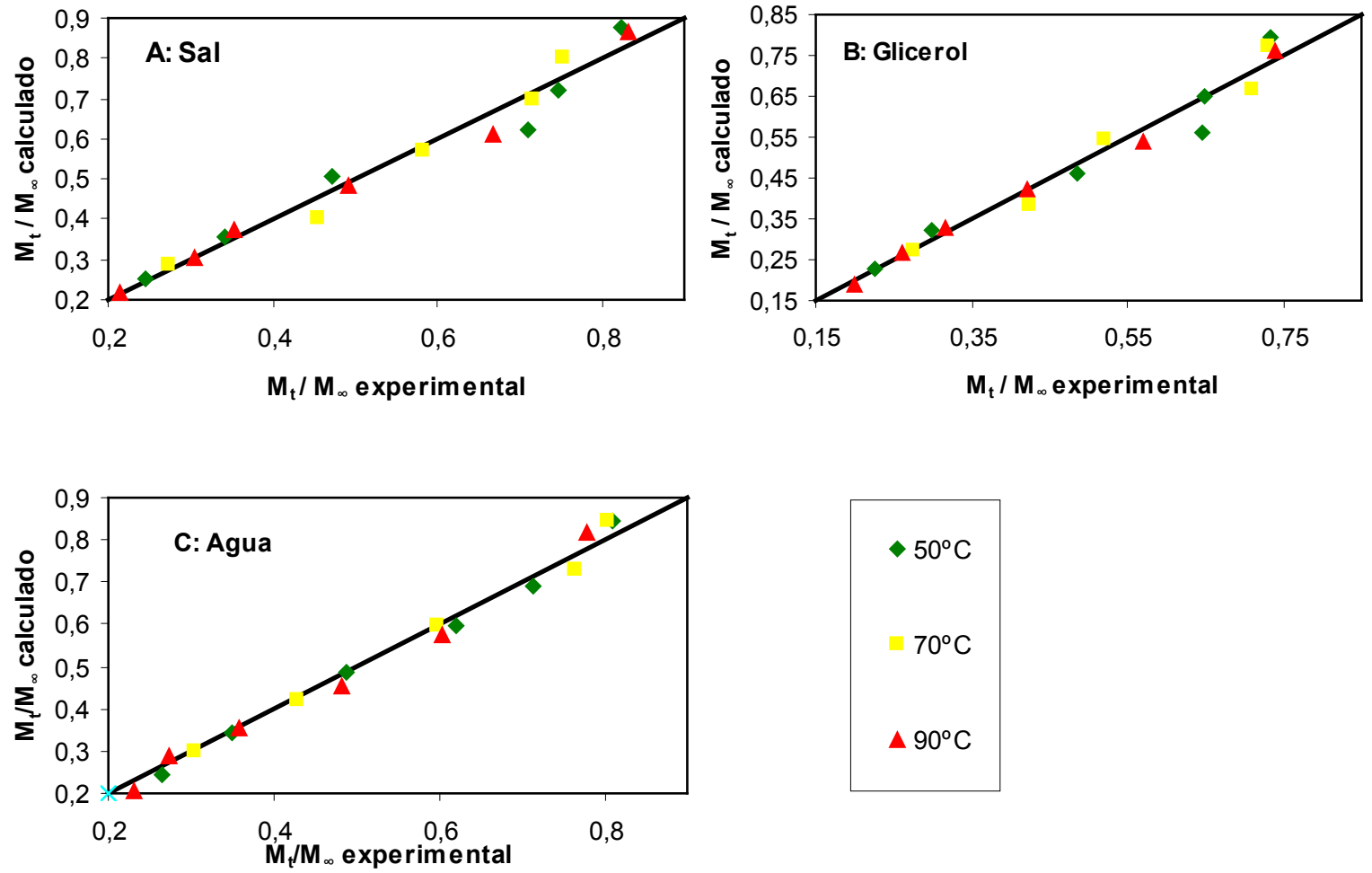

Figura 2.7 Comparación entre datos experimentales y estimados por el modelo de Crank a diferentes temperaturas

Se puede ver en la Figura 2.7 que todos los puntos tienen una buena aproximación a la línea bisectriz, esto indica la bondad de la predicción. El modelo de Crank puede ser utilizado para explicar la cinética de la transferencia de masa durante la DO. Esto se puede verificar también mediante los parámetros estadísticos $R^{2} y$ RMSE (Tabla 2.3).

La ecuación de Arrhenius (Ecuación 2.28) fue aplicada para estudiar la influencia de la temperatura en los coeficientes de difusión. Se observó que los valores de $D$ para la pérdida de agua y la ganancia de solutos aumentaron al incrementar la temperatura de proceso siguiendo la ecuación de Arrhenius.

Los valores de $R^{2}$ fueron: 0,$977 ; 0,962$ y 0,998 para $D_{\text {sal }}, D_{\text {glicerol }}$ y $D_{\text {agua }}$ respectivamente. Los valores de $E_{a}$ fueron 10,$401 ; 7,532$ y $8,139 \mathrm{~kJ} / \mathrm{mol}$ para sal, glicerol y agua respectivamente. Favetto y col. (1981) reportaron un valor de $E_{a}$ similar para la difusión de glicerol en bife de vaca. El valor de $E_{a}$ para la difusión de sal está de acuerdo con lo reportado por Favetto y col. (1981) en bife y con Del Valle y Nickerson (1967) en pez espada. Sin embargo, este valor es menor al reportado por Uribe y col. (2011) en calamar. 


\section{Modelo de Zugarramurdi \& Lupín (Z \& L)}

El parámetro $\mathrm{K}$ y los parámetros estadísticos del ajuste realizado con el modelo de $Z$ \& $L$ se presentan en la Tabla 2.4

Tabla 2.4 Parámetros y valores de equilibrio del modelo de Z \& L

\begin{tabular}{cccccccc}
\hline & Temp. $\left({ }^{\circ} \mathbf{C}\right)$ & $\boldsymbol{K}$ & $\mathbf{R}^{\mathbf{2}}$ & $\mathbf{R M S E}$ & $\begin{array}{c}\boldsymbol{X}_{\text {eq }} \\
\text { Experim }\end{array}$ & $\boldsymbol{X}_{\text {eq }} \mathbf{Z}$ \& L & $\begin{array}{c}\text { Error } \\
\text { Relativo(E) }\end{array}$ \\
\cline { 2 - 8 } Sal & $\mathbf{5 0}$ & 1,14 & 0,98 & 0,006 & 0,138 & 0,136 & 1,45 \\
& $\mathbf{7 0}$ & 1,53 & 0,97 & 0,008 & 0,150 & 0,143 & 4,67 \\
& $\mathbf{9 0}$ & 1,82 & 0,98 & 0,006 & 0,152 & 0,146 & 3,95 \\
Glicerol & $\mathbf{5 0}$ & 1,01 & 0,96 & 0,059 & 0,993 & 0,954 & 3,93 \\
& $\mathbf{7 0}$ & 1,32 & 0,96 & 0,054 & 0,926 & 0,898 & 3,02 \\
& $\mathbf{9 0}$ & 1,40 & 0,97 & 0,055 & 1,046 & 1,011 & 3,35 \\
Agua & $\mathbf{5 0}$ & 1,23 & 0,86 & 0,088 & 1,295 & 1,275 & 1,54 \\
& $\mathbf{7 0}$ & 2,08 & 0,98 & 0,038 & 1,251 & 1,226 & 2,00 \\
& $\mathbf{9 0}$ & 2,52 & 0,95 & 0,055 & 1,123 & 1,178 & 4,90 \\
\hline
\end{tabular}

Se observó que la constante de velocidad específica $(K)$ del modelo de $Z$ \& $L$ aumentó su valor al incrementar la temperatura de proceso. Este aumento de la velocidad de transferencia de masa podría explicarse por un aumento de la fuerza impulsora del agua y los solutos, así como también por una disminución de la viscosidad de la solución osmótica a temperaturas más altas. Resultados similares fueron reportados por Corzo y Bracho (2005) en láminas de sardina.

El parámetro $\mathrm{K}$ aumentó al aumentar la temperatura siguiendo la relación de Arrhenius $\left(R^{2}=0,99\right)$. Los valores de $E_{a}$ para sal, glicerol y agua obtenidos con el modelo de $Z$ \& L fueron: 11,$44 ; 8,05$ y 17,62 kJ/mol respectivamente. Según los resultados obtenidos, el parámetro $\mathrm{K}$ puede ser considerado como pseudo-coeficiente de difusión (Lemus-Mondaca y col., 2009a). 

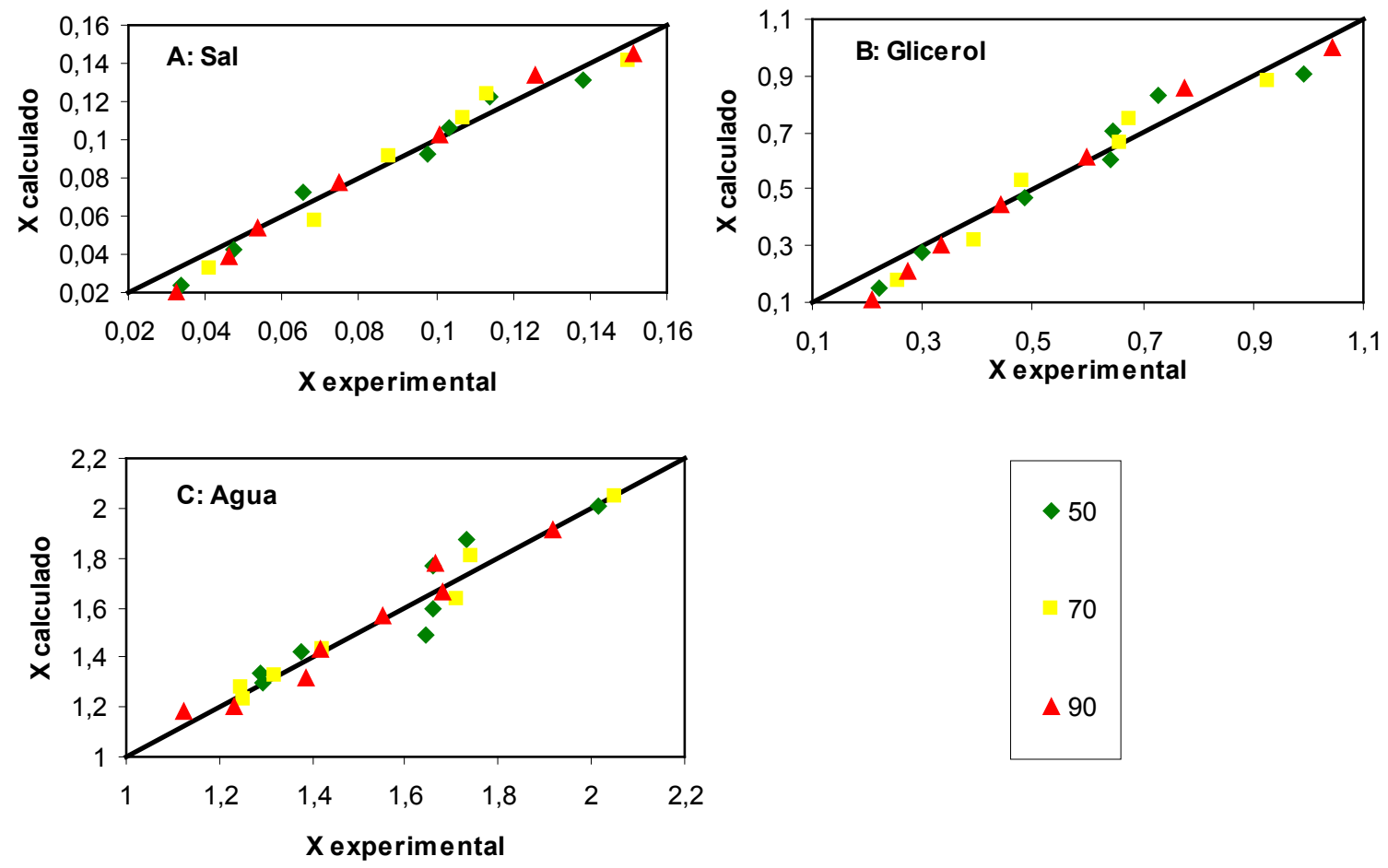

Figura 2.8 Comparación entre datos experimentales y estimados con el modelo de $Z$ \& L a diferentes temperaturas

Los valores experimentales de agua, sal y glicerol ajustaron a los modelos de Z \& L (Figura 2.8), siendo este modelo capaz de predecir la pérdida de agua y la ganancia de solutos durante la DO de rodajas de caballa. Esto pudo ser verificado también con los altos coeficientes de correlación y los bajos RMSE (Tabla 2.4).

En la Tabla 2.4 se muestran los valores de equilibrio obtenidos experimentalmente y los estimados por el modelo de Z \& L. Este modelo fue capaz de predecir satisfactoriamente los valores de equilibrio de agua y solutos.

\section{Modelo de Weibull}

Los parámetros del ajuste realizado mediante el modelo de Weibull se presentan en la Tabla 2.5 . 
Tabla 2.5 Parámetros del modelo de Weibull

\begin{tabular}{lccccc}
\hline & Temp. $\left({ }^{\circ} \mathbf{C}\right)$ & $\boldsymbol{\beta}$ & $\boldsymbol{\alpha}$ & $\mathbf{R}^{\mathbf{2}}$ & RMSE \\
\cline { 2 - 6 } Sal & $\mathbf{5 0}$ & 0,81 & 0,94 & 0,97 & 0,036 \\
& $\mathbf{7 0}$ & 0,69 & 0,77 & 0,99 & 0,020 \\
& $\mathbf{9 0}$ & 0,77 & 0,64 & 0,99 & 0,022 \\
\multirow{4}{*}{ Glicerol } & $\mathbf{5 0}$ & 0,71 & 1,19 & 0,97 & 0,031 \\
& $\mathbf{7 0}$ & 0,68 & 0,86 & 0,97 & 0,030 \\
& $\mathbf{9 0}$ & 0,71 & 0,89 & 0,99 & 0,019 \\
\multirow{4}{*}{ Agua } & & & & & \\
& $\mathbf{5 0}$ & 0,68 & 0,73 & 0,71 & 0,125 \\
& $\mathbf{7 0}$ & 1,05 & 0,45 & 0,95 & 0,058 \\
& $\mathbf{9 0}$ & 0,66 & 0,52 & 0,94 & 0,049 \\
\hline
\end{tabular}

El parámetro de forma $(\beta)$ del modelo de Weibull no mostró una tendencia clara con respecto a la temperatura de proceso ni para el agua ni para los solutos. El parámetro de escala $(\alpha)$ para agua y solutos disminuyó a medida que aumentó la temperatura de proceso. Resultados similares fueron obtenidos por Uribe y col. (2011) durante la DO de calamar y por Schmidt y col. (2009) durante la DO de pechugas de pollo con $5 \%$ de $\mathrm{NaCl}$.

El parámetro a (inversa de la velocidad) disminuyó al aumentar la temperatura siguiendo la relación de Arrhenius $\left(R^{2}=0,89\right)$. Los valores de $E_{a}$ para sal, glicerol y agua obtenidos con el modelo de Weibull fueron: 9,36; 7,15 y $8,25 \mathrm{~kJ} / \mathrm{mol}$ respectivamente. Basándose en los resultados obtenidos, el parámetro a puede ser considerado como pseudo-coeficiente de difusión (Lemus-Mondaca y col., 2009a).

Los valores experimentales de agua, sal y glicerol ajustaron al modelo de Weibull (Figura 2.9), siendo capaz de predecir la pérdida de agua y la ganancia de solutos durante la DO de rodajas de caballa. Esto pudo ser verificado también con los altos coeficientes de correlación y los bajos RMSE (Tabla 2.4). La única excepción fue la predicción del comportamiento de la pérdida de agua a $50^{\circ} \mathrm{C}$ con el modelo de Weibull donde se obtuvieron valores inferiores de $R^{2}(0,71)$ y mayores de RMSE $(0,125)$. 

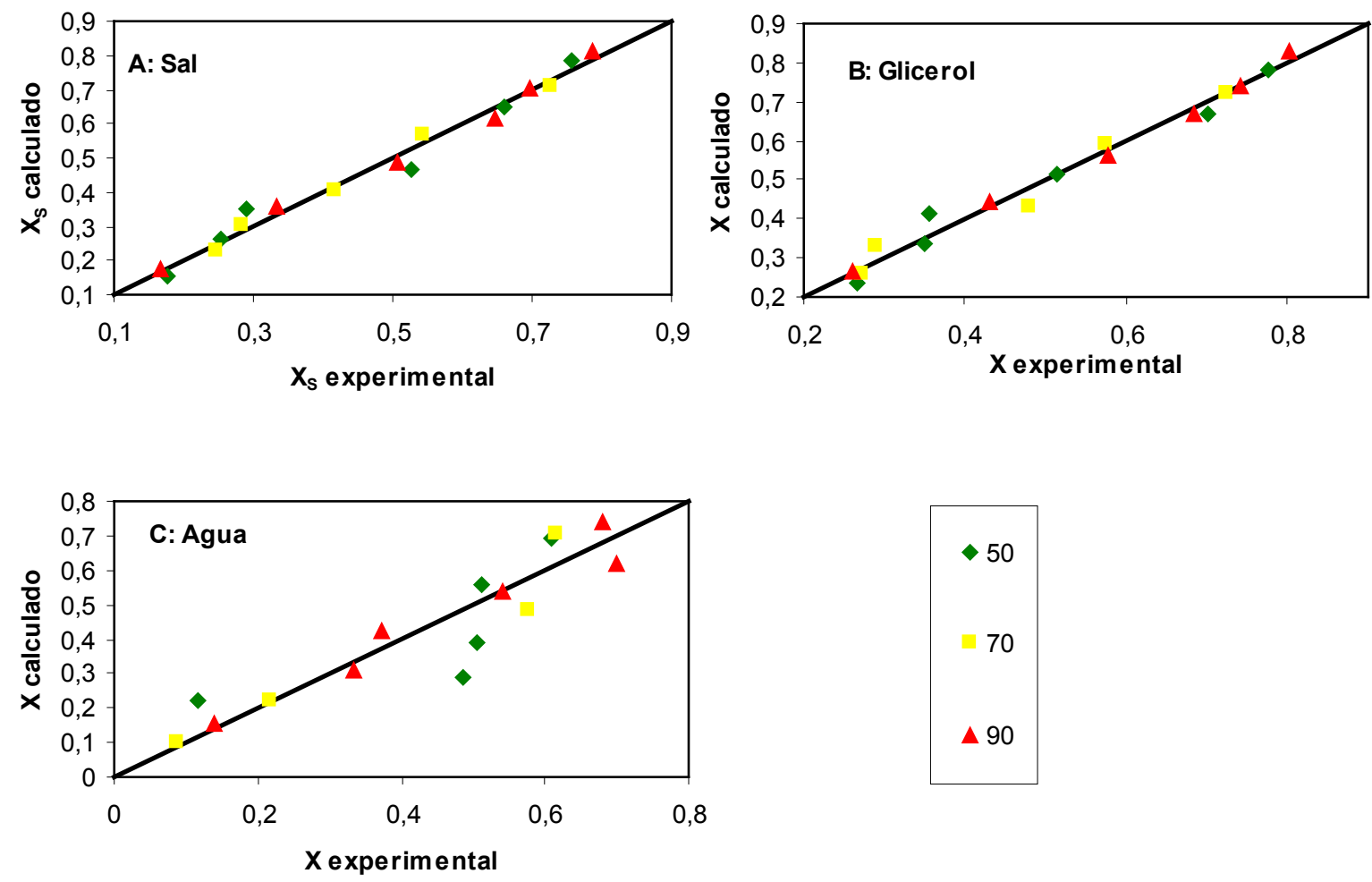

Figura 2.9 Comparación entre datos experimentales y los estimados con el modelo de Weibull a diferentes temperaturas

\section{Modelo de Peleg}

Los parámetros y los valores de equilibrio para agua, sal y glicerol estimados con el modelo de Peleg a diferentes temperaturas se muestran en la Tabla 2.6.

Tabla 2.6 Parámetros y valores de equilibrio del modelo de Peleg

\begin{tabular}{ccccccccc}
\hline & $\begin{array}{c}\text { Temp. } \\
\left({ }^{\circ} \mathbf{C}\right)\end{array}$ & $\boldsymbol{K}_{\mathbf{1}}$ & $\boldsymbol{K}_{\mathbf{2}}$ & $\mathbf{R}^{\mathbf{2}}$ & $\mathbf{R M S E}$ & $\boldsymbol{X}_{\text {eq }}$ Peleg & $\begin{array}{c}\boldsymbol{X}_{\text {eq }} \\
\text { Experim }\end{array}$ & $\begin{array}{c}\text { Error } \\
\text { Relativo }(\boldsymbol{E})\end{array}$ \\
\cline { 2 - 8 } Sal & $\mathbf{5 0}$ & 5,26 & 5,704 & 0,99 & 0,005 & 0,175 & 0,138 & 26,84 \\
& $\mathbf{7 0}$ & 3,436 & 5,775 & 0,99 & 0,004 & 0,173 & 0,15 & 15,33 \\
& $\mathbf{9 0}$ & 2,947 & 5,67 & 0,99 & 0,004 & 0,176 & 0,152 & 16,44 \\
& & & & & & & & \\
Glicerol & $\mathbf{5 0}$ & 0,854 & 0,803 & 0,97 & 0,048 & 1,245 & 0,993 & 25,37 \\
& $\mathbf{9 0}$ & 0,639 & 0,909 & 0,98 & 0,037 & 1,1 & 0,926 & 18,85 \\
& $\mathbf{9 0}$ & 0,566 & 0,799 & 0,99 & 0,036 & 1,251 & 1,046 & 19,69 \\
Agua & $\mathbf{5 0}$ & 0,761 & 1,166 & 0,92 & 0,057 & 1,155 & 1,295 & 10,81 \\
& $\mathbf{7 0}$ & 0,428 & 1,022 & 0,97 & 0,052 & 1,072 & 1,251 & 14,34 \\
& $\mathbf{9 0}$ & 0,396 & 1,165 & 0,97 & 0,039 & 1,056 & 1,123 & 5,96 \\
\hline
\end{tabular}


La constante de velocidad de Peleg $\left(\mathrm{K}_{1}\right)$ disminuyó de 0,761 a 0,396 h/(g/gbs) para la pérdida de agua; de 5,526 a $2,947 \mathrm{~h} /(\mathrm{g} / \mathrm{gbs})$ para ganancia de sal y de 0,944 a 0,566 h/(g/gbs) para ganancia de glicerol, respectivamente, con el aumento de la temperatura de proceso desde 50 a $90^{\circ} \mathrm{C}$. Dado que la inversa de $\mathrm{K}_{1}$ (Ecuación 2.23) está relacionada a la velocidad de transferencia de masa, la pérdida de agua y la ganancia de solutos se ven incrementadas con el aumento de la temperatura. Un comportamiento similar fue encontrado por Corzo y Bracho (2006) en láminas de sardina y por Turhan y col. (2002) en garbanzo. No se encontró información disponible en la literatura de la ganancia de glicerol.

La constante de capacidad de Peleg no mostró una tendencia clara con respecto a la temperatura de proceso ni para agua ni para los solutos. Corzo y Bracho (2006) encontraron resultados similares para la DO de láminas de sardina.

El coeficiente de determinación $\left(R^{2}\right)$ varió desde 0,90 a 0,99 para pérdida de agua y ganancia de solutos. Los valores de RMSE fueron menores a 0,09 en todos los casos. De acuerdo a los parámetros estadísticos utilizados para analizar la bondad de ajuste (RMSE y $\mathrm{R}^{2}$ ), el modelo de Peleg describe adecuadamente la cinética de la transferencia de masa durante la DO de rodajas de caballa.

El ajuste de los datos experimentales al modelo de Peleg se puede ver en la Figura 2.10.
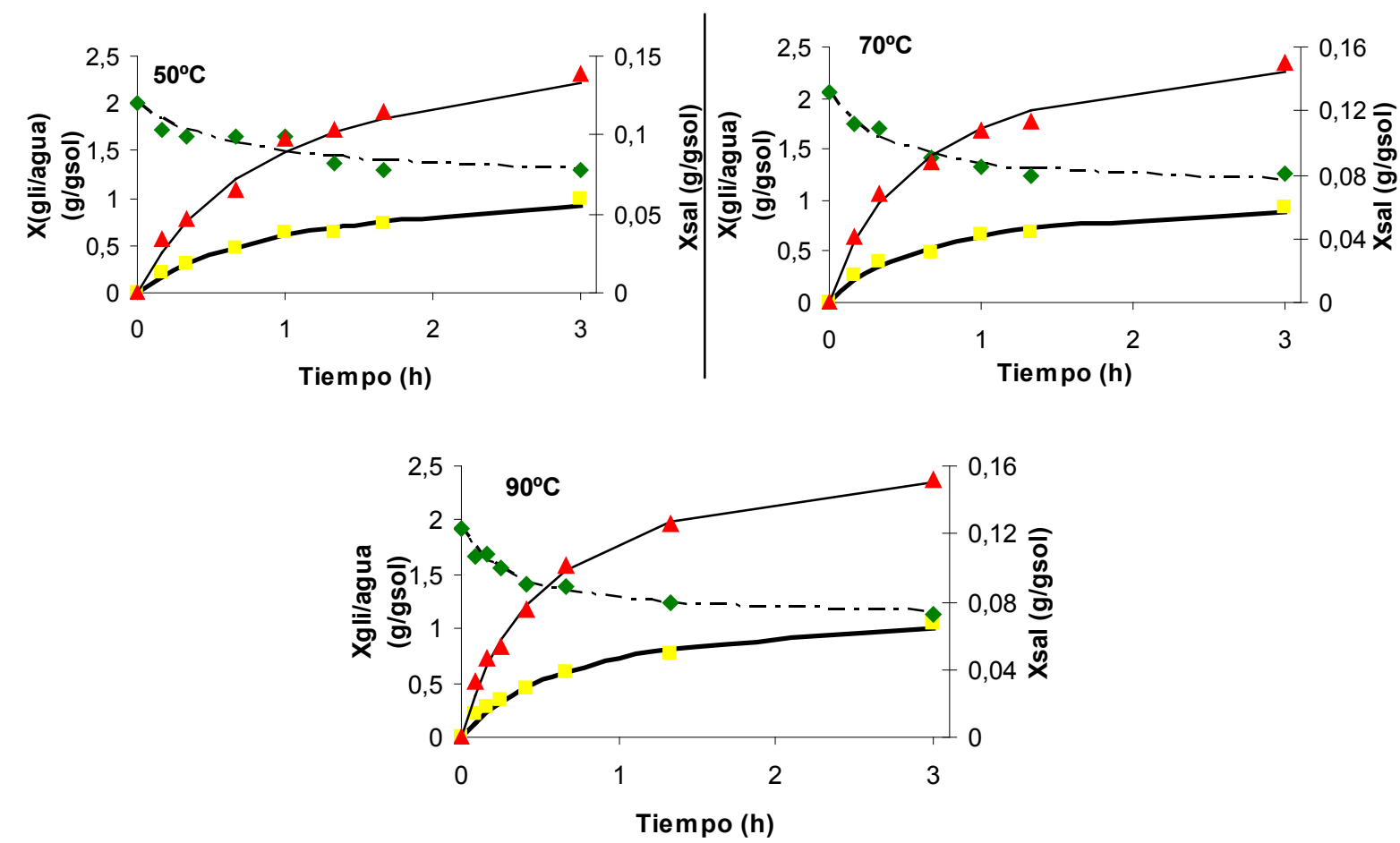

Figura 2.10 Ajuste del modelo de Peleg a la pérdida de agua y ganancia de sal y glicerol: agua experimental ( $\downarrow)$, agua estimado $(-\cdot-\cdot)$; glicerol experimental $(\bullet)$, glicerol estimado (-); sal experimental $(\boldsymbol{\Delta})$, sal estimado $(-)$ 
Los datos experimentales y los estimados para la transferencia de agua y solutos son comparados en la Figura 2.11. Se puede observar que el modelo ajustó los valores satisfactoriamente, lo cual fue verificado con los parámetros estadísticos $R^{2}$ y RMSE (Tabla 2.6)
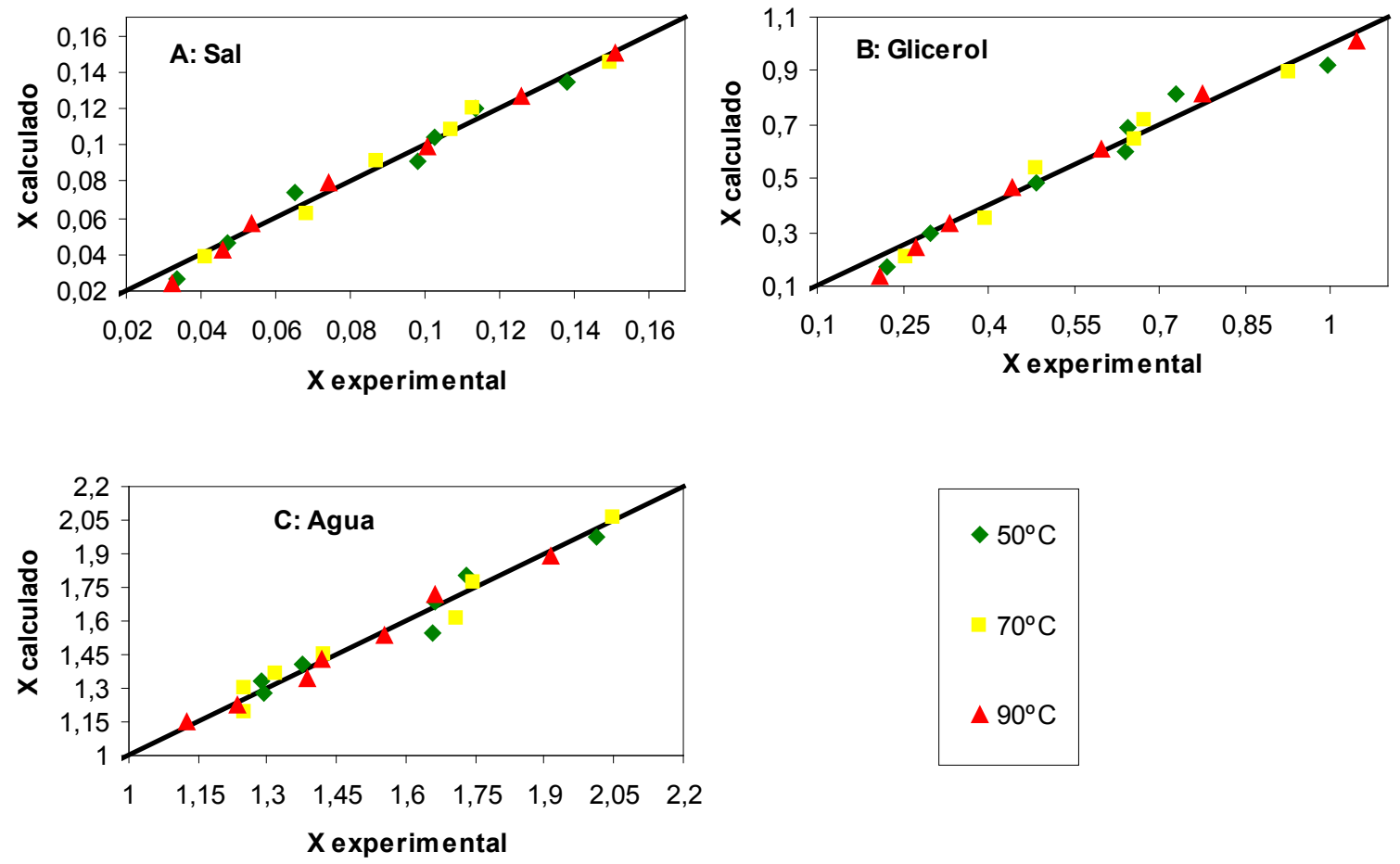

Figura 2.11 Comparación entre datos experimentales y los estimados con el modelo de Peleg a diferentes temperaturas

Los valores de equilibrio obtenidos a partir de la Ecuación 2.24 se muestran en la Tabla 2.6. Los valores de la pérdida de agua en el equilibrio para tiempos de inmersión largos estimados por el modelo de Peleg fueron, en todos los casos, menores que los valores experimentales. El modelo de Peleg tendió a subestimar la pérdida de agua. Schmidt y col. (2009) reportaron resultados similares durante la DO de pechuga de pollo. Sin embargo, los valores de equilibrio de sal y glicerol obtenidos con el modelo de Peleg para tiempos de inmersión largos fueron mayores en comparación con los valores experimentales. Estos resultados indican que el modelo de Peleg sobreestimó la ganancia de sal y glicerol.

La dependencia de la constante de velocidad de Peleg de la temperatura fue representada con la ecuación de Arrhenius linealizada (Ecuación 2.28). La constante de velocidad de Peleg para pérdida de agua y ganancia de sal y glicerol en función de la temperatura de proceso representó una relación de Arrhenius $\left(0,862<R^{2}<0,961\right)$. Valores mayores de $E_{a}$ indican una sensibilidad mayor a la temperatura. La constante 
de velocidad de Peleg para la pérdida de agua $\left(E_{a}=16,14 \mathrm{~kJ} / \mathrm{mol}\right)$ fue más sensible a la temperatura que para la pérdida de sal $\left(E_{a}=14,21 \mathrm{~kJ} / \mathrm{mol}\right)$ y glicerol $\left(E_{a}=10,12 \mathrm{~kJ} / \mathrm{mol}\right)$. Los valores de $E_{a}$ fueron similares a los obtenidos por otros autores en procesos de DO de pescado (Corzo y Bracho, 2006) y de carne (Favetto y col., 1981).

La cinética de transferencia de agua, sal y glicerol durante la DO fue ajustada adecuadamente por los modelos de Crank, Peleg, Weibull y Z \& L. La ventaja que presentaron los modelos de Peleg y $Z$ \& $L$ fue que sirvieron para predecir los valores de equilibrio, siendo el modelo de $Z$ \& $L$ el que mejor predicciones logró.

Por lo anteriormente mencionado, el modelo de $Z$ \& $L$ fue capaz de ajustar adecuadamente la transferencia de masa de agua, sal y glicerol y, además, predecir satisfactoriamente los valores de equilibrio.

\subsubsection{Deshidratación osmótica de lomitos de caballa}

\section{Estimación de los coeficientes de difusión (modelo de Crank)}

Los coeficientes efectivos de difusión de agua y solutos fueron calculados ajustando las soluciones de la segunda ley de Fick (Ecuaciones 2.14, 2.15 y 2.16) a los datos experimentales. Los valores predichos de los coeficientes de difusión de agua, sal y glicerol para cilindro infinito con 1, 3 y 5 términos de la serie y para cilindro finito se muestran en la Tabla 2.7. Los valore de $R^{2}$, RMSE y $P$ se muestran en la Tabla 2.8.

Tabla 2.7. Coeficientes de difusión de agua y solutos

\begin{tabular}{lcccc}
\hline $\begin{array}{l}\text { Modelo de } \\
\text { Crank }\end{array}$ & $\begin{array}{c}\text { Cilindro infinito } \\
\text { (5 términos de la } \\
\text { serie) }\end{array}$ & $\begin{array}{c}\text { Cilindro infinito } \\
(3 \text { términos de la } \\
\text { serie) }\end{array}$ & $\begin{array}{c}\text { Cilindro } \\
\text { infinito } \\
\text { (linealizado) }\end{array}$ & Cilindro finito \\
\hline $\begin{array}{l}\text { Pérdida de } \\
\text { agua }\end{array}$ & $2,63 \times 10^{-9}$ & $2,63 \times 10^{-9}$ & $2,88 \times 10^{-9}$ & $2,30 \times 10^{-9}$ \\
$\begin{array}{l}\text { Ganancia de } \\
\text { sal }\end{array}$ & $4,14 \times 10^{-9}$ & $4,11 \times 10^{-9}$ & $4,04 \times 10^{-9}$ & $3,67 \times 10^{-9}$ \\
$\begin{array}{l}\text { Ganancia de } \\
\text { glicerol }\end{array}$ & $4,25 \times 10^{-9}$ & $4,25 \times 10^{-9}$ & $4,06 \times 10^{-9}$ & $3,78 \times 10^{-9}$ \\
\hline
\end{tabular}


Tabla 2.8. Parámetros estadísticos de los modelos utilizados

\begin{tabular}{|c|c|c|c|c|c|}
\hline \multicolumn{3}{|c|}{ Modelo de Crank } & $\begin{array}{c}\text { Pérdida de } \\
\text { agua }\end{array}$ & $\begin{array}{c}\text { Ganancia } \\
\text { de sal }\end{array}$ & $\begin{array}{c}\text { Ganancia } \\
\text { de glicerol }\end{array}$ \\
\hline \multirow{9}{*}{$\begin{array}{l}\text { Cilindro } \\
\text { infinito }\end{array}$} & \multirow{3}{*}{$\begin{array}{l}5 \text { términos } \\
\text { de la serie }\end{array}$} & $\mathbf{R}^{2}$ & 0,95 & 0,98 & 0,99 \\
\hline & & RMSE & 0,045 & 0,03 & 0,023 \\
\hline & & $\mathbf{P}(\%)$ & 8,46 & 4,17 & 4,32 \\
\hline & \multirow{3}{*}{$\begin{array}{l}3 \text { términos } \\
\text { de la serie }\end{array}$} & $\mathbf{R}^{2}$ & 0,95 & 0,98 & 0,99 \\
\hline & & RMSE & 0,048 & 0,032 & 0,024 \\
\hline & & $\mathbf{P}(\%)$ & 8,88 & 4,35 & 4,48 \\
\hline & \multirow{3}{*}{ Linealizado } & $\mathrm{R}^{2}$ & 0,93 & 0,98 & 0,99 \\
\hline & & RMSE & 0,18 & 0,12 & 0,1 \\
\hline & & $\mathbf{P}(\%)$ & 14,9 & 8,75 & 7,82 \\
\hline \multirow{3}{*}{$\begin{array}{c}\text { Cilindro } \\
\text { finito }\end{array}$} & & $\mathbf{R}^{2}$ & 0,92 & 0,97 & 0,98 \\
\hline & & RMSE & 0,057 & 0,039 & 0,025 \\
\hline & & P (\%) & 10 & 5,69 & 4,34 \\
\hline
\end{tabular}

En todos los casos $\mathrm{R}^{2}$ fue mayor que 0,92 y la RMSE fue menor que 0,18 , esto indica que el modelo propuesto es aceptable. Además, los valores de $\mathrm{P}$ fueron menores al $10 \%$ excepto para la perdida de agua estimada con la ecuación linealizada.

No hubo diferencia en los valores de $D$ al considerar 3 o 5 términos de la serie para cilindro infinito. Estos resultados concuerdan con los reportados por Ramallo y col. (2004) en la DO de piña en solución de sacarosa. Cuando los D fueron estimados con la ecuación linealizada la RMSE fue mayor $(0,10<R M S E<0,18) y$, además, el valor de $\mathrm{P}$ para pérdida de agua fue mayor a $10 \%$.

La validación de los modelos se muestra en la Figura 2.8. Como se puede apreciar, los modelos siguieron la tendencia general de las curvas experimentales de la DO. Los valores de la pérdida de agua y ganancia de sal y glicerol predichos por el modelo de Crank para cilindro infinito y para cilindro finito fueron cercanos a los valores experimentales. El modelo basado en la solución de la ley de Fick para cilindro infinito con términos de orden superior fue el mejor ajuste para pérdida de agua y ganancia de sal. Para la ganancia de glicerol no hubo diferencias en los parámetros estadísticos estudiados $\left(\mathrm{R}^{2}\right.$, RMSE y $\left.\mathrm{P}\right)$ para cilindro infinito y finito. 


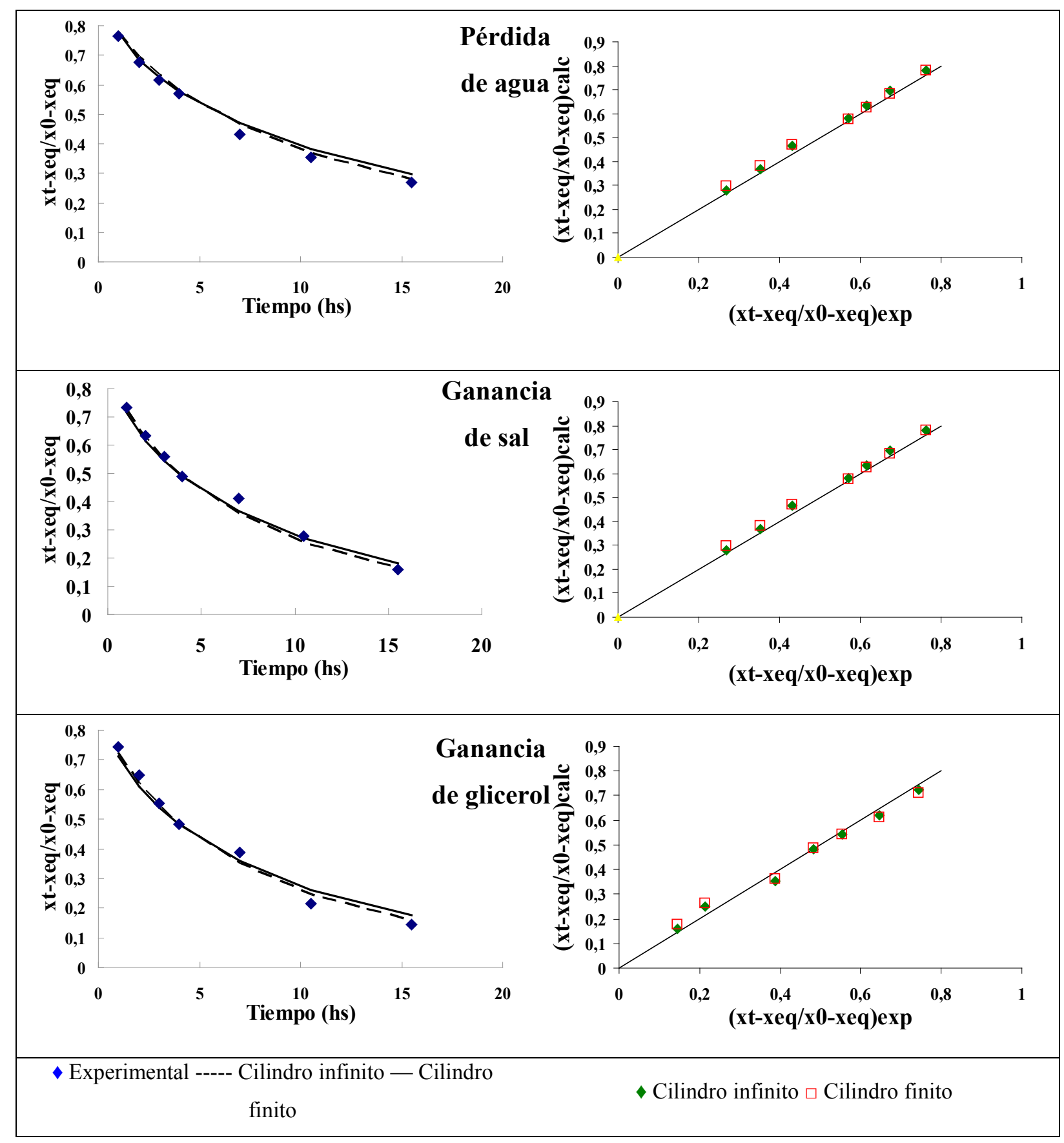

Figura 2.9. Ajuste de los datos experimentales al modelo de Crank

\section{Cinética de la deshidratación osmótica y modelado mediante Z \& L y Azuara}

Los modelos desarrollados por Z \& L y Azuara (ecuaciones 2.18 y 2.25 ) fueron utilizados para predecir la cinética de la DO y para determinar pérdida de agua y contenido de solutos en el equilibrio. La Tabla 2.9 muestra los valores de los parámetros de los modelos y los parámetros estadísticos $R^{2}$, RMSE y $P$. Para la ganancia de solutos, en todos los casos el $\mathrm{R}^{2}$ fue mayor a 0,93, RMSE fue menor a 
0,016 y $P$ fue menor o igual a 10 , lo que indica la aceptabilidad de los modelos de $Z$ \& L y Azuara. Para pérdida de agua, el valor de $P$ fue mayor a 10.

La validación de los modelos se muestra en la Figura 2.10. La pérdida de agua y la ganancia de solutos se incrementaron de forma no lineal con el tiempo y los valores estimados fueron cercanos a los experimentales.

La comparación de los valores de equilibrio experimentales con los estimados se muestra en la Tabla 2.10. El modelo de $Z$ \& $L$ subestimó los valores de equilibrio del contenido de agua y solutos. En el caso del modelo de Azuara, los valores de equilibrio estimados concordaron con los experimentales de acuerdo con los bajos valores de $\mathrm{E}$.

Tabla 2.9. Parámetros de los modelos de $Z$ \& $L$ y Azuara

\begin{tabular}{lcccccccccc}
\hline & \multicolumn{3}{c}{$\mathbf{Z} \& \mathbf{L}$} & \multicolumn{6}{c}{ Azuara } \\
\cline { 2 - 10 } & $\mathbf{k}\left(\mathbf{h}^{-1}\right)$ & $\boldsymbol{x}_{\text {eq }}$ & $\mathbf{R}^{2}$ & $\mathbf{R M S E}$ & $\mathbf{P ( \% )}$ & $\boldsymbol{S}\left(\mathbf{h}^{-1}\right)$ & $\boldsymbol{x}_{\text {eq }}$ & $\mathbf{R}^{2}$ & $\mathbf{R M S E}$ & $\mathbf{P}(\%)$ \\
\cline { 2 - 10 } $\begin{array}{l}\text { Pérdida de } \\
\text { agua }\end{array}$ & 0,1863 & 0,451 & 0,97 & 0,018 & 11,81 & 0,1548 & 0,615 & 0,98 & 0,017 & 10,62 \\
$\begin{array}{l}\text { Ganancia } \\
\text { de sal }\end{array}$ & 0,2981 & 0,055 & 0,97 & 0,002 & 7,88 & 0,2920 & 0,069 & 0,99 & 0,002 & 5,56 \\
$\begin{array}{l}\text { Ganancia } \\
\text { de glicerol }\end{array}$ & 0,3422 & 0,385 & 0,93 & 0,024 & 10,00 & 0,3584 & 0,471 & 0,97 & 0,016 & 6,01 \\
\hline
\end{tabular}

Tabla 2.10. Comparación de los valores de equilibrio experimentales y estimados por los modelos de Z \& L y Azuara

\begin{tabular}{|c|c|c|c|c|c|c|}
\hline & & $X_{\text {eqExp. }}$ & $x_{\text {eqZ\&L }}$ & $E^{a}$ & $\boldsymbol{X}_{\text {eq Azuara }}$ & $E^{a}$ \\
\hline $\begin{array}{l}\text { Pérdida } \\
\text { agua }\end{array}$ & de & 0,560 & 0,451 & 19,46 & 0,615 & 9,82 \\
\hline $\begin{array}{l}\text { Ganancia } \\
\text { sal }\end{array}$ & de & 0,069 & 0,055 & 20,29 & 0,069 & 0 \\
\hline $\begin{array}{l}\text { Ganancia } \\
\text { glicerol }\end{array}$ & de & 0,503 & 0,381 & 24,25 & 0,471 & 6,36 \\
\hline
\end{tabular}

a: $E=\left|\frac{x_{i}-x_{i p}}{x_{i}}\right| 100 \quad E$ : Error relativo, $x_{i}$ valor experimental $\mathrm{y} \mathrm{x}_{\mathrm{ip}}$ valor predicho. 


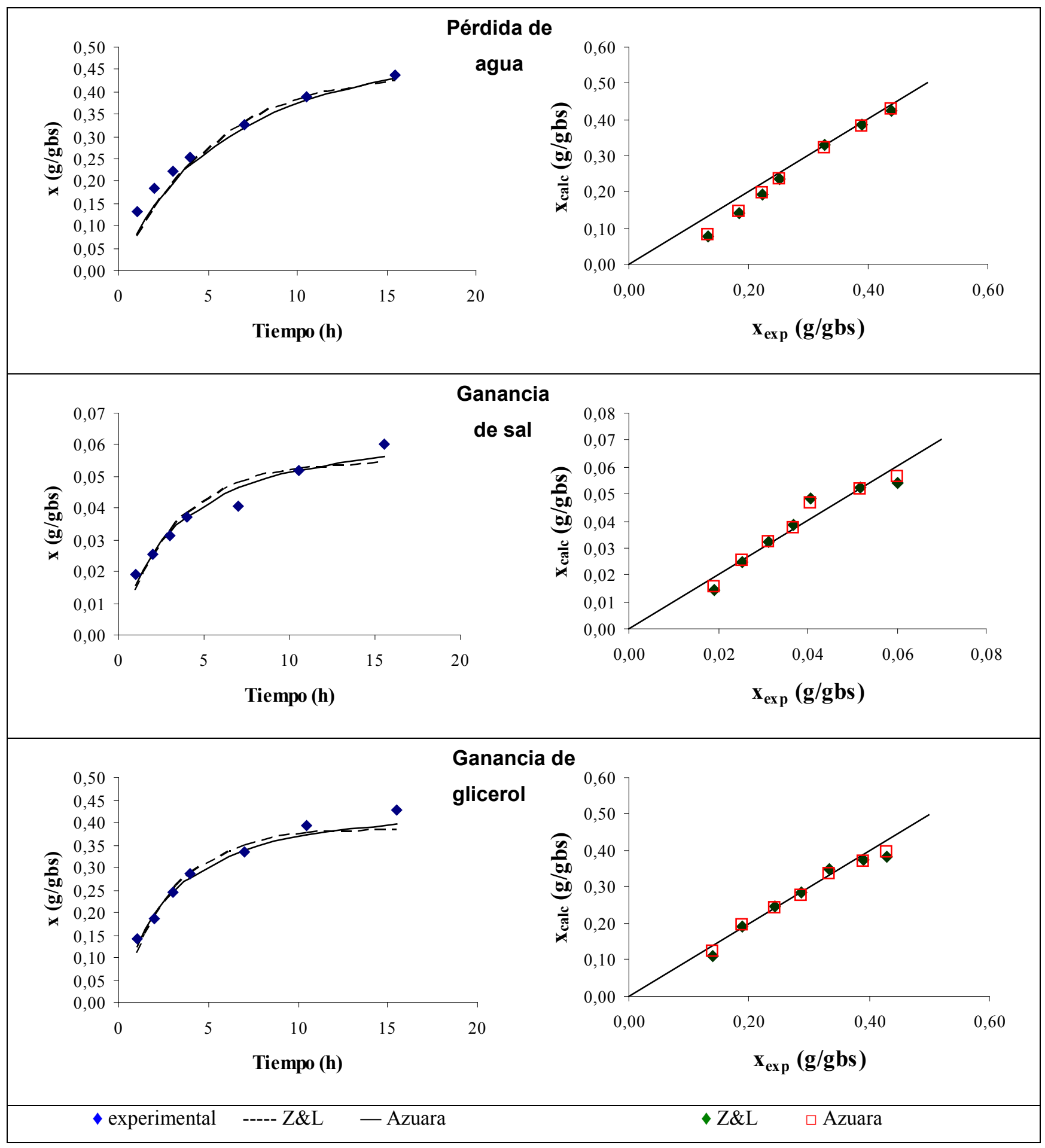

Figura 2.10. Ajuste de los datos experimentales a los modelos de Azuara y $Z$ \& $L$

\section{Perfiles de agua y solutos durante la deshidratación osmótica}

Luego de comprobar que los valores estimados por el modelo de Crank para pérdida de agua y ganancia de solutos se ajustaron a los datos experimentales (Figura 
2.9), se predijo la distribución del agua y de los solutos dentro los cilindros de caballa. La Ecuación 2.27 fue resuelta utilizando los coeficientes de difusión efectivos (Tabla 2.8). Los contenidos adimensionales de agua, sal y glicerol vs. el tiempo adimensional $\left(\mathrm{T}=\mathrm{Dt} / \mathrm{R}^{2}\right)$ fueron graficados como función del radio adimensional $(\mathrm{x}=\mathrm{r} / \mathrm{R})$ (Figura 2.11). En esta Figura se observa que el punto central tuvo el máximo contenido de agua y el mínimo contenido de sólidos (para agua $C_{0}>C_{\text {eq }}$ y para solutos $C_{0}=0$ y $\mathrm{C}_{0}<\mathrm{C}_{\text {eq }}$ ). Por lo tanto, el agua se transfirió desde el interior hacia la superficie y los solutos en dirección inversa. Como puede verse en la Figura 2.11, la disminución del contenido de agua y el aumento en el contenido de solutos se llevó a cabo mayormente en la región superficial de los cilindros y luego progresó lentamente hacia el interior. Al final de la DO los contenidos de agua y solutos alcanzaron el equilibrio con la solución osmótica. 
Capítulo 2: Difusión de agua y solutos durante la DO

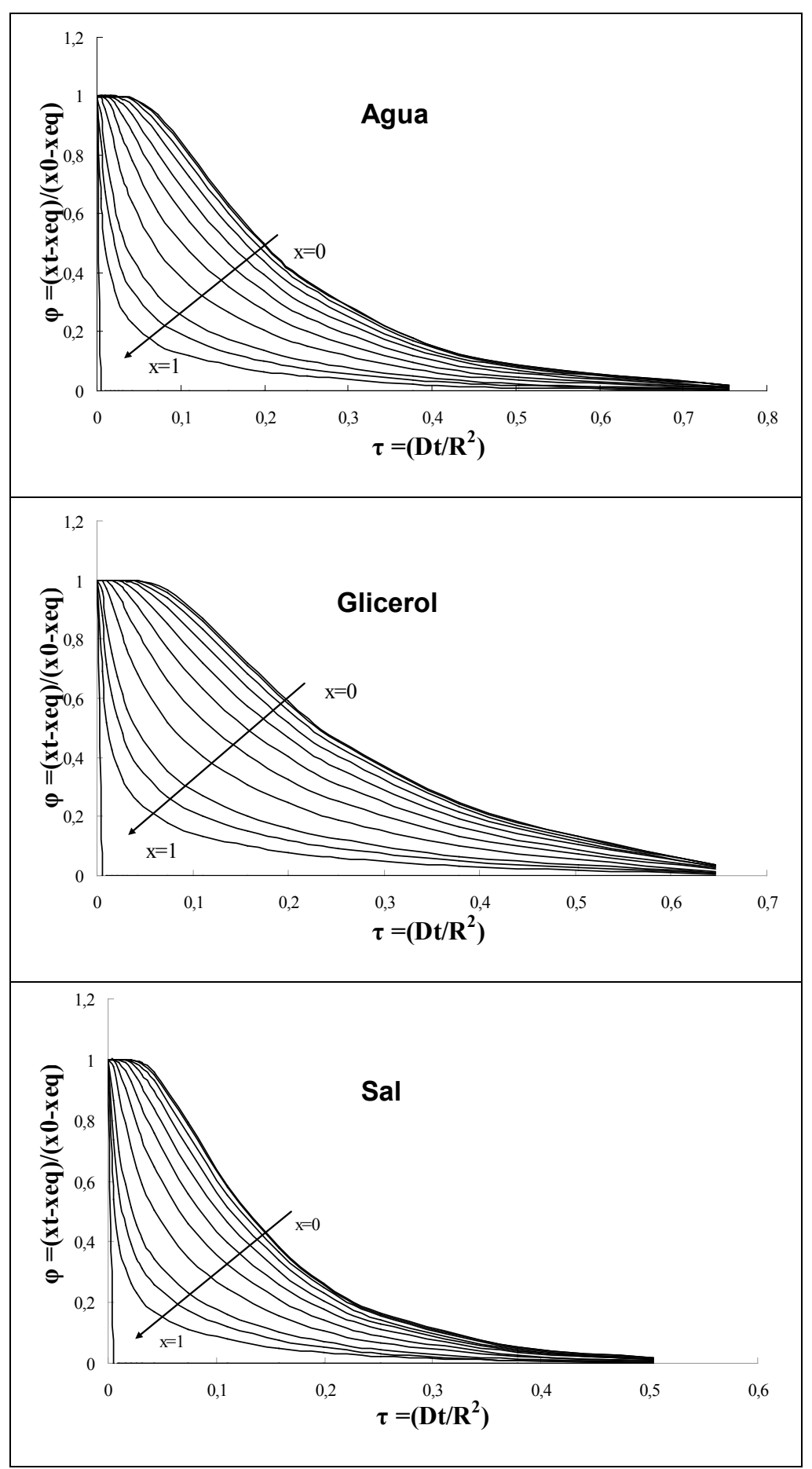

Figura 2.11. Distribución adimensional de agua, glicerol y sal dentro de los cilindros de caballa durante la deshidratación osmótica 


\subsection{Conclusiones}

\section{Deshidratación osmótica de rodajas}

El rango de temperatura entre 50 y $90^{\circ} \mathrm{C}$ influyó en los fenómenos de transferencia de masa durante el proceso de DO de rodajas de caballa inmersas en una solución de glicerol $(54 \% \mathrm{p} / \mathrm{p})$ y sal $(7 \% \mathrm{p} / \mathrm{p})$. Una mayor temperatura de proceso promovió mayor pérdida de agua y ganancia de solutos durante la deshidratación osmótica de las rodajas. Como resultado, el tiempo requerido para alcanzar un valor de $a_{w}$ determinado disminuyó a medida que aumentó la temperatura.

La cinética de transferencia de masa de agua, sal y glicerol durante la DO fue ajustada adecuadamente por los modelos de Crank, Peleg, Z \& L y Weibull. Los coeficientes de difusión (D) y los parámetros de los modelos de Zugarramurdi \& Lupín, Peleg y Weibull $\left(\mathrm{K}, \mathrm{K}_{1}\right.$ y $\left.\alpha\right)$ mostraron una dependencia con la temperatura siguiendo la relación de Arrhenius.

Los modelos de Peleg y de $Z$ \& L brindaron mayor información ya que también predijeron el contenido de agua y solutos en el equilibrio. Esta información es relevante para el desarrollo de este tipo de productos. Es importante aclarar que el modelo de Peleg subestimó el contenido de agua en el equilibrio y sobreestimó los contenidos de solutos en el equilibrio comparados con los valores experimentales. En cambio, el modelo de $Z$ \& $L$ realizó un mejor acercamiento a los valores de equilibrio de agua y solutos.

Por lo tanto, el modelo de Z \& L fue capaz de ajustar adecuadamente los datos de transferencia de masa y, además, predecir satisfactoriamente los contenidos de agua y solutos en el equilibrio.

\section{Deshidratación osmótica de lomitos}

El modelo de Crank para cilindro finito e infinito y los modelos empíricos de Zugarramurdi \& Lupín y Azuara predijeron mejor la ganancia de sal y glicerol que la pérdida de agua durante la deshidratación osmótica de cilindros de caballa en la solución hipertónica de agua, sal y glicerol.

Tres términos en la solución analítica de la ecuación de Fick para cilindro infinito fueron apropiados para determinar los coeficientes de difusión.

El modelo basado en la solución de la ley de Fick para cilindro infinito resultó la mejor opción para representar la pérdida de agua y la ganancia de solutos. 
Los valores de equilibrio estimados con el modelo de Azuara se ajustaron correctamente a los valores experimentales.

Utilizando los valores de difusividad efectiva estimados, se logró predecir la distribución de agua y solutos en las muestras de cilindros de caballa. Los cambios en las concentraciones de agua, glicerol y sal estuvieron confinados principalmente en la región de la superficie y progresaron lentamente hacia el interior. Al final de la DO los contenidos de agua y solutos en el lomito de caballa alcanzaron el equilibrio con la solución osmótica. 


\section{CAPITULO 3:}

Efectividad de las barreras de stress microbiano

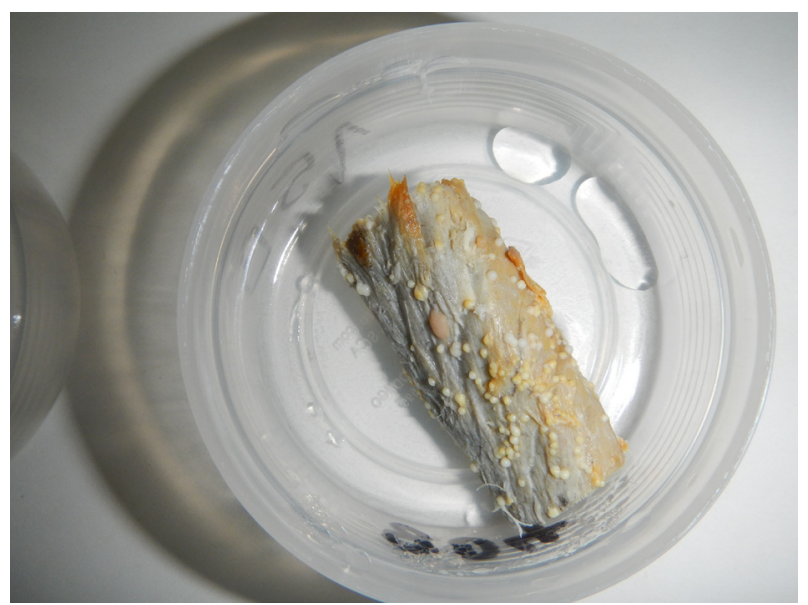




\subsection{Resumen}

En este capítulo se analizó el efecto de las barreras de stress microbiano sobre la microflora nativa de la preserva de lomitos de caballa. Se determinaron microorganismos psicrótrofos, mesófilos, Staphilococcus spp., mohos y levaduras y clostridio sulfito-reductores en la materia prima, en los lomitos durante el procesado y en la preserva pasteurizada durante el almacenamiento a tres temperaturas $(5,25 \mathrm{y}$ $35^{\circ} \mathrm{C}$ ). Además, se analizó el comportamiento microbiológico de la preserva sin el proceso de pasteurización con el fin de determinar la importancia de esta etapa. Los datos de crecimiento microbiano obtenidos a partir de este estudio fueron modelados mediante los modelos de Gompertz modificado y logístico.

Se realizó también un estudio de reto microbiano donde se inoculó una cepa de Staphylococcus aureus, se pasteurizó y se analizó la presencia de dicho microorganismo durante el almacenamiento. Este análisis sirvió para validar experimentalmente el cálculo teórico de la pasteurización realizado en el Capítulo 1. Además, como se inoculó un número alto de microorganismos (del orden de 7 log UFC/g), al finalizar la pasteurización se contó con un recuento del orden de 2 log UFC/g. Esta flora sobreviviente fue utilizada para analizar su comportamiento durante el almacenamiento de la preserva a 5,25 y $35^{\circ} \mathrm{C}$.

\subsection{Introducción}

Existen distintos tipos de estudios de reto microbiano que investigan la validación de los procesos de inocuidad alimentaria, las condiciones de almacenamiento del producto y la vida útil. Los estudios de reto microbiano relacionados con la inocuidad de alimentos difieren dependiendo del tipo de producto y del proceso productivo. Existen tres tipos de estudio (NACMCF, 2010):

Estudios de inhibición de crecimiento de patógenos. Estos estudios se utilizan para evaluar la capacidad de una formulación de producto alimenticio en particular con un tipo específico de elaboración y envasado para inhibir el crecimiento de ciertos patógenos bacterianos cuando se mantiene en condiciones de almacenamiento específicas (tiempo y temperatura). El objetivo de un estudio de crecimiento puede ser para pedir una exención (o una variación) de algún requerimiento definido por alguna regulación local, nacional o bien dada por el Código Alimentario; puede ser también para demostrar la inocuidad de alguna 
formulación; para determinar si una formulación o cambio en el proceso es requerido si el producto es sometido a un abuso de temperatura; o bien para determinar el efecto de la modificación de una formulación, proceso o tecnología de empaque.

> Estudios de inactivación de patógenos. Estos estudios se utilizan para evaluar la capacidad de una formulación de un producto alimenticio en particular, una práctica de fabricación de alimentos específicos o su combinación para causar la inactivación de ciertos patógenos bacterianos. Estos estudios también pueden verse afectados por el almacenamiento y las condiciones de envasado y deben tener en cuenta estas variables. Los estudios de inactivación pueden ser utilizados para determinar si un proceso térmico provee una adecuada reducción decimal de un patógeno objetivo. Por ejemplo, el requerimiento de inactivación de 5-log de Escherichia coli O157:H7 en salchichas secas fermentadas (FSIS, 2001).

$>$ Combinación de estudios de crecimiento e inactivación. Se pueden usar estudios combinados para evaluar la capacidad de un alimento o proceso particular para inactivar determinados patógenos bacterianos y para inhibir el crecimiento de ciertas otras bacterias patógenas o para conseguir un nivel de inactivación seguido por la inhibición del crecimiento de los supervivientes o contaminantes introducido después de procesar. FSIS (2009), expone un ejemplo de un elaborador de carne procesada que necesita, por regulación, demostrar una etapa de destrucción de Listeria monocytogenes de 2 ciclos logarítmicos mediante un proceso de altas presiones, seguido de una inhibición de crecimiento mediante la formulación del producto durante el almacenamiento refrigerado.

De acuerdo a lo anteriormente mencionado se consideró adecuado trabajar con la combinación de estudios de crecimiento e inactivación. Se buscó determinar si el tratamiento térmico provee una adecuada reducción logarítmica de Staphylococcus aureus como así también analizar la efectividad de los obstáculos diseñados en esta preserva durante el almacenamiento.

Distintos autores han realizado estudios de reto microbiano con $S$. aureus como microorganismo objetivo. Chawla y Chander (2004), realizaron una combinación de estudio de inactivación y de crecimiento. Ellos determinaron la inocuidad de un alimento de humedad intermedia (AHI) elaborado a partir de carne de cordero combinando las tecnologías de irradiación, reducción de la $a_{w}$ y envasado al vacío. Determinaron la efectividad de la irradiación sobre $S$. aureus, Clostridium sporogenes 
y Bacillus cereus y estudiaron el crecimiento de estos microorganismos durante el almacenamiento. Vora y col. (2003), inocularon tres AHI (carne, pan y pollo) con una cepa de $S$. aureus y modelaron su comportamiento durante el almacenamiento a temperatura ambiente. Walkling-Ribeiro y col. (2008), estudiaron la inactivación de $S$. aureus en jugo de manzana mediante distintas tecnologías (irradiación ultravioleta, pre-calentamiento y campos eléctricos pulsados) y realizaron una comparación contra una pasteurización convencional.

Dado que el crecimiento de bacterias patógenas y la producción de toxinas como resultado de un abuso de tiempo y temperatura de almacenamiento de productos de la pesca puede producir enfermedades en el consumidor (DHHS, 2011), en la presente investigación, además de estudiar el almacenamiento en refrigeración se estudió el comportamiento a temperaturas superiores.

\subsection{Objetivos}

- Analizar el comportamiento microbiológico durante el procesamiento de la preserva y durante el almacenamiento a distintas temperaturas $\left(5,25\right.$ y $\left.35^{\circ} \mathrm{C}\right)$.

$>$ Estudiar y modelar el crecimiento microbiano de la preserva sin el proceso de pasteurización.

$>$ Realizar un estudio de reto microbiano con el fin de validar experimentalmente la etapa de pasteurización de la preserva y analizar el comportamiento de la carga de Staphylococcus aureus sobreviviente al proceso de pasteurización durante el almacenamiento.

\subsection{Materiales y métodos}

\subsubsection{Materia prima}

Se utilizó caballa (Scomber japonicus) capturada en el mes de octubre de 2012 en las costas de la provincia de Buenos Aires y conservada a bordo con hielo. Luego de su arribo al puerto de la ciudad de Mar del Plata la materia prima fue transportada al laboratorio en envases térmicos con hielo. Se utilizaron 41 caballas de $38 \pm 3 \mathrm{~cm}$ de largo con un peso de 0,560 $\pm 0,04 \mathrm{~kg}$. 


\subsubsection{Análisis fisicoquímicos}

Se determinó la composición química proximal de la materia prima (contenido de agua, lípidos, proteínas y cenizas) y la composición química proximal, $\mathrm{pH}, \mathrm{a}_{\mathrm{w}}$, humedad y contenido de sal, glicerol y ácido cítrico de la preserva. Las técnicas para realizar estas determinaciones se describen en la Sección 1.4.2.

\subsubsection{Estudio de la flora nativa}

En la planificación de un estudio de reto microbiano es esencial tener información de las características microbiológicas de la materia prima. Es también necesario determinar cómo el procesamiento modificará la carga microbiana del producto, qué microorganismos están involucrados y el comportamiento del producto ante la posibilidad de recontaminación. Asimismo, es importante determinar los recuentos del producto final (Notermans, 1983). De acuerdo a lo anteriormente expresado se consideró necesario realizar un estudio de la flora nativa de la materia prima, durante el procesamiento y el almacenamiento.

\section{Muestreo}

El proceso para la obtención de las muestras es el mismo que el descripto en la Sección 1.5 .4 con la diferencia que para este estudio se utilizó caballa fresca (sin congelar).

Se monitoreó el comportamiento de la flora nativa en la materia prima cruda, en los troncos de caballa luego de la cocción al vapor y durante el almacenamiento de la preserva pasteurizada y sin pasteurizar. Se utilizaron tres temperaturas de almacenamiento: 5,25 y $35^{\circ} \mathrm{C}$ y los tiempos de muestreo fueron: $0,1,2,3,4,5,7,9$ y 12 meses para 5 y $25^{\circ} \mathrm{C}$ y $0 ; 0,5 ; 1 ; 1,5 ; 2 ; 2,5 ; 3 ; 4 ; 5 ; 7 ; 9$ y 12 meses para $35^{\circ} \mathrm{C}$.

Por tratarse de alimentos sólidos se requirió el tratamiento previo de las muestras a fin de liberar los microorganismos en un medio fluido (ICMSF, 1983). Para ello, se procesaron $10 \mathrm{~g}$ de muestra con $90 \mathrm{ml}$ de diluyente en un homogeneizador circular (Stomacher 400$)$. El diluyente consistió en una solución salina $(0,85 \% \mathrm{NaCl})$ con $0,1 \%$ de peptona (ICMSF, 1983). La muestra se sacó en forma aséptica de cada envase cerrado. Los recuentos de microorganismos se realizaron por siembra en profundidad o en superficie según correspondiera para cada grupo en particular, considerando en cada caso el factor de dilución específico. Los recuentos de 
microorganismos totales y el aislamiento de los grupos microbianos determinados se realizaron utilizando los medios de cultivo y condiciones de incubación de acuerdo a ICMSF (1983). Los análisis se realizaron por triplicado y los resultados se expresaron como log UFC/g (Unidades Formadoras de Colonias por gramo de muestra).

\section{$\underline{\text { Recuento de Bacterias Psicrótrofas (BP) }}$}

Las bacterias psicrótrofas Gram-negativas constituyen el principal grupo de microorganismos responsables del deterioro en los productos de la pesca frescos (Gram y Dalgaard, 2002; Gram y Huss, 2000; Huss, 1995) y son capaces de desarrollarse a bajas temperaturas, como las de refrigeración $\left(2-8^{\circ} \mathrm{C}\right)(\mathrm{ICMSF}, 1983)$.

Se realizó siembra en profundidad utilizando Agar para Recuento en Placa. Se incubó a $25 \pm 0,5^{\circ} \mathrm{C}$ durante 96 hs (ICMSF, 1983) y se cuantificaron las BP.

\section{$\underline{\text { Recuento de Bacterias Aerobias Mesófilas totales (BAM) }}$}

El recuento de BAM es utilizado como indicador microbiológico de la calidad higiénica de los alimentos y da una idea de la contaminación por estas bacterias durante el procesamiento de los productos pesqueros (ICMSF, 1983).

Se realizó siembra en profundidad utilizando Agar para Recuento en Placa. Se incubó a $35 \pm 0,5^{\circ} \mathrm{C}$ durante 48 hs (ICMSF, 1983) y se cuantificaron las BAM.

\section{$\underline{\text { Recuento de mohos y levaduras (M\&L) }}$}

Los mohos y levaduras son microorganismos indicadores de calidad sanitaria que pueden crecer a una mayor velocidad que las bacterias en medios más hostiles, como alimentos con baja actividad de agua (ICMSF, 1983), por lo tanto, se consideró apropiado investigarlos en los lomitos de caballa.

Se realizó siembra en placa en superficie con espátula de Drigalsky utilizando Agar H\&L (Britania). Se incubó a $25 \pm 0,5{ }^{\circ} \mathrm{C}$ durante 5 días (ICMSF, 1983) y se cuantificó.

Recuento de Staphylococcus spp. Investigación de Staphylococcus aureus (S. aureus).

Los estafilococos suelen encontrarse en las fosas nasales, boca, oídos y en la piel de las personas. Una inadecuada higiene y/o manipulación podría llevar a la 
presencia de estas bacterias en los alimentos (ICMSF, 1983). A este grupo pertenecen S. aureus, S. epidermidis, S. saprophyticus, entre otras. Se cuantificaron bacterias Staphylococcus spp. por siembra en superficie en Agar Baird Parker incubando a $35 \pm$ $0,5^{\circ} \mathrm{C}$ durante 48 horas (ICMSF, 1983).

Dado que los lomitos poseen una $a_{w}$ de 0,89 $\pm 0,01$ y un $\mathrm{pH}$ de 5,11 $\pm 0,06$ se decidió utilizar como organismo de control durante la pasteurización al $S$. aureus debido a que es el único microorganismo patógeno capaz de desarrollarse a esa $a_{w}$ (NACMCF, 2006).

Para identificación de $S$. aureus se sembró en agar manitol salado, agar dnasa y se realizó test de coagulasa (ICMSF, 1983).

$\underline{\text { Investigación de microorganismos clostridio sulfito-reductores (CSR) }}$

Los clostridio sulfito-reductores (CSR) son microorganismos del género Clostridium que tienen la capacidad de reducir el sulfito a sulfuro (ICMSF, 1983). A este grupo pertenecen los microorganismos patógenos $C$. perfringens y $C$. botulinum (ICMSF, 1983), siendo este último el de mayor importancia por la posibilidad de generar toxina mortal. Considerando que los CSR son microorganismos anaerobios, éstos podrían desarrollarse en los productos envasados al vacío, por lo que se investigó su presencia.

Se sembró $1 \mathrm{ml}$ de muestra en Agar Sulfito Polimixina-Sulfadiazina (SPS) en placa. El medio SPS es selectivo para sulfito-reductores ya que al contener sulfito sódico, el mismo es reducido a sulfuro por la mayor parte de los clostridios. A su vez, el sulfuro reacciona con el citrato de hierro, dando lugar a sulfuro de hierro, que se manifiesta por la formación de un precipitado negro alrededor de las colonias. Se incubó en jarras de anaerobiosis a $35 \pm 0,5^{\circ} \mathrm{C}$ y $46 \pm 0,5^{\circ} \mathrm{C}$ durante 48 horas.

\subsubsection{Modelado matemático}

Modelo de Gompertz modificado

Se utilizó el modelado matemático para analizar el efecto de la temperatura de almacenamiento sobre el comportamiento microbiológico de la preserva. Uno de los modelos mas utilizados para describir el crecimiento microbiano está dado por la ecuación de Gompertz modificada (Gibson y col., 1988) cuya expresión es la siguiente: 
$\log N=A+C \exp (-\exp (-B(t-M)))$

donde $\log N$ es el logaritmo decimal del recuento de microorganismos (log CFU/g) a tiempo $\mathrm{t}$, A el recuento logarítmico asintótico a medida que el tiempo disminuye indefinidamente (aproximadamente equivalente al logaritmo del recuento inicial de bacterias (log CFU/g)), $\mathrm{C}$ es el incremento del recuento logarítmico a medida que el tiempo crece indefinidamente (esto es el número de ciclos de crecimiento (log CFU/g)), $\mathrm{B}$ es la velocidad máxima relativa de crecimiento a tiempo $\mathrm{M}\left(\right.$ meses $\left.^{-1}\right)$ y $\mathrm{M}$ el tiempo requerido para alcanzar la máxima velocidad de crecimiento (meses).

La velocidad específica de crecimiento se puede calcular de acuerdo a $\mu=\frac{B C}{e}$ $((\log \mathrm{CFU} / \mathrm{g}) /$ meses $)$ con $e=2,7182$, la duración de la fase de latencia $D F L=M-\left(\frac{1}{B}\right)$ (meses) y la máxima densidad de población $M D P=A+C(\log \mathrm{UFC} / \mathrm{g})$.

Los datos fueron ajustados a la ecuación de Gompertz modificada mediante regresión no lineal con el programa OriginPro versión 8 (OriginLab Corporation, Northampton, MA).

El efecto de la temperatura de almacenamiento $\left(5,25\right.$ y $\left.35^{\circ} \mathrm{C}\right)$ sobre la velocidad específica de crecimiento $(\mu)$ fue estudiado mediante el modelo de Arrhenius según la siguiente ecuación:

$\ln (\mu)=\ln \left(A^{\prime}\right)-\left(\frac{E_{\mu}}{R T}\right)$

donde $\mu$ es la velocidad específica de crecimiento ((log UFC/g)/meses), $T$ es la temperatura absoluta $(\mathrm{K}), E_{\mu}$ la energía de activación $(\mathrm{kJ} / \mathrm{mol}), A^{\prime}$ el factor preexponencial ((log UFC/g)/meses) y $R$ la constante general de los gases $(8,314$ $(\mathrm{J} /(\mathrm{mol} \mathrm{K}))$.

\section{Modelo logístico}

Se aplicó el modelo logístico de acuerdo a:

$\log N=A+C /(1+\exp (D-F t))$ 
donde $\log N$ es el logaritmo decimal del recuento de microorganismos (log CFU) a tiempo $t$, A el recuento logarítmico asintótico a medida que el tiempo disminuye indefinidamente (aproximadamente equivalente al logaritmo del recuento inicial de bacterias(log CFU)), $\mathrm{C}$ es el incremento del recuento logarítmico a medida que el tiempo crece indefinidamente (esto es el número de ciclos de crecimiento (log CFU)), $\mathrm{D}$ es un parámetro adimensional, $\mathrm{F}$ es el parámetro del crecimiento de la velocidad relativa a la mitad del tiempo de la fase exponencial $\left(\right.$ meses $\left.^{-1}\right)$.

La velocidad específica de crecimiento se puede calcular de acuerdo a $\mu=\frac{C F}{4}$, la duración de la fase de latencia $D F L=\frac{D-2}{F}$.

\subsubsection{Análisis estadístico}

Los datos experimentales fueron ajustados a la ecuación de Gompertz modificada y al modelo logístico mediante regresión no lineal con el programa OriginPro versión 8 (OriginLab Corporation, Northampton, MA).

El ajuste de los datos experimentales realizado por los modelos fue evaluado mediante la Suma de los Cuadrados de los Residuos (SCR) y el coeficiente de determinación ajustado $\left(R^{2}{ }_{\text {aj }}\right)$. Considerando que SCR es una medida de la diferencia entre los datos experimentales y los calculados, un bajo valor de SCR indica un buen ajuste del modelo.

\subsubsection{Reto microbiano}

Con el estudio de reto microbiano se buscó validar el estudio teórico de la etapa de pasteurización desarrollado en el Capítulo $1 \mathrm{y}$, por otro lado, estudiar el comportamiento durante el almacenamiento de la flora de Staphylococcus aureus sobreviviente al proceso de pasteurización.

\section{Diseño experimental}

\section{Proceso de elaboración de lomitos}

Las etapas del proceso de elaboración de lomitos para el estudio de reto microbiano se muestran en la Figura 3.1. 


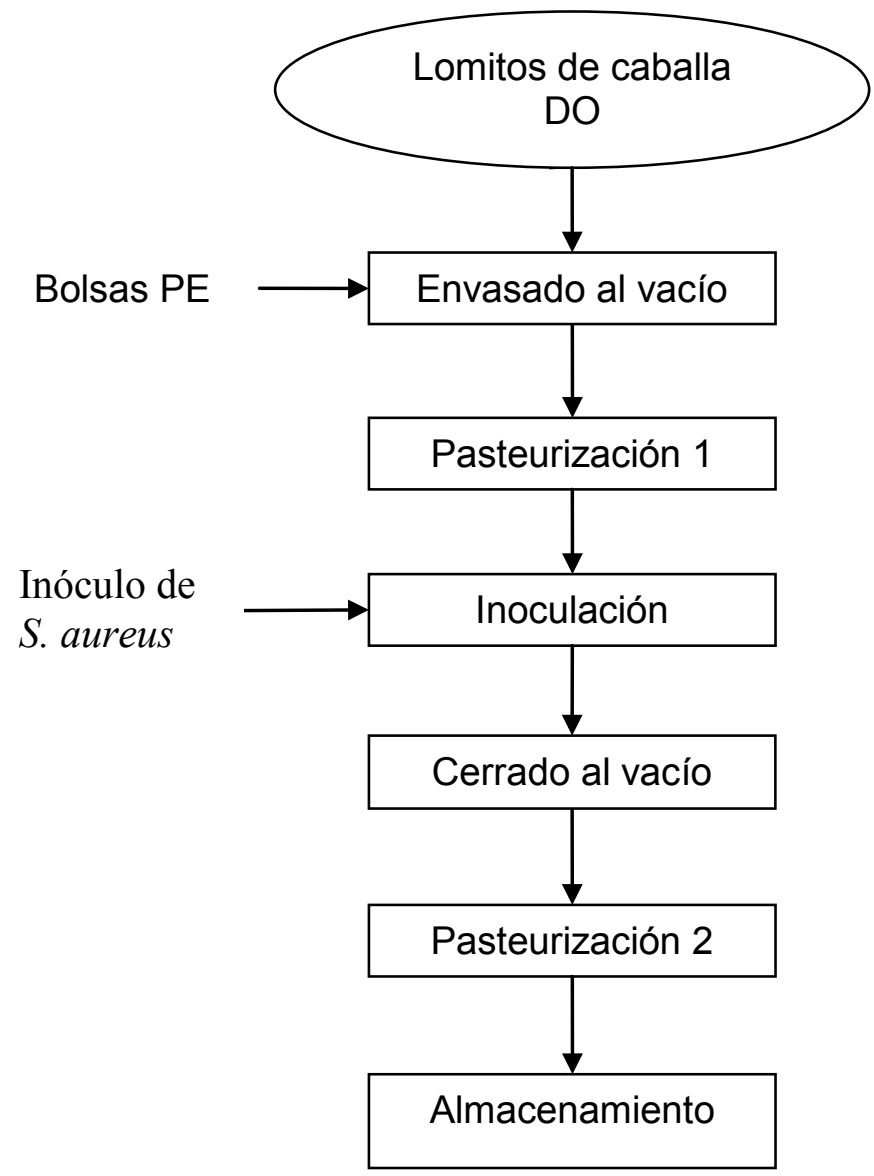

Figura 3.1 Diagrama de Flujo del proceso de elaboración de lomitos para el estudio de reto microbiano

Los lomitos fueron deshidratados osmóticamente como se describe en la Sección 1.5.4. Luego de la DO se envasaron al vacío individualmente $10 \pm 0,1 \mathrm{~g}$ de producto y se los pasteurizó en baño termostatizado a $90^{\circ} \mathrm{C}$ por $15 \mathrm{~min}$. Esta pasteurización no formó parte del proceso de elaboración de los lomitos, se realizó sólo en el estudio de reto microbiano con el fin de eliminar la flora competitiva y realizar la inoculación en una matriz estéril.

Una vez realizada dicha pasteurización se abrieron las bolsas en ambiente estéril y, con la ayuda de una micropipeta con tips plásticos descartables, se procedió a inocular las muestras. La inoculación se realizó dentro del lomito, lo más cercano posible al centro geométrico de la muestra. Un factor muy importante a tener en cuenta para mantener las características intrínsecas del producto es el hecho de minimizar el volumen del inóculo. Dado que, típicamente, el volumen del inóculo no debe ser mayor al 1\% del volumen del producto (IFT, 2003) se decidió trabajar con un volumen de 0,1 $\mathrm{ml}$. Luego, las muestras fueron cerradas al vacío nuevamente y se realizó la segunda pasteurización (a $60^{\circ} \mathrm{C}$ durante 54 minutos) de acuerdo a lo 
estudiado en el Capítulo 1. Se enfriaron las muestras en un baño de agua a $18^{\circ} \mathrm{C}$ durante 30 minutos, se secaron con papel absorbente y se almacenaron a 5, 25 y $35^{\circ} \mathrm{C}$

$\underline{\text { Muestreo }}$

Se tomaron muestras previo al inoculado, luego del inoculado, luego de la etapa de pasteurización a $60^{\circ} \mathrm{C}$ y durante el almacenamiento. Las muestras inoculadas y pasteurizadas fueron almacenadas a tres temperaturas distintas: 5, 25 y $35^{\circ} \mathrm{C}$ y los tiempos de muestreo fueron: $0,3,10,17,24$ y 31 días y 2, 4, 6, 9 y 12 meses.

\section{Microorganismo objetivo}

Para identificar el microorganismo patógeno objetivo de la experiencia se tuvieron en cuenta las características fisicoquímicas de la preserva. La principal barrera que presenta el producto es su $a_{w}$ reducida $(0,89 \pm 0,01)$. Otro factor importante a tener en cuenta es el $\mathrm{pH}$, cuyo valor es de 5,11 $\pm 0,06$. Dentro de esta combinación de $\mathrm{a}_{\mathrm{w}}$ y $\mathrm{pH}$ el único patógeno que podría crecer es el Staphylococcus aureus (IFT, 2003; NACMCF, 2010).

\section{Preparación del inóculo}

La cepa de Staphylococcus aureus utilizada en este estudio fue aislada en el laboratorio del Grupo de Investigación en Preservación y Calidad de Alimentos a partir de un ejemplar de salmón de mar (Pseudopercis semifasciata). La cepa fue aislada sembrando en medio Baird Parker (en superficie) incubando a $35 \pm 0,5^{\circ} \mathrm{C}$ durante 48 horas (ICMSF, 1983; Tapia, 2003). Las colonias típicas de S. aureus fueron removidas de las placas y sometidas a una serie de pruebas bioquímicas incluyendo la siembra en agar manitol salado y los test de producción de dnasa y coagulasa (ICMSF, 1983).

Las colonias que presentaron las características típicas de $S$. aureus (dieron positivo a las pruebas mencionadas anteriormente) fueron mantenidas en Agar Nutritivo Semisólido a $4 \pm 1^{\circ} \mathrm{C}$. Para preparar el inóculo para el estudio de reto microbiano la cepa fue repicada en $5 \mathrm{ml}$ de caldo infusión cerebro corazón y mantenida a $35^{\circ} \mathrm{C}$ durante $24 \mathrm{~h}$ (Vora y col., 2003). Luego de la incubación, una alícuota de $1 \mathrm{ml}$ del cultivo fue transferida a $9 \mathrm{ml}$ de solución fisiológica dentro de un tubo estéril. 
Posteriormente se realizaron diluciones sucesivas $\left(10^{-1}-10^{-9}\right)$ y se mantuvieron a $4 \pm$ $1^{\circ} \mathrm{C}$. El número de células de $S$. aureus por mililitro de las suspensiones obtenidas fue estimado mediante recuento en placa (agar Baird Parker). Finalmente, se utilizó la suspensión con una concentración final de $10^{9} \mathrm{UFC} / \mathrm{ml}$.

Nivel del inóculo

Para realizar estudios de inactivación, se suele utilizar altos niveles de microorganismos, entre 6 y 7 log UFC/g (IFT, 2003; NACMCF, 2010). En este caso el nivel del inóculo utilizado fue de 9 log UFC/ml. Al inocular $0,1 \mathrm{ml}$ de esta suspensión en $10 \mathrm{~g}$ de muestra se obtuvo una concentración de 7 log UFC/g con el propósito de documentar altos niveles de inactivación. Además, se buscó contar con microorganismos sobrevivientes a la pasteurización para realizar el estudio de crecimiento durante el almacenamiento.

\subsection{Resultados y discusión}

\subsubsection{Análisis fisicoquímicos}

Se investigó la composición química proximal de los lomitos crudos y de la preserva (Tabla 3.1). Además, en la misma tabla se detalla el contenido de sal, glicerol y ácido cítrico de la preserva (el porcentaje de sal forma parte del contenido de cenizas).

Tabla 3.1 Composición química proximal (\% en base húmeda) y contenido de glicerol, sal y ácido cítrico de los lomitos crudos y de la preserva

\begin{tabular}{cccccccc}
\hline & Humedad & Proteínas & Lípidos & Cenizas & Glicerol & NaCl & Ac. cítrico \\
\hline $\begin{array}{c}\text { Lomitos } \\
\text { crudos }\end{array}$ & $69,01 \pm 0,89$ & $21,99 \pm 0,41$ & $6,51 \pm 0,31$ & $1,29 \pm 0,02$ & - & - & - \\
Preserva & $51,98 \pm 0,37$ & $22,02 \pm 0,51$ & $6,02 \pm 0,85$ & $3,30 \pm 0,06$ & $16,03 \pm 0,63$ & $2,01 \pm 0,05$ & $0,17 \pm 0,02$ \\
\hline
\end{tabular}

La preserva tuvo un valor de $\mathrm{pH}$ de $5,11 \pm 0,06$ y una $\mathrm{a}_{\mathrm{w}}$ de $0,89 \pm 0,01$.

\subsubsection{Estudio de la flora nativa}

Se realizó un estudio de la flora nativa de la materia prima, durante el procesamiento y el almacenamiento de la preserva para conocer cómo el procesamiento podría modificar la carga microbiana del producto, qué 
microorganismos podrían estar involucrados y estudiar el comportamiento del producto ante la posibilidad de recontaminación. Este estudio es muy importante para conocer las características microbiológicas de la materia prima y así poder planificar adecuadamente un estudio de reto microbiano.

\section{Análisis microbiológico}

Se realizaron recuentos de bacterias psicrótrofas (BP), aerobias mesófilas (BAM), Staphylococcus spp., Clostridio sulfito-reductoras (CSR) y mohos y levaduras (M\&L) durante el procesado y durante el almacenamiento de la preserva.

En la Figura 3.2 se muestra el comportamiento de los microorganismos estudiados durante el procesado. Se analizó la materia prima cruda, se analizó también la materia prima luego de la cocción al vapor durante 20 minutos y por último se analizó la preserva a tiempo 0 (los lomitos deshidratados, envasados al vacío y pasteurizados).

No se detectó crecimiento de S. aureus ni CSR en la materia prima, ni durante el procesamiento, ni durante el almacenamiento por 12 meses a las tres temperaturas.

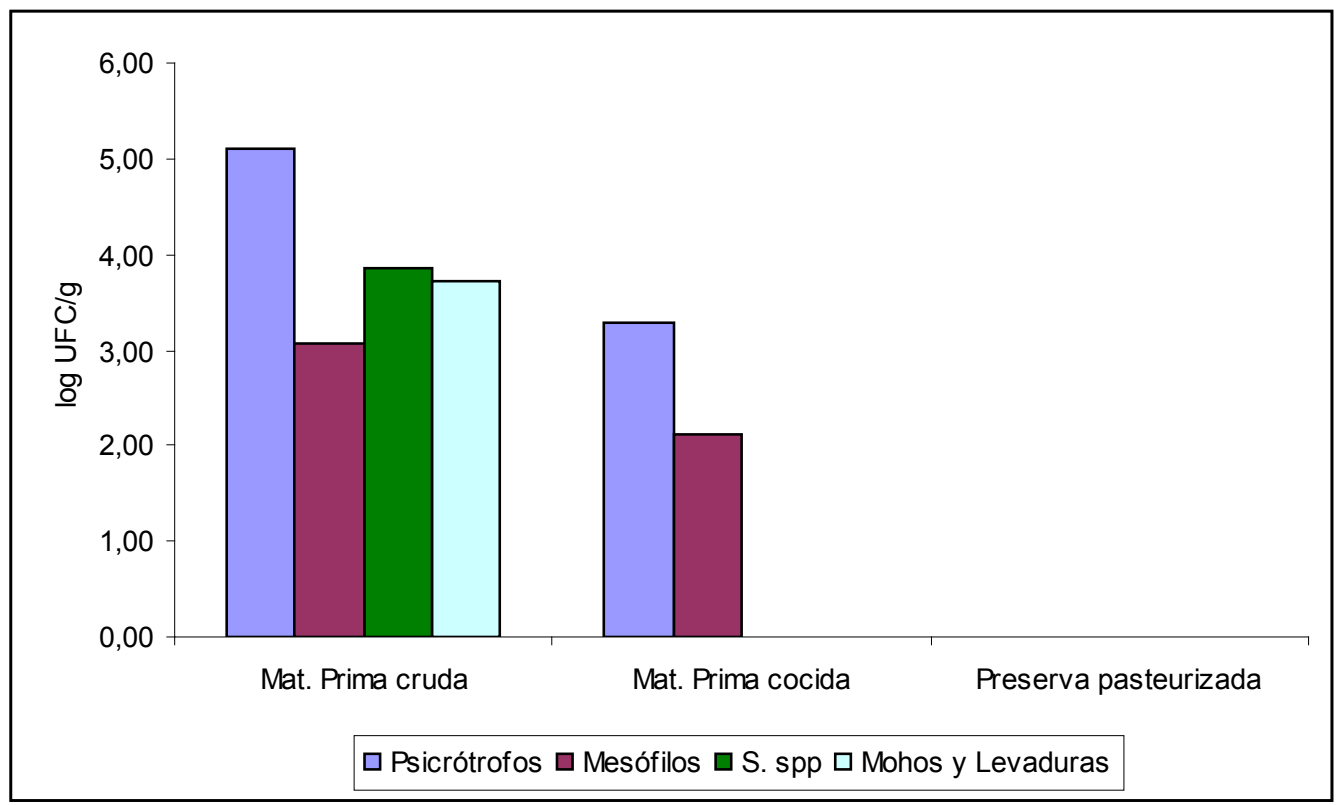

Figura 3.2 Recuento de microorganismos psicrótrofos, mesófilos, Staphylococcus spp. y mohos y levaduras durante el procesamiento de la preserva

El recuento inicial de bacterias psicrótrofas en la materia prima cruda fue de $1,3 \times 10^{5} \mathrm{UFC} / \mathrm{g}$. Luego del proceso de cocción al vapor el recuento fue de $1,9 \times 10^{3}$ 
UFC/g. Es decir que la cocción al vapor por 20 min. redujo 2 ciclos logarítmicos la población de BP.

El recuento inicial de bacterias aerobias mesófilas en la materia prima cruda fue de $1,2 \times 10^{3} \mathrm{UFC} / \mathrm{g}$. Al finalizar la cocción el recuento fue de $1,3 \times 10^{2} \mathrm{UFC} / \mathrm{g}$. La cocción al vapor redujo un ciclo logarítmico la población de BAM.

Con respecto a Staphylococcus spp. y M\&L, hubo un recuento inicial en la materia prima cruda de $7,3 \times 10^{3}$ y $5,2 \times 10^{3} \mathrm{UFC} / g$ respectivamente. Luego del proceso de cocción no se detectó desarrollo de estos microorganismos. Es decir que esta etapa redujo tres ciclos logarítmicos la población de Staphylococcus spp. y M\&L.

También se realizaron análisis microbiológicos luego de envasar al vacío los lomitos (previo a la pasteurización). La población de BP, BAM y Staphylococcus spp. fue de $1,10 \times 10^{2} ; 2,00 \times 10^{1}$ y $3,30 \times 10^{2} \mathrm{UFC} / \mathrm{g}$ respectivamente. No hubo recuentos de M\&L. Estos resultados indican que luego de la cocción de la caballa hubo una contaminación de los lomitos con Staphylococcus spp.. Estimativamente, entre el 50 y $60 \%$ de la población humana carga con cepas de Staphylococcus spp. en la piel y en las fosas nasales (Huss, 1997; Kennedy y col., 2005). Dado que los lomitos se separan manualmente luego de la cocción de la caballa, esta manipulación pudo haber sido la causa de la contaminación con Staphylococcus spp.

Por último, se analizó la preserva luego de la pasteurización y no se detectó crecimiento de BP, BAM, Staphylococcus spp. ni M\&L. La pasteurización redujo a valores no detectables la carga microbiana estudiada y durante los 12 meses que duró el almacenamiento no se registraron recuentos microbiológicos a ninguna de las tres temperaturas estudiadas.

\section{$\underline{\text { Análisis microbiológico de la preserva sin pasteurizar }}$}

Además de analizar microbiológicamente a la preserva pasteurizada, se estudió también el comportamiento de la microflora de los lomitos deshidratados y envasados al vacío pero sin el proceso de pasteurización final. El objetivo de este estudio fue analizar la importancia de la pasteurización sobre la preserva.

No se detectó crecimiento de $S$. aureus ni CSR durante el almacenamiento a las tres temperaturas.

El comportamiento de las BP, BAM y Staphylococcus spp. en los lomitos sin pasteurizar durante el almacenamiento a 5,25 y $35^{\circ} \mathrm{C}$ se muestra en la Figura 3.3. 


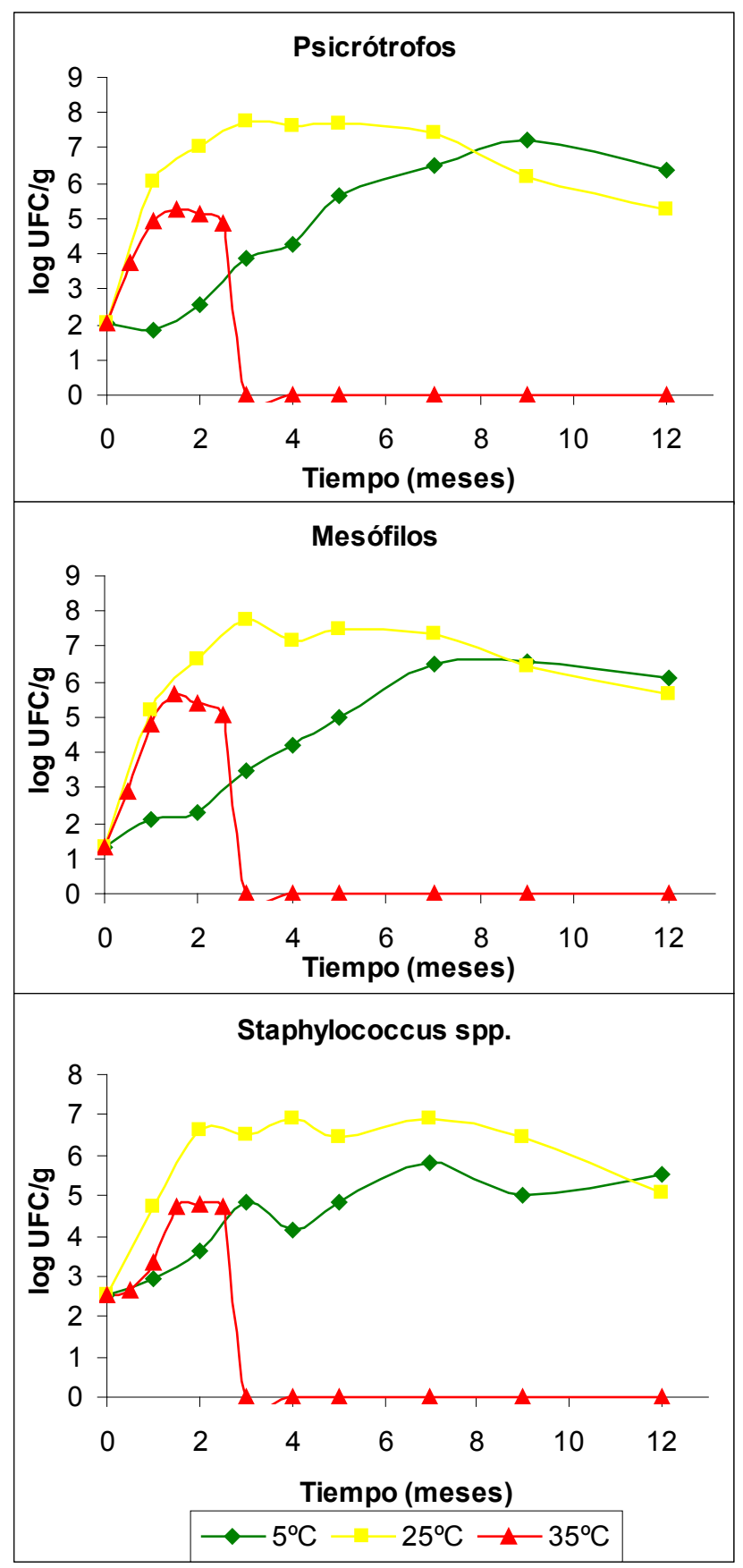

Figura 3.3 Recuento de microorganismos psicrótrofos, mesófilos y Staphylococcus spp. en la preserva sin pasteurizar durante el almacenamiento a 5,25 y $35^{\circ} \mathrm{C}$

Los recuentos iniciales fueron de $1,10 \times 10^{2} ; 2,00 \times 10^{1}$ y $3,30 \times 10^{2}$ para BP, BAM y Staphylococcus spp. respectivamente. Puede observarse en la Figura 3.3 que los tres grupos de microorganismos estudiados siguieron una tendencia similar. A $5^{\circ} \mathrm{C}$ tuvieron un incremento en los recuentos hasta el período comprendido entre los 7 y los 9 meses de almacenamiento. En el caso de las BP el recuento máximo fue de $1,71 \times 10^{7}$ UFC/g y el máximo para las BAM y Staphylococcus spp. fue de $3,56 \times 10^{6}$ y $6,43 \times 10^{5}$ respectivamente. Luego de los 9 meses, los recuentos se mantuvieron sin mayores cambios hasta el final del almacenamiento. 
A $25^{\circ} \mathrm{C}$ la velocidad de crecimiento fue mayor y se registraron recuentos máximos más altos. Los tres grupos estudiados tuvieron un rápido incremento en su población (de forma exponencial) hasta llegar a un máximo entre los 3 y 4 meses de almacenamiento. Los valores máximos registrados fueron de $6,00 \times 10^{7} ; 5,25 \times 10^{7}$ y $8,50 \times 10^{6} \mathrm{UFC} / \mathrm{g}$ para el caso de las BP, BAM y Staphylococcus spp. respectivamente. Además, se observa como, a partir del mes 7 aproximadamente, los recuentos sufren un descenso constante hasta el mes 12.

Mediante el análisis de estos resultados se pudo comprobar la importancia de la temperatura de almacenamiento ya que la refrigeración a $5^{\circ} \mathrm{C}$ logró retardar el crecimiento microbiológico con respecto al almacenamiento a $25^{\circ} \mathrm{C}$. Para alcanzar un recuento del orden de $10^{6}$ a $25^{\circ} \mathrm{C}$ requirió un tiempo de entre 1 y 2 meses para los tres grupos estudiados mientras que a $5^{\circ} \mathrm{C}$ fue necesario aproximadamente un tiempo de 7 meses.

A $35^{\circ} \mathrm{C}$ los tres grupos siguieron la misma tendencia. Se observó un rápido crecimiento hasta aproximadamente los 45 días de almacenamiento (crecimiento exponencial) con un recuento máximo de $1,81 \times 10^{5} ; 4,40 \times 10^{5}$ y $6,20 \times 10^{4} \mathrm{UFC} / \mathrm{g}$ para BP, BAM y Staphylococcus spp. respectivamente. Si bien siguen un crecimiento exponencial, los recuentos alcanzados a $35^{\circ} \mathrm{C}$ no son tan altos como a $25^{\circ} \mathrm{C}$. Luego de los 75 días se observó un marcado descenso hasta los 90 días. A partir de los 90 días no se registraron recuentos hasta el final del almacenamiento.

La preserva tuvo un valor inicial de $a_{w} y$ humedad (\%) de 0,89 $\pm 0,01$ y de 51,98 $\pm 0,37$ respectivamente. Durante el almacenamiento a 5 y $25^{\circ} \mathrm{C}$ no se observaron cambios significativos $(p>0,05)$ en los valores de $a_{w} y$ humedad de las muestras durante los 12 meses. Sin embargo, a $35^{\circ} \mathrm{C}$, a partir de los 3 meses de almacenamiento, ambos parámetros comenzaron a descender significativamente. A los 4 meses la $a_{w}$ descendió a 0,88 $\pm 0,01$ y la humedad (\%) a 46,17 $\pm 0,44$ y a los 7 meses los valores de $a_{w}$ y humedad fueron de $0,84 \pm 0,01$ y 31,85 $\pm 0,25$ respectivamente. Este marcado descenso de la $\mathrm{a}_{\mathrm{w}}$ de la preserva almacenada a $35^{\circ} \mathrm{C}$ pudo haber sido la causa por la cual no se registraron recuentos de los microorganismos estudiados a partir de los 3 meses.

Los resultados obtenidos a partir del análisis microbiológico de la preserva sin pasteurizar indican la importancia del proceso de pasteurización de la preserva. Ante un posible abuso de temperatura de almacenamiento durante cualquier etapa de la cadena productiva los recuentos podrían crecer de forma exponencial como se observa en la Figura 3.3. 


\section{Modelado matemático}

Los datos experimentales del crecimiento microbiano durante el almacenamiento de la preserva sin pasteurizar fueron ajustados a los modelos de Gompertz modificado y logístico. En la Tabla 3.2 se muestran los parámetros estadísticos del ajuste realizado.

Tabla 3.2 Coeficientes de determinación ajustado $\left(R^{2}{ }_{\text {aj }}\right)$ y suma de los cuadrados de los residuos (SCR) de los ajustes realizados mediante los modelos de Gompertz modificado y

\begin{tabular}{lccccc} 
& \multicolumn{3}{c}{ logístico } \\
& $\begin{array}{c}\text { Temperatura } \\
\left({ }^{\circ} \mathbf{C}\right)\end{array}$ & $\mathbf{R}^{2}{ }^{2}$ & $\mathbf{S C R}$ & $\mathbf{R}^{2}{ }^{2}$ & Logístico \\
\cline { 2 - 6 } Mesófilos & $\mathbf{5}$ & 0,97 & 0,703 & 0,98 & 0,510 \\
& $\mathbf{2 5}$ & 0,98 & 0,402 & 0,97 & 0,654 \\
& $\mathbf{3 5}$ & 0,97 & 0,224 & 0,97 & 0,243 \\
Psicrótrofos & $\mathbf{5}$ & 0,97 & 0,842 & 0,96 & 0,932 \\
& $\mathbf{2 5}$ & 0,98 & 0,258 & 0,98 & 0,367 \\
Staphylococcus & $\mathbf{3 5}$ & 0,98 & 0,085 & 0,98 & 0,094 \\
spp. & $\mathbf{5}$ & 0,86 & 1,106 & 0,84 & 1,258 \\
& $\mathbf{2 5}$ & 0,98 & 0,199 & 0,98 & 0,202 \\
& $\mathbf{3 5}$ & 0,99 & 0,027 & 0,99 & 0,009 \\
\hline
\end{tabular}

Ambos modelos ajustaron satisfactoriamente los datos experimentales del crecimiento de los tres microorganismos estudiados dado que presentaron altos valores de $R_{\text {aj }}^{2}$ y bajos valores de SCR. Distintos autores han informado de la bondad de ajuste de los datos experimentales de crecimiento microbiano en distintos alimentos utilizando el modelo de Gompertz modificado y logístico (Galati y col., 2011; Gianuzzi y col., 1998; Huang, 2010; Tomac y col., 2013).

Debido a que los parámetros estadísticos de ambos modelos fueron muy similares, en la Figura 3.4 sólo se muestra el ajuste realizado mediante el modelo de Gompertz. Los datos experimentales están representados por puntos y el ajuste mediante una línea negra. Se puede ver que los datos presentan un patrón sigmoidal. 


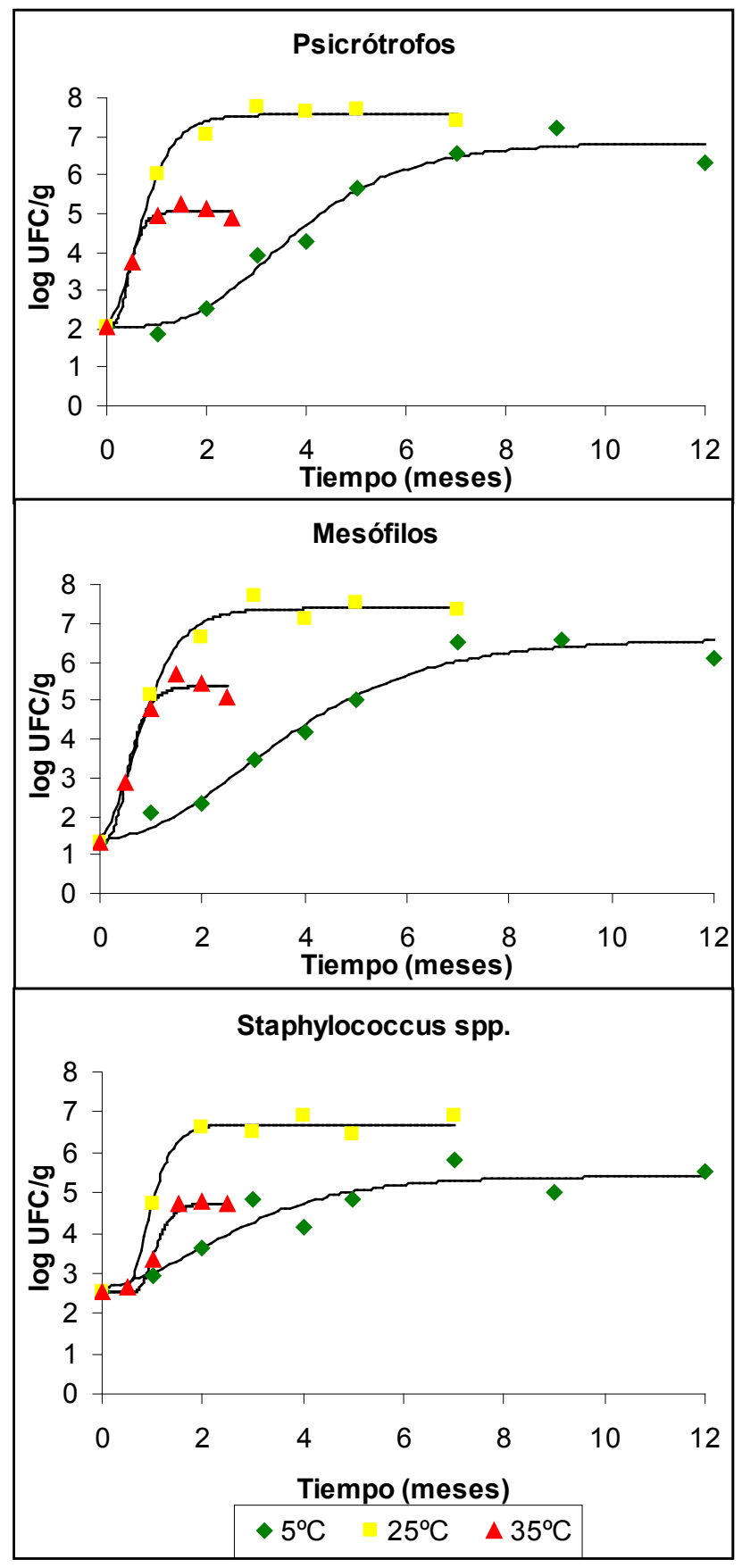

Figura 3.4 Ajuste del modelo de Gompertz a los recuentos de microorganismos psicrótrofos, mesófilos y Staphylococcus spp. en la preserva sin pasteurizar durante el almacenamiento a 5 , 25 y $35^{\circ} \mathrm{C}$

Los valores obtenidos de la velocidad específica de crecimiento $(u)$, de la duración de la fase de latencia (DFL) y de la máxima densidad de población (MDP) a partir de los parámetros del modelo de Gompertz modificado se muestran en la Tabla 3.3. 
Tabla 3.3 Valores de los parámetros $u$ ((log CFU/g)/meses), DFL (meses), MDP (log UFC/g)

\begin{tabular}{lcccc}
\multicolumn{5}{c}{ obtenidos a partir del modelo de Gompertz modificado } \\
\cline { 2 - 5 } Memp. $\left({ }^{\circ} \mathbf{C}\right)$ & $\boldsymbol{u}$ & DFL & MDP \\
\cline { 2 - 5 } Mesófilos & $\mathbf{5}$ & 1,004 & 0,883 & 6,659 \\
& $\mathbf{2 5}$ & 4,492 & 0,141 & 7,545 \\
& $\mathbf{3 5}$ & 6,071 & 0,243 & 5,372 \\
Psicrótrofos & & & & \\
& $\mathbf{5}$ & 1,172 & 1,711 & 6,838 \\
& $\mathbf{2 5}$ & 4,899 & 0,142 & 7,781 \\
Staphylococcus & $\mathbf{3 5}$ & 6,086 & 0,220 & 5,068 \\
spp. & $\mathbf{5}$ & 0,670 & 0,328 & \\
& $\mathbf{2 5}$ & 5,327 & 0,582 & 6,504 \\
& $\mathbf{3 5}$ & 7,822 & 0,892 & 4,741 \\
\hline
\end{tabular}

Los resultados obtenidos indican que la velocidad específica de crecimiento $(u)$ aumentó con el aumento de la temperatura de almacenamiento para los tres microorganismos estudiados.

El efecto de la temperatura sobre la fase de latencia del crecimiento microbiano fue evidente para los microorganismos mesófilos y psicrótrofos ya que ambos presentaron mayores valores de DFL a $5^{\circ} \mathrm{C}$. A esta temperatura les llevó mas tiempo comenzar la fase exponencial. La duración de la fase de latencia depende de una variedad de factores como la población microbiana, las condiciones del medio y el tiempo requerido para recobrarse de los daños físicos sufridos durante el procesamiento del alimento (Leistner, 2000; Tomac y col., 2013).

Con respecto a la máxima densidad de población (MDP) se observó que los microorganismos mesófilos y psicrótrofos presentaron valores mayores de MDP con respecto a Staphylococcus spp.. Además, en los tres grupos microbiológicos estudiados, se observó que la mayor densidad poblacional se desarrolló a $25^{\circ} \mathrm{C}$, seguido por $5^{\circ} \mathrm{C}$ y, por último, a $35^{\circ} \mathrm{C}$.

A $35^{\circ} \mathrm{C}$ se observó que los microorganismos de los 3 grupos estudiados crecen a mayor velocidad dado que poseen los valores más grandes de $u$ pero a su vez se encontraron los valores de densidad poblacional más bajos. Si bien la velocidad de crecimiento fue alta a una temperatura de $35^{\circ} \mathrm{C}$, no se alcanzaron recuentos tan altos como a 5 y $25^{\circ} \mathrm{C}$. Como se explicó anteriormente, la causa de este comportamiento pudo ser el descenso de la $\mathrm{a}_{\mathrm{w}}$ de la preserva almacenada $35^{\circ} \mathrm{C}$. 
Efecto de la temperatura de almacenamiento sobre la velocidad específica de crecimiento $(\mu)$

El efecto de la temperatura de almacenamiento sobre la velocidad específica de crecimiento $(\mu)$ fue estudiado mediante el modelo de Arrhenius (Ecuación 3.2).

Se graficó el In $\mu$ en función de la inversa de la temperatura absoluta (1/T) para los tres grupos microbianos estudiados (Figura 3.5). Mediante regresión lineal se obtuvo la ecuación de la recta con pendiente $-E_{\mu} / R$. Los altos coeficientes de regresión $\left(0,9654<R^{2}<0,9771\right)$ indican la bondad de ajuste del modelo aplicado.

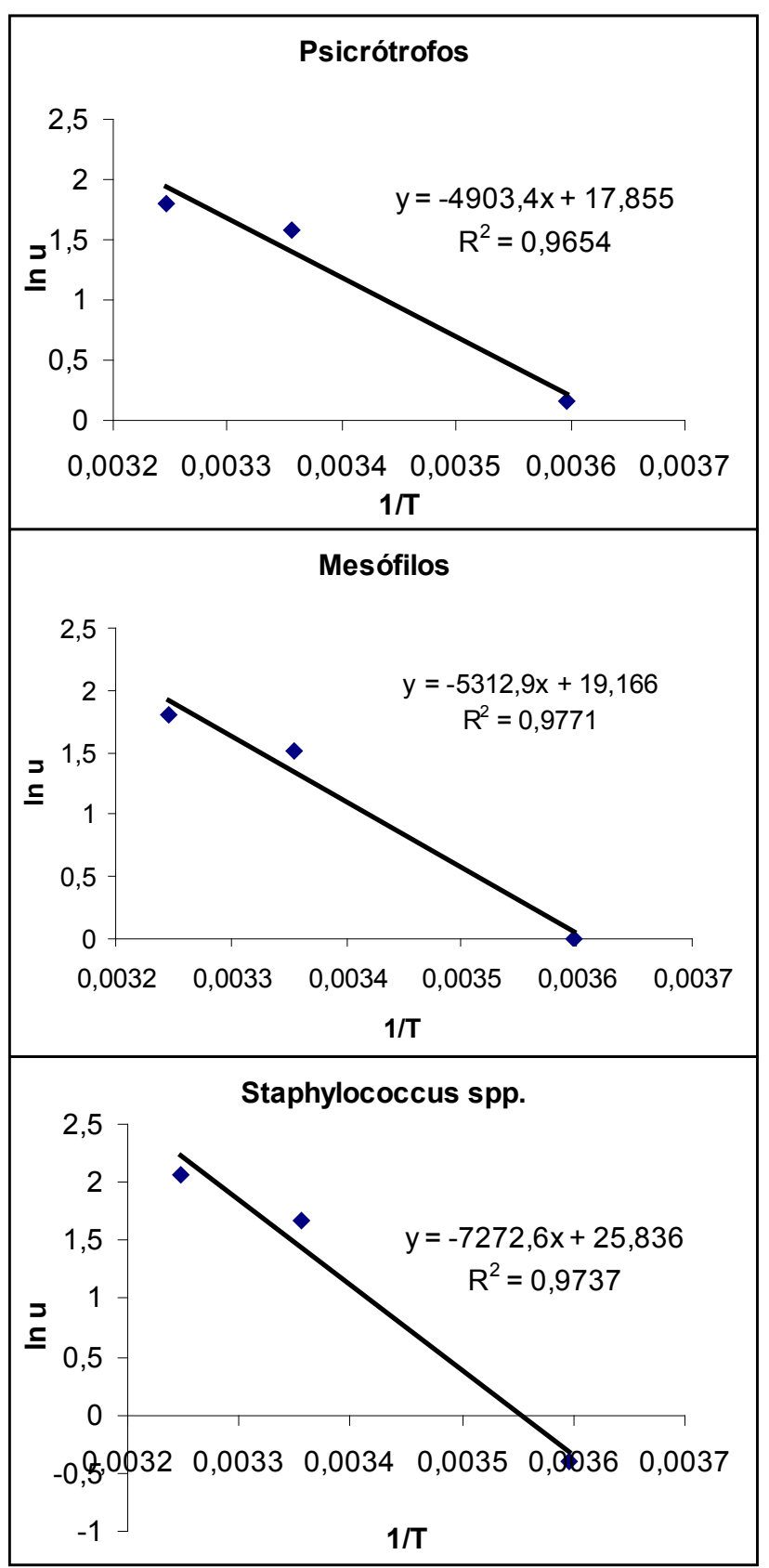

Figura 3.5 Efecto de la temperatura sobre la velocidad de crecimiento específica $(\mu)$ de microorganismos psicrótrofos, mesófilos y Staphylococcus spp. 
Los microorganismos Staphylococcus spp. presentaron el mayor valor de $\mathrm{E}_{\mu}$ $(60,46 \mathrm{~kJ} / \mathrm{mol})$, seguido por los mesófilos y por los psicrótrofos $(44,17$ y 40,77 kJ/mol respectivamente).

\subsubsection{Reto microbiano}

El potencial crecimiento de $S$. aureus en productos pasteurizados y refrigerados es muy bajo ya que es muy sensible al calor. Si se mantiene una correcta cadena de frío durante la distribución del producto este microorganismo no tiene la capacidad de crecer (FDA, 1992; Silva y Gibbs, 2010). De todas maneras, se consideró necesario realizar un estudio para comprobar el efecto de la pasteurización sobre el único microorganismo patógeno capaz de crecer en la preserva ( $S$. aureus) y, además, comprobar si la posible carga de $S$. aureus sobreviviente al proceso de pasteurización podría desarrollarse durante el almacenamiento refrigerado del producto.

Además, luego de la pasteurización, el producto fue almacenado a dos temperaturas superiores a la de refrigeración $\left(25\right.$ y $\left.35^{\circ} \mathrm{C}\right)$ con el fin de simular un posible abuso en la temperatura de almacenamiento y comprobar el posible desarrollo de S. aureus.

\section{$\underline{\text { Inactivación bacteriana }}$}

Como se explicó en la Sección 3.4.2, se prepararon muestras de $10 \mathrm{~g}$ con los lomitos deshidratados osmóticamente, se envasaron al vacío y se les dio un tratamiento térmico a fin de disminuir la flora competitiva. Luego de esta primera pasteurización se analizaron las muestras para comprobar si hubo desarrollo de $S$. aureus. Los resultados indicaron que no hubo desarrollo de $S$. aureus en las muestras previo a la inoculación.

A continuación, se inocularon las muestras en el centro geométrico de las mismas con $0,1 \mathrm{ml}$ de la suspensión, con el objetivo de contar con una carga de $S$. aureus del orden de 7 log UFC por gramo de muestra. La carga microbiana de la solución del inóculo utilizado fue de 9 log UFC/ml.

Luego de la inoculación se cerraron al vacío. En este punto se realizó un

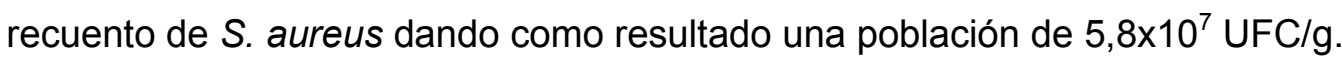


Las muestras fueron pasteurizadas a $60^{\circ} \mathrm{C}$ durante 54 min., se las enfrió en baño de agua a $18^{\circ} \mathrm{C}$ por 30 minutos y se las secó. Luego de dicho proceso se analizaron nuevamente las muestras y se obtuvo un recuento de $2,0 \times 10^{2} \mathrm{UFC} / \mathrm{g}$. Conforme con los resultados esperados, la pasteurización redujo 5 ciclos logarítmicos la población de $S$. aureus en la preserva.

De esta manera, se logró validar el proceso de pasteurización analizado de forma teórica en el Capítulo 3 dado que dicho estudio fue pensado para reducir la carga del microorganismo objetivo entre 5 y 6 log UFC/g.

\section{Comportamiento de la flora sobreviviente al pasteurizado}

Las muestras inoculadas y pasteurizadas fueron almacenadas a 5,25 y $35^{\circ} \mathrm{C}$. Los resultados del recuento de $S$. aureus durante el almacenamiento se muestran en la Figura 3.6.

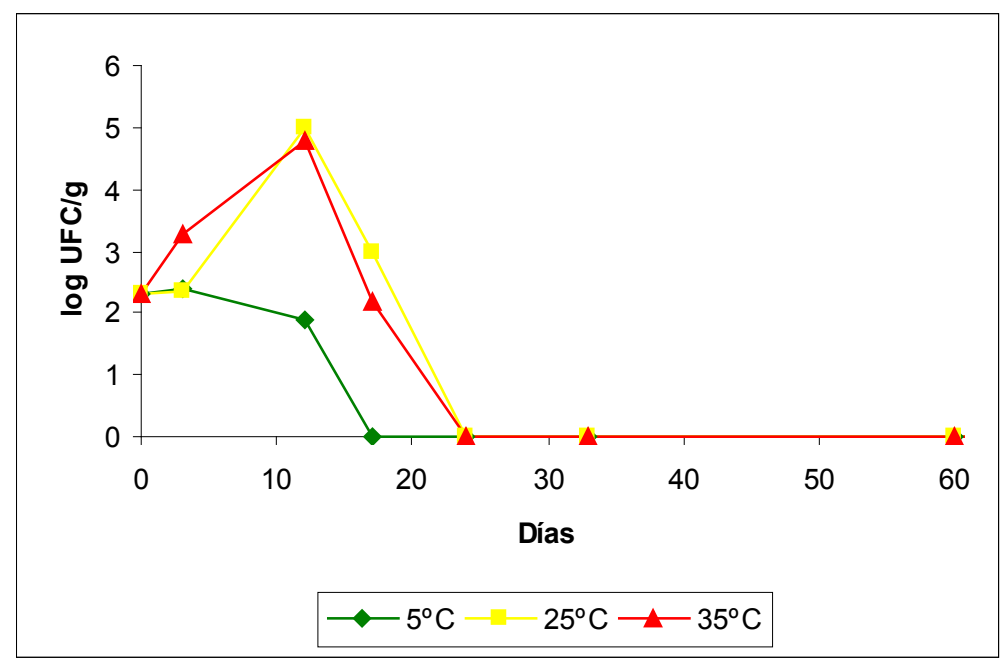

Figura 3.6 Recuento de Staphylococcus aureus en la preserva inoculada durante el almacenamiento a 5,25 y $35^{\circ} \mathrm{C}$

El estudio del comportamiento de la flora sobreviviente al proceso de pasteurización revela que la población de $S$. aureus almacenada a $5^{\circ} \mathrm{C}$ se redujo casi un ciclo logarítmico al día 12 de almacenamiento y que desde el día 17 no se detectó crecimiento hasta el final del estudio (12 meses). En la Figura 3.4 se muestra un tiempo máximo de 60 días pero el análisis duró hasta los 12 meses.

A 25 y $35^{\circ} \mathrm{C}$ hubo un comportamiento similar representado por un incremento poblacional de 2 ciclos logarítmicos a los 12 días (a $25^{\circ} \mathrm{C}$ hubo un recuento de $9,50 \times 10^{4}$ y a $35^{\circ} \mathrm{C}$ de $6,11 \times 10^{4} \mathrm{UFC} / \mathrm{g}$ ) seguido por una reducción posterior de 2 ciclos 
logarítmicos a los 17 días y desde el día 24 en adelante no se detectó desarrollo durante los 12 meses.

EI S. aureus no produce suficiente toxina como para causar enfermedad en humanos hasta que alcanza las 100.000 a 1.000 .000 UFC/g (DHHS, 2011). Es decir que, efectuando un proceso de pasteurización eficaz y manteniendo las condiciones de almacenamiento dentro de la temperatura de refrigeración, este producto no presentaría ningún problema de inocuidad. Se debe considerar además que las condiciones de esta experiencia de Reto Microbiano se realizaron en las condiciones ideales para el crecimiento del $S$. aureus (eliminando la flora competitiva) y un nivel de inóculo elevado que difícilmente pueda darse en la práctica industrial.

\subsection{Conclusiones}

La caballa cruda contó con valores de $1,3 \times 10^{5} ; 1,2 \times 10^{3} ; 7,3 \times 10^{3}$ y $5,2 \times 10^{3}$ UFC/g de bacterias psicrótrofas (BP), bacterias aerobias mesófilas (BAM), Staphylococcus spp. y mohos y levaduras (M\&L) respectivamente.

No se detectó presencia de Staphylococcus aureus ni de clostridio sulfitoreductores en la materia prima, durante el procesado o durante el almacenamiento de la preserva a las tres temperaturas $\left(5,25\right.$ y $\left.35^{\circ} \mathrm{C}\right)$.

Luego del proceso de cocción de la caballa al vapor por 20min, la población de BP se redujo en 2 ciclos logarítmicos, en un ciclo la de BAM y no se detectó presencia de Staphylococcus spp. ni M\&L.

Las barreras utilizadas durante la elaboración de la preserva (cocción al vapor de la materia prima, deshidratación osmótica, envasado al vacío y pasteurización) le dieron una excelente estabilidad microbiológica dado que no se detectó presencia de ninguno de los grupos de microorganismos que se estudiaron durante 12 meses. Dado que este comportamiento se observó a las 3 temperaturas, se puede afirmar que la temperatura de almacenamiento no es relevante en el aspecto microbiológico del producto. Si se trabaja bajo estrictas normas de calidad, cumpliendo por ejemplo con las directrices de un plan HACCP, la preserva podría ser almacenada a temperatura ambiente. Por lo tanto, la vida útil de los lomitos de humedad intermedia pasteurizados estaría dada por aspectos sensoriales o fisicoquímicos más que microbiológicos. La vida útil sensorial se estudia en el Capítulo 4.

Se analizó el comportamiento microbiológico de la preserva sin pasteurizar. Se logró modelar satisfactoriamente el crecimiento de BP, BAM y Staphylococcus spp. mediante los modelos de Gompertz modificado y logístico. Los resultados obtenidos a 
partir del análisis microbiológico de la preserva sin pasteurizar indican la necesidad del proceso de pasteurización de la preserva.

De acuerdo a los resultados del estudio de reto microbiano, la etapa de la pasteurización redujo 5 ciclos logarítmicos la población de Staphylococcus aureus inoculada. Esta fue la reducción buscada en el cálculo teórico del tiempo de pasteurización (Capítulo 1). De esta manera, se logró validar exitosamente el proceso de pasteurización.

Como se inoculó un número alto de microorganismos (del orden de 7 log UFC/g) durante el estudio de reto microbiano, al finalizar la pasteurización se obtuvo un recuento de $2,0 \times 10^{2} \mathrm{UFC} / \mathrm{g}$. Se analizó el comportamiento de esta población determinando que las barreras aplicadas fueron efectivas para evitar el crecimiento de S. aureus durante el almacenamiento refrigerado. 


\section{CAPITULO 4:}

Vida útil de la preserva

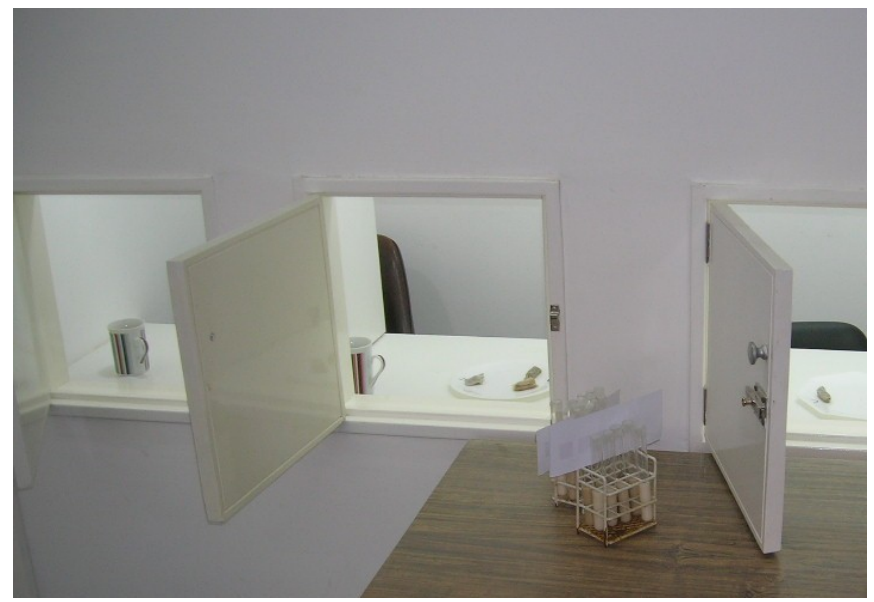




\subsection{Resumen}

El propósito de este capítulo fue estimar la vida útil de la preserva almacenada en refrigeración $\left(5^{\circ} \mathrm{C}\right)$. Se realizó un estudio de vida útil sensorial acelerado utilizando tres temperaturas de almacenamiento: 15,25 y $35^{\circ} \mathrm{C}$. Los atributos sensoriales color amarillo-rojizo y aroma rancio fueron empleados como indicadores de deterioro.

Durante el almacenamiento a las tres temperaturas estudiadas se realizaron muestreos a diferentes tiempos realizándose análisis sensoriales (evaluación de aroma rancio y color amarillo-rojizo) y fisicoquímicos $\left(a_{w}\right.$, humedad, TBA, color instrumental y perfil de ácidos grasos). La evaluación sensorial se realizó mediante un panel de 10 evaluadores entrenados.

El tiempo de vida útil a 15,25 y $35^{\circ} \mathrm{C}$ se determinó cuando el valor de los indicadores críticos de deterioro llegó a valores inaceptables sensorialmente. A partir de los resultados obtenidos se definió la cinética de la reacción de deterioro y se obtuvo la $\mathrm{E}_{\mathrm{a}}$ utilizando el modelo de Arrhenius.

Finalmente, se halló una relación para estimar la vida útil de la preserva a distintas temperaturas. A partir de esta relación se extrapolaron los resultados a temperatura de refrigeración.

\subsection{Introducción}

Los alimentos son sistemas fisicoquímicos y biológicos activos, por lo que la calidad de los mismos es un estado dinámico que paulatinamente va reduciendo sus niveles con el paso del tiempo. Existe un tiempo determinado, después de haber sido producido, en que el producto mantiene un nivel requerido de sus propiedades sensoriales y de inocuidad, bajo ciertas condiciones de almacenamiento. La vida útil de un alimento representa aquel período de tiempo durante el cual el alimento se conserva apto para el consumo desde el punto de vista sanitario, manteniendo las características sensoriales, funcionales y nutricionales por encima de los límites de calidad previamente establecidos como aceptables (Hough y Wittig, 2005).

Durante los últimos años, los desarrollos tecnológicos así como nuevos materiales de empaque han servido para el desarrollo de las modernas técnicas de preservación de alimentos que puedan satisfacer la creciente demanda por parte de los consumidores de alimentos seguros, durables y con altos estándares sensoriales y nutritivos (Walking-Ribeiro y col., 2009). Estas tecnologías requieren estudios de estabilidad para asegurar que los alimentos sean inocuos y posean una aceptable 
calidad al momento del consumo. En este contexto, la estimación de la vida útil de los productos alimenticios ha ganado importancia en los últimos años (Giménez y col., 2012).

La vida útil de un producto depende de factores ambientales, de la humedad, de la temperatura de exposición, del proceso térmico al que se somete y de la calidad de las materias primas, entre otros. El efecto de estos factores se manifiesta como el cambio en las cualidades del alimento que repercuten sobre el consumidor: cambios de sabor, apariencia, textura o pérdida de nutrientes (García y col., 2011).

Para determinar la vida útil de un alimento primero deben identificarse las reacciones químicas o biológicas que influyen en la calidad y/o seguridad del mismo, considerando la composición del alimento y el proceso a que es sometido. El tiempo de vida útil se puede estimar mediante distintos métodos. Pueden tomarse valores reportados en la literatura especializada de alimentos similares y bajo condiciones similares al producto de nuestro interés; se pueden monitorear las quejas de los consumidores para orientar los posibles valores de vida útil o se pueden evaluar atributos de calidad del alimento que varían durante la vida útil (a tiempo real o mediante pruebas aceleradas) (García y Molina, 2008). Para los estudios acelerados se debe planear cuidadosamente el diseño experimental que contemple las variables por evaluar y controlar las variables que no se desean evaluar para evitar que interfieran en las mediciones, y por ende, en los resultados (Labuza y Schmidt, 1985).

En los productos de larga vida útil tales como productos esterilizados o congelados, la determinación de la vida útil a tiempo real llevaría años, lo cual no es práctico. En estos casos se aplican modelos predictivos para estimar la vida útil en un periodo de tiempo menor al real, mediante estudios de envejecimiento acelerado. Para acelerar la vida útil de los alimentos, y obtener así en menor tiempo datos sobre su cinética de deterioro, es necesario almacenar el producto a varias temperaturas superiores a la normalmente utilizada y hacer un seguimiento de la evolución de los parámetros de calidad del producto a cada una de esas temperaturas. A partir de los datos obtenidos, se puede predecir la vida útil a la temperatura real de conservación del producto (AZTI/DAPA, 2008; Pedro y Ferreira, 2006).

Una metodología muy utilizada ha sido la medición de la intensidad de algún atributo sensorial a través del almacenamiento, estimando la vida útil como el tiempo en que la intensidad del atributo crítico seleccionado alcanza un valor predeterminado (Giménez y col., 2012). En este método, un grupo de panelistas entrenados generan una respuesta numérica (utilizando una escala) que refleja la percepción de la intensidad del atributo sensorial generada al evaluar el producto. Esta metodología ha sido utilizada para estimar la vida útil de diferentes alimentos. Natress y col. (2004), 
estimaron la influencia de la pasta de avellanas sobre la vida útil de chocolate amargo. A lo largo del almacenamiento, se les pidió a un grupo de 10 panelistas entrenados que evalúen la intensidad del sabor rancio utilizando una escala no estructurada de $15 \mathrm{~cm}$. Nielsen y col. (1997), le pidieron a entre 9 y 12 panelistas entrenados que evalúen la intensidad del sabor oxidado utilizando una escala estructurada de 16 puntos para evaluar la vida útil sensorial de leche en polvo. Los valores mayores a 10 fueron considerados como aceptables, mientras que los valores menores a 10 se consideraron como muestras defectuosas. Otro ejemplo de estimación de la vida útil sensorial midiendo la intensidad de los atributos fue reportado por Piagentini y col. (2005), donde se evaluaron aspectos como el aroma y la apariencia general de cortes de lechuga fresca utilizando escalas de $15 \mathrm{~cm}$ no estructuradas. Estos autores consideraron el límite de aceptabilidad un valor de 7,5 puntos.

En el Capítulo 3 se determinó que las barreras utilizadas en la elaboración de la preserva de caballa le otorgaron estabilidad microbiológica por lo que este producto podría sufrir deterioro fisicoquímico y/o sensorial. Según OTA (1979), en los productos de humedad intermedia en los que se reduce la $a_{w}$ por agregado de humectantes, azúcares y/o sal y se combina este efecto con la disminución de $\mathrm{pH}$, agregado de agentes antimicóticos, tratamiento térmico moderado, vacío y/o refrigeración, el deterioro suele ser químico, no microbiológico.

\subsection{Objetivos}

Analizar sensorial y fisicoquímicamente la preserva almacenada a 15, 25 y $35^{\circ} \mathrm{C}$.

$>$ Estudiar el comportamiento de los factores de deterioro durante los estudios de vida útil a tiempo acelerado y analizar su cinética de reacción.

$>$ Estimar la vida útil a temperatura de refrigeración (temperatura real de conservación) a partir del estudio a tiempo acelerado.

\subsection{Materiales y métodos}

\subsubsection{Materia Prima}

Se utilizó caballa (Scomber japonicus) capturada en el mes de octubre de 2012 en las costas de la provincia de Buenos Aires y mantenida a bordo con hielo. Luego de 
su arribo al puerto de la ciudad de Mar del Plata, la materia prima fue transportada en cajones con hielo para su posterior lavado, envasado y congelado en la planta procesadora MIA S.A. La etapa de congelado se realizó en un túnel de congelación a $38 \pm 4^{\circ} \mathrm{C}$ y se almacenó en freezer a $-18 \pm 2^{\circ} \mathrm{C}$ hasta su utilización. Para los ensayos de vida útil se utilizaron aproximadamente 50 piezas de $42 \pm 3 \mathrm{~cm}$ de largo con un peso de $0,61 \pm 0,11 \mathrm{~kg}$.

\subsubsection{Proceso de elaboración}

El proceso de elaboración de los lomitos se explicó en la Sección 1.5.4.

\subsubsection{Análisis fisicoquímicos}

Se determinó la composición química proximal de la materia prima (agua, lípidos, proteínas y cenizas) y contenido de sal, glicerol y ácido cítrico. Además, se analizó $\mathrm{pH}, \mathrm{a}_{\mathrm{w}}$, humedad y color instrumental de las muestras durante el almacenamiento . Estas técnicas se describen en la Sección 1.4.2.

A continuación se detallan las técnicas utilizadas exclusivamente durante el estudio de vida útil (TBARS y perfil de ácidos grasos).

Determinación de la oxidación de lípidos. Sustancias reactivas al ácido 2Tiobarbitúrico (TBARS).

Teniendo en cuenta que los lípidos de las especies pesqueras se caracterizan por presentar una gran cantidad de ácidos grasos insaturados que los hacen muy susceptibles a la oxidación (Huss, 1995), se consideró importante efectuar la determinación química del grado de oxidación de los lomitos durante su almacenamiento.

Los productos primarios de la oxidación lipídica son hidroperóxidos que pueden ser determinados mediante la técnica del índice de peróxidos. Estos hidroperóxidos son inestables y se descomponen generando ácidos grasos e hidrocarburos de cadena corta como aldehídos, cetonas, entre otros, que participan en la formación de "off odors" relacionados con la rancidez. Precisamente una de las metodologías mas utilizada para determinar el grado de oxidación en productos pesqueros es la determinación de las sustancias reactivas al ácido 2-tiobarbitúrico (TBA-RS) (Czerner 
y Yeannes, 2010). A partir de esta reacción entre los productos aldehídicos secundarios provenientes de la oxidación de los ácidos grasos insaturados y el ácido 2-tiobarbitúrico (TBA) se obtienen compuestos coloreados que son analizados por espectrofotometría. La medición del TBA-RS se realiza a una longitud de onda de 532 $\mathrm{nm}$, utilizando el malonaldehído (MDA) como estándar para su cuantificación (Fernández y col., 1997).

Se realizó la extracción de acuerdo a Tironi y col. (2007). Dos gramos de muestra fueron homogeneizados con $16 \mathrm{ml}$ de ácido tricloroacético (TCA) al 5\% p/v. Luego $2 \mathrm{ml}$ de TBA al $0.5 \% \mathrm{p} / \mathrm{v}$ fueron agregados a $2 \mathrm{ml}$ del filtrado e incubados a 70 ${ }^{\circ} \mathrm{C}$ durante 30 minutos (Botsoglou y col., 1994). La absorbancia se midió en un espectrofotómetro (Shimadzu® UV-1601 PC, Kyoto, Japón) a una longitud de onda de $532 \mathrm{~nm}$. Para cuantificar MDA, el número de TBA-RS ${ }_{532}$ se expresó como mg de MDA por $\mathrm{kg}$ de muestra húmeda. Las extracciones fueron realizadas por duplicado y las incubaciones con TBA por duplicado de cada duplicado. El número de TBA-RS se determinó de acuerdo a la siguiente ecuación.

$$
m g M D A / K g=\frac{(A b s-B) * M * V f * V e * 1000}{\varepsilon * l * V a * m}
$$

siendo Abs la absorbancia medida a $532 \mathrm{~nm}, B$ la absorbancia del blanco ( $2 \mathrm{~mL}$ TCA + $2 \mathrm{ml}$ TBA), $M$ el peso molecular $\left(\mathrm{g} \mathrm{mol}^{-1}\right)$ del MDA, $V_{f}(\mathrm{ml})$ el volumen final de la reacción $\left(V_{a}+V_{T B A}\right), V_{e}(\mathrm{ml})$ el volumen del extracto $(16 \mathrm{ml}), V a$ el volumen de la alícuota $(2 \mathrm{ml}), \varepsilon$ el coeficiente de absortividad molar $\left(\mathrm{L} \mathrm{mol}^{-1} \mathrm{~cm}^{-1}\right)$ y $l$ el camino óptico $(1 \mathrm{~cm})$.

\section{Perfil de ácidos grasos}

Se estudió el comportamiento de los ácidos grasos de las muestras con el objetivo de analizar los posibles cambios generados durante el almacenamiento.

El perfil de ácidos grasos de los lomitos fue determinado mediante cromatografía gaseosa, luego de la metilación de los mismos. Para la separación y cuantificación de los metil esteres de ácidos grasos se utilizó un cromatógrafo gaseoso (Shimadzu® GC-17A, Japón) equipado con una columna capilar de sílica fundida (Omegawax 320, Supelco Inc., Bellefonte, PA, USA) (30 m x 0.32 mm ID, $0.25 \mu \mathrm{m}$ fase de film) y un detector por ionización de llama. El volumen inyectado fue $1 \mu \mathrm{l}$ y se hizo por duplicado. El gas portador fue nitrógeno. La temperatura del puerto inyector y del detector se mantuvo a $250{ }^{\circ} \mathrm{C}$. La temperatura del horno de la columna se incrementó 
desde 150 a $225{ }^{\circ} \mathrm{C}$, a una velocidad de $1,5{ }^{\circ} \mathrm{C} \mathrm{min}^{-1}$. Los ácidos grasos se identificaron por comparación de su tiempo de retención y las áreas de los picos utilizando como referencia un estándar (PUFA-1, Marine Source Supelco®, Cat. No. 47033). Los ácidos grasos fueron cuantificados como la relación de porcentaje del área de cada pico con respecto al área total.

\subsubsection{Diseño experimental}

Un estudio de vida útil consiste en realizar una serie de controles preestablecidos en el tiempo, de acuerdo con una frecuencia establecida, hasta alcanzar el deterioro elegido como limitante o hasta alcanzar los límites prefijados (Gámbaro, 2005). Para poder efectuar satisfactoriamente esta serie de controles, se debe aplicar un correcto diseño experimental. A continuación se detalla el diseño aplicado para la determinación de la vida útil.

\section{Selección de las condiciones del ensayo}

Debido a que se decidió realizar un estudio acelerado, se trabajó con tres temperaturas de almacenamiento. Según Labuza y Schmidt (1985), para realizar un estudio de vida útil acelerado se debe trabajar mínimamente con tres temperaturas. Las temperaturas seleccionadas fueron: 15,25 y $35^{\circ} \mathrm{C}$.

Determinación del tiempo máximo de muestreo y selección de los tiempos de muestreo.

En base a estudios previos se estimaron los tiempos máximos de muestreo para cada temperatura. Siendo los mismos de un mes, 2 meses y 6 meses para 35, 25 y $15^{\circ} \mathrm{C}$ respectivamente. Para temperaturas altas el tiempo es menor debido a que el enranciamiento se ve favorecido y se acorta la vida útil. Se trabajó con un total de 8 tiempos de muestreo para cada temperatura estudiada.

Definición de las condiciones de almacenamiento del control

Se almacenó la muestra control a una temperatura de $5^{\circ} \mathrm{C}$ para mantener las cualidades fisicoquímicas y sensoriales durante el tiempo del ensayo de vida útil acelerado. 


\section{Muestreo}

Se aplicó un diseño básico. Se elaboró un solo lote, se lo dividió en tres y se almacenó a 15,25 y $35^{\circ} \mathrm{C}$. Los tiempos de muestreo se muestran en la Tabla 4.1.

Para cada tiempo de muestreo se realizaron los análisis fisicoquímicos $\left(a_{w}\right.$, humedad, TBARS y color instrumental) y sensoriales (evaluación de olor a rancio y color). Además, se analizó el perfíl de ácidos grasos a las muestras almacenadas a $35^{\circ} \mathrm{C}$.

Tabla 4.1 Muestreo para el estudio de vida útil acelerado

\begin{tabular}{cccccccccc}
\hline Temperatura & \multicolumn{10}{c}{ Muestreo (días) } \\
\hline $\mathbf{1 5}^{\circ} \mathbf{C}$ & 0 & 12 & 25 & 36 & 53 & 85 & 116 & 146 & 175 \\
$\mathbf{2 5}^{\circ} \mathbf{C}$ & 0 & 8 & 15 & 21 & 27 & 35 & 43 & 53 & 63 \\
$\mathbf{3 5}^{\circ} \mathbf{C}$ & 0 & 5 & 11 & 14 & 17 & 19 & 21 & 23 & 25 \\
\hline
\end{tabular}

\section{Lugar de los ensayos}

La evaluación sensorial se realizó en las instalaciones del Grupo de Investigación en Preservación y Calidad de Alimentos perteneciente al Departamento de Ingeniería Química y de Alimentos de la Facultad de Ingeniería, Universidad Nacional de Mar del Plata. El grupo cuenta con cabinas especialmente diseñadas para realizar evaluaciones sensoriales y mesadas para trabajos en grupo.

\subsubsection{Análisis sensorial}

Se realizó el estudio de vida útil sensorial mediante un panel de 10 evaluadores con experiencia previa en productos pesqueros. Se trabajó con los evaluadores seleccionados para la realización del perfil sensorial de los lomitos (el proceso de selección se explica en detalle en la Sección 1.4.4).

Un panel de consumidores es la herramienta más apropiada para determinar cuándo un alimento llega al fin de su vida útil. Sin embargo, un ensayo realizado con consumidores en múltiples sesiones, necesarias para un estudio de vida útil, es demasiado costoso y poco práctico. Un panel de evaluadores entrenados es mucho más simple de convocar (Curia y col., 2005).

En esta tesis se realizó un estudio con consumidores para determinar el punto final sensorial y luego se trabajó con el panel entrenado.

Con el fin de describir los cambios sensoriales producidos durante el almacenamiento, los panelistas evaluaron 5 muestras almacenadas durante $0,7,11$, 
19 y 25 días a $35^{\circ} \mathrm{C}$. En una sesión posterior, los evaluadores y el líder del panel consensuaron los descriptores críticos que mejor representaran el enranciamiento de las muestras. Los descriptores seleccionados fueron: aroma a rancio y color amarillorojizo (color característico del producto enranciado).

Una vez que se seleccionaron los descriptores, se entrenó a los panelistas analizando muestras almacenadas a $35^{\circ} \mathrm{C}$ durante distintos tiempos utilizando escalas estructuradas de $10 \mathrm{~cm}$. Se decidió utilizar para el entrenamiento dos anclajes sobre las escalas, el valor 0 se le asignó a la muestra a tiempo 0 de almacenamiento y el valor 7 a la muestra almacenada a $35^{\circ} \mathrm{C}$ durante 21 días.

Para la evaluación sensorial del color se presentaron las muestras en el envase original en que se almacenó la preserva. En cambio, para el análisis del aroma se presentaron muestras de lomitos de aproximadamente $15 \mathrm{~g}$ dentro de un envoltorio de papel de aluminio de fácil apertura. En ambos casos las muestras se presentaron a temperatura ambiente $\left(18 \pm 2^{\circ} \mathrm{C}\right)$, se etiquetaron con un código aleatorio de tres dígitos y se solicitó a los panelistas que evaluaran de a una muestra por vez. Las evaluaciones fueron realizadas en cabinas individuales y en cada sesión se evaluaron no más de 4 muestras.

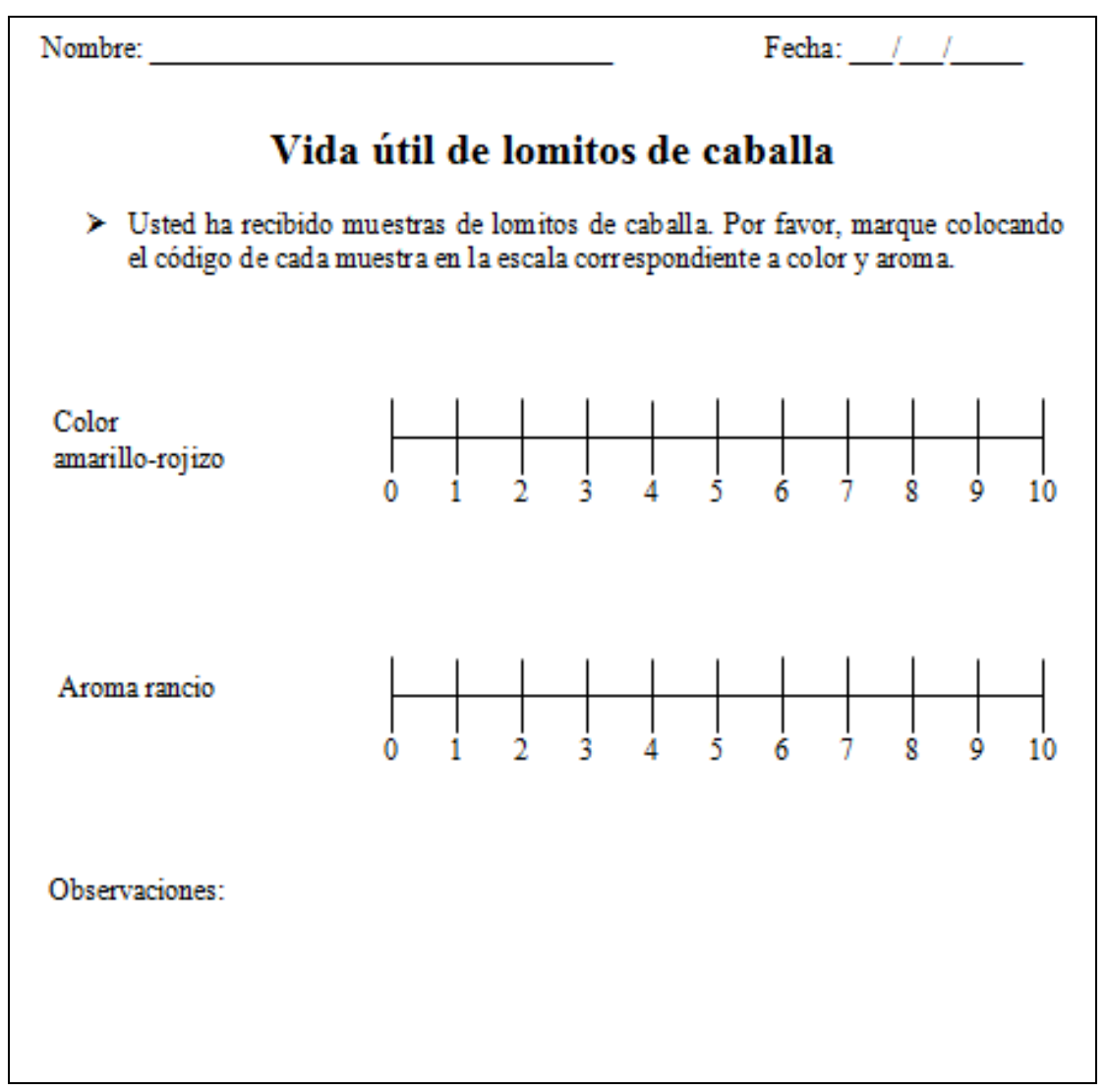

Figura 4.3 Planilla para evaluación sensorial de la vida útil 
En la Figura 4.3 se muestra la planilla de evaluación. Los panelistas evaluaron el aroma y el color de cada muestra y expresaron sus impresiones sobre escalas de $10 \mathrm{~cm}$ estructuradas.

\section{Determinación del punto final sensorial}

Se puede establecer el punto final sensorial como una disminución específica de la aceptabilidad o un cambio perceptible en el producto en uno o más atributos críticos (Gámbaro, 2005). Se determinó el punto final sensorial combinando un ensayo de aceptabilidad con consumidores y un ensayo con evaluadores entrenados.

Para el ensayo de aceptabilidad, se prepararon muestras almacenadas a $35^{\circ} \mathrm{C}$ durante $0,11,14,17,19$ y 21 días y se presentaron en envases cerrados herméticamente a temperatura ambiente. Las muestras fueron evaluadas por un panel de 20 consumidores, se les pidió que contestaran si consumirían el producto o no basándose en su apariencia y olor.

Se determinó que el tiempo del punto final sensorial para las muestras almacenadas a $35^{\circ} \mathrm{C}$ fue el tiempo en que el $50 \%$ de los consumidores rechazaron el producto. Este tiempo se obtuvo a partir de la regresión lineal del porcentaje de rechazo en función del tiempo.

Con esta determinación se obtuvo el tiempo en que la muestra almacenada a $35^{\circ} \mathrm{C}$ llegó al punto final sensorial. Para obtener el puntaje de los atributos críticos en el tiempo final sensorial se realizo un ensayo con panelistas entrenados almacenando las muestras a $35^{\circ} \mathrm{C}$ durante los mismos tiempos que la prueba de aceptabilidad. A partir de esta evaluación se obtuvo un puntaje para cada tiempo de muestreo. Mediante regresión lineal del atributo sensorial estudiado (color y aroma rancio) en función del tiempo de almacenamiento se obtuvo el puntaje del punto final sensorial para los dos atributos sensoriales. Este puntaje fue utilizado para determinar la vida útil a las otras dos temperaturas $\left(15\right.$ y $\left.25^{\circ} \mathrm{C}\right)$.

\subsubsection{Estimación de la vida útil}

La vida útil sensorial puede ser determinada como el tiempo requerido por un determinado atributo sensorial para alcanzar un valor predeterminado (Gámbaro y col., 2006). Se puede representar la pérdida de la calidad de un alimento de la siguiente forma:

$$
-\frac{d A}{d t}=k A^{n}
$$


donde $A$ es la calidad del factor medido, $t$ el tiempo, $k$ la constante de velocidad de reacción dependiente de la temperatura, $n$ el exponente indicativo del orden de reacción y $\frac{d A}{d t}$ la proporción del cambio de $A$ en función del tiempo.

El deterioro de los alimentos sigue modelos de orden cero o de primer orden. En alimentos con un alto contenido de lípidos predominan las reacciones de oxidación y estas suelen seguir un comportamiento de orden cero (García y col., 2011)

Si la reacción es de orden cero, en la ecuación $4.3 n=0$, y se expresa del siguiente modo:

$-\frac{d A}{d t}=k$

En cambio, si en la Ecuación $4.3 n=1$, la reacción es de primer orden y se expresa de este modo:

$-\frac{d A}{d t}=k A$

Resolviendo estas ecuaciones se obtienen las siguientes expresiones:

De orden cero:

$A=A_{0}-k t$

De primer orden:

$$
\ln (A)=\ln \left(A_{0}\right)-k t
$$

donde $A$ es la calidad a tiempo $t, A_{0}$ la calidad a tiempo cero, $k$ la constante de velocidad de reacción y $t$ el tiempo de almacenamiento.

En consecuencia, si se representa el grado de calidad en función del tiempo y se obtiene una línea recta, el orden de reacción es cero. Si al representar el logaritmo del grado de calidad en función del tiempo se obtiene una línea recta, la reacción es de primer orden.

\section{Dependencia con la temperatura}

Como se mencionó anteriormente, la constante de velocidad de la reacción $(k)$ depende de la temperatura. En la gran mayoría de las reacciones de pérdida de calidad sensorial el valor de k varía en función de la temperatura según la ecuación de 
Arrhenius (Hough y Garitta, 2005). A continuación se puede ver la ecuación de Arrhenius linealizada:

$$
\ln (k)=\ln (A)-\left(\frac{E_{a}}{R T}\right)
$$

donde $k$ es la constante de velocidad de reacción a la temperatura $T, A$ el factor de frecuencia, $E_{a}$ la energía de activación $\left(\mathrm{J} \mathrm{mol}^{-1}\right), R$ la constante general de los gases $(8,314(\mathrm{~J} /(\mathrm{mol} \mathrm{K}))$ y $T$ la temperatura absoluta $(\mathrm{K})$.

A partir de la Ecuación 4.8 se estimó la $E_{a}$ mediante la representación del $\ln (k)$ en función de la inversa de la temperatura absoluta $\left(T^{-1}\right)$. Al graficar se obtuvo una recta con pendiente $-E_{d} / R$.

\section{Determinación de la vida útil a temperatura de refrigeración}

Utilizando los datos obtenidos a las tres temperaturas estudiadas, se determinó la vida útil de la preserva a temperatura de refrigeración $\left(5^{\circ} \mathrm{C}\right)$ mediante la pseudotransformación resultante del gráfico entre el logaritmo de la vida útil en función de la temperatura de almacenamiento (García y Molina, 2008). Mediante regresión lineal se puede estimar la vida útil a diferentes temperaturas.

\subsubsection{Análisis Estadístico}

Los resultados se analizaron mediante análisis de varianza (ANOVA) con dos factores (tiempo y temperatura) para analizar si el efecto de los mismos fue significativo $(p<0,05)$ sobre los parámetros estudiados (aroma rancio, color sensorial, color instrumental, $\mathrm{pH}$ y TBARS). En análisis posteriores se compararon las medias mediante el Test de Tukey $(p<0,05)$. El análisis estadístico se llevó a cabo con el programa InfoStat, 2011 (Grupo InfoStat, FCA, Universidad Nacional de Córdoba, Argentina). 


\subsection{Resultados y discusión}

\subsubsection{Análisis fisicoquímicos}

\section{Composición química proximal}

La composición química proximal de los lomitos crudos y de la preserva se muestra en la Tabla 4.2. Además, en la misma tabla se detalla el contenido de sal, glicerol y ácido cítrico de la preserva (el porcentaje de sal forma parte del contenido de cenizas).

Tabla 4.2 Composición química proximal (\% en base húmeda) y contenido de glicerol, sal y ácido cítrico de lomitos crudos y de la preserva

\begin{tabular}{lccccccc}
\hline & Humedad & Proteínas & Lípidos & Cenizas & Glicerol & $\mathrm{NaCl}$ & Ac. cítrico \\
\hline $\begin{array}{l}\text { Lomitos } \\
\text { crudos }\end{array}$ & $70,92 \pm 0,47$ & $21,91 \pm 0,40$ & $6,08 \pm 0,52$ & $1,22 \pm 0,02$ & - & - & - \\
Preserva & $51,09 \pm 0,11$ & $22,66 \pm 0,39$ & $6,76 \pm 0,69$ & $3,05 \pm 0,04$ & $16,62 \pm 0,74$ & $1,99 \pm 0,06$ & $0,17 \pm 0,02$ \\
\hline
\end{tabular}

Humedad, $\mathrm{pH}$ y $\mathrm{a}_{\mathrm{w}}$

La preserva presentó un valor inicial de $\mathrm{pH}$ de 5,09 $\pm 0,06$; una $\mathrm{a}_{\mathrm{w}}$ de 0,89 \pm 0,01 y una humedad de $51,09 \pm 0,11$. No hubo cambios significativos $(p>0,05)$ en los valores de $\mathrm{pH}, \mathrm{a}_{\mathrm{w}} \mathrm{y}$ humedad durante todo el almacenamiento para las tres temperaturas evaluadas. Los valores iniciales y finales de estos parámetros fisicoquímicos se muestran en la Tabla 4.3.

Tabla 4.3 Valores iniciales y finales de $\mathrm{pH}, \mathrm{a}_{\mathrm{w}} \mathrm{y}$ humedad a las tres temperaturas de almacenamiento $\left(15,25\right.$ y $\left.35^{\circ} \mathrm{C}\right)$

\begin{tabular}{lccc}
\hline \multicolumn{1}{c}{ Tiempo (días) } & $\mathbf{p H}$ & Humedad (\%) & $\mathbf{a}_{\mathbf{w}}$ \\
\hline $\mathbf{0}$ (inicial) & $5,09 \pm 0,06$ & $51,09 \pm 0,10$ & $0,89 \pm 0,01$ \\
$\mathbf{2 5}$ (final a $\mathbf{3 5}^{\circ} \mathbf{C}$ ) & $4,97 \pm 0,13$ & $51,34 \pm 0,35$ & $0,89 \pm 0,01$ \\
$\mathbf{6 3}$ (final a $\mathbf{2 5}^{\circ} \mathbf{C}$ ) & $5,01 \pm 0,14$ & $50,85 \pm 0,47$ & $0,89 \pm 0,01$ \\
$\mathbf{1 7 5}$ (final a $\mathbf{1 5}^{\circ} \mathbf{C}$ ) & $5,08 \pm 0,10$ & $51,73 \pm 0,31$ & $0,89 \pm 0,01$ \\
\hline
\end{tabular}

\section{$\underline{\text { TBARS }}$}

El valor inicial de la preserva fue de 1,96 $\pm 0,05 \mathrm{mg} \mathrm{MDA} / \mathrm{kg}$. No se apreció una clara tendencia en los valores de TBARS durante todo el almacenamiento para las tres temperaturas de almacenamiento estudiadas. 
El hecho de que no haya habido una clara tendencia en el valor de TBARS durante el almacenamiento a las tres temperaturas estudiadas no se correlaciona con los resultados sensoriales que indican la existencia de enranciamiento (aumento en el color amarillo-rojizo y en el aroma rancio) ni con el estudio del perfil de ácidos grasos.

Kwon y Watts (1964) informaron que el test TBA posee una limitación con los alimentos deshidratados, debido a que a estados avanzados de oxidación lipídica, los valores de MDA seguían siendo bajos. Estos autores sugirieron que, debido al bajo contenido de agua, el MDA producido se encuentra en forma volátil y quelada, lo cual no le permite ser retenido en el alimento.

La limitación más importante que posee el TBARS es que el MDA y otros productos de la oxidación lipídica no son estables en el tiempo. Esto es porque la oxidación de estos productos genera ácidos y alcoholes orgánicos que no son detectados por el test (Fernández y col., 1997).

Otra posible causa por la cual no se detectaron cambios en los valores de TBARS podría ser la presencia de glicerol en la preserva. Este compuesto podría estar interfiriendo en su medición. Fernández y col. (1997) informan de la existencia de sustancias que interfieren con las mediciones del TBARS, según estos autores algunos problemas de interferencia podrían deberse, entre otros, a ciertos azúcares y sus productos de degradación.

Dado que no se detectaron cambios en los valores de TBARS, se utilizó el perfil de ácidos grasos para determinar la rancidez de la preserva.

\section{Perfil de ácidos grasos}

La composición de ácidos grasos en los lomitos de caballa durante el almacenamiento a $35^{\circ} \mathrm{C}$ se presenta en la Tabla 4.4. 
Tabla 4.4 Cambios en el perfil de ácidos grasos durante el almacenamiento a $35^{\circ} \mathrm{C}$

\begin{tabular}{|c|c|c|c|c|c|c|c|c|c|}
\hline \multirow{2}{*}{$\begin{array}{l}\text { Acidos Grasos } \\
\text { (g/100g grasas) }\end{array}$} & \multicolumn{9}{|c|}{ Tiempo de almacenamiento (días) } \\
\hline & $\mathbf{0}$ & 5 & 11 & 14 & 17 & 19 & 21 & 23 & 25 \\
\hline C14:0 & 5,44 & 5,33 & 5,33 & 5,36 & 5,59 & 5,33 & 5,37 & 5,25 & 5,33 \\
\hline C15:0 & ND & ND & ND & ND & ND & ND & 0,36 & 0,16 & 0,21 \\
\hline C15:1 & 0,26 & 0,27 & 0,27 & 0,26 & 0,29 & ND & 0,31 & ND & 0,31 \\
\hline C16:0 & 16,71 & 16,11 & 15,80 & 16,47 & 17,36 & 18,52 & 19,30 & 19,24 & 19,20 \\
\hline C16:1 $\omega 7$ & 11,31 & 10,99 & 10,82 & 10,46 & 10,87 & 6,81 & 6,72 & 6,98 & 6,85 \\
\hline C16:3 & ND & ND & ND & ND & ND & 0,71 & 0,43 & 0,55 & 0,62 \\
\hline C16:4 & ND & ND & ND & ND & ND & 0,28 & ND & ND & ND \\
\hline C17:0 & 0,16 & ND & 0,19 & 0,16 & 0,15 & 0,50 & 0,55 & 0,55 & 0,51 \\
\hline C17:1 & ND & ND & ND & ND & ND & 0,34 & 0,39 & 0,38 & 0,33 \\
\hline C18:0 & ND & ND & ND & ND & ND & 3,69 & 4,18 & 4,68 & 3,96 \\
\hline C18:1 $\omega 7$ & 11,31 & ND & ND & 12,86 & ND & 2,44 & 2,17 & 2,08 & 1,59 \\
\hline C18:1 w9 & 18,31 & 29,28 & 29,38 & 16,03 & 28,76 & 21,67 & 21,59 & 21,89 & 21,70 \\
\hline C18:2 w6 & 2,18 & 2,14 & 2,09 & 2,19 & 2,10 & 2,07 & 2,08 & 1,74 & 2,13 \\
\hline C18:3 w6 & ND & ND & ND & ND & ND & 0,44 & 0,46 & 0,38 & 0,38 \\
\hline C18:3 w3 & 1,25 & 1,29 & 1,27 & 1,23 & ND & 1,09 & 1,02 & 0,94 & 1,03 \\
\hline C18:4 w3 & 5,29 & 3,23 & 5,18 & 5,12 & 5,14 & 4,64 & 4,45 & 4,28 & 4,79 \\
\hline C20:0 & ND & ND & ND & ND & ND & 0,17 & 0,16 & ND & 0,13 \\
\hline C20:1 w11 & 0,60 & 0,05 & 0,46 & 0,66 & 0,08 & 1,29 & 1,37 & 1,30 & 1,33 \\
\hline C20:1 w9 & 0,13 & ND & 0,42 & 0,13 & ND & 0,15 & 0,15 & 0,18 & 0,13 \\
\hline C20:1 $\omega 7$ & 0,65 & ND & 0,84 & 0,82 & ND & 0,32 & ND & 0,31 & ND \\
\hline C20:2 w6 & ND & ND & ND & 0,09 & ND & ND & ND & ND & ND \\
\hline C20:3 $\omega 6$ & 0,20 & ND & 0,26 & 0,16 & ND & ND & 0,27 & ND & 0,21 \\
\hline C20:3 w3 & ND & ND & ND & ND & ND & ND & 0,08 & ND & ND \\
\hline C20:4 $\omega 6$ & 0,09 & 0,21 & ND & ND & ND & 0,38 & 0,44 & 0,49 & 0,38 \\
\hline C20:4 w3 & 0,45 & 0,48 & 0,53 & 0,50 & 0,43 & 0,60 & 0,57 & 0,55 & 0,54 \\
\hline C20:5 w3 EPA & 4,68 & 4,82 & 5,00 & 4,59 & 5,14 & 3,87 & 4,30 & 4,37 & 4,25 \\
\hline C21:5 w3 & 0,13 & ND & 0,10 & 0,08 & ND & 0,63 & 0,61 & 1,03 & 1,10 \\
\hline C22:1 w11 & 1,27 & 2,18 & 1,28 & 2,09 & 1,56 & 5,00 & 2,14 & 1,88 & 2,09 \\
\hline C22:1 $\omega 9$ & 1,67 & 2,74 & 2,34 & 3,03 & 2,13 & ND & 1,72 & 1,41 & 1,87 \\
\hline C22:5 w6 & 0,54 & 0,11 & 0,67 & 0,08 & 0,11 & 0,89 & 0,76 & 0,84 & 0,80 \\
\hline C22:5 $\omega 3$ DPA & ND & 0,65 & 0,04 & 0,23 & 0,58 & 0,86 & 0,86 & 0,55 & 0,55 \\
\hline C22:6 w3 DHA & 17,22 & 18,25 & 17,66 & 17,40 & 18,45 & 15,88 & 15,42 & 16,23 & 16,18 \\
\hline AGS & 22,31 & 21,44 & 21,32 & 22,00 & 23,10 & 28,21 & 29,92 & 29,88 & 29,35 \\
\hline AGMI & 45,51 & 45,51 & 45,81 & 46,34 & 43,69 & 38,02 & 36,56 & 36,41 & 36,21 \\
\hline AGPI & 32,04 & 31,18 & 32,81 & 31,67 & 33,22 & 32,33 & 31,76 & 32,12 & 33,03 \\
\hline
\end{tabular}

ND: no detectable.

Al inicio del almacenamiento $(t=0)$ la composición de los ácidos grasos fue la siguiente: $22,31 \%$ de ácidos grasos saturados (AGS); $45,51 \%$ de ácidos grasos monoinsaturados (AGMI) y 32,04\% de ácidos grasos poliinsaturados (AGPI). Entre los AGPI, el ácido docosahexaenoico (DHA) (C22:6 w3) fue el más abundante seguido por el ácido eicosapentaenoico (EPA) (C20:5 w3). El DHA fue 3,68 veces superior al EPA. Según Chaijan y col. (2006) usualmente el porcentaje de DHA en pescado es alrededor de 3 veces superior que el de EPA. 
En la Figura 4.4 se observa la evolución del DHA y el EPA durante el almacenamiento a $35^{\circ} \mathrm{C}$. No se aprecian cambios en los porcentajes de ninguno de los dos ácidos grasos hasta el día 17. Entre el día 17 y el 19 se observó un marcado descenso y a partir del día 21 se mantuvo sin cambios hasta el final. Si se evalúa el cambio desde el día 0 hasta el final del almacenamiento (día 25), el DHA presentó un descenso del $6,0 \%$ y el EPA del $9,2 \%$. Este comportamiento pudo haber estado relacionado a la oxidación de estos ácidos grasos poliinsaturados. Agustinelli (2014) y Tironi y col. (2010b), reportaron disminución en los valores de DHA y EPA debido a su oxidación durante almacenamiento congelado de caballa (Scomber japónicus) y salmón de mar (Pseudopercis semifasciata) respectivamente.

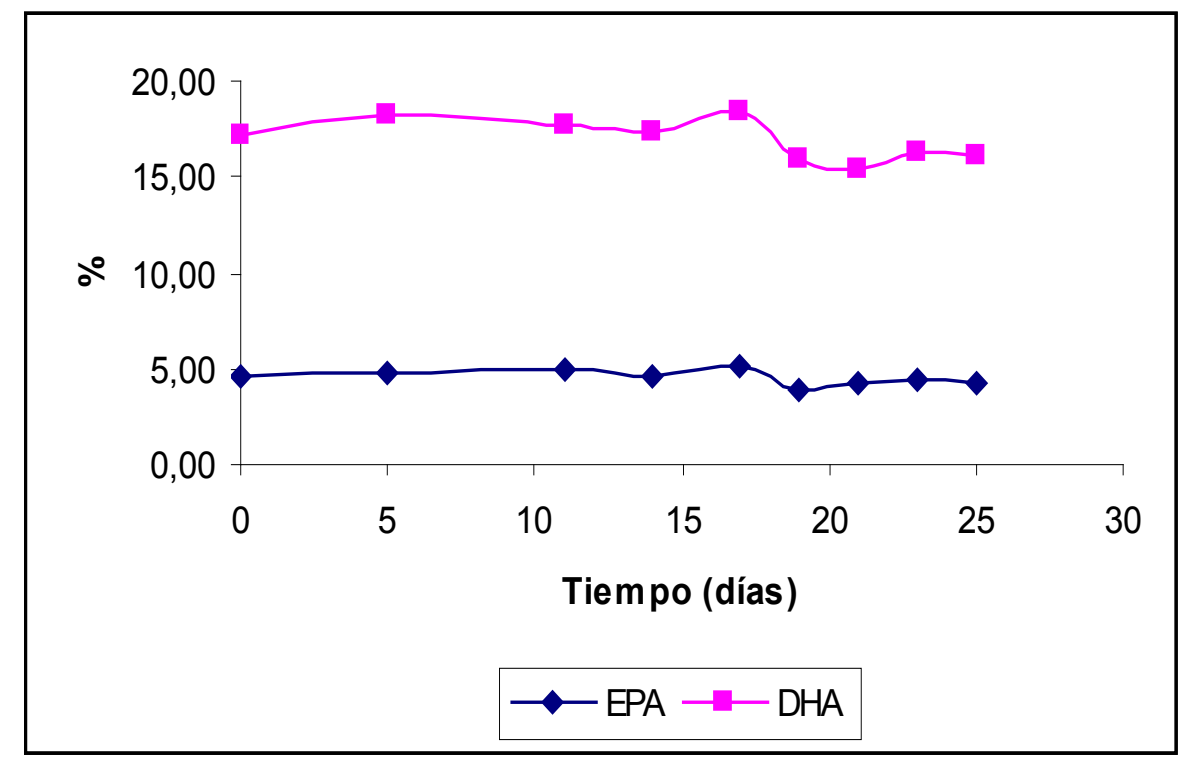

Figura 4.4 Evolución de los ácidos grasos DHA y EPA durante el almacenamiento de la preserva a $35^{\circ} \mathrm{C}$

En la Figura 4.5 se muestra la evolución durante el almacenamiento a $35^{\circ} \mathrm{C}$ de los AGS, AGMI y AGPI. 


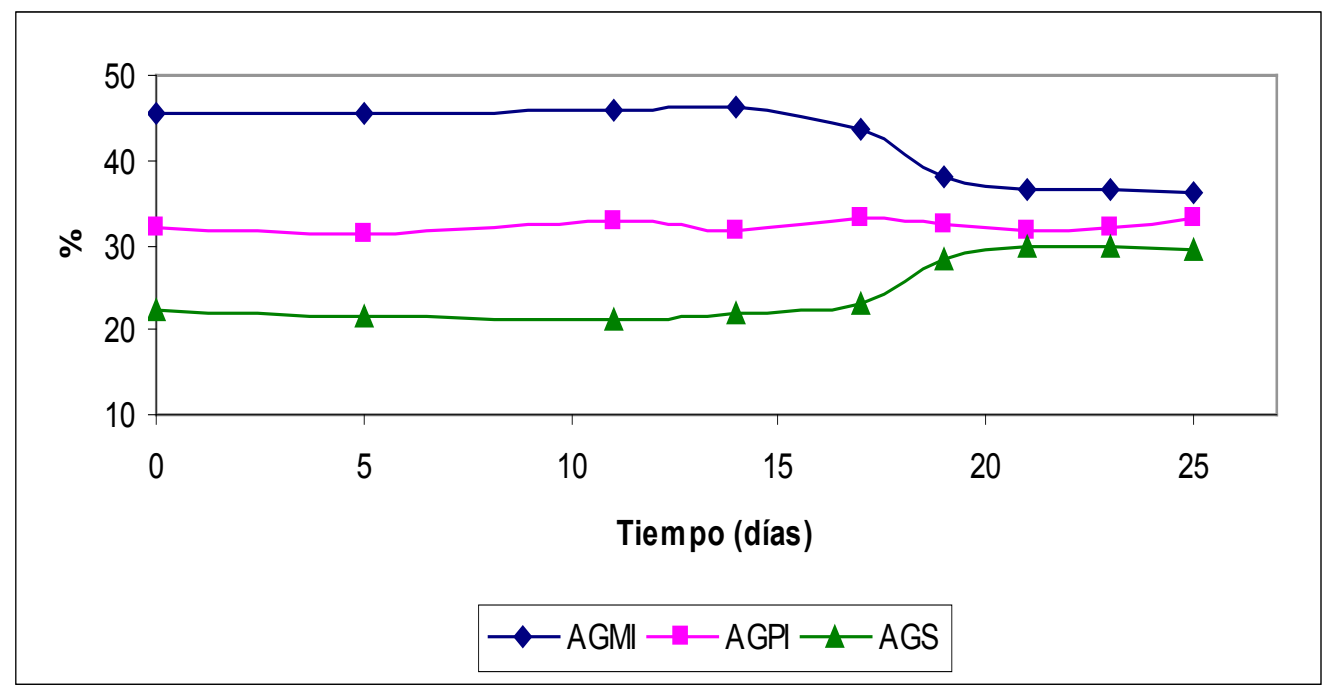

Figura 4.5 Evolución de los ácidos grasos durante el almacenamiento de la preserva a $35^{\circ} \mathrm{C}$

Si bien anteriormente se observó un leve descenso en los porcentajes de DHA y EPA durante el almacenamiento (Figura 4.4), si se analiza el comportamiento de la suma de los AGPI se observa que no hubo cambios significativos. Esto se debe a que, junto al descenso de DHA y EPA se produjo un aumento en otros AGPI como el C21:5 $\omega 3$ y el C22:5 $\omega 3$ (DPA) entre otros. El aumento del porcentaje de este grupo de AGPI y el descenso de EPA y DHA pudo deberse a la oxidación de estos últimos.

En cuanto a los AGS, no se observaron cambios durante los primeros 14 días.

A partir del día 14 aumentó su porcentaje hasta el día 21 en que se mantuvo sin variaciones hasta el final (día 25).

En el caso de los AGMI, no se observaron cambios durante los primeros 14 días en que comenzó a disminuir su porcentaje hasta el día 21. Luego del día 21 se mantuvo sin cambios hasta el final del almacenamiento (día 25).

El aumento de los AGS y la disminución de los AGMI pueden estar relacionados a la oxidación de los AGMI. Como se puede observar en la Tabla 4.4, la fracción de C16:1 w7 disminuyó desde 11,31 a 6,72\% (alrededor de 3,5\%) desde el día 0 hasta el día 21. A su vez, esto se corresponde con un aumento de la fracción de C16:0 desde 16,71 (día 0) hasta 19,30\% (alrededor del 2,5\%) en el día 21. Esto puede deberse a la oxidación del doble enlace de este grupo de AGMI (C16:1 $\omega 7)$ que pasan a ser parte del grupo de C16:0. Resultados similares se observaron con la fracción de ácidos grasos de cadena de 18 carbonos, ya que si se suman las fracciones de C18:1 $\omega 7$ y 18:1 $\omega 9$ da como resultado que, desde el principio del almacenamiento hasta el día 17 inclusive, el porcentaje fue de alrededor del 29\%. En cambio, a partir del día 19 y hasta el final, la suma de estas dos fracciones fue de alrededor del $24 \%$. Esta disminución del $5 \%$ en el porcentaje de AGMI de 18 carbonos se corresponde con un 
aumento del $4 \%$ en la fracción de C18:0 ya que desde el inicio del almacenamiento hasta el día 17 no se detectaron valores de C18:0 y a partir del día 19 en adelante se obtuvieron valores cercanos al $4 \%$.

Debido a que el análisis de TBARS no pudo ser utilizado para comprobar la oxidación lipídica, el análisis del perfil de los ácidos grasos representa una buena alternativa para explicar esta oxidación durante el almacenamiento de la preserva. Distintos autores utilizaron el análisis de los ácidos grasos como criterio para evaluar la rancidez oxidativa en pescado por efecto del tiempo de almacenamiento (Agustinelli, 2014; Chaijan, 2006; Ke y col., 1977).

\section{$\underline{\text { Color instrumental }}$}

El color es un atributo de calidad muy importante para la determinación del tiempo de vida útil de un producto y una de las características sensoriales más apreciadas por los consumidores (Birkeland y Bjerkeng, 2005; Corzo y col., 2008; Sohn y col., 2005; Valencia García y col., 2012). Si bien se realizó un análisis sensorial del cambio en el color del producto, también se midió este parámetro de forma objetiva mediante el uso de un colorímetro a fin de correlacionar los valores obtenidos con la evaluación sensorial. Las mediciones se realizaron directamente sobre el producto envasado utilizando un colorímetro portátil.

Las Figuras 4.6, 4.7, 4.8 y 4.9 muestran el comportamiento de los parámetros $a^{*}, b^{*}, L$ y $\Delta E$ durante el almacenamiento a 15,25 y $35^{\circ} \mathrm{C}$.

Al observar los gráficos de los parámetros estudiados se distingue un marcado aumento de la pendiente de las curvas de los datos a mayor temperatura. Esto se debe a que a mayor temperatura de almacenamiento más rápido son las reacciones de enranciamiento del producto. Estas reacciones son las responsables de la generación del color característico de la preserva enranciada (color amarillo-rojizo). 


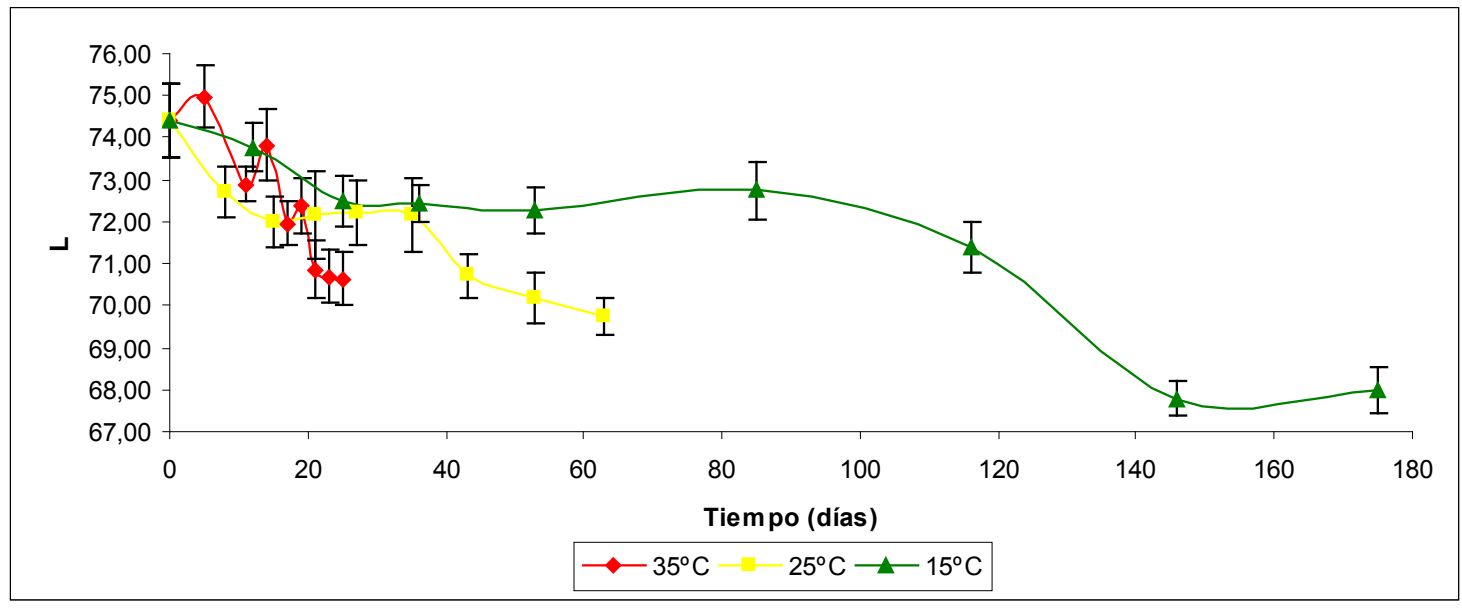

Figura 4.6 Análisis instrumental del color (parámetro $L^{*}$ ) en muestras almacenadas a 15, 25 y $35^{\circ} \mathrm{C}$

El parámetro $L^{*}$ disminuyó significativamente $(p<0,05)$ durante el almacenamiento a 15,25 y $35^{\circ} \mathrm{C}$. Si bien se observó un descenso paulatino del parámetro $L^{*}$ durante los primeros tiempos de muestreo, es al final del almacenamiento donde se observó una disminución significativa $(p<0,05)$. El parámetro $L^{*}$ es un indicador de la luminosidad del producto (varía entre el color negro (0) y blanco (100)), es por esto que se puede afirmar que durante el almacenamiento las muestras se oscurecieron.

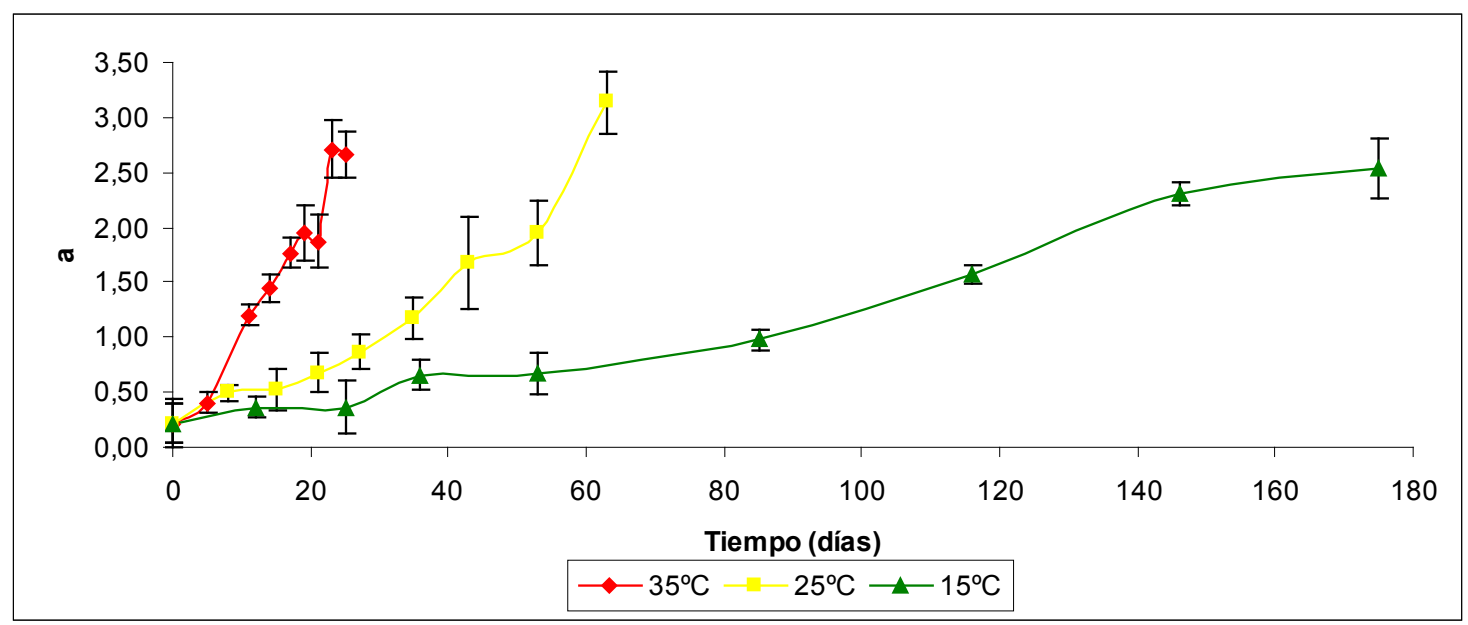

Figura 4.7 Análisis instrumental del color (parámetro a*) en muestras almacenadas a 15, 25 y $35^{\circ} \mathrm{C}$

El parámetro $a^{*}$ presentó un aumento significativo $(p<0,05)$ de su valor a las tres temperaturas estudiadas. Este comportamiento se observó desde el inicio hasta el final del almacenamiento. El aumento del parámetro $a^{*}$ indica que hubo un aumento de la intensidad del color rojo en el producto, el cual puede ser asociado con el contenido y la forma en que se encuentra la mioglobina (Chaijan y col., 2005; Lindahl y col., 
2001). Czerner y col. (2010), informaron un aumento en el valor de $a^{*}$ debido al enranciamiento durante la maduración de anchoitas saladas.

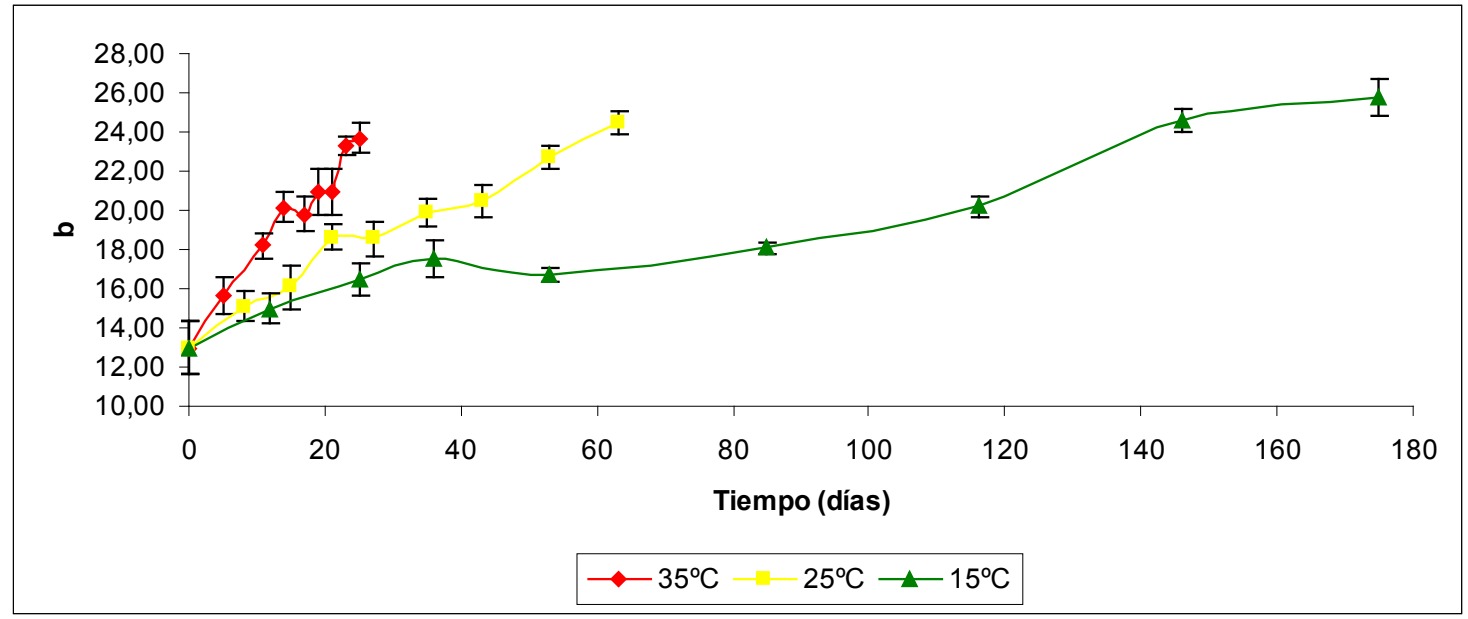

Figura 4.8 Análisis instrumental del color (parámetro b*) en muestras almacenadas a 15, 25 y $35^{\circ} \mathrm{C}$

El parámetro $b^{*}\left(\right.$ al igual que $\left.a^{*}\right)$ aumentó significativamente $(p<0,05)$ desde el comienzo hasta el final del almacenamiento a las tres temperaturas. Esto indicaría un aumento en el color amarillo de las muestras. Tironi y col. (2010a) informaron un aumento significativo en el valor de $b^{*}$ durante el almacenamiento congelado de róbalo. El incremento en el valor de $b^{*}$ durante el almacenamiento de pescado congelado ha sido ampliamente registrado en la literatura. Esto se debe a la aparición de pigmentos amarillos derivados de la oxidación lipídica y otros procesos de pardeamiento (Haard, 1992).

Sohn y col. (2005) reportaron que la oxidación de los lípidos en el músculo de pescado es promovida por auto-oxidación de la mioglobina, siendo la oxidación de la mioglobina la causa principal en el desarrollo del color y olor indeseables durante el almacenamiento de pescado en hielo. De acuerdo a los resultados obtenidos por Thanonkaew y col. (2006) en calamar y por Thanonkaew y col. (2007) en jibia, la aparición de pigmentos amarillos se debe a la interacción entre grupos aldehídos, producidos durante la oxidación lipídica, con grupos amino libres provenientes de fosfolípidos y proteínas que forman las bases de Schiff. Los cambios de color en lomitos de caballa almacenados a distintas temperaturas podrían ser explicados por estas reacciones.

Además, con los datos de los parámetros $L^{*}, a^{*}$ y $b^{*}$ se calculó la diferencia total de color de acuerdo a:

$$
\Delta E=\sqrt{\Delta L^{*^{2}}+\Delta a^{*^{2}}+\Delta b^{*^{2}}}
$$


En la Figura 4.9 se muestran los valores de $\Delta \mathrm{E}$ durante el almacenamiento de la preserva. Se puede ver que, a las tres temperaturas estudiadas, la diferencia de color con la muestra inicial se fue incrementando con el paso del tiempo de almacenamiento.

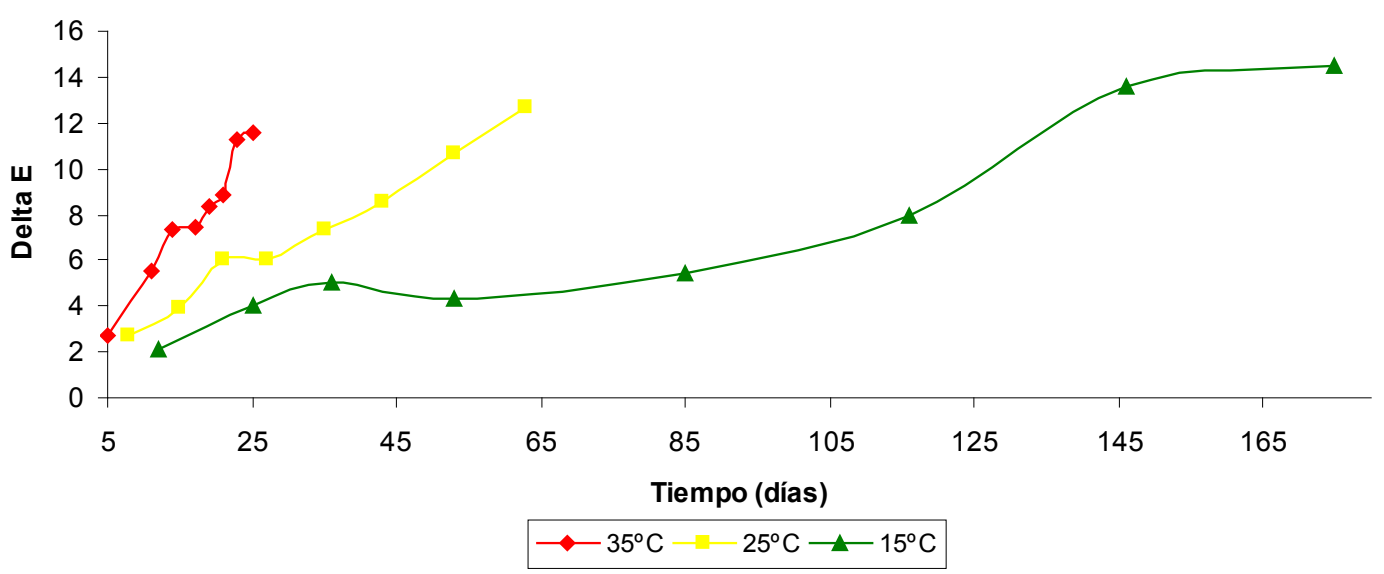

Figura 4.9 Análisis instrumental del color $(\Delta \mathrm{E})$ en muestras almacenadas a 15,25 y $35^{\circ} \mathrm{C}$

\subsubsection{Análisis sensorial}

El resultado del análisis sensorial realizado a la preserva durante el almacenamiento a 15,25 y $35^{\circ} \mathrm{C}$ se puede observar en la Tabla 4.5. Los valores presentados en esta tabla son los promedios de las evaluaciones realizadas por los 10 panelistas entrenados para cada tiempo de muestreo.

Tabla 4.5 Resultados de la evaluación sensorial a las tres temperaturas de almacenamiento de la preserva

\begin{tabular}{|c|c|c|c|c|c|c|c|c|}
\hline \multicolumn{3}{|c|}{$15^{\circ} \mathrm{C}$} & \multicolumn{3}{|c|}{$25^{\circ} \mathrm{C}$} & \multicolumn{3}{|c|}{$35^{\circ} \mathrm{C}$} \\
\hline Días & Color & Aroma & Días & Color & Aroma & Días & Color & Aroma \\
\hline 0 & $0,55 \pm 0,50$ & $1,15 \pm 0,34$ & 0 & $0,55 \pm 0,50$ & $1,15 \pm 0,34$ & 0 & $0,55 \pm 0,50$ & $1,15 \pm 0,34$ \\
\hline 12 & $0,85 \pm 0,47$ & $1,45 \pm 0,69$ & 8 & $1,15 \pm 0,47$ & $1,25 \pm 0,68$ & 5 & $1,90 \pm 0,39$ & $1,00 \pm 0,58$ \\
\hline 25 & $0,70 \pm 0,48$ & $1,05 \pm 1,44$ & 15 & $1,05 \pm 0,55$ & $1,05 \pm 0,86$ & 11 & $2,40 \pm 0,52$ & $1,75 \pm 0,79$ \\
\hline 36 & $1,25 \pm 0,79$ & $1,10 \pm 0,61$ & 21 & $1,95 \pm 0,72$ & $1,75 \pm 0,92$ & 14 & $4,40 \pm 0,52$ & $4,20 \pm 0,63$ \\
\hline 53 & $1,25 \pm 0,42$ & $1,80 \pm 0,75$ & 27 & $2,60 \pm 0,66$ & $1,60 \pm 0,84$ & 17 & $5,95 \pm 0,72$ & $5,25 \pm 0,79$ \\
\hline 85 & $2,40 \pm 0,52$ & $1,85 \pm 0,75$ & 35 & $3,95 \pm 0,60$ & $3,60 \pm 0,84$ & 19 & $6,05 \pm 0,69$ & $5,50 \pm 0,85$ \\
\hline 116 & $3,80 \pm 0,79$ & $3,70 \pm 0,82$ & 43 & $5,50 \pm 0,47$ & $4,25 \pm 0,63$ & 21 & $6,70 \pm 0,71$ & $6,90 \pm 0,77$ \\
\hline 146 & $5,00 \pm 0,67$ & $5,05 \pm 0,69$ & 53 & $5,70 \pm 0,59$ & $5,35 \pm 0,58$ & 23 & $7,05 \pm 0,80$ & $6,85 \pm 0,71$ \\
\hline 175 & $5,85 \pm 0,75$ & $5,80 \pm 0,79$ & 63 & $7,55 \pm 0,44$ & $6,75 \pm 0,72$ & 25 & $7,65 \pm 0,53$ & $7,35 \pm 0,75$ \\
\hline
\end{tabular}




\section{Color amarillo-rojizo}

En la Figura 4.10 se muestra la evolución del color amarillo-rojizo analizado por el panel sensorial durante el almacenamiento a 15,25 y $35^{\circ} \mathrm{C}$.

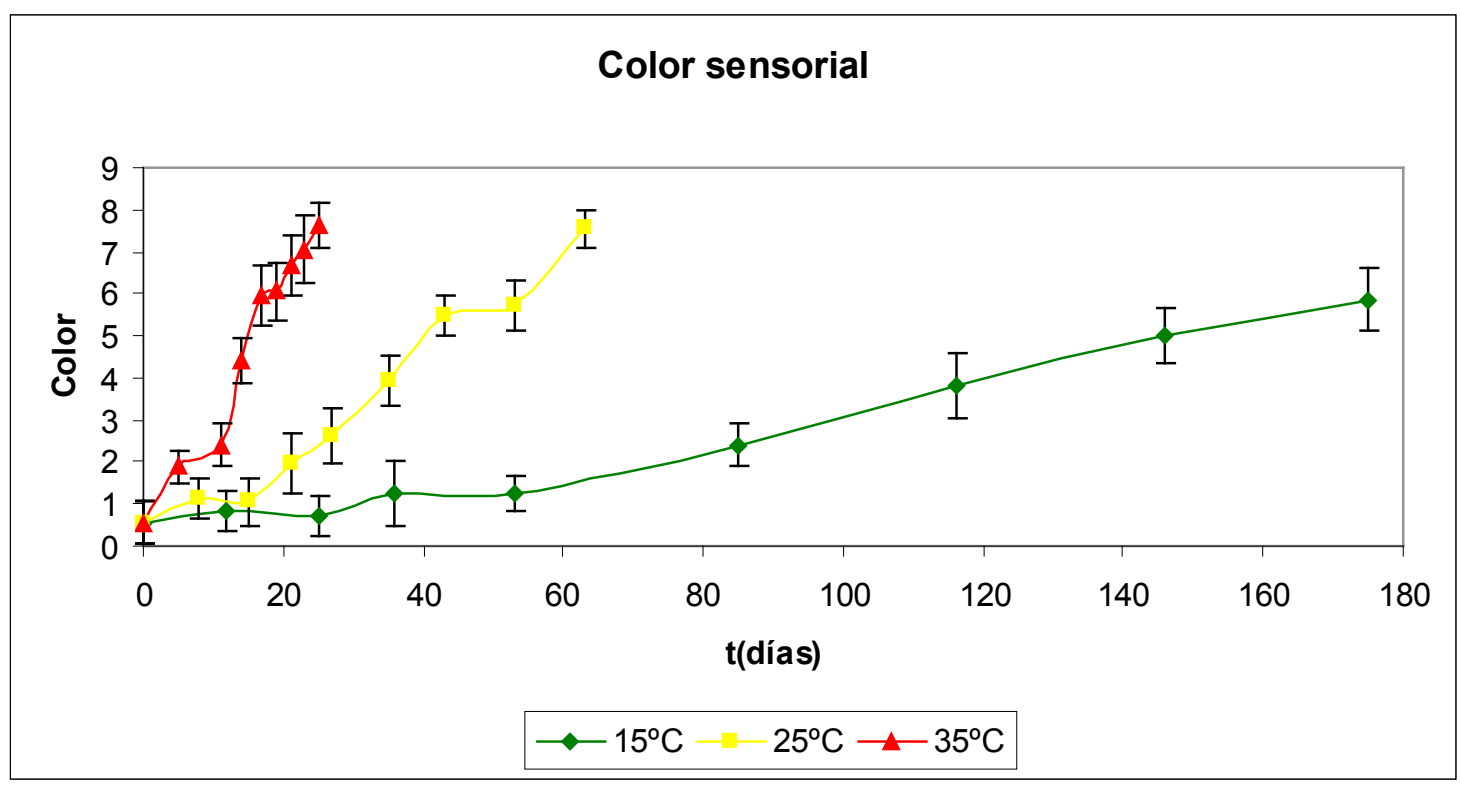

Figura 4.10 Evolución del color en función del tiempo en muestras almacenadas a 15, 25 y $35^{\circ} \mathrm{C}$.

El color aumentó significativamente $(p<0,05)$ durante el almacenamiento a las tres temperaturas estudiadas. $A 15^{\circ} \mathrm{C}$ se mantuvo sin cambios $(p>0,05)$ durante 53 días de almacenamiento. Recién a partir del día 85 se observó un aumento significativo $(p<0,05)$ que se mantuvo hasta el final del almacenamiento. A $25^{\circ} \mathrm{C}$ se observó que a partir del día 21 hubo un aumento significativo $(p<0,05)$ del color y a $35^{\circ} \mathrm{C}$ hubo un aumento significativo $(p<0,05)$ desde el comienzo de la toma de muestras (día 3) hasta el final del almacenamiento.

Este análisis demostró cómo influye la temperatura de almacenamiento sobre la percepción sensorial del enranciamiento de los lípidos del pescado estudiado. A mayor temperatura de almacenamiento se acelera el enranciamiento.

Resultados similares fueron hallados por García y Molina (2008) durante el almacenamiento de mayonesa a 21,35 y $45^{\circ} \mathrm{C}$. La vida útil hallada en función del enranciamiento de los lípidos en mayonesa a 21,35 y $45^{\circ} \mathrm{C}$ fue de 149,40 y 21 días respectivamente. 


\section{Aroma rancio}

En la Figura 4.11 se muestra la evolución del aroma rancio analizado por el panel sensorial durante el almacenamiento a 15,25 y $35^{\circ} \mathrm{C}$.

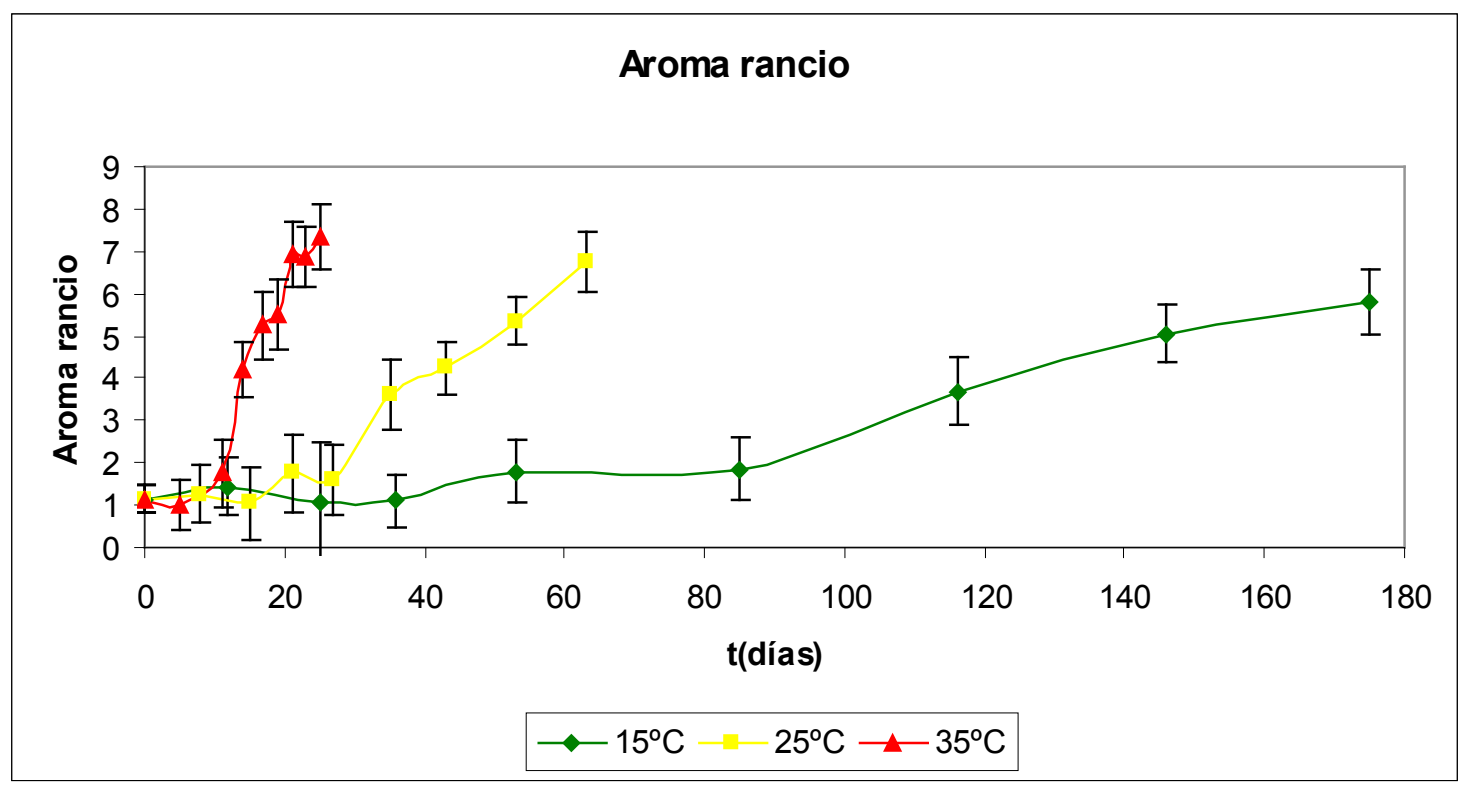

Figura 4.11 Evolución del aroma rancio en función del tiempo en muestras almacenadas a 15, 25 y $35^{\circ} \mathrm{C}$

El aroma rancio aumentó significativamente $(p<0,05)$ durante el almacenamiento a las tres temperaturas estudiadas. $A 15^{\circ} \mathrm{C}$ se mantuvo sin cambios $(p>0,05)$ durante 85 días de almacenamiento. Recién a partir del día 116 se observó un aumento significativo $(p<0,05)$ que se mantuvo hasta el final del almacenamiento. $A$ $25^{\circ} \mathrm{C}$ se observó que a partir del día 35 hubo un aumento significativo $(p<0,05)$ del color. A $35^{\circ} \mathrm{C}$ hubo un aumento significativo $(p<0,05)$ desde el día 14 hasta el día 21 y desde el día 21 se mantuvo sin cambios $(p>0,05)$ hasta el final del almacenamiento (día 25).

Al igual que en el caso del color, se percibió, mediante la evaluación sensorial del aroma rancio, que el enranciamiento se aceleró con el aumento de la temperatura de almacenamiento.

\subsubsection{Correlación entre color instrumental y sensorial}

Se realizaron análisis instrumentales del color de la preserva durante su almacenamiento con el fin de obtener mediciones objetivas de este parámetro y poder 
correlacionar con el análisis sensorial. Los resultados de dicha correlación se presentan en las Figuras 4.12, 4.13 y 4.14.
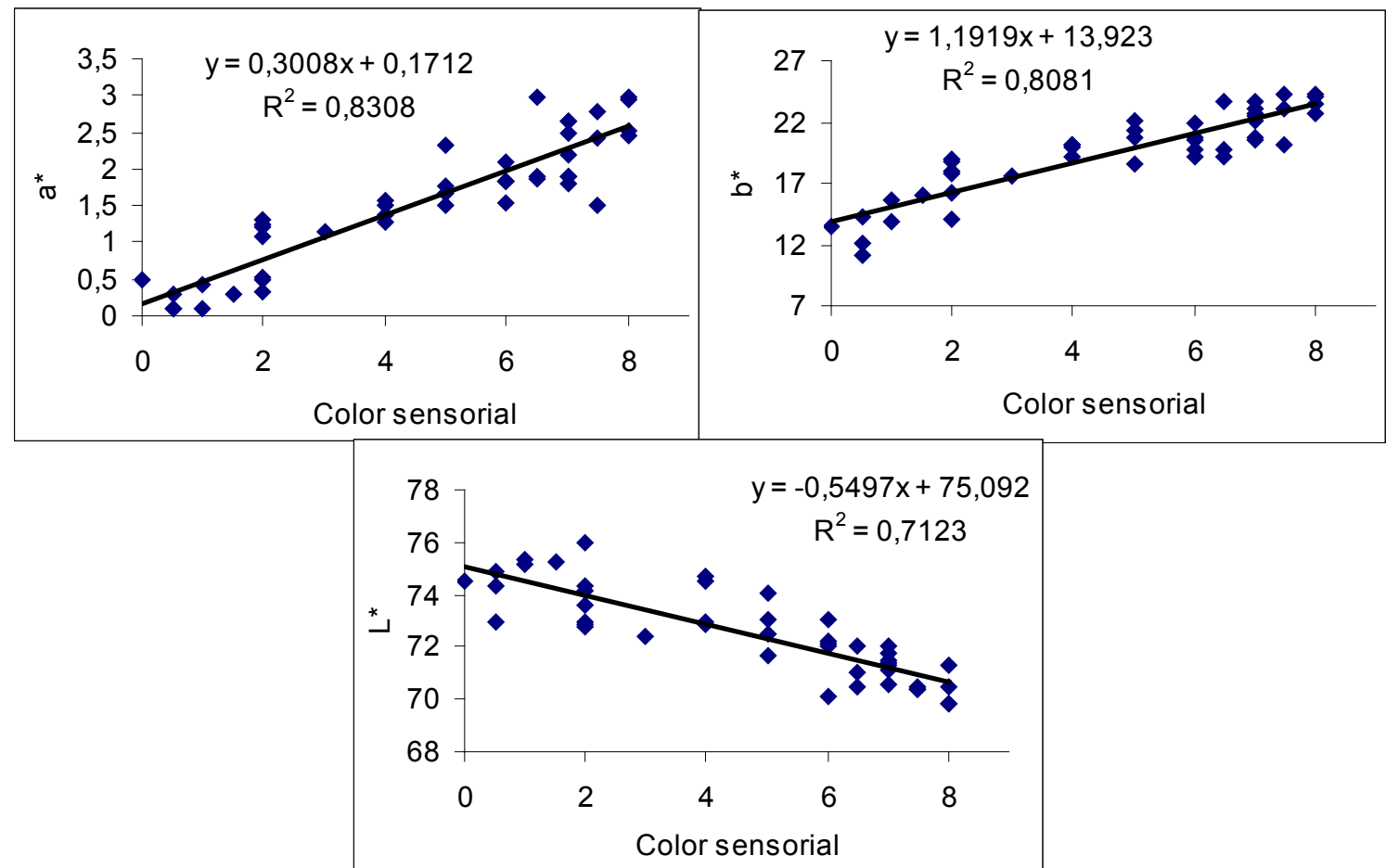

Figura 4.12 Correlación lineal entre las mediciones de color evaluadas sensorial e instrumentalmente $\left(a^{*}, b^{*} y L^{*}\right)$ a $35^{\circ}$

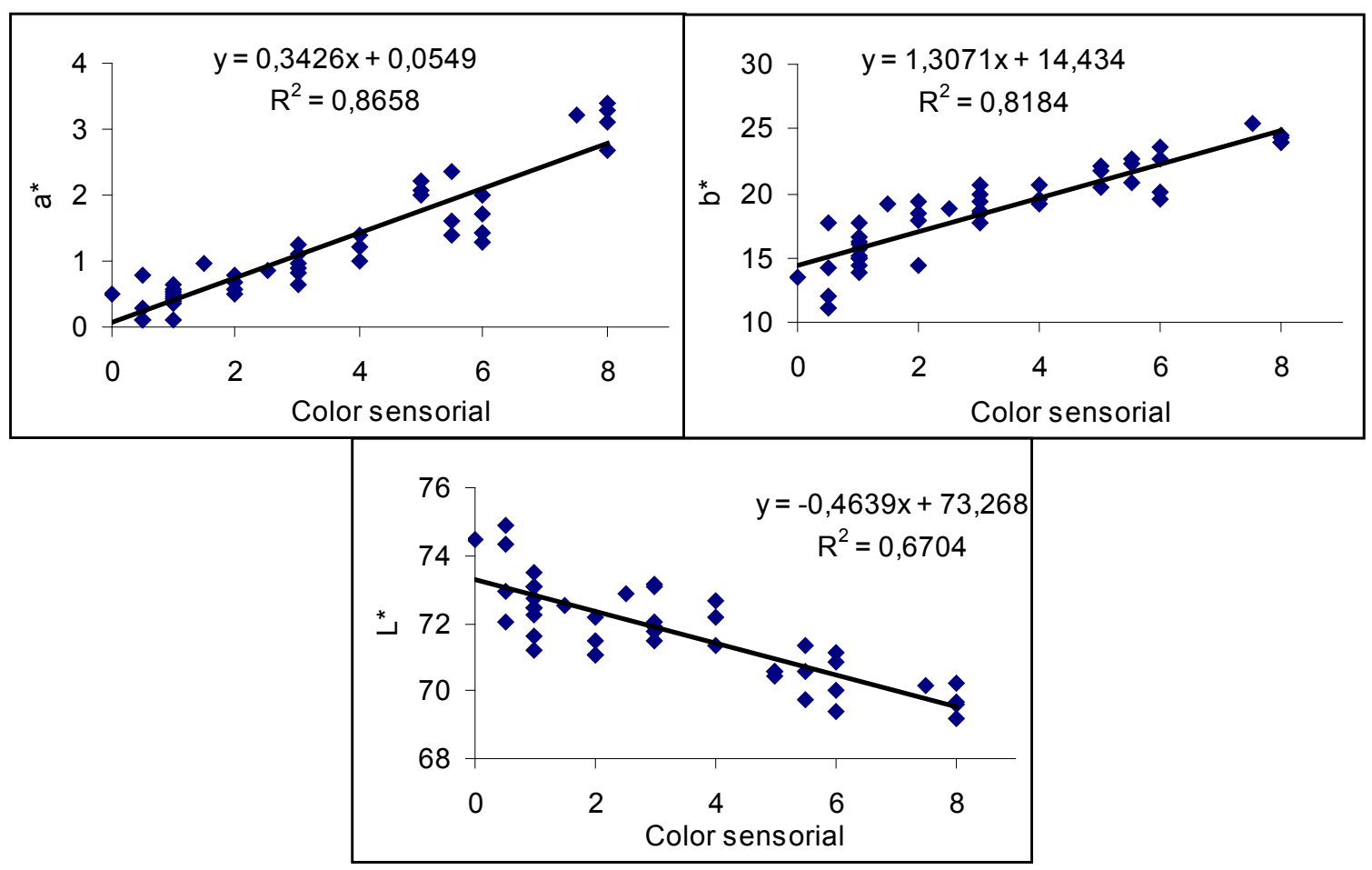

Figura 4.13 Correlación lineal entre las mediciones de color evaluadas sensorial e instrumentalmente $\left(a^{*}, b^{*}\right.$ y $\left.L^{*}\right)$ a $25^{\circ} \mathrm{C}$ 


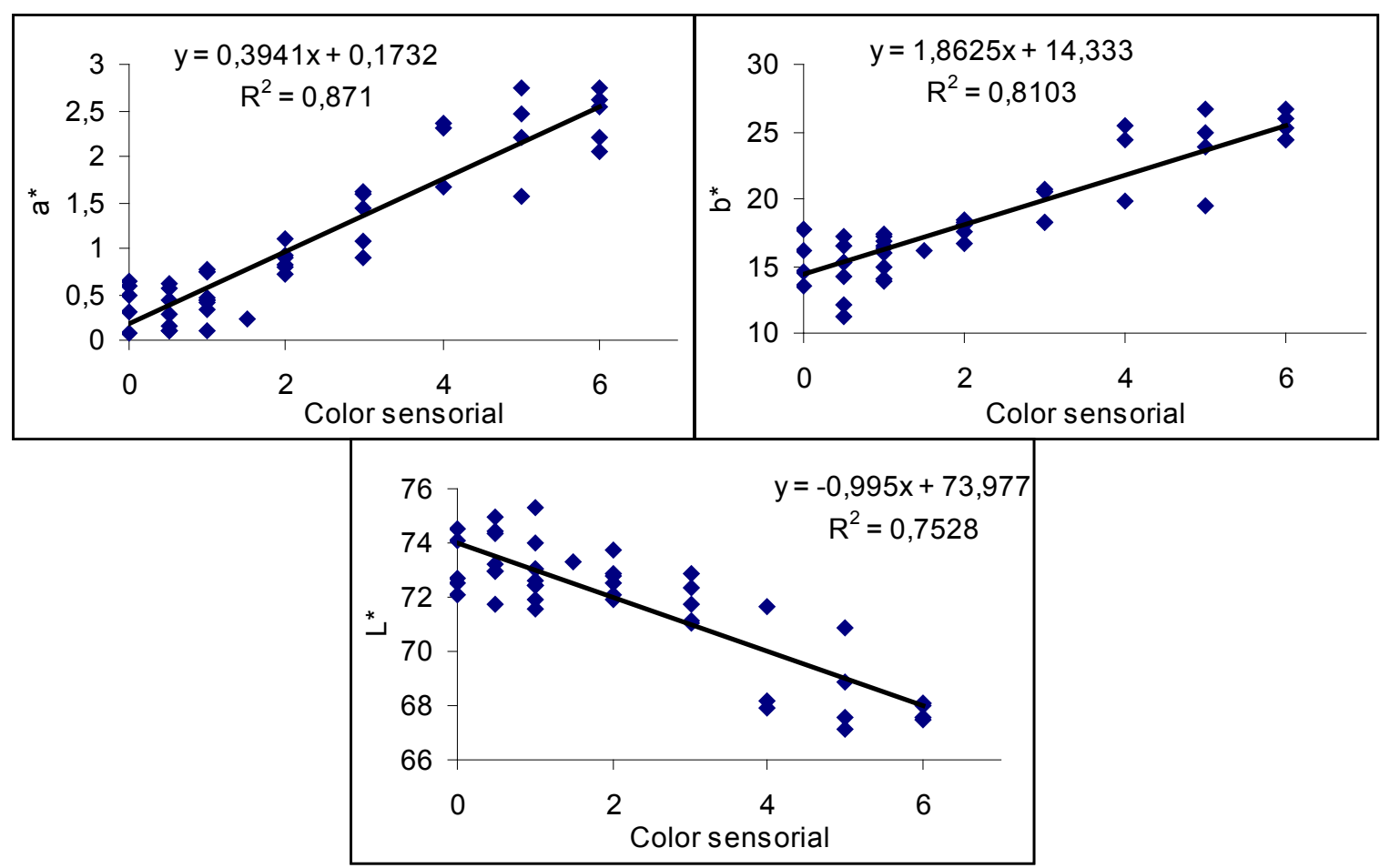

Figura 4.14 Correlación lineal entre las mediciones de color evaluadas sensorial e instrumentalmente $\left(a^{*}, b^{*}\right.$ y $\left.L^{*}\right)$ a $15^{\circ} \mathrm{C}$

El parámetro $a^{*}$ fue el que presentó la más alta correlación con el análisis sensorial a las tres temperaturas estudiadas con un valor de $R^{2}$ entre 0,8308 y 0,8710.

Con respecto al parámetro $\mathrm{b}^{*}$, también tuvo una alta correlación a las tres temperaturas con un valor de $R^{2}$ entre 0,8081 y 0,8184 .

La peor correlación de los tres parámetros estuvo representada por L*. Este parámetro tuvo valores de $\mathrm{R}^{2}$ entre 0,6704 y 0,7528 .

La correlación obtenida, tanto con el parámetro $a^{*}$ como con $b^{*}$, indica que se podría realizar una evaluación objetiva de la preserva analizando el color de las muestras mediante el uso del colorímetro.

Este estudio permitió comprobar instrumentalmente el cambio de color ocurrido en la preserva durante el almacenamiento a las tres temperaturas.

\subsubsection{Determinación del tiempo del punto final sensorial (vida útil) a $35^{\circ} \mathrm{C}$}

En la Tabla 4.6 se muestran los resultados del análisis de aceptabilidad realizado por 20 consumidores sobre muestras almacenadas a $35^{\circ} \mathrm{C}$ durante distintos tiempos. Se preguntó si consumirían o no el producto en base al aroma y a la apariencia. 
Tabla 4.6 Datos obtenidos a partir del análisis de aceptabilidad hecho por 20 consumidores sobre el producto almacenado a $35^{\circ} \mathrm{C}$

\begin{tabular}{|c|c|c|c|c|c|c|}
\hline \multirow{2}{*}{ Consumidor } & \multicolumn{6}{|c|}{ Tiempo (días) } \\
\hline & 0 & 11 & 14 & 17 & 19 & 21 \\
\hline 1 & si & si & si & si & no & no \\
\hline 2 & si & si & no & no & no & no \\
\hline 3 & si & si & si & no & no & no \\
\hline 4 & si & si & no & no & no & no \\
\hline 5 & si & si & si & si & si & no \\
\hline 6 & si & si & si & no & no & no \\
\hline 7 & si & si & no & no & no & no \\
\hline 8 & si & si & si & si & si & no \\
\hline 9 & si & si & no & no & no & no \\
\hline 10 & si & si & no & no & no & no \\
\hline 11 & si & si & si & no & no & no \\
\hline 12 & si & si & si & no & no & no \\
\hline 13 & si & si & si & no & si & no \\
\hline 14 & si & si & si & si & no & no \\
\hline 15 & si & si & no & si & no & no \\
\hline 16 & si & si & si & no & no & no \\
\hline 17 & si & si & no & no & no & no \\
\hline 18 & no & si & no & no & no & no \\
\hline 19 & si & si & si & si & si & no \\
\hline 20 & si & si & si & no & no & no \\
\hline
\end{tabular}

si: si consumiría ; no: no consumiría

Dado que un consumidor rechazó la muestra a tiempo 0 de almacenamiento, se dedujo que no le gustó el producto en sí. Es por esto que no se tuvieron en cuenta sus evaluaciones.

Los porcentajes de rechazos obtenidos a partir de la Tabla 4.6 se pueden ver en la Tabla 4.7.

Tabla 4.7 Porcentajes de rechazos obtenidos a partir del análisis de aceptabilidad hecho por 20 consumidores sobre el producto almacenado a $35^{\circ} \mathrm{C}$

\begin{tabular}{cc}
\hline Tiempo (días) & $\%$ Rechazo \\
\hline 0 & 0 \\
11 & 0 \\
14 & 42 \\
17 & 74 \\
19 & 84 \\
21 & 100 \\
\hline
\end{tabular}

Se realizó el gráfico del porcentaje de rechazo en función del tiempo y se regresionó linealmente desde los 11 días (0\% de rechazo) hasta los 21 días (100\% de rechazo) obteniendo un $\mathrm{R}^{2}$ de 0,973 (Figura 4.15). 


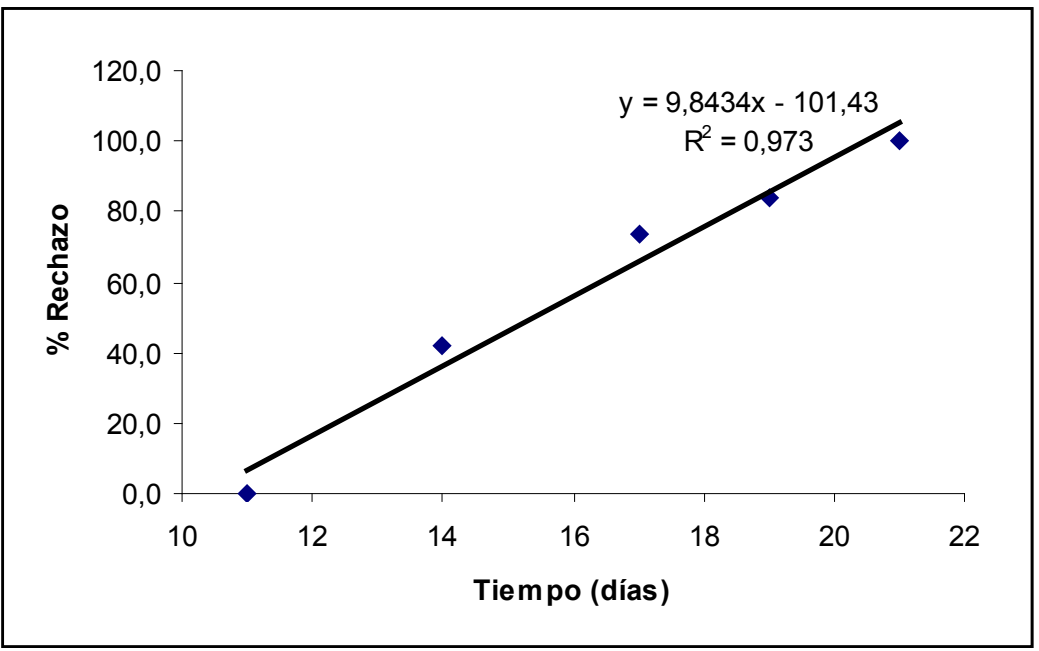

Figura 4.15 Porcentaje de rechazo en función del tiempo de almacenamiento para muestras almacenadas a $35^{\circ} \mathrm{C}$

En base a la ecuación obtenida en la Figura 4.15 (\% Rechazo = 9,8434t $101,43)$ se despejó el tiempo para un $50 \%$ de rechazo y se obtuvo un valor de 15,43 días. Es decir que, según el estudio de aceptabilidad realizado con muestras almacenadas a $35^{\circ} \mathrm{C}$, el punto final sensorial se alcanzó a los 15 días. Este es el valor de la vida útil de la preserva almacenada a $35^{\circ} \mathrm{C}$.

En la Figura 4.16 se observa una muestra al inicio del almacenamiento (tiempo 0) y una muestra almacenada a $35^{\circ} \mathrm{C}$ durante 17 días. Se puede ver claramente el cambio de color debido al enranciamiento de la preserva.
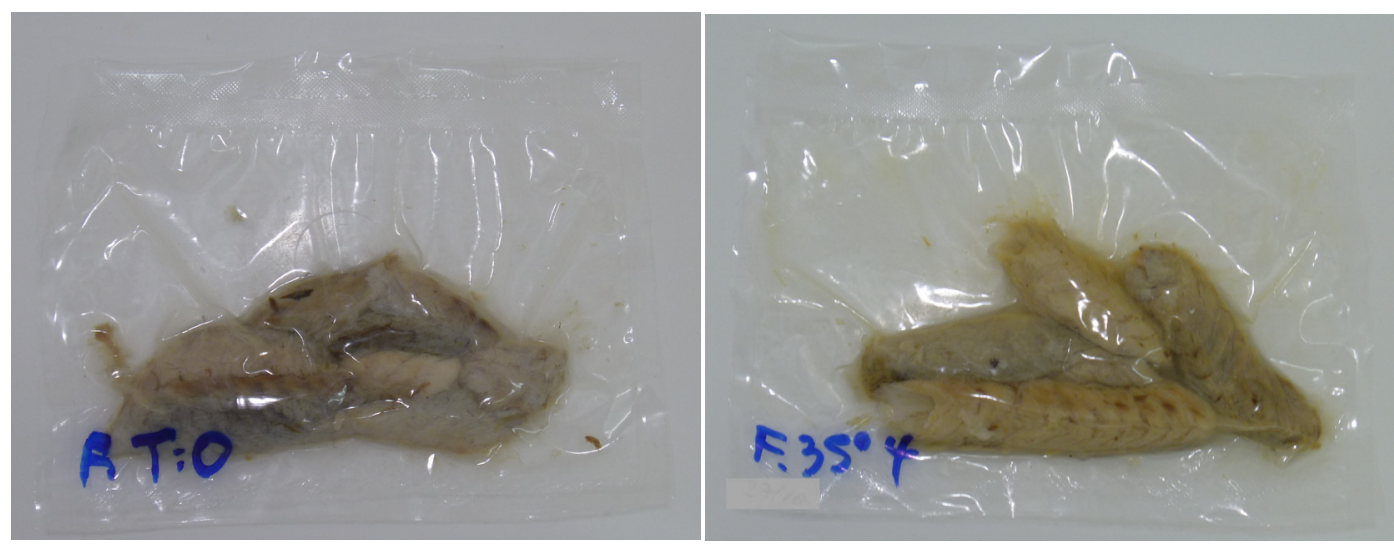

Figura 4.16 Muestras almacenadas a $35^{\circ} \mathrm{C}$ durante 0 y 17 días. 
En la Sección 4.5.2 se analizó el perfil de los ácidos grasos durante el almacenamiento a $35^{\circ} \mathrm{C}$. Este estudio evidenció un inicio de enranciamiento de los ácidos grasos monoinsaturados aproximadamente a partir del día 14. Es decir que, la vida útil establecida en 15 días para una temperatura de $35^{\circ} \mathrm{C}$ está acorde con el enranciamiento determinado mediante el perfil de ácidos grasos.

\subsubsection{Estudio acelerado de la Vida Útil Sensorial}

El objetivo de este estudio fue determinar el deterioro a tres temperaturas de almacenamiento más elevadas $\left(15,25\right.$ y $\left.35^{\circ} \mathrm{C}\right)$ para poder predecir la vida útil de la preserva a temperatura de refrigeración $\left(5^{\circ} \mathrm{C}\right)$.

Si se representa el parámetro estudiado (color o aroma rancio) en función del tiempo y se obtiene una línea recta, el orden de reacción es cero. En cambio, si al representar el logaritmo del parámetro en función del tiempo se obtiene una línea recta, la reacción es de primer orden. Como se puede observar en las Figuras 4.17 y 4.18, tanto para el aroma rancio como para el color, ambos parecerían seguir una tendencia lineal con respecto al tiempo. Esto se comprobó mediante regresión lineal de cada una de las curvas.

Al suponer que el aroma rancio y el color en función del tiempo siguen una cinética de orden cero, se aplicó la ecuación 4.6. Se siguió la misma metodología para los dos parámetros estudiados. Para cada una de las temperaturas de almacenamiento se realizó una regresión lineal del parámetro con el tiempo, cuya pendiente fue igual a k. En las Figuras 4.17 y 4.18 se pueden ver las correlaciones lineales realizadas. 


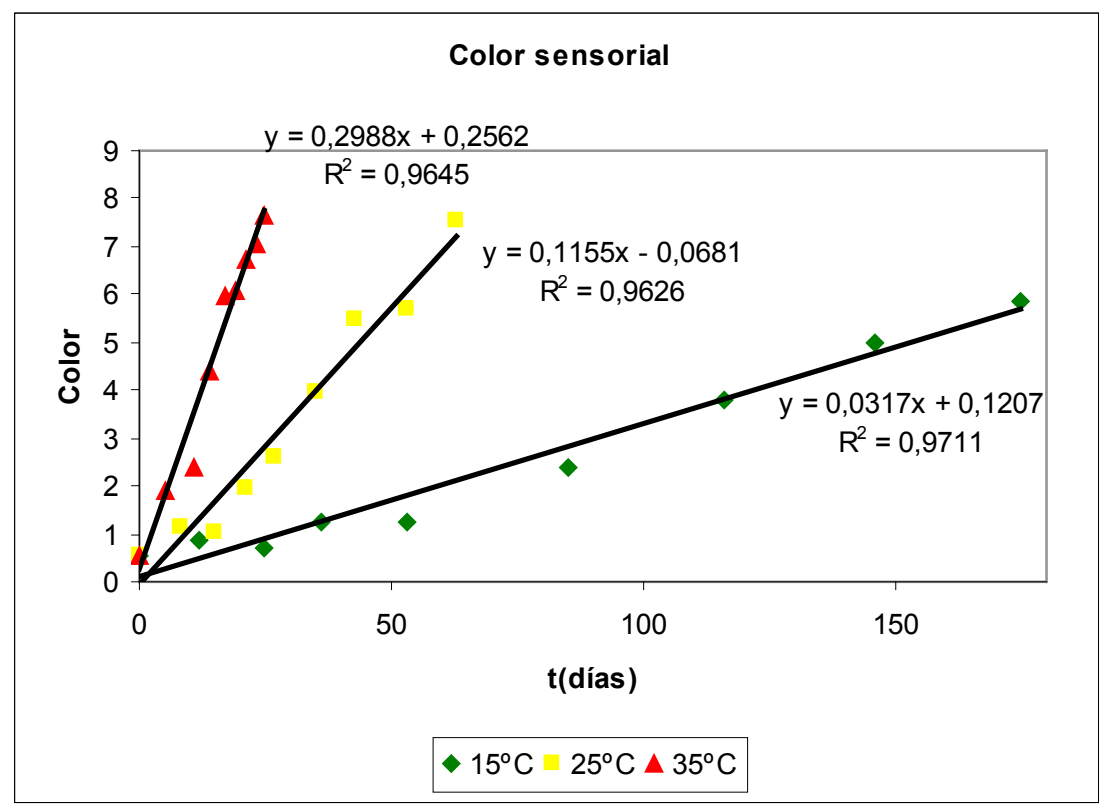

Figura 4.17 Regresión lineal de la evaluación sensorial de color en función del tiempo a las tres temperaturas

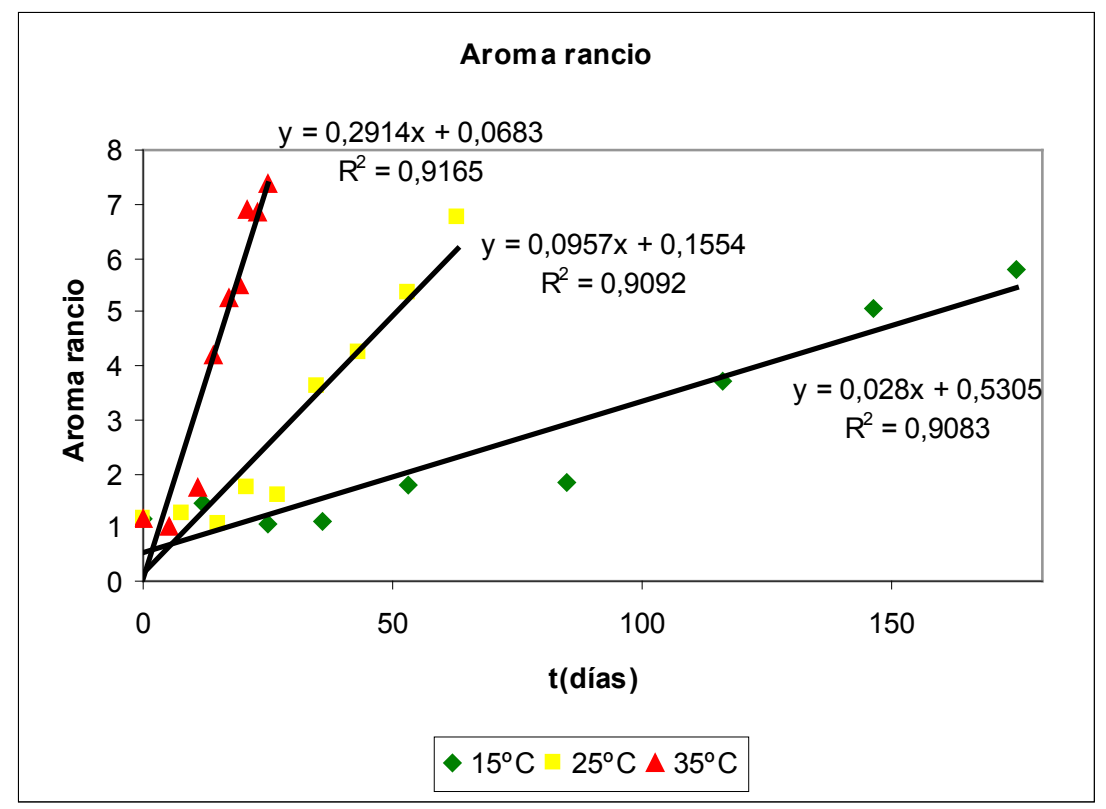

Figura 4.18 Regresión lineal de la evaluación de aroma rancio en función del tiempo a las tres temperaturas

Tanto en color como en aroma rancio se comprobó que los ajustes fueron satisfactorios para las tres temperaturas $\left(0,9083<R^{2}<0,9711\right)$. A partir de estos resultados se confirmó que el orden de reacción fue cero. Estos datos concuerdan con lo expresado por Labuza y Schmidt (1985), informando que las reacciones de orden cero se aplican, entre otros, a la oxidación de lípidos en alimentos congelados y deshidratados. Las ecuaciones de las regresiones lineales obtenidas de las Figuras 
4.17 y 4.18 se presentan en la Tabla 4.8. Donde P es el parámetro sensorial evaluado y t el tiempo de almacenamiento.

Tabla 4.8 Ecuaciones de las regresiones lineales de color y aroma rancio a las tres temperaturas analizadas

\begin{tabular}{ccl}
\hline Temp. $\left({ }^{\circ} \mathbf{C}\right)$ & \multicolumn{1}{c}{ Color sensorial } & \multicolumn{1}{c}{ Aroma rancio } \\
\hline $\mathbf{1 5}$ & $\mathrm{P}_{\text {color }}=0,0317 \mathrm{t}+0,1207$ & $\mathrm{P}_{\text {a.rancio }}=0,028 \mathrm{t}+0,5305$ \\
$\mathbf{2 5}$ & $\mathrm{P}_{\text {color }}=0,1155 \mathrm{t}-0,0681$ & $\mathrm{P}_{\text {a.rancio }}=0,0957 \mathrm{t}+0,1554$ \\
$\mathbf{3 5}$ & $\mathrm{P}_{\text {color }}=0,2988 \mathrm{t}+0,2562$ & $\mathrm{P}_{\text {a.rancio }}=0,2914 \mathrm{t}+0,0683$ \\
\hline
\end{tabular}

A partir de las ecuaciones a $35^{\circ} \mathrm{C}$ de color sensorial y aroma rancio (Tabla 4.8) y utilizando el tiempo del punto límite sensorial obtenido anteriormente ( $t=15,43$ días) se calculó el valor del punto límite sensorial de la preserva. Para color sensorial fue 4,86 y para aroma rancio 4,56 .

A partir de las ecuaciones a 15 y $25^{\circ} \mathrm{C}$ (Tabla 4.8) se despejó el valor de la vida útil $(t)$ a estas temperaturas utilizando los valores del punto límite sensorial $\left(P_{\text {color }}=\right.$ 4,86 y $\left.\mathrm{P}_{\text {a rancio }}=4,56\right)$. A $25^{\circ} \mathrm{C}$ se obtuvieron valores de vida útil de 43 días según color y de 46 días según aroma rancio. $\mathrm{A} 15^{\circ} \mathrm{C}$ se obtuvieron valores de vida útil de 150 días según color y de 144 días según aroma rancio.

Esta metodología de trabajo para obtener la vida útil acelerada de productos alimenticios ha sido aplicada por distintos autores. García y Molina (2008), estimaron la vida útil de mayonesa mediante pruebas aceleradas tomando como parámetro de deterioro el enranciamiento de los lípidos y encontraron que el orden de reacción también fue cero. Torres y col. (2001) utilizaron esta metodología para hallar la vida útil de una fórmula dietética en función de la lisina disponible (en este caso el orden de reacción fue de 1). García y col. (2011) estudiaron la vida útil acelerada de pasta de tomate con esta metodología teniendo como parámetro de deterioro el color (con un orden de reacción de cero).

\section{Dependencia con la temperatura}

Además de determinar el valor de vida útil a las temperaturas ensayadas, las ecuaciones que se muestran en la Tabla 4.8 se utilizaron para determinar la constante de velocidad de reacción $(k)$ representada por la pendiente de la recta. Como se puede observar en la Tabla 4.9, el valor de K aumentó al aumentar la temperatura de almacenamiento. Estos resultados son coherentes dado que al aumentar la 
temperatura, la velocidad de reacción (enranciamiento) aumenta. Hough y Garitta (2005) reportaron la misma tendencia de aumento de la constante de velocidad de reacción (en sabor oxidado de mayonesa) con similares temperaturas de almacenamiento $\left(20,35\right.$ y $\left.45^{\circ} \mathrm{C}\right)$.

Tabla 4.9 Constantes de velocidad de reacción (K) para los parámetros color y aroma rancio para las tres temperaturas de almacenamiento

\begin{tabular}{ccc}
\hline \multirow{2}{*}{ Temp. $\left({ }^{\circ} \mathrm{C}\right)$} & \multicolumn{2}{c}{$\mathbf{K}$} \\
\cline { 2 - 3 } & Color sensorial & Aroma rancio \\
\hline $\mathbf{1 5}$ & 0,0317 & 0,028 \\
$\mathbf{2 5}$ & 0,1155 & 0,0957 \\
$\mathbf{3 5}$ & 0,2988 & 0,2914 \\
\hline
\end{tabular}

Con los valores de $\mathrm{k}$ a las tres temperaturas estudiadas, se aplicó el modelo de Arrhenius (Ecuación 4.8). A partir de la pendiente de la correlación lineal entre $\ln (k)$ en función de $1 / T(K)$, se obtuvo la energía de activación como se representa en las Figuras 4.19 y 4.20 .

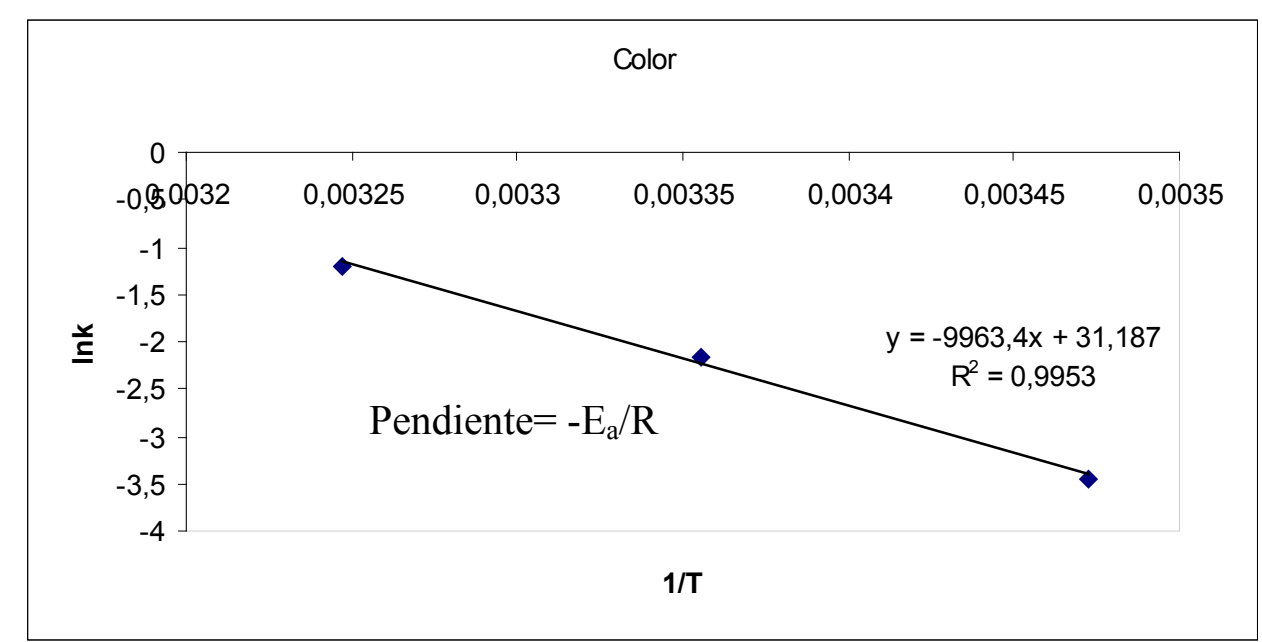

Figura 4.19 Logaritmo de la constante de velocidad de reacción del color en función de la inversa de la temperatura 


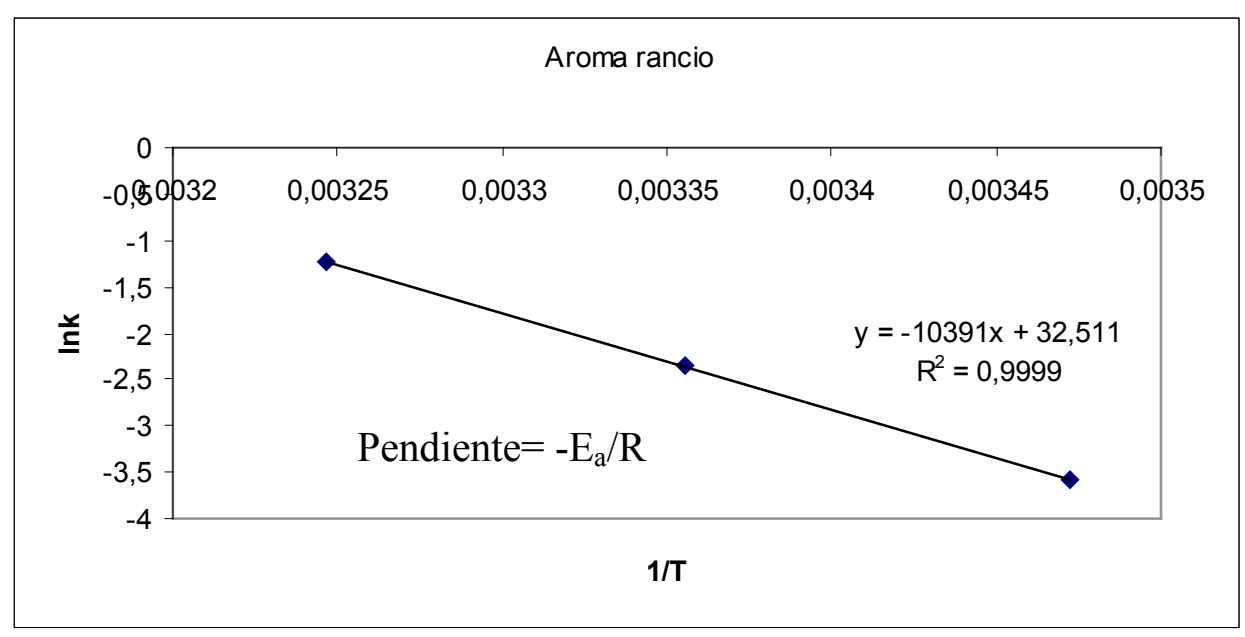

Figura 4.20 Logaritmo de la constante de velocidad de reacción del aroma rancio en función de la inversa de la temperatura

La $E_{a}$ obtenida para el color fue de $82,83 \mathrm{~kJ} / \mathrm{mol}$ y para el aroma rancio fue de $86,39 \mathrm{~kJ} / \mathrm{mol}$. Estos valores de $\mathrm{E}_{\mathrm{a}}$ se encuentran en el rango de valores presentados por otros autores. Según Torres y col. (2001), la energía de activación para reacciones de oxidación de lípidos se encuentra en el orden de 41,84 a 104,60 kJ/mol. García y Molina (2008) reportaron un valor de $E_{a}$ de $80,96 \mathrm{~kJ} / \mathrm{mol}$ para el enranciamiento de los lípidos en mayonesa.

\section{Determinación de la vida útil a temperatura de refrigeración}

A partir del gráfico entre el logaritmo de la vida útil en función de la temperatura de almacenamiento (Figuras 4.21 y 4.22 ), mediante regresión lineal se obtuvieron las ecuaciones 4.9 y 4.10 .

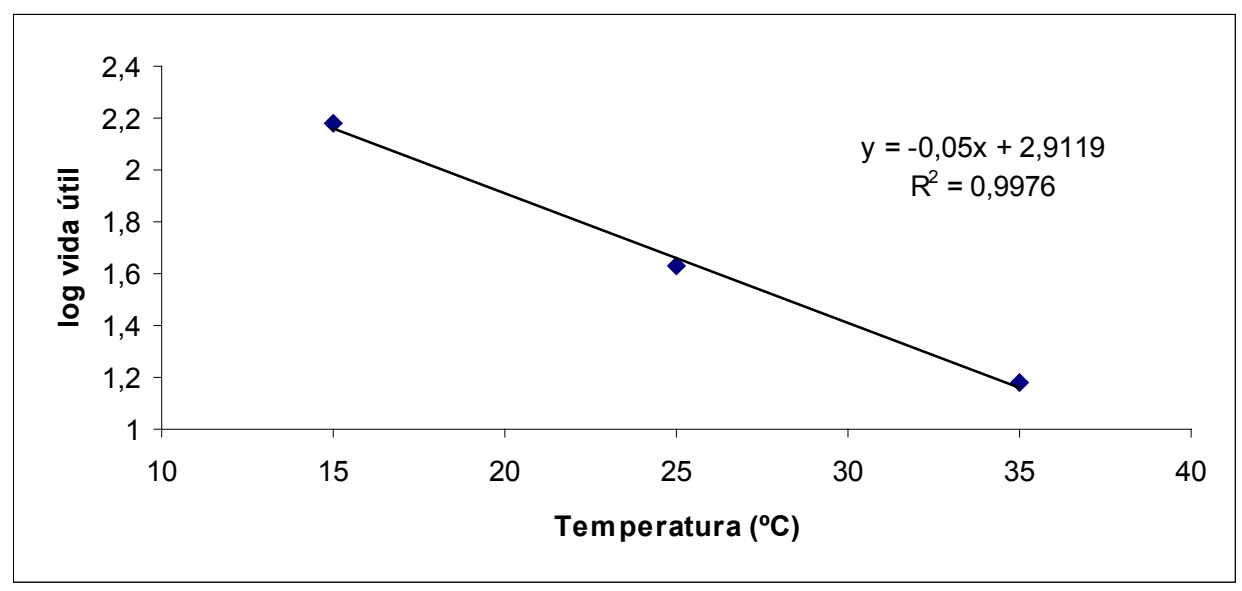

Figura 4.21 Logaritmo de la vida útil (según color sensorial) en función de la temperatura de almacenamiento 


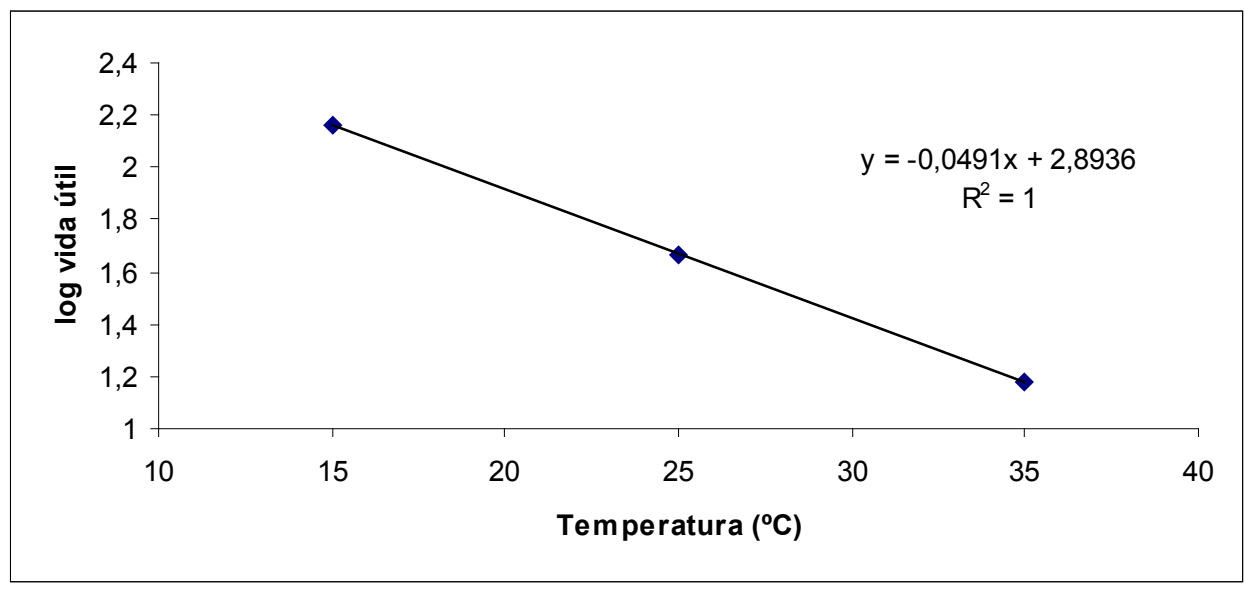

Figura 4.22 Logaritmo de la vida útil (según aroma rancio) en función de la temperatura de almacenamiento

$\log \left(\right.$ v.util $\left._{\text {color }}\right)=-0,05 T+2,9119$

$\log \left(\right.$ v.util $\left._{\text {a.rancio }}\right)=-0,0491 T+2,8936$

Y despejando:

v.útil $l_{\text {color }}=10^{(-0,0492 T+2,9076)}$

v.útil ${ }_{\text {a.rancio }}=10^{(-0,0487 T+2,9311)}$

Utilizando las ecuaciones 4.11 y 4.12 se estimó el tiempo de vida útil de la preserva almacenada a temperatura de refrigeración $\left(T=5^{\circ} \mathrm{C}\right)$. De acuerdo a la estimación hecha en base al color, el tiempo de vida útil de los lomitos almacenados a $5^{\circ} \mathrm{C}$ fue de 459 días y en base al aroma rancio de 445 días.

\subsection{Conclusiones}

Se realizó el estudio de vida útil sensorial acelerado utilizando tres temperaturas de almacenamiento: 15,25 y $35^{\circ} \mathrm{C}$. El tiempo de vida útil para las temperaturas ensayadas se determinó cuando el valor de los indicadores críticos de deterioro llegó a valores inaceptables sensorialmente. La preserva almacenada a $35^{\circ} \mathrm{C}$ presentó una vida útil de 15 días, a $25^{\circ} \mathrm{C}$ de 43 días y a $15^{\circ} \mathrm{C}$ de 146 días. 
Se realizó un estudio instrumental del cambio de color utilizando un colorímetro y se encontró una muy buena correlación entre el color sensorial y los parámetros $a^{*}$ y $b^{*}$.

De acuerdo a las ecuaciones obtenidas para el aumento de los índices de deterioro sensorial (color amarillo-rojizo y aroma rancio) en función del tiempo de almacenamiento, el orden de reacción obtenido fue cero. Se calcularon las constantes de velocidad de reacción $(\mathrm{K})$ para cada índice y para cada temperatura y se obtuvo una $E_{a}$ de $82,83 \mathrm{~kJ} / \mathrm{mol}$ para el color amarillo-rojizo y de $86,39 \mathrm{~kJ} / \mathrm{mol}$ para el aroma rancio. Estas $E_{a}$ halladas se encuentran en el orden de las $E_{a}$ halladas por otros autores para reacciones de oxidación de lípidos en alimentos.

Finalmente, se halló una relación para estimar la vida útil de la preserva a distintas temperaturas. Extrapolando los resultados a temperatura de refrigeración, se determinó que a una temperatura de $5^{\circ} \mathrm{C}$ la vida útil de la preserva es de 459 días en base al color amarillo-rojizo y de 445 días en base al aroma rancio. 


\section{CONCLUSIONES GENERALES}

A partir de los distintos estudios realizados en esta tesis, se logró cumplir con los objetivos planteados. Luego de desarrollar el proceso de elaboración de la preserva de caballa, se estudió la estabilidad microbiológica y se determinó la vida útil. En virtud de ello, a continuación se detallan las conclusiones generales:

> Se diseño el proceso de elaboración de la preserva de caballa. Las etapas del proceso de elaboración de lomitos de humedad intermedia fueron: descongelado de la caballa, eviscerado y corte de cabezas y colas, cocción al vapor, oreo, separación de los lomitos, deshidratación osmótica, envasado al vacío, pasteurización y almacenamiento refrigerado.

> Mediante la DO en solución de glicerol (40\%), sal $(5 \%)$ y ácido cítrico $(0,5 \%)$ se obtuvo un producto con un contenido de humedad del 50,32 $\pm 0,02 \%$, un $1,99 \pm 0,01 \%$ de $\mathrm{NaCl}$, un $16,03 \pm 0,63 \%$ de glicerol y un 0,16 $\pm 0,01 \%$ de ácido cítrico. Además, el $\mathrm{pH}$ fue 5,11 $\pm 0,05$ y la $\mathrm{a}_{\mathrm{w}}$ 0,89 $\pm 0,01$. De acuerdo a estas características fisicoquímicas, el único microorganismo patógeno capaz de crecer en la preserva es el Staphylococcus aureus, por lo que se diseñó la etapa de pasteurización teniendo a este microorganismo como referencia. El tiempo de pasteurización para lograr una letalidad de 5D (5 reducciones decimales) determinado por el método general fue de 53,5 min. y de 52,0 y 52,5 min. por el método de Stumbo y de Hayakawa respectivamente.

$>$ Se realizó un perfil sensorial mediante el método del Análisis Descriptivo Cualitativo analizando aspecto, aroma, textura y sabor de los lomitos de humedad intermedia. Para este fin se seleccionó un grupo de panelistas y se los entrenó para poder evaluar los descriptores característicos del producto bajo estudio.

> Para describir los cambios sensoriales producidos debido a la DO, se comparó el producto final con lomitos cocidos (sin deshidratar). La DO no cambió el color, ni la jugosidad, ni los aromas a rancio y a pescado, ni el sabor a rancio ni el gusto amargo. En cambio, esta etapa aumentó significativamente la dureza (tanto al corte como en boca), el aroma dulzón, los gustos dulce, ácido y salado, y disminuyó significativamente el sabor a pescado. 
Además, los cambios en textura y color debido a la etapa de deshidratación fueron analizados instrumentalmente. La DO generó una mayor dureza en los lomitos pero no afectó a la adhesividad ni a la cohesividad. En cuanto al color, este parámetro no se vio afectado por la DO. Los resultados instrumentales de textura y color estuvieron en concordancia con los sensoriales.

$>$ El rango de temperatura entre 50 y $90^{\circ} \mathrm{C}$ influyó en los fenómenos de transferencia de masa durante el proceso de DO de rodajas de caballa inmersas en una solución de glicerol $(54 \% \mathrm{p} / \mathrm{p})$ y sal $(7 \% \mathrm{p} / \mathrm{p})$. Una mayor temperatura de proceso promovió mayor pérdida de agua y ganancia de solutos durante la deshidratación osmótica de las rodajas. Como resultado, el tiempo requerido para alcanzar un valor de $a_{w}$ determinado disminuyó a medida que aumentó la temperatura. La cinética de transferencia de masa de agua, sal y glicerol durante la DO fue ajustada adecuadamente por los modelos de Crank, Peleg, $Z$ \& $L$ y Weibull. Los coeficientes de difusión (D) y los parámetros de los modelos de Zugarramurdi \& Lupín, Peleg y Weibull $\left(\mathrm{K}, \mathrm{K}_{1}\right.$ y $\left.\alpha\right)$ mostraron una dependencia con la temperatura siguiendo la relación de Arrhenius. Los modelos de Peleg y de $Z$ \& L brindaron mayor información ya que también permitieron la predicción del contenido de agua y solutos en el equilibrio (siendo $Z \&$ L el modelo que realizó las mejores predicciones). Por lo tanto, el modelo de $Z$ \& $L$ fue capaz de ajustar adecuadamente los datos de transferencia de masa y, además, predecir satisfactoriamente los contenidos de agua y solutos en el equilibrio.

> Durante la deshidratación osmótica de cilindros de caballa en la solución hipertónica de agua, sal y glicerol el modelo de Crank para cilindro finito e infinito y los modelos empíricos de Zugarramurdi \& Lupín y Azuara predijeron mejor la ganancia de sal y glicerol que la pérdida de agua. Tres términos en la solución analítica de la ecuación de Fick para cilindro infinito fueron apropiados para determinar los coeficientes de difusión. El modelo basado en la solución de la ley de Fick para cilindro infinito resultó la mejor opción para representar la pérdida de agua y la ganancia de solutos. Los valores de equilibrio estimados con el modelo de Azuara se ajustaron correctamente a los valores experimentales. Se logró predecir la distribución de agua y solutos en las muestras de cilindros de caballa. Los cambios en las concentraciones de agua, glicerol y sal estuvieron confinados principalmente en la región de la superficie y progresaron lentamente hacia el interior. Al final de la DO los contenidos de agua y solutos en el lomito de caballa alcanzaron el equilibrio con la solución osmótica. 
$>$ Las barreras utilizadas durante la elaboración de la preserva (cocción al vapor de la materia prima, deshidratación osmótica, envasado al vacío y pasteurización) le dieron una excelente estabilidad microbiológica dado que no se detectó presencia de ninguno de los grupos de microorganismos que se estudiaron durante 12 meses. Dado que este comportamiento se observó a las 3 temperaturas, se puede afirmar que la temperatura de almacenamiento no es relevante en el aspecto microbiológico del producto. Si se trabaja bajo estrictas normas de calidad, cumpliendo por ejemplo con las directrices de un plan HACCP, la preserva podría ser almacenada a temperatura ambiente.

> Se analizó el comportamiento microbiológico de la preserva sin pasteurizar. Los resultados obtenidos a partir de este análisis confirman la importancia del proceso de pasteurización de la preserva. Se logró modelar satisfactoriamente el crecimiento de BP, BAM y Staphylococcus spp. mediante los modelos de Gompertz modificado y logístico.

> De acuerdo a los resultados del estudio de reto microbiano, la etapa de la pasteurización redujo 5 ciclos logarítmicos la población de Staphylococcus aureus inoculada. Esta fue la reducción buscada en el cálculo teórico del tiempo de pasteurización (Capítulo 1). De esta manera, se logró validar exitosamente el proceso de pasteurización.

> Se analizó el comportamiento de la población de $S$. aureus sobreviviente a la pasteurización determinando que las barreras aplicadas fueron efectivas para evitar el crecimiento de $\mathrm{S}$. aureus durante el almacenamiento refrigerado.

Se realizó el estudio de vida útil sensorial acelerado utilizando tres temperaturas de almacenamiento: 15,25 y $35^{\circ} \mathrm{C}$. El tiempo de vida útil para las temperaturas ensayadas se determinó cuando el valor de los indicadores críticos de deterioro llegó a valores inaceptables sensorialmente. La preserva almacenada a $35^{\circ} \mathrm{C}$ presentó una vida útil de 15 días, a $25^{\circ} \mathrm{C}$ de 43 días y a $15^{\circ} \mathrm{C}$ de 146 días.

$>$ De acuerdo a las ecuaciones obtenidas para el aumento de los índices de deterioro sensorial (color amarillo-rojizo y aroma rancio) en función del tiempo de almacenamiento, el orden de reacción obtenido fue cero. Se calcularon las constantes de velocidad de reacción $(\mathrm{K})$ para cada índice y para cada temperatura y se obtuvo 
una $E_{a}$ de $82,83 \mathrm{~kJ} / \mathrm{mol}$ para el color amarillo-rojizo y de $86,39 \mathrm{~kJ} / \mathrm{mol}$ para el aroma rancio.

Se halló una relación para estimar la vida útil de la preserva a distintas temperaturas. Extrapolando los resultados a temperatura de refrigeración, se determinó que a una temperatura de $5^{\circ} \mathrm{C}$ la vida útil de la preserva es de 459 días en base al color amarillo-rojizo y de 445 días en base al aroma rancio.

En base a los resultados obtenidos, se puede concluir que se logró desarrollar satisfactoriamente una preserva de caballa utilizando la tecnología de obstáculos. Se obtuvo un producto del tipo "listo para consumir" con una excelente estabilidad microbiológica y una vida útil de, al menos, 12 meses.

Se espera que estos resultados contribuyan al aumento de nuevos productos con mayor valor agregado, con una vida comercial más extensa, saludables y que puedan ser distribuidos a largas distancias abasteciendo mercados nacionales e internacionales.

Como perspectivas a futuro, se espera poder realizar la transferencia hacia el sector industrial pesquero, tan relevante para la ciudad de Mar del Plata. Para lograr esto, se propone la realización de estudios de aceptabilidad del producto (para analizar distintas formas de presentación) así como también estudios de optimización del proceso productivo. 


\section{NOMENCLATURA}

$\begin{array}{ll}\text { AGMI } & \text { Acidos grasos monoinsaturados } \\ \text { AGPI } & \text { Acidos grasos poliinsaturados } \\ \text { AGS } & \text { Acidos grasos saturados } \\ \text { AHI } & \text { Alimentos de humedad intermedia } \\ \alpha & \text { Parámetro de escala (modelo de Weibull) } \\ \alpha_{0} & \text { Difusividad térmica (K/(pCp)) } \\ a_{w} & \text { Actividad de agua } \\ \text { BAM } & \text { Bacterias aerobias mesófilas } \\ \beta & \text { Parámetro de forma (modelo de Weibull) } \\ \text { Bi } & \text { Número de Biot } \\ \text { BP } & \text { Bacterias psicrótrofas } \\ \text { Cp } & \text { Calor específico } \\ \text { D } & \text { Coeficiente de difusión } \\ \text { DO } & \text { Deshidratación osmótica / Deshidratado osmóticamente } \\ \mathrm{E}_{a} & \text { Energía de activación } \\ \text { EAM } & \text { Envasado en atmósfera modificada } \\ \mathrm{K}_{0} & \text { Conductividad térmica } \\ \mathrm{K} & \text { Constante de velocidad específica (modelo de Z \& L) } \\ \mathrm{K}_{1} & \text { Constante de velocidad de Peleg } \\ \mathrm{K}_{2} & \text { Constante de capacidad de Peleg } \\ \mathrm{N} & \text { Newton } \\ \mathrm{NaCl} & \text { Cloruro de sodio } \\ \mathrm{NaOH} & \text { Hidróxido de sodio } \\ \mathrm{P} & \text { Desviación relativa media } \\ \mathrm{R}^{2} & \text { Coeficiente de determinación } \\ \rho & \text { Densidad } \\ \mathrm{RMSE} & \text { Raíz del error cuadrático medio } \\ \mathrm{S} & \text { Constante del modelo de Azuara } \\ \mathrm{S} . \text { aureus } & \text { Staphylococcus aureus } \\ \mathrm{t} & \text { Tiempo } \\ \mathrm{T} & \text { Temperatura } \\ \text { TBARS } & \text { Sustancias reactivas al ácido 2-tiobarbitúrico } \\ \text { TPA } & \text { Texture profile análisis } \\ \mathrm{UFC} & \text { Unidades formadoras de colonias } \\ \text { Z\&L } & \text { Zugarramurdi y Lupín } \\ \% \text { IS } & \text { Porcentaje de Incorporación de Solutos } \\ & \end{array}$




\section{BIBLIOGRAFÍA}

Agustinelli S. P. 2014. Estudio del Proceso de Ahumado en Frío de Filetes de Caballa (Scomber japónicus). Evaluación y Modelado de Parámetros Tecnológicos. Tesis presentada para optar al grado de Doctor en Ingeniería. UNLP.

An H., Weerasinghe V., Seymour T.A. y Morrissey M.T. 1994. Cathepsin degradation of Pacific whiting surimi protease. Journal of Food Science, 59: 1013-1017.

AOAC - Association of Official Analytical Chemists - 1990. Official Methods of Analysis. 15th ed. Washington, D.C.

Arashisar A., Hisar O., Kaya M. y Yanik T. 2004. Effects of modified atmosphere and vacuum packaging on microbiological and chemical properties of rainbow trout (Oncorynchus mykiss) fillets. International Journal of Food Microbiology, 97: 209-214.

Atanassova V., Meindl A. y Ring C.. 2001. Prevalence of Staphylococcus aureus and staphylococcal enterotoxins in raw pork and uncooked smoked ham-a comparison of classical culturing detection and RFLP-PCR. International Journal of Food Microbiology, 68: 105-113.

Ayala Aponte, A.A., Serna-Cock, L., Giraldo-Cuartas, C.J. 2009. Efecto de la agitación sobre la deshidratación osmótica de pitahaya amarilla (Selenicereus megalanthus $\mathrm{S}$.) empleando soluciones de sacarosa. Interciencia, 34(7):492-497.

Azoubel P. M. y Murr F. E. X. 2003. Optimisation of osmotic dehydration of cashew apple (Anacardium occidentale $L$ ) in sugar solutions. Food Science and Technology International, 9(6), 427-433.

Azuara E., Cortés R., García H. S., Beristain C. I. 1992. Kinetic model for osmotic dehydration and its relationship with Fick's second law. International Journal of Food Science and Technology, 27, 409-418.

Azuara E., Beristain C. I., Gutierrez G. F. 1998. A Method for Continuous Kinetic Evaluation of Osmotic Dehydration. Lebensmittel Wissenschaft und Technolgie, 31: 317-321. 
AZTI/DAPA. 2008. FOODPREDICT - Estudios de predicción de la vida útil en productos alimentarios preparados. Dpto. Agricultura, Pesca y Alimentación, Eusko Jaurlaritza . Gobierno Vasco.

Barat J.M. 1998. Desarrollo de un modelo de la deshidratación osmótica como operación básica. Tesis Doctoral. Universidad Politécnica de Valencia.

Barda N. B. 2012. Curso: Introducción al análisis sensorial como herramienta de control de calidad de alimentos. Facultad de Ingeniería, UNMDP. Mar del Plata.

Bennett R. W. y Lancette G. A. 1995. Staphylococcus aureus. Chapter 12. En: Bacteriological Analytical Manual. Food and Drug Administration. $8^{\text {th }}$ Edition. AOAC International, Gaithersburg, USA.

Betts G. D. y Gaze J. E. 1992. Food pasteurization treatments. Technical Manual No. 27, part II. Gloucestershire, UK: Campden. Food and Drink Research Association.

Birkeland S. y Bjerkeng B. 2005. The quality of cold-smoked Atlantic salmon (Salmo salar) as affected by salting method, time and temperature. International Journal of Food Science and Technology, 40:963-976.

Bonnans S. y Noble A. C. 1993. Effect of sweetener type and of sweetener and acid levels on temporal perception of sweetness, sourness and fruitiness. Chemical Senses, 18 (3) 273-283.

Botsoglou N. A., Fletouris D. J., Papageorgiou G. E., Vassilopoulos V. N., Mantis A. J. y Trakatellis A. G. 1994. Rapid, sensitive, and specific thiobarbituric acid method for measuring lipid peroxidation in animal tissue, food, and feedstuff samples. J Agr Food Chem, 42 (9), 1931-1937.

Bourne M. C. 1978. Texture profile analysis. Food Technology, 41(2), 163-178.

Brockman M. C. 1970. Development of intermediate moisture foods for military use. Food Technol. 24, 60-64. 
Burhan Uddin M., Ainsworth P. y Ibanoglu S. 2004. Evaluation of mass exchange during osmotic dehydration of carrots using response surface methodology. Journal of Food Engeneering, 65, 473-477.

Casales M. R. y Yeannes M. I. 1987. Evaluación sensorial de caballa: influencia de la materia prima en el producto final. Revista de ciencias agrarias, 8(3-4): 19-26.

Casales M. R. y Yeannes, M. I. 2006. Análisis de difusión múltiple y de equilibrio en el proceso de marinación de anchoita (Engraulis anchoita). En: Congreso Argentino de Ciencia y Tecnología de Alimentos. Mar del Plata: Libro de Actas, (4) 1217-1224.

Casales M.R., Capaccioni M.E. y Yeannes M.I. 2009. Obtainment of equilibrium times and diffusion coefficients of acid and salt to design the marinating process of Engraulis anchoita fillets. Ciência e Tecnologia de Alimentos. Campinas, 29(4): 933-937.

Castillejo-Rodríguez A. M., García Gimeno R. M., Zurera Cosano G., Barco Alcalá E. y Rodríguez Perez M. R. 2002. Assessments of mathematical models for predicting Staphylococcus aureus growth in cooked meat products. Journal of Food Protection, 65 (4): 659-665.

Chaijan M., Benjakul S., Visessanguan W. y Faustman C. 2005. Changes of pigments and color in sardine (Sardinella gibbosa) and mackerel (Rastrelliger kanagurta) muscle during iced storage. Food Chem. 93 (4): 607-617.

Chaijan M., Benkajul S., Visessanguan W. y Faustman C. 2006. Changes of lipids in sardine (Sardinella gibbosa) muscle during iced storage. Food Chemistry, 99: 83-91.

Chawla S. P. y Chander R. 2004. Microbiological safety of shelf-stable meat products prepared by employing hurdle technology. Food Control, 15: 559-563.

Chiralt A. y Talens P. 2005. Physical and chemical changes induced by osmotic dehydration in plant tissues. Journal of Food Engineering, 67 (1-2): 167-177.

Chirife J., Scorza O. C., Vigo M. S., Bertoni M. H. y Cattaneo P. 1979. Preliminary studies on the storage stability of intermediate moisture beef formulated with varius water binding agents. Journal of Food Technology, 14: 421-428. 
CIE. 1978. Recommendations on uniform colour spaces, colour difference equations, psychometric colour terms. CIE publication No.15 (E.-1.3.1) 1971, Supplement No.2. Viena.

Collignan A. y Montet D. 1998. Tenderizing squid mantle by marination at different $\mathrm{pH}$ and temperature levels. Lebensmittel Wissenschaft und Technolgie, 31 (7): 673-679.

Collignan A., Bohuon P., Deumier F., Poligné I. 2001. Osmotic treatment of fish and meat products. Journal of Food Engeneering, 49, 153-162.

Connell J.J. 1990. Control of Fish Quality. Fishing News Books, Blackwell Scientific Publications, London.

Connor W. E. 2000. Importance of n-3 fatty acids in health and disease. American Society for Clinical Nutrition, 71(1): 171-175.

Corzo O. y Bracho N. 2005. Osmotic dehydration kinetics of sardine sheets using Zugarramurdi and Lupín model. Journal of Food Engeneering, 66, 51-56.

Corzo O. y Bracho N. 2006. Application of Peleg model to study mass transfer during osmotic dehydration of sardine sheets. Journal of Food Engeneering, 75, 535-541.

Corzo O. y Bracho N. 2007. Water effective diffusion coefficient of sardine sheets during osmotic dehydration at different brine concentrations and temperatures. Journal of Food Engeneering, 80(2): 497-502.

Corzo O. y Bracho N. 2008. Application of Weibull distribution model to describe the vacuum pulse osmotic dehydration of sardine sheets. LWT-Food Science and Technology. 41, 1108-1115.

Corzo, O. Bracho N. y Millán R. 2008. Cambios de color en las láminas de sardina durante la deshidratación osmótica. Revista Científica, 18(4): 424-430.

Corzo O. y Bracho N. 2009. Aplicación del modelo de weibull normalizado en la deshidratación osmótica de láminas de sardina. Revista Científica, XIX (4): 400-407. 
Corzo O., Bracho N. y Rodriguez J. 2012. Comparison of Peleg and Azuara et al. models in the modeling mass transfer during pile salting of goat sheets. LWT - Food Science and Technology, 46, (2): 448-452.

Cousseau M. y Perrota R. 2000. Peces marinos de Argentina. Editado por el Instituto Nacional de Investigación y Desarrollo Pesquero (INIDEP).

Crank J. 1975. The Mathematics of Diffusion. Second ed., Oxford Clarendon Press.

Cunha L. M., Oliveira F. A. R. y Oliveira J. C. 1998. Optimal experimental design for estimating the kinetic parameters of process described by the Weibull probability distribution function. Journal of Food Engineering, 37, 175-191.

Curia A. V., Garita L., Restrepo P. y López C. 2005. Metodología de Punto de Corte. En: Estimación de la Vida Util Sensorial de los Alimentos. Ed.: Programa CYTED, Madrid, España.

Czerner M. y Yeannes M. I. 2010. Brining kinetics of different cuts of anchovy (Engraulis anchoita). International Journal of Food Science \& Technology, 45(10), 2001-2007.

Czerner M., Tomás M. C. y Yeannes M. I. 2010. Ripening of salted anchovy (Engraulis anchoita): development of lipid oxidation, colour and other sensorial characteristics. Journal of Science and Food Agricultural, DOI 10.1002/jsfa.4221.

Dalla Rosa M. y Giroux F. 2001. Osmotic treatment (OT) and problems related to the solution management. Journal of Food Engineering, 49: 223-236.

Del Valle F.R. y Nickerson J.T.R. 1967. Studies on salting and drying fish. II. Dynamic aspects of the salting of fish. Journal of Food Science. 32, 218-224.

DeVita M.D., Wadhera R.K., Theis M.L. y Ingham S.C. 2007. Assessing the potential of Streptococcus pyogenes and Staphylococcus aureus transfer to foods and customers via a survey of hands, hand-contact surfaces and food-contact surfaces at foodservice facilities. Journal of Foodservice, 18: 76-79. 
DHHS. 2011. Department of Health and Human Services. Public Health Service. Food and Drug Administration. Center for Food Safety and Applied Nutrition. Office of Food Safety. Fish and Fishery Products, Hazards and Controls Guidance. Fourth Edition. http://www.fda.gov/downloads/Food/GuidanceRegulation/UCM251970.pdf. Ultimo acceso: 04/02/2015.

DESA (Departamento de Evaluación Sensorial de Alimentos), ISETA. 2010. Introducción y Funciones de la Evaluación Sensorial. Curso Taller de Evaluación Sensorial. UNLP, La Plata.

EFSA, 2007. The community summary report on trends and sources of zoonoses, zoonotic agents, antimicrobial resistance and foodborne outbreaks in the European Union in 2006. EFSA Journal 94, 1-288.

Farahnaky A., Ansari S. y Majzoobi M. 2009. Effect of glycerol on the moisture sorption isotherms of figs. Journal of Food Engineering, 93: 468-473.

Favetto G., Chirife J. y Bartholomai G. B. 1981. A study of water lowering in meat during immersion-cooking in sodium chloride-glycerol solutions. I. equilibrium considerations and difussional analyses of solute uptake. Journal of Food Technology, 16, 609-619.

FDA. 1992. Foodborne pathogenic microorganisms and natural toxins handbook. Center for food safety \& applied nutrition. US Food and Drug Administration. http://pdf.usaid.gov/pdf docs/PNADO152.pdf. Ultimo acceso: 04/02/2015.

Fernández J., Pérez Álvarez J. A. y Fernández-López J. A. 1997. Thiobarbituric acid test for monitoring lipid oxidation in meat. Food Chemistry, 59(3), 345-353.

Fito P. 1994. Modelling of vacuum osmotic dehydration of food. Journal of Food Engineering,22: 313-328.

FSA. 2008. Food Standards Agency guidance on the safety and shelf-life of vacuum and modified atmosphere packed chilled foods with respect to non-proteolytic Clostridium botulinum. http://multimedia.food.gov.uk/multimedia/pdfs/publication/vacpacguide.pdf. Ultimo acceso: 04/02/2015. 
FSIS. 2001. Food Safety and Inspection Service. U.S. Department of Agriculture. Performance standards for the production of processed meat and poultry products; proposed rule. Fed. Regist. 66:1289-12636.

FSIS. 2009. Food Safety and Inspection Service. U.S. Department of Agriculture. Title 9 animal and animal products. Part 430, requirements for specific classes of products. Code of Federal Regulations. U.S. Government Printing Office, Washington, DC.

Galati S., Giannuzzi L. y Giner S. A. 2011. Modelling the effect of temperature and water activity on the growth of Aspergillus parasiticus on irradiated Argentinian flint maize. Journal of Stored Products Research, 47: 1-7.

Gámbaro A. 2005. Diseño de Ensayos de Vida Util de Alimentos. En: Estimación de la Vida Util Sensorial de los Alimentos. Ed.: Programa CYTED, Madrid, España.

Gámbaro A., Ares G. y Giménez A. 2006. Shelf life estimation of apple baby food. Journal of Sensory Studies, 21, 101-111.

García B. C., Chacón V. G. y Molina C. M.E. 2011. Evaluación de la vida útil de una pasta de tomate mediante pruebas aceleradas por temperatura. Ingeniería, Revista Semestral de la Universidad de Costa Rica, 21 (2): 31-38.

García B. C. y Molina M. 2008. Estimación de la vida útil de una mayonesa mediante pruebas aceleradas. Ingeniería, Revista Semestral de la Universidad de Costa Rica, $18(1,2): 57-64$

Garciarena A. D. y Buratti C. C. 2012. Análisis de los desembarques de caballa (Scomber japonicus) capturada al sur de $39^{\circ} \mathrm{S}$ por la flota comercial durante 2011. Informe Técnico Interno INIDEP 008.

Generoso S., Rodríguez S. del C. y Yeannes M. I. 2005. Evaluación sensorial de tamales a través de la aplicación del análisis descriptivo. Proceeding del Congreso Latinoamericano Ingeniería y Ciencias Aplicadas, pp.39- 40. 
Generoso S., Rodríguez S. del C. y Yeannes M. I. 2006. Caracterización sensorial de tamales y determinación del punto de corte sensorial para establecer la vida útil. Proceedings del $X$ Congreso de Ciencia y Tecnología de Alimentos. 1er Simposio Internacional de Nuevas Tecnologías. Ed. Ciencia Actual. Tomo II, pp.454- 461.

Gerla P. E. y Rubiolo A. C. 2003. A model for determination of multicomponent diffusion coefficients in foods. Journal of Food Engineering, 56:401-410.

Giannuzzi L., Pinotti A. y Zaritzky N. 1998. Mathematical modelling of microbial growth in packaged refrigerated beef stored at different temperatures. International Journal of Food Microbiology, 39, 101-110.

Gibson A.M., Bratchell, N. y Roberts T.A. 1988. Predicting microbial growth: growth responses of salmonellae in a laboratory medium as affected by $\mathrm{pH}$, sodium chloride and storage temperature. International Journal of Food Microbiology, 6: 155-78.

Giménez A., Ares F. y Ares G. 2012. Sensory shelf-life estimation: A review of current methodological approaches. Food Research International, 49: 311-325.

Godiksen H., Morzel M., Hyldig G. y Jessen F. 2009. Contribution of cathepsins B, L and $D$ to muscle protein profiles correlated with texture in rainbow trout (Oncorhynchus mykiss). Food Chemistry, 113: 889-896.

Gokoglu N. 2002. A Descriptive Method for Sensory Evaluation of Mussels. Lebensm.Wiss. u.-Technol., 355:63-567.

Gou P., Comaposada J. y Arnau J. 2003. NaCl content and temperature effects on moisture diffusivity in the Gluteus medius muscle of pork ham. Meat Science, 63: 2934.

Graiver N., Pinotti A., Califano A. y Zaritzky N. 2006. Diffusion of sodium chloride in pork tissue. Journal of Food Engineering, 77: 910-918.

Gram L. y Dalgaard P. 2002. Fish spoilage bacteria: problems and solutions. Curr. Opin. Biotech., 13: 262-266. 
Gram L. y Huss H. H. 2000. Fresh and processed fish and shellfish. In: Lund B.M., T.C. Baird-Parker y G.W. Gould (eds.). The Microbiological Safety and Quality of Foods. Aspen Publishers Inc., Gaitherburg, Maryland, USA. p. 472-506.

Graü C., Sánchez D., Zerpa A., Vallenilla O. y Berti O. 2003. Estudio de la microflora asociada a la formación de histamina en sardina (Sardinella aurita). Revista Científica, 13(3): 199-204.

Guizani N., Al-Busaidy M. A., Al-Belushi I. M., Mothershaw A. y Rahman M. S. 2005. The effect of storage temperature on histamine production and the freshness of yellowfin tuna (Thunnus albacares). Food Research International, 38(2): 215-222.

Haard N. 1992. Biochemistry and chemistry of color and color changes in seafoods. In G. Flick, \& R. Martin (Eds.), Advances in seafood biochemistry. Lancaster: Technomic Publishing Co. 305-360.

Hashiba H., Gocho H., Komiyama J. 2009. Dual mode diffusion and sorption of sodium chloride in pork meats under cooking conditions. LWT - Food Science and Technology, 42, 1153-1163.

Hernandez-Herrero M.M. Duflos, G., Malle P. y Bouquelet S. 2003. Collagenase activity and protein hydrolysis as related to spoilage of iced cod (Gadus morhua). Food Research International, 36: 141-147.

Hough G. y Garitta L. 2005. Estudios acelerados. En: Estimación de la Vida Util Sensorial de los Alimentos. Ed.: Programa CYTED, Madrid, España.

Hough G. y Wittig E. 2005. Introducción al análisis sensorial. En: Estimación de la Vida Util Sensorial de los Alimentos. Ed.: Programa CYTED, Madrid, España.

Huang L. 2010. Growth kinetics of Escherichia coli 0157:H7 in mechanicallytenderized beef. International Journal of Food Microbiology, 140: 40-48.

Huss H. H. 1995. Quality and quality changes in fresh fish. FAO. Fisheries Technical Paper - 348. Food and agriculture organization of the United Nations. http://www.fao.org/docrep/V7180E/V7180e09.htm. Ultimo acceso: 04/02/2015. 
Huss H. H. 1997. Aseguramiento de la calidad de los productos pesqueros. FAO. Documento Técnico de Pesca $334 . \quad$ Roma, FAO. http://www.fao.org/docrep/003/T1768S/T1768S00.htm\#TOC. Ultimo acceso: 04/02/2015.

Huss H.H. 1999. El pescado fresco: su calidad y cambios de su calidad. FAO Fisheries Technical Paper - 348. Food and agriculture organization of the United Nations. http://www.fao.org/docrep/V7180S/V7180S00.HTM. Ultimo acceso: 09/02/2015.

Hyldig G. y Nielsen D. 2001. A review of sensory and instrumental methods used to evaluate the texture of fish muscle. Journal of Texture Studies, 32: 219-242.

ICMSF. 1983. International Commission on Microbiological Specifications for Foods. Microorganismos de los alimentos 1: Técnicas de análisis microbiológico y 2: Métodos de muestreo para análisis microbiológicos: Principios y aplicaciones específicas. Ed. Acribia. España.

IFT. 2003. Institute of Food Technologists. Evaluation and definition of potentially hazardous foods. Comprehensive Reviews in Food Science and Food Safety. 2(Supplement): 1-109.

IRAM 20005-1/2. 1996. Análisis Sensorial. Guía general para la selección, entrenamiento y seguimiento de los evaluadores.

Ke P. J., Ackman R. G., Linke B. A. y Nash D. M. 1977. Differential lipid oxidation in various parts of frozen mackerel. International Journal of Food Science \& Technology, 12(1), 37-47.

Kennedy J., Blair I. S., McDowell D. A. y Bolton D. J. 2005. An investigation on the termal inactivation of Staphylococcus aureus and the potencial for increased thermotolerance as a result of chilled storage. Journal of Applied Microbiology, 99: 1229-1235.

Keqing D. Xue 2004. Optimización del secado por aire caliente de pera (Variedad Blanquilla). Tesis doctoral, Universidad politécnica de Valencia, España. 
Kirk R., Sawyer R. y Egan H. 1996. Composición y Análisis de Alimentos de Pearson. 2. ed. México: Editorial Continental S.A. C.V.

Kołakowski E. y Bednarczyk B. 2002. Physical and sensory changes in headed and gutted Baltic herring during immersed salting in brine with the addition of acetic acid. Part 1. Weight losses, colour of flesh and its sensory properties. Electronic Journal of Polish Agricultural Universities, 5(2) \#9.

Kwon T. y Watts B. M. 1964. Malonaldehyde in Aqueous Solution and Its, Role as a Measure of Lipid Oxidation in Foods. Journal of Food Science, 29: (3) 294-302.

Labuza T. y Schmidt M. 1985. Accelerated shelf-life dating of foods. Food Technology, 39 (9), 57-134.

Lehane L. y Olley J. 2000. Histamine fish poisoning revisited. International Journal of Food Microbiology, 58(1-2): 1-37.

Leistner L., W. Rodel. 1976. The stability of intermediate moisture foods with respect to microorganisms. En: Intermediate Moisture Foods, eds Davies, R., Birch, G.G. \& Parker, K.J. Applied Science Publishers, London, UK, pp 12-137.

Leistner L. 1987. Shelf-stable products and intermediate moisture foods based on meat. En: Water Activity: Theory and Applications, ed. Rockland, L.B. and Beuchal, L.R. IFT/ Marcel Dekker, Inc, New York. USA. pp 295-323.

Leistner L. 1994. Further developments in the utilization of hurdle technology for food preservation. Journal of Food Engineering, 22:421-432

Leistner L. 1999. Combined Methods for Food Preservation. En: Handbook of Food Preservation, Marcel Dekker, New York. pp 457-485.

Leistner, L. 2000. Basic aspects of food preservation by hurdle technology. International Journal of Food Microbiology. 55:181-186

Lemus-Mondaca R., Miranda M., Andres A., Briones V., Villalobos R. y Vega-Galvez A. 2009. Effect of osmotic pre-treatment on hot-air drying kinetics and quality of Chilean papaya (Carica pubescens). Drying Technology, 27(10): 1105-1115. 
Lindahl G., Lundström K. y Tornberg E. 2001. Contribution of pigment content, myoglobin forms and internal reflectance to the colour of pork loin and ham from pure breed pigs. Meat Sci. 59 (2): 141-151.

Lombard G. E., Weinert I. A. G., Minaar A. y Taylor J. R. N. 2000. Preservation of South African Steamed Bread Using Hurdle Technology. Lebensmittel Wissenschaft und Technolgie, 33: 138-143.

Lund D. B. 1975. Heat Processing. En O. R. Fennema (Ed.), Principles of food science. Part II. Physical principles of foods preservation,p. 32-92. New York: Marcel Dekker.

MAGYP. 2011. Ministerio de Agricultura, Ganadería y Pesca. Desembarques, Período: 01/01/2011- 31/12/2011. http://www.minagri.gob.ar/site/pesca/pesca maritima/02desembarques/lectura.php?imp=1\&tabla=especie mes 2011. Ultimo acceso: $31 / 01 / 2012$.

MAGYP. 2013. Ministerio de Agricultura, Ganadería y Pesca. Disponible en: http://www.minagri.gob.ar/site/pesca/pesca maritima/02-desembarques/index.php. Ultimo acceso: 12/02/2015.

MAGYP, 2015. Ministerio de Agricultura, Ganadería y Pesca. Disponible en: http://www.minagri.gob.ar/site/pesca/index.php?edit accion=noticia\&id info=15020615 0433. Ultimo acceso: 12/02/2015.

Marsh K. 2003. The use of fruit pulps to explore flavour in kiwifruit. ISHS Act Horticulturae, 610, 229-237.

Marsh K. 2006. Perception of flavour in standardised fruit pulps with addition of acids or sugars. Food Quality and Preferences, 17 (5) 376-386.

Masniyom P. 2011. Deterioration and shelf-life extension of fish and fishery products by modified atmosphere packaging. Songklanakarin Journal of Science and Technology, 33(2): 181-192.

McLay R. Marinades. Aberdeen, Scotland: Ministry of Agriculture, 1972. (Torry Advisore Note, 56) 
Montero P. y Borderias J. 1990. Effect of rigor mortis and ageing on collagen in trout (Salmo irideus) muscle. Journal of the Science of Food and Agriculture, 52: 141-146.

Montouto-Graña M., Fernández-Fernández E., Vázquez-Odériz M. L. y RomeroRodríguez M. A. 2002. Development of a sensory profile for the specific denomination Galician potato. Food Quality and Preference 13: 99-106.

Moreira R., Chenlo F., Torres M. D. y Vázquez G. 2007. Effect of stirring in the osmotic dehydration of chestnut using glycerol solutions. LWT-Food Science and Technology, 40: 1507-1514.

Moreira R. y Sereno A. M. 2003. Evaluation of mass transfer coefficients and volumetric shrinkage during osmotic dehydration of apple using sucrose solutions in static and non-static conditions. Journal of Food Engineering, 57: 25-31.

Muguruma M., Nishimura T., Umetsu R., Goto I. y Yamaguchi M. 1987. Humectants Improve Myosin Extractability and Water Activity of Raw, Cured Intermediate Moisture Meats. Meat Science, 20: 179-194.

Multon J. L. 1988. Aditivos y auxiliares de fabricación en las industrias agroalimentarias. Ed. Acribia, Zaragoza.

NACMCF. 2006. National Advisory Committee on Microbiological Criteria for Foods. Requisite scientific parameters for establishing the equivalence of alternative methods of pasteurization. Journal of Food Protection, 69: 1190-1216.

NACMCF, 2010. National Advisory Committee on Microbiological Criteria for Foods. Parameters for determining inoculated pack/challenge study protocols. Journal of Food Protection, 73 (1): 140-202.

Nattress L. A., Ziegler G. R., Hollender R. y Peterson D. G. 2004. Influence of hazelnut paste on the sensory properties and shelf-life of dark chocolate. Journal of Sensory Studies, 19: 133-148.

Nielsen B. R., Stapelfeldt H. y Skibsted L. H. 1997. Early prediction of the shelf-life of medium-heat whole milk powders using stepwise multiple regression and principal component analysis. International Dairy Journal, 7: 341-348. 
Notermans S. y Heuvelman C.J. 1983. Combined Effect of Water Activity, pH and Suboptimal Temperature on Growth and Enterotoxin Production of Staphylococcus aureus. Journal of Food Science. 48:1832-1835.

Ochoa Martinez C. y Ayala Aponte A. 2005. Modelos matemáticos de transferencia de masa en deshidratación osmótica. Ciencia y Tecnología Alimentaria, 4: 330-342.

Ólafsdóttir G., Martindóttir E., Oehlenschläger J, Dalgaard P., Jensen B., Undeland I., Mackie I.M., Henehan G., Nielsen J. y Nilsen, H. 1997. Methods to evaluate fish freshness in research and industry. Trends in Food Science \& Technology, 8: 258-432.

Opara L. U., Al-Jufaili S. M. y Rahman M. S. 2007. Postharvest Handling and Preservation of Fresh Fish and Seafood. Handbook of Food Preservation. CRC Press, Second Edition. Boca Raton.

OriginPro 8. OriginLab Corporation. Massachusetts, USA. http://www.OriginLab.com.

OTA, 1979. Office of Technology Assessment. Open Shelf-Life Dating of Food. Washington, D.C.

Pantazi D., Papavergou A., Pournis N., Kontominas M.G. y Savvaidis I.N. 2008. Shelflife of chilled fresh Mediterranean swordfish (Xiphias gladius) stored under various packaging conditions: microbiological, biochemical and sensory attributes. Food Microbiology, 25: 136-143.

Parjoko K.A., Rahman M.S., Buckle K.A. y Perera C.O. 1996. Osmotic dehydration kinetics of pineapple hedges using palm sugar. Lebensmittel Wissenschaft und Technolgie, 29: 452-459.

Park H. S., Sung B. Y. y Ryu K. 2012. Predictive Model for Growth of Staphylococcus aureus in Blanched Spinach with Seasoning. J. Korean Soc. Appl. Biol. Chem, 55: 529533.

Pedro A. M. K. y Ferreira M. M. C. 2006. Multivariate accelerated shelf-life testing: a novel approach for determining the shelf-life of foods. Journal of Chemometrics. 20: 76-83. 
Peleg M. 1988. An empirical model for the description of moisture sorption curves. Journal of Food Science, 53: 1216-1219.

Peleg M. y Cole M. B. 1998. Reinterpretation of microbial survival curves. Critical Reviews in Food Science and Nutrition, 38, 353-380.

Pepe O., Blaiotta G., Bucci F., Anastasio M., Aponte M. y Villani F. 2006. Staphylococcus aureus and staphylococcal enterotoxin A in breaded chicken products: detection and behavior during the cooking process. Applied and Environmental Microbiology, 72: 7057-7062.

Pereira D. C. y Molina J. M. 2001. Tiempo de guarda de la caballa (Scomber japonicus) acondicionada en hielo. Evaluación del NBV como indicador de calidad. Revista Tecnología y Ciencia. UTN. ISSN 1666-6933. 2: 57-67.

Pereira de Abreu D.A., Paseiro Losada P., Maroto J. y Cruz J.M. 2010. Evaluation of the effectiveness of a new active packaging film containing natural antioxidants (from barley husks) that retard lipid damage in frozen Atlantic salmon (Salmo salar L.) Food Research International, 43: 1277-1282.

Perrotta R. G. 1992. Growth of mackerel (Scomber japonicus) from the Buenos Airesnorth patagonian region (Argentine Sea). Scientia Marina, 56(1): 7-16.

Perrotta R. G., Viñas M. D., Hernandez D. R. y Tringali L. 2001. Temperature conditions in the Argentine chub mackerel (Scomber japonicus) fishing ground: implications for fishery management. Fisheries Oceanography, 10(3): 275-283.

Piagentini A. M., Mendez J. C., Guemes D. R. y Pirovani M. E. 2005. Modelling changes of sensory attributes for individual and mixed fresh-cut leafy vegetables. Postharvest Biology and Technology, 38: 202-212.

Pigott G.M. y Tucker B.W. 1990. Seafood: Effects of Technology on Nutrition, pp. 108112, Marcel Dekker, Inc., New York, NY.

Poligné I. y Collignan A. 2000. Quick marination of anchovies (Engraulis enchrasicolus) using acetic and gluconic acids. Quality and stability of the end product. Lebensmittel Wissenschaft und Technolgie, 33 (3): 202-209. 
Rahman M. S. 2007. Handbook of Food Preservation. CRC Press, Second Edition. Boca Raton.

Ramallo L. A., Schvezov C. y Mascheroni R. H. 2004. Mass transfer during osmotic dehydration of pineapple. Food Science and Technology International, 10: 323-332.

Ramallo L. A. 2010. Estudio teórico y validación experimental de la dehidrocongelación de ananá. Tesis Doctoral, Facultad de Ingeniería, UNLP. La Plata.

Rastogi N. K. y Raghavarao K. S. M. S. 1996. Kinetics of osmotic dehydration under vacuum. Lebensmittel Wissenschaft und Technolgie, 29: 669-672.

Rastogi N.K. y Raghavarao K.S.M.S. 2002. Recent developments in osmotic dehydration: methods to enhance mass transfer. Trends in Food Science and Technology, 13(2): 48-59.

Ravi-Sankar C.N., Lalitha K.V., Jose L., Manju S. y Gopal T.K.S. 2008. Effect of packaging atmosphere on the microbial attributes of pearlspot (Etroplus suratensis Bloch) stored at $0-2^{\circ} \mathrm{C}$. Food Microbiology, 25: 518-528.

Restuccia D., Spizzirri G.U., Parisi I.O., Cirillo G., Curcio M., lemma F., Puoci F., Vinci G. y Picci, N. 2010. New EU regulation aspects and global market of active and intelligent packaging for food industry applications. Food Control, 21: 1425-1435.

Rodger G., Hastings R., Cryne C. y Bailey J. 1984. Diffusion properties of salt and acetic acid into herring and their subsequent effect on the muscle tissue. Journal of Food Science, 49:714-720.

Ruiz-Ramírez J., Arnau J., Serra X. y Gou P. 2005. Relationship between water content, $\mathrm{NaCl}$ content, $\mathrm{pH}$ and texture parameters in dry-cured muscles. Meat Science, 70: 579-587.

Sablani S. S. y Rahman M. S. 2003. Effect of syrup concentration, temperature and sample geometry on equilibrium distribution coefficients during osmotic dehydration of mango. Food Research International, 36: 65-71. 
Sánchez Pascua G.L., Casales M.R. y Yeannes M.I. 1994. Preliminary development of intermediate moisture, pasteurized chub mackerel (Scomber japonicus marplatensis) chunks. Journal of the Science of Food and Agriculture, 64, 199-204.

Sánchez Pascua G.L., Casales M.R. y Yeannes M.I. 1998. Aplicación de la metodología de infusión húmeda en troncos de caballa (Scomber japónicus marplatensis). Frente Marítimo, 17 (B): 93-96.

Sánchez Pascua G.L., Casales M.R. y Yeannes M.I. 2001. Influence of water and glycerol contents on the $a_{w}$ of fish pastes. Journal of Aquatic Food Product Technology, 10 (1): $89-100$.

Sánchez Pascua G., Casales M. R. y Yeannes M. I. 2010. Psichophysics estimation of acid intensity and determination of interaction sweet-acid fish paste containing glycerol. Ciencia e tecnologia de Alimentos. Brasil. 30(Supl.1): 260-263.

Sanjay S. y Sudhir K. S. 2007. Diffusion and equilibrium distribution coefficients of salt within vegetable tissue: Effects of salt concentration and temperature. Journal of Food Engineering 82, 377-382.

Sattar S.A., Springthorpe S., Mani S., Gallant M., Nair R.C., Scott E. y Kain J. 2001.

Transfer of bacteria from fabrics to hands and other fabrics: development and application of a quantitative method using Staphylococcus aureus as a model. Journal of Applied Microbiology, 90: 962-970.

Schifferstein H. N. J. y Frijters J. E. R. 1990. Sensory integration in citric acid/sucrose mixtures. Chemical Senses, 15 (1) 87-109,

Schmidt F., Carciofi B. y Laurindo J. 2009. Application of diffusive and empirical models to hydration, dehydration and salt gain during osmotic treatment of chicken breast cuts. Journal of Food Engineering, 91:553-559.

Silva F. V. M. y Gibbs P. A. 2010. Non-proteolytic Clostridium botulinum spores in lowacid cold distributed foods and design of pasteurization processes. Trends in Food Science \& Technology, 21: 95-105. 
Simon S.S. y Sanjeev S. 2007. Prevalence of enterotoxigenic Staphylococcus aureus in fishery products and fish processing factory workers. Food Control, 18: 1565-1568.

Singh R.P. 1996. Computer Application in Food Technology. Use of Spreadsheets in Graphical, Statistical, and Process Analysis. Elsevier.

Singh R.P., Heldman, D.R. 1993. Introducción a la Ingeniería de Alimentos. $2^{\text {da }}$ Edición. Acribia. Zaragoza. España.

Sivertsvik M., Jeksrud W.K. y Rosnes J.T. 2002. A review of modified atmosphere packaging of fish and fishery products-significance of microbial growth, activities and safety. International Journal of Food Science and Technology, 37: 107-127.

Sneed J., Strohbehn C., Shirley A.G. y Mendonca, J. 2004. Microbiological evaluation of foodservice contact surfaces in lowa assisted-living facilities. Journal of the American Dietetic Association, 104: 1722-1724.

Sohn J.H., Taki Y., Ushio H., Kohata T., Shioya I. y Ohshima T. 2005. Lipid oxidations in ordinary and dark Muscles of fish: Influences on rancid off-odor development and color darkening of yellowtail flesh during ice storage. Journal of Food Science, 70(7): 490-496.

Soriano J.M., Font G., Moltó J.C. y Mañes J., 2002. Enterotoxigenic staphylococci and their toxins in restaurant foods. Trends of Food Science and Technology 13, 60-67.

Stumbo C.R. 1973. Thermobacteriology in Food Processing. 2nd Edition. Academic Press, New York.

Suzuki T. 1987. Tecnología de las proteínas de pescado y krill. Editorial Acribia, España.

Tapia M. S. 2003. La evaluación microbiológica por metodología de reto microbiano. En: Programa Iberoamericano de Ciencia y Tecnología para el Desarrollo. Ed: CYTED, Mexico.

Taylor S. L. 1986. Histamine food poisoning: toxicology and clinical aspects. Critical reviews in toxicology, 17(2): 91-128. 
Telis V., Romanelli P., Gabas A. y Telis-Romero J. 2003. Salting kinetics and salt diffusivities in farmed pantanal caiman muscle. Pesquisa Agropecuária Brasileira, 38:529-535.

Thanonkaew A., Benjakul S. y Visessanguan W., Decker, E. A. 2006. Development of yellow pigmentation in squid (Loligo peali) as a result of lipid oxidation. Journal of Agricultural and Food Chemistry, 54:956-962.

Thanonkaew A., Benjakul S., Visessanguan W. y Decker E. A. 2007. Yellow discoloration of the liposome system of cuttlefish (Sepia pharaonis) as influenced by lipid oxidation. Food Chemistry 102:219-224.

Tironi V.A., Tomás M.C. y Añón M.C. 2007. Lipid and protein deterioration during the chilled storage of sea salmon (Pseudopercis semifasciata). J Sci Food Agr, 87, 2239_ 2246.

Tironi V., Lamballerie M. y Le-Bail A. 2010a. Quality changes during the frozen storage of sea bass (Dicentrarchus labrax) muscle after pressure shift freezing and pressure assisted thawing. Innovative Food Science and Emerging Technologies, 11: 565-573.

Tironi V. A., Tomás M. C. y Añón M. C. 2010b. Quality loss during the frozen storage of sea salmon (Pseudopercis semifasciata). Effect of rosemary (Rosmarinus officinalis L.) extract.

Todd E.C.D., Greig J.D., Bartleson C.A. y Michaels B.S.. 2008. Outbreaks where food workers have been implicated in the spread of foodborne disease. Part 4. Infective doses and pathogen carriage. Journal of Food Protection, 71 (11): 2339-2373.

Toledo R.T. 2007. Fundamentals of Food Process Engineering. $3^{\text {rd }}$ Edition. Food Science Text Series. Georgia.

Tomac A. 2013. Irradiación gamma en anillas de calamar (Illex argentinus) y filetes marinados de anchoíta (Engraulis anchoita). Aspectos tecnológicos y de calidad. Tesis presentada para optar al grado de Doctor en Ingeniería. UNLP. 
Tomac A., Mascheroni R. H. y Yeannes M. I. 2013. Modelling the effect of gamma irradiation on the inactivation and growth kinetics of psychrotrophic bacteria in squid rings during refrigerated storage. Shelf-life predictions. Journal of Food Engineering, 117: 211-216.

Tonon R. V., Baroni A. F. y Hubinger M. D. 2007. Osmotic dehydration of tomato in ternary solutions: Influence of process variables on mass transfer kinetics and an evaluation of the retention of carotenoids. Journal of Food Engineering, 82: 509-517.

Torres A., Guerra M. y Rosquete Y. 2001. Estimación de la vida útil de una fórmula dietética en función de la disminución de lisina disponible. Ciencia y Tecnología de Alimentos, Brasil, 21(2).

Tortoe C. 2010. A review of osmodehydration for food industry. African Journal of Food Sciense, 4, 303-324.

Trinchero J., Monti M. y Ceroli P. 2007. Características sensoriales de papas fritas en bastones. Revista Latinoamericana de la Papa, 14(1): 33-40.

Turhan M., Sayar S. yGunasekaran S. 2002 Application of Peleg model to study water absorption in chickpea during soaking. Journal of Food Engineering, 53: 153-159.

Urbicain M. J. y Lozano J. E. 1997. Thermal and rheological properties of foodstuffs. K.J. Valentas, E. Rotstein, R.P. Singh (Eds.), Handbook of Food Engineering Practice, CRC Press LLC, New York (1997), p. 698.

Uribe E., Miranda M., Vega-galvez,A., Quispe I., Clavería R. y Di Scala K. 2011. Mass transfer modelling during osmotic dehydration of jumbo squid (Dosidicus gigas): Influence of temperature on diffusion coefficients and kinetic parameters. Food Bioprocess Technology, 4, 320-326.

Valencia García, F.E., Cortés Rodríguez, M. y Román Morales, M.O. 2012. Cinética del color durante el almacenamiento de caramelos blandos de uchuva adicionados de calcio y sin sacarosa. Revista Lasallista de Investigación, 9(2): 11-25. 
Valero A., Perez-Rodriguez F., Carrasco E., Fuentes-Alventosa J. M., García-Jimeno R. M. y Zurera G. 2009. Modelling the growth boundaries of Staphylococcus aureus: Effect of temperature, $\mathrm{pH}$ and water activity. International Journal of Food Microbiology, 133: 186-194.

Vora P., Senecal A. y Schaffner D. W. 2003. Survival of Staphylococcus aureus ATCC 13565 in Intermediate Moisture Foods is Highly Variable. Risk Analysis, 23: 1.

Walkling-Ribeiro M., Noci F., Cronin D. A., Riener, J., Lyng J. G. y Morgan D. J. 2008. Reduction of Staphylococcus aureus and quality changes in apple juice processed by ultraviolet irradiation, pre-heating and pulsed electric fields. Journal of Food Engineering, 89: 267-273.

Wang D., Tang J. y Correia L. 2000. Salt diffusivities and salt diffusion in farmed Atlantic salmon muscle as influenced by rigor mortis. Journal of Food Engeneering, 43, $115-123$.

Wilbey R.A. 2014. Heat Treatment of Food. Principles of Pasteurization. Encyclopedia of Food Microbiology (Second Edition).

Yeannes M. I. 1995. Histamina en productos pesqueros. En: Toxicología de los Alimentos. Cap VII. Ed. Hemisferio Sur S.A. Argentina. Pp: 30- 45.

Zugarramurdi A. y Lupín H. M. 1980. A model to explain observed behavior on fish salting. Journal of Food Science, 45, 1305-1311 y 1317. 


\section{ANEXOS}

Anexo 1 Condiciones límites de crecimiento de bacterias patógenas de interés según DHHS,

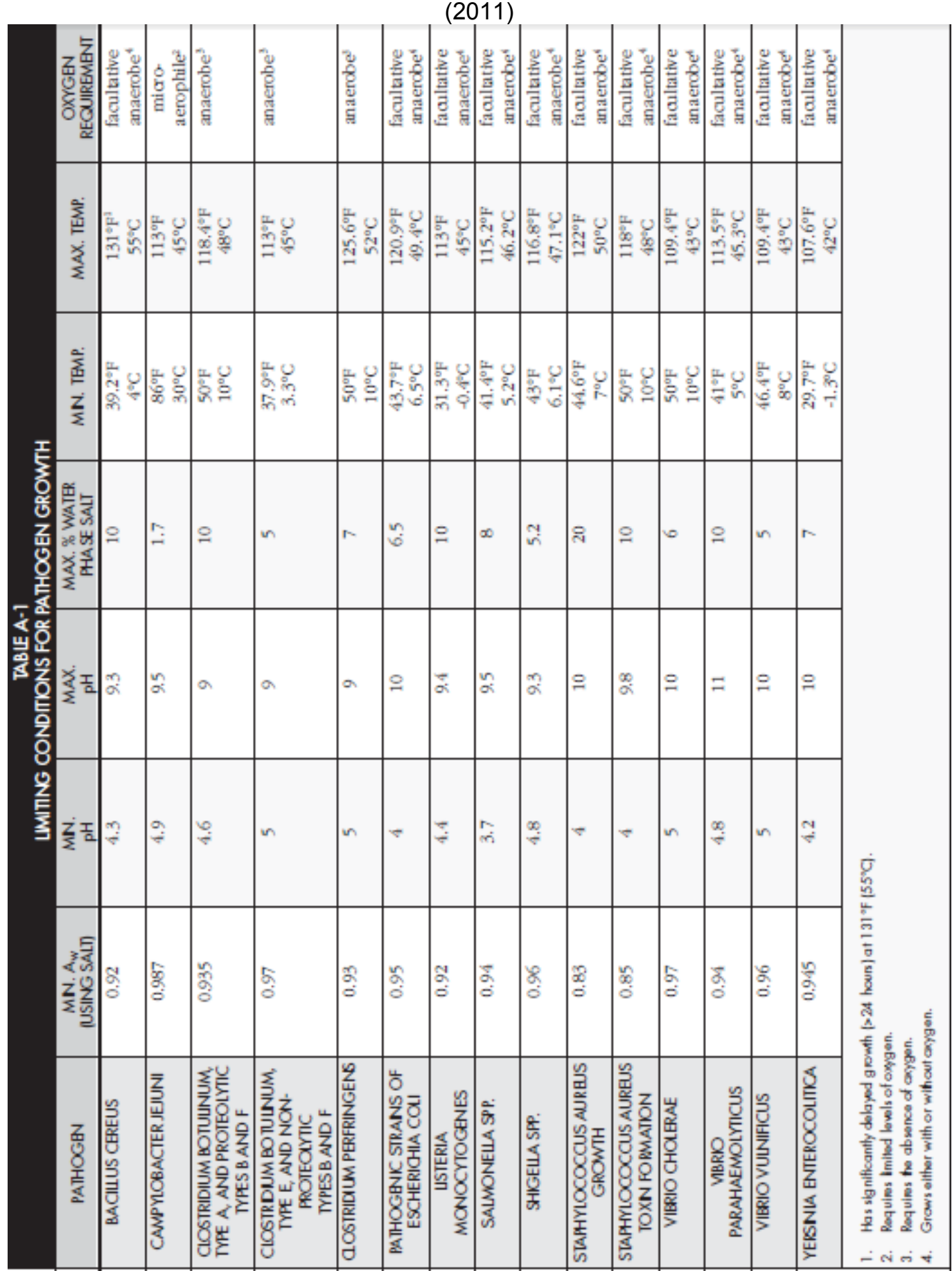


Anexo 2 Valores de letalidad expresados como $f_{h} / U$ vs g (para $Z=12$ ) de la fórmula de Stumbo

\section{TABLE A.5}

$f_{\mathrm{A}} / U: g$ Relationships when $z=12$

Values of $g$ when $j$ of cooling curve is:

\begin{tabular}{|c|c|c|c|c|c|c|c|c|c|}
\hline $\mathrm{fa} / \mathrm{C}$ & 0.40 & 0.60 & 0.80 & 1.00 & 1.20 & 1.40 & 1,60 & 1.80 & 2.00 \\
\hline 0.20 & $2 \cdot 66-05$ & $3.03-05$ & $3.21-05$ & $3.39-05$ & $3.57-05$ & $3.74-05$ & $3.92-05$ & $4.10-05$ & $4.27-0.5$ \\
\hline 0.30 & $1=16-03$ & $1 \cdot 26-0.3$ & $1.35-0^{3}$ & $1.45-03$ & $1.54-03$ & $1.64-0^{3}$ & $1.73-0^{3}$ & $1 \cdot 83-03$ & $1.92-03$ \\
\hline 0.40 & $8 \cdot 18-03$ & $8.82-03$ & $9.47-03$ & $1.01-02$ & $1.08-02$ & $1.14-02$ & $1.21-02$ & $1.27-02$ & $1.33-02$ \\
\hline 0.50 & $2 \cdot 72-02$ & $2.92-02$ & $3 \cdot 12-02$ & $3 \cdot 32-02$ & $3.52-02$ & $3 \cdot 72-02$ & $3.92-02$ & $4.12-02$ & $4.32-02$ \\
\hline 0.60 & $6.13-02$ & $6.56-02$ & $6.98-02$ & $7.41-02$ & $7.83-02$ & $8.26-02$ & $8.68-02$ & $9.10-02$ & $9.53-02$ \\
\hline 0.70 & 0.111 & 0.118 & 0.125 & 0.132 & 0.139 & 0.147 & 0.154 & 0.161 & 0.168 \\
\hline 0.80 & 0.173 & 0.184 & 0.194 & 0.205 & 0.216 & 0.226 & 0.237 & 0.248 & 0.258 \\
\hline 0.90 & 0.246 & 0.260 & 0.274 & 0.289 & 0.303 & 0.318 & 0.332 & 0.347 & 0.361 \\
\hline 1.00 & 0.326 & 0.344 & 0.363 & 0.381 & 0.399 & 0.418 & 0.436 & 0.455 & 0.473 \\
\hline 2.00 & 1.20 & 1.26 & $1 \cdot 32$ & 1.38 & 1.44 & 1.49 & 1.55 & 1.61 & 1.67 \\
\hline 3.00 & 1.91 & 2.01 & 2.11 & 2.21 & $2 \cdot 31$ & 2.41 & 2.51 & 2.61 & 2.71 \\
\hline 4.00 & 2.47 & 2.61 & 2.75 & 2.89 & 3.03 & 3.17 & $3 \cdot 31$ & 3.45 & 3.59 \\
\hline 5.00 & 2.92 & 3.10 & 3.28 & 3.46 & 3.64 & 3.62 & 4.00 & $4 \cdot 18$ & $4 \cdot 36$ \\
\hline 6.00 & 3.31 & 3.52 & 3.74 & 3.96 & 4.18 & 4.40 & 4.62 & 4.83 & 5.05 \\
\hline 7.00 & 3.65 & 3.90 & 4.15 & 4.41 & 4.66 & 4.92 & 5.17 & 5.42 & 5.68 \\
\hline 8.00 & 3.96 & 4.24 & 4.53 & $4 \cdot 81$ & 5.10 & 5.39 & 5.67 & 5.96 & 6.25 \\
\hline 9.00 & 4.24 & 4.56 & 4.87 & 5.19 & 5.51 & 5.82 & 6.14 & 6.46 & 6.77 \\
\hline 10.00 & 4.50 & 4.85 & 5.19 & 5.54 & 5.88 & 6.22 & 6.57 & 6.91 & 7.26 \\
\hline 15.00 & 5.61 & 6.06 & 6.52 & 6.98 & 7.4 .4 & 7.89 & 8.35 & $3 \cdot 81$ & 9.27 \\
\hline 20.00 & 6.49 & 7.03 & 7.57 & 8.10 & 8.64 & 9.18 & 9.72 & 10.26 & $10 \cdot 79$ \\
\hline 25.00 & 7.24 & 7.83 & 8.43 & 9.03 & 9.62 & 10.22 & 10.81 & 11.41 & 12.01 \\
\hline 30.00 & 7.89 & 8.53 & 9.17 & 9.81 & 10.44 & 11.08 & 11.72 & $12 \cdot 36$ & $: 3.00$ \\
\hline 35.00 & 8.47 & 9.14 & 9.81 & 10.48 & 11.15 & $11 \cdot 82$ & 12.49 & 13.16 & 13.83 \\
\hline 40.00 & 8.99 & 9.68 & $10 \cdot 38$ & $11.0^{7}$ & 11.76 & 12.46 & $13 \cdot 15$ & 13.85 & 14.54 \\
\hline 45.00 & 9.46 & 10.17 & 10.88 & 11.59 & $12 \cdot 31$ & 13.02 & 13.73 & 14.44 & $15 \cdot 15$ \\
\hline 50.00 & 9.89 & 10.61 & 11.34 & 12.07 & 18.79 & 17.52 & 14.24 & 14.97 & 15.69 \\
\hline $60=00$ & 10.6 & 11.4 & 12.1 & 12.9 & $13 \cdot 6$ & 14.4 & 15.1 & 15.9 & 16.6 \\
\hline 70.00 & $11 \cdot 3$ & 12.1 & 12.8 & 13.6 & 14.3 & 15.1 & $15 \cdot 9$ & 16.6 & 17.4 \\
\hline 80.00 & 11.9 & 12.6 & 13.4 & $14 \cdot 2$ & 14.9 & 15.7 & 16.5 & $17 \cdot 3$ & 18.0 \\
\hline 90.00 & $12 \cdot 3$ & 13.1 & 13.9 & 14.7 & $15 \cdot 5$ & $1 \in \cdot 3$ & 17.0 & 17.8 & 18.6 \\
\hline 100.00 & 12.8 & 13.6 & 14.4 & $15 \cdot 2$ & 15.9 & 16.7 & 17.5 & $18 \cdot 3$ & 19.1 \\
\hline 50.00 & 14.3 & 15.2 & 16.0 & 16.9 & 17.8 & 18.6 & $19 \cdot 5$ & 20.4 & 21.2 \\
\hline 00.00 & $15 \cdot 3$ & 16.2 & 17.2 & $18 \cdot 1$ & 19.1 & 20.0 & 21.0 & 21.9 & $22 \cdot 8$ \\
\hline $50 \cdot 00$ & 16.0 & 17.0 & $18 \cdot 0$ & 19.1 & 20.1 & $21 \cdot 1$ & $22 \cdot 2$ & $27 \cdot 2$ & 24.2 \\
\hline 00.00 & 16.5 & 17.6 & 18.7 & 19.8 & $20 \cdot 9$ & $22 \cdot 1$ & $23 \cdot 2$ & $24 \cdot 3$ & 25.4 \\
\hline 50.00 & 16.9 & 18.1 & $19 \cdot 3$ & $20 \cdot 5$ & $21 \cdot 7$ & $22 \cdot 9$ & $24 \cdot 0$ & $25 \cdot 2$ & 26.4 \\
\hline $00 \cdot 00$ & $17 \cdot 3$ & 18.5 & 19.8 & $21 \cdot 0$ & $22 \cdot 3$ & 23.6 & 24.8 & $26 \cdot 1$ & $27 \cdot 3$ \\
\hline 50.00 & 17.6 & 18.9 & $20 \cdot 2$ & 21.5 & $22 \cdot 9$ & 24.2 & $25 \cdot 5$ & 26.8 & 28.2 \\
\hline 00.00 & $17 \cdot \theta$ & 19.2 & $20 \cdot 6$ & $22 \cdot 0$ & $23 \cdot 4$ & 24.8 & $26 \cdot 1$ & $27 \cdot 5$ & 28.9 \\
\hline 00.00 & 18.3 & 19.8 & $21 \cdot 3$ & 22.8 & $24 \cdot 2$ & $25 \cdot 7$ & $27 \cdot 2$ & 28.7 & $30 \cdot 2$ \\
\hline 50.00 & 18.7 & 20.3 & $21 \cdot 8$ & 23.4 & $25 \cdot 0$ & 26.6 & $2 e \cdot 1$ & $29 \cdot 7$ & $31 \cdot 3$ \\
\hline 00.00 & 19.1 & 20.7 & $22 \cdot 4$ & 24.0 & 25.6 & $27 \cdot 3$ & 28.9 & $30 \cdot 5$ & $32 \cdot 1$ \\
\hline 0.00 & 19.5 & 21.2 & $22 \cdot 8$ & $24 \cdot 5$ & $26 \cdot 2$ & 27.9 & 29.5 & $3: \cdot 2$ & 32.9 \\
\hline 9.99 & 19.8 & 21.6 & $23 \cdot 3$ & $25 \cdot 0$ & 26.7 & 28.4 & $30 \cdot 1$ & $31 \cdot 8$ & 33.5 \\
\hline
\end{tabular}


Anexo 3 Valores de letalidad de la etapa de calentamiento expresados como $\mathrm{g} / \mathrm{K}_{\mathrm{s}} \mathrm{vs}$ $\mathrm{U} / \mathrm{f}_{\mathrm{h}}$ de la fórmula de Hayakawa

Table $9.16 \mathrm{~g} / K_{s}$ vs. $U / f_{h}$ tables used for calculating the lethality of the heating part of a thermal process by Hayakawa's procedure

\begin{tabular}{|c|c|c|c|c|c|}
\hline$g / K_{s}\left({ }^{\circ} \mathrm{F}\right)$ & $U / f_{n}$ & $g / K_{s}\left({ }^{\prime} F\right)$ & $U / f_{n}$ & $g / K_{s}(' F)$ & $U / f_{h}$ \\
\hline 100.0000 & $0.4165(-06)$ & 33.0000 & $0.2095(-02)$ & 0.35000 & $0.1161(01)$ \\
\hline 98.0000 & $0.5152(-06)$ & 32.0000 & $0.2413(-02)$ & 0.30000 & $0.1226(01)$ \\
\hline 96.0000 & $0.6420(-06)$ & 31.0000 & $0.2780(-02)$ & 0.25000 & $0.1303(01)$ \\
\hline 94.0000 & $0.8051(-06)$ & 30.0000 & $0.3205(-02)$ & 0.20000 & $0.1397(01)$ \\
\hline 92.0000 & $0.1015(-05)$ & 29.0000 & $0.3699(-02)$ & 0.15000 & $0.1519(01)$ \\
\hline 90.0000 & $0.1284(-05)$ & 28.0000 & $0.4272(-02)$ & 0.10000 & $0.1693(01)$ \\
\hline 88.0000 & $0.1632(-05)$ & 27.0000 & $0.4939(-02)$ & 0.09000 & $0.1738(01)$ \\
\hline 86.0000 & $0.2079(-05)$ & 26.0000 & $0.5715(-02)$ & 0.08000 & $0.1789(01)$ \\
\hline 84.0000 & $0.2655(-05)$ & 25.0000 & $0.6620(-02)$ & 0.07000 & $0.1846(01)$ \\
\hline 82.0000 & $0.3398(-05)$ & 24.0000 & $0.7677(-02)$ & 0.06000 & $0.1913(01)$ \\
\hline 80.0000 & $0.4356(-05)$ & 23.0000 & $0.8914(-02)$ & 0.05000 & $0.1992(01)$ \\
\hline 78.0000 & $0.5593(-05)$ & 22.0000 & $0.1036(-01)$ & 0.04000 & $0.2088(01)$ \\
\hline 76.0000 & $0.7191(-05)$ & 21.0000 & $0.1206(-01)$ & 0.03500 & $0.2146(01)$ \\
\hline 74.0000 & $0.9256(-05)$ & 20.0000 & $0.1407(-01)$ & 0.03000 & $0.2212(01)$ \\
\hline 72.0000 & $0.1193(-04)$ & 19.0000 & $0.1643(-01)$ & 0.02500 & $0.2291(01)$ \\
\hline 70.0000 & $0.1539(-04)$ & 18.0000 & $0.1922(-01)$ & 0.02000 & $0.2388(01)$ \\
\hline 68.0000 & $0.1986(-04)$ & 17.0000 & $0.2254(-01)$ & 0.01500 & $0.2513(01)$ \\
\hline 66.0000 & $0.2567(-04)$ & 16.0000 & $0.2648(-01)$ & 0.01000 & $0.2688(01)$ \\
\hline 64.0000 & $0.3321(-04)$ & 15.0000 & $0.3119(-01)$ & 0.00900 & $0.2734(01)$ \\
\hline 62.0000 & $0.4300(-04)$ & 14.0000 & $0.3684(-01)$ & 0.00800 & $0.2785(01)$ \\
\hline 60.0000 & $0.5573(-04)$ & 13.0000 & $0.4365(-01)$ & 0.00700 & $0.2844(01)$ \\
\hline 58.0000 & $0.7229(-04)$ & 12.0000 & $0.5191(-01)$ & 0.00600 & $0.2909(01)$ \\
\hline 56.0000 & $0.9388(-04)$ & 11.0000 & $0.6198(-01)$ & 0.00500 & $0.2989(01)$ \\
\hline 54.0000 & $0.1220(-03)$ & 10.0000 & $0.7435(-01)$ & 0.00400 & $0.3085(01)$ \\
\hline 52.0000 & $0.1589(-03)$ & 9.0000 & $0.8970(-01)$ & 0.00350 & $0.3143(01)$ \\
\hline 50.0000 & $0.2070(-03)$ & 8.0000 & $0.1090(00)$ & 0.00300 & $0.3210(01)$ \\
\hline 49.0000 & $0.2364(-03)$ & 7.0000 & $0.1335(00)$ & 0.00250 & $0.3290(01)$ \\
\hline 48.0000 & $0.2701(-03)$ & 6.0000 & $0.1652(00)$ & 0.00200 & $0.3384(01)$ \\
\hline 47.0000 & $0.3087(-03)$ & 5.0000 & $0.2073(00)$ & 0.00150 & $0.3509(01)$ \\
\hline 46.0000 & $0.3529(-03)$ & 4.0000 & $0.2652(00)$ & 0.00100 & $0.3685(01)$ \\
\hline 45.0000 & $0.4036(-03)$ & 3.5000 & $0.3029(00)$ & 0.00090 & $0.3734(01)$ \\
\hline 44.0000 & $0.4618(-03)$ & 3.0000 & $0.3490(00)$ & 0.00080 & $0.3780(01)$ \\
\hline 43.0000 & $0.5286(-03)$ & 2.5000 & $0.4067(00)$ & 0.00070 & $0.3842(01)$ \\
\hline 42.0000 & $0.6053(-03)$ & 2.0000 & $0.4816(00)$ & 0.00060 & $0.3903(01)$ \\
\hline 41.0000 & $0.6934(-03)$ & 1.5009 & $0.5839(00)$ & 0.00050 & $0.3986(01)$ \\
\hline 40.0000 & $0.7947(-03)$ & 1.0000 & $0.7367(00)$ & 0.00040 & $0.4073(01)$ \\
\hline 39.0000 & $0.9113(-03)$ & 0.9000 & $0.7777(00)$ & 0.00035 & $0.4143(01)$ \\
\hline 38.0000 & $0.1045(-02)$ & 0.8000 & $0.8241(00)$ & 0.00030 & $0.4204(01)$ \\
\hline 37.0000 & $0.1200(-02)$ & 0.7000 & $0.8773(00)$ & 0.00025 & $0.4274(01)$ \\
\hline 36.0000 & $0.1378(-02)$ & 0.6000 & $0.9395(00)$ & 0.00020 & $0.4358(01)$ \\
\hline 35.0000 & $0.1584(-02)$ & 0.5000 & $0.1014(01)$ & 0.00015 & $0.4505(01)$ \\
\hline 34.0000 & $0.1821(-02)$ & 0.4000 & $0.1106(01)$ & 0.00010 & $0.4659(01)$ \\
\hline
\end{tabular}

Values in parentheses indicate powers of 10 by which tabulated values are to be multiplied; e.g., $U_{h / f}$ for $g / K_{s}=$ $40^{\circ} \mathrm{F}$ is 0.0006646 .

Source: Hayakawa, k., Food Technol. 24: 1407, 1970. Corrected table courtesy of K. Hayakawa. 
Anexo 4 Valores de letalidad de la etapa de enfriamiento expresados como $\mathrm{g} / \mathrm{K}_{\mathrm{s}}$ vs $\mathrm{U} / \mathrm{f}_{\mathrm{c}}$ de la fórmula de Hayakawa

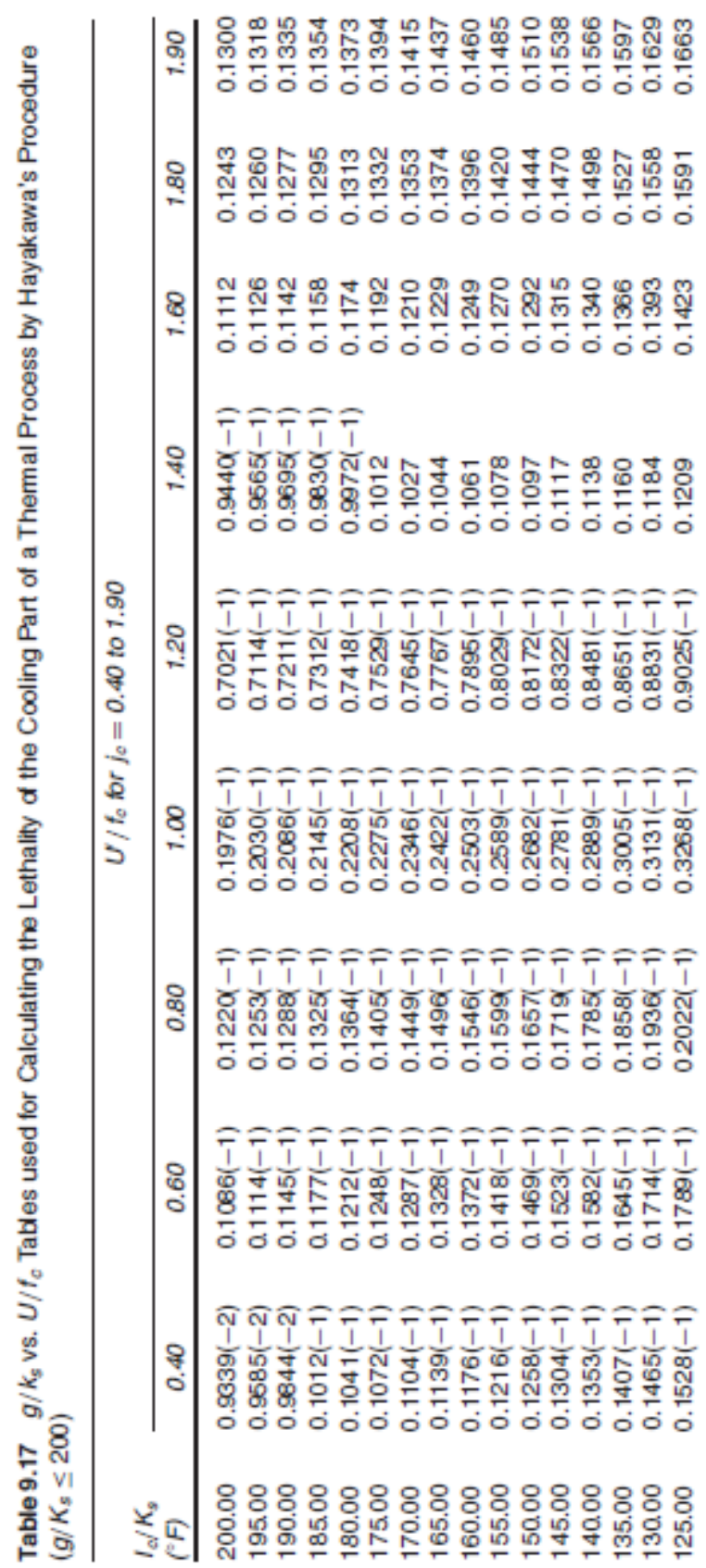

